\title{
Digital Image Transformations and Image Stacking of Latent Prints Processed Using Multiple Physical and Chemical Techniques
}

Danielle Tague

Follow this and additional works at: https://researchrepository.wvu.edu/etd

\section{Recommended Citation}

Tague, Danielle, "Digital Image Transformations and Image Stacking of Latent Prints Processed Using Multiple Physical and Chemical Techniques" (2015). Graduate Theses, Dissertations, and Problem Reports. 6765.

https://researchrepository.wvu.edu/etd/6765

This Thesis is protected by copyright and/or related rights. It has been brought to you by the The Research Repository @ WVU with permission from the rights-holder(s). You are free to use this Thesis in any way that is permitted by the copyright and related rights legislation that applies to your use. For other uses you must obtain permission from the rights-holder(s) directly, unless additional rights are indicated by a Creative Commons license in the record and/ or on the work itself. This Thesis has been accepted for inclusion in WVU Graduate Theses, Dissertations, and Problem Reports collection by an authorized administrator of The Research Repository @ WVU. For more information, please contact researchrepository@mail.wvu.edu. 


\title{
Digital Image Transformations and Image Stacking of Latent Prints Processed Using Multiple Physical and Chemical Techniques
}

\author{
Danielle Tague \\ Thesis Submitted \\ to the Eberly College of Arts and Sciences \\ at West Virginia University
}

in partial fulfillment of the requirement for the degree of

Master of Science in

Forensic and Investigative Science

Keith Morris, Ph. D., Chair

Jacqueline Speir, Ph. D.

Robert Johnson, Sgt.

Department of Forensic and Investigative Science

Morgantown, West Virginia

2015

Keywords: forensic, fingerprints, latent, image processing, minutia, image registration, image fusion, fingerprint quality

Copyright 2015 Danielle Tague 


\section{ABSTRACT \\ Digital Image Transformations and Image Stacking of Latent Prints Processed Using Multiple Physical and Chemical Techniques}

\section{Danielle Tague}

Latent fingerprints are highly common among evidence that is found at crime scenes. While fingerprint evidence can be very reliable, comparison and identification of a print is highly affected by the quality of the fingerprint image. Fingerprint experts ideally want to have an image with the best quality possible, in order to make an accurate identification and avoid missing pertinent details. This is a thesis presented on the use of digital image processing to merge multiple images of one fingerprint to obtain a final image with greater quality. The research was conducted using different latent fingerprint processing techniques that have been widely used in the forensic science community: ninhydrin, DFO, zinc chloride, cyanoacrylate, and fluorescent dye-stains. The latents were photographed after each technique was utilized. Images of the same print under different wavelengths and filters were merged to create a final image with ideally better contrast, quality, and friction ridge detail than were observed in the original images prior to merging. Quality was determined using three different scoring methods; NFIQ, Bandey scale, and AFIX Tracker. A print was considered to be improved if the merged score was better than the scores of the original images. There were $12.1 \%$ of prints that were improved based on NFIQ scores, $2.8 \%$ based on Bandey scores, and $15.0 \%$ based on AFIX match scores. Image fusion for increasing quality of latent fingerprint images is a method that shows small benefits for the examiner when performing a comparison. 


\section{TABLE OF CONTENTS}

List of Tables $\quad$ iii

List of Figures $\quad$ iv

Introduction $\quad 1$

Previous Research $\quad 2$

Methodology $\quad 5$

Materials $\quad 5$

Methods $\quad 5$

Fingerprint Deposition $\quad 5$

Processing Techniques $\quad 6$

DFO 6

Ninhydrin 6

Zinc Chloride $\quad 7$

$\begin{array}{ll}\text { Cyanoacrylate Fuming } & 7\end{array}$

Dusting using Black Powder 8

Sequence of Processing Techniques $\quad 8$

Digital Image Processing and Forensics $\quad 9$

$\begin{array}{ll}\text { Image Contrast Adjustment } & 9\end{array}$

Digital Image Registration Using Photoshop Auto-Align 9

Canny Edge Detector $\quad 10$

Laplacian of Gaussian $\quad 10$

Digital Image Merging Using Photoshop Auto-Blend 10

NIST Fingerprint Image Quality (NFIQ)

Bandey Scale 16

$\begin{array}{lr}\text { AFIX } & 18\end{array}$

$\begin{array}{lr}\text { Results } & 18\end{array}$

$\begin{array}{ll}\text { NFIQ } & 18\end{array}$

Bandey Scale $\quad 20$

AFIX 22

Quality Improvement $\quad 24$

$\begin{array}{ll}\text { Chi-square Test } & 27\end{array}$

ANOVA 29

Justification for Elimination of Cardboard and Paper Samples 30

$\begin{array}{ll}\text { Spurious Minutia } & 30\end{array}$

Examiners' Subjectivity 31

Conclusion

Future Research 32

Field Application in Forensics $\quad 32$

References

Appendix A $\quad 36$

$\begin{array}{ll}\text { Appendix B } & 57\end{array}$

$\begin{array}{ll}\text { Appendix C } & 76\end{array}$

$\begin{array}{lr}\text { Appendix D } & 88\end{array}$ 


\section{LIST OF TABLES}

Table 1. List of dye stains used after fuming, wavelengths, and filters

Table 2. The total number of images for each process and merged images

Table 3. Feature vector description of MINDTCT algorithm

Table 4. Bandey fingerprint quality grading scheme

Table 5. NFIQ scores and average score of all merged fingerprints

Table 6. NFIQ scores and average score of all original fingerprints

Table 7. Bandey scale scores and average score of all merged images

Table 8. Bandey scale scores and average score of all original images

Table 9. Average match scores, average percent of lines drawn, number of matches, and number of non-matches for each processing technique

Table 10. Percentage of true matches made by AFIX

Table 11. NFIQ, Bandey, and AFIX results showing percentage of improvement in images and prints

Table 12. NFIQ and Bandey scale scores and average score of glass, cyano

Table 13. NFIQ and Bandey scale scores and average score of glass, basic red 28

Table 14. NFIQ and Bandey scale scores and average score of glass, basic yellow 40

Table 15. NFIQ and Bandey scale scores and average score of glass, MBD

Table 16. NFIQ and Bandey scale scores and average score of glass, rhodamine 6G

Table 17. NFIQ and Bandey scale scores and average score of glass, merged

Table 18. NFIQ and Bandey scale scores and average score of plastic, cyano

Table 19. NFIQ and Bandey scale scores and average score of plastic, basic red 28

Table 20. NFIQ and Bandey scale scores and average score of plastic, MBD

Table 21. NFIQ and Bandey scale scores and average score of plastic, rhodamine 6G

Table 22. NFIQ and Bandey scale scores and average score of plastic, merged

Table 23. Chi-square results for NFIQ scores

Table 24. Chi-square results for Bandey scores 
Table 25. ANOVA results for AFIX scores

\section{LIST OF FIGURES}

Figure 1. (A) and (B) show a fingerprint on a curved surface with lighting at two different angles. Image $(\mathrm{C})$ is the merged image of $(\mathrm{A})$ and $(\mathrm{B})$

Figure 2. (A) and (B) are partial prints, image (C) is the final print after image mosaicing was done on $(\mathrm{A})$ and $(\mathrm{B})$

Figure 3. Flow chart showing the sequence of processing techniques

Figure 4. Individual images of print \#172 before merging. Deposited on glass and photographed under four different conditions; (A) fumed with cyanoacrylate,(B) dye-stained with Rhodamine $6 \mathrm{G}$ at $540 \mathrm{~nm},(\mathrm{C})$ dye-stained with Rhodamine $6 \mathrm{G}$ at $515 \mathrm{~nm}$,(D) dye-stained with Rhodamine $6 \mathrm{G}$ at $500 \mathrm{~nm}$

Figure 5. Merged image of print \#172

Figure 6. Individual images of print \#16 before merging. Deposited on plastic and photographed under four different conditions; (A) dye-stained with Basic Red 28 at 470nm, (B) dye-stained with Basic Red 28 at 500nm, (C) dye-stained with Basic Red at 550nm, (D) fumed with cyanoacrylate

Figure 7. Merged image of print \#16

Figure 8. FP \#159 stained with BR28, at 470nm

Figure 9. FP \#159 stained with BR28, at 550nm

Figure 10. MINTCT minutia detection process

Figure 11. FP \#10 cyanoacrylate fumed

Figure 12. FP \#80 cyanoacrylate fumed

Figure 13. Percentages of each score from 1 (highest quality) to 5 (lowest quality) in original images vs. merged images

Figure 14. Percentages of each score from 0 (lowest quality) to 4 (highest quality) in original images vs. merged images

Figure 15. Average match scores for each processing technique and substrate

Figure 16.3D bar graph showing the fraction of images that were enhanced by merging 


\section{INTRODUCTION}

Latent fingerprints are highly common among evidence that is found and collected at crime scenes. They can represent a unique individual, and are therefore very valuable to the examiner to identify possible suspects. While forensic experts are very knowledgeable about fingerprint identification and performing comparisons, there are many discussions regarding ways to improve the quality of a latent fingerprint image. Quality is essential when examining latent fingerprint images, and the importance of capturing a print with decent friction ridge detail can be pertinent to an investigation. Examiners strive to achieve the best level of quality in a fingerprint image in order to ensure performing their best analysis of the print when marking minutia and comparing latent prints. Low quality on a fingerprint causes difficulty in performing comparisons. The purpose of this study is to determine a method for increasing the quality of a single fingerprint by photographing the print under different conditions, and performing image fusion to create a final image of better quality for comparison. Better quality is defined as more contrast between the background and friction ridge detail of the fingerprint.

Image fusion technology is an increasingly effective method used in forensic analysis of material evidence. Other forensic disciplines have already begun using this technology, such as tool mark and handwriting examination. Experts utilize different lighting conditions and camera settings in order to capture multiple images of the evidence, and then merge these images together to obtain a better quality image than the original. Considering the substantial use and success of image fusion in areas such as surveillance, medical imaging, and biometrics, image fusion of latent fingerprints could become an important part of latent fingerprint identification.

A definition of image fusion that has been accepted among the remote sensing community is stated by Wang et al. as "data fusion is a formal framework in which are expressed means and tools for the alliance of data originating from different sources. It aims at obtaining information of greater quality; the exact definition of 'greater quality' will depend upon the application" [11]. Zitova and Flusser have discussed possibilities of error when referring to image registration in prior research, which will be addressed in this research. They stated that there is a possibility of localization error, matching error, alignment error, and test point error, but that each of these can be controlled by consistency checks and analysis by the examiner of the image [14].

Automated matching systems are typically the method of comparison for latent fingerprint identification. The algorithm matches prints based on the locations and rotations of extracted minutiae that are marked on the print [5]. The friction ridge impressions that compose the fingerprint must be of good quality in order for the minutia to be identified by the system. NIST states the importance of quality to biometrics and fingerprint identification systems:

"Performance of biometric systems is dependent on the quality of the acquired input samples. If quality can be improved, either by sensor design, by user interface design, or by standards compliance, better performance can be realized." [5] 
NIST determined that for the aspects of quality that cannot be controlled, there must be a way to analyze the quality of a sample. In 2004, they developed the NIST Fingerprint Image Quality (NFIQ) which predicts the expected matching performance of fingerprint images [5]. The 2004 NIST report Fingerprint Image Quality states that:

"Presenting the matcher with good quality fingerprint images will result in high matcher performance, and vice versa, the matcher will perform poorly for poor quality fingerprints."

The important determination regarding this method is whether multiple images of the same fingerprint can be fused to create a new image with better quality. To determine this, each original fingerprint was given an NFIQ quality score. Once the multiple images of one print were merged, that image was also given an NFIQ quality score. The scores were then compared to determine if the merging of the original images improved the quality compared to the originals prior to merging. A second scoring system was used along with NFIQ, denoted the Bandey scale. The Bandey scale is a quality assessment based off of the examiners analysis of each individual print. All images were then uploaded into an automated matching system (AFIX) and minutiae extracted. The images were searched against a database of rolled tenprints, which contained the subjects fingerprint. Match scores for all fingerprints were recorded. If the image fusion was successful between multiple images of the same latent print, then the image quality of the new, merged image would be better, therefore resulting in higher match scores when searched on the automated matching system. A print was considered to be improved if the merged score was better than the scores of all the original images.

\section{PREVIOUS RESEARCH}

Research on image fusion and forensic evidence has been done with one common goal; to increase the quality of images used for comparisons by fusing multiple images together. This method has so commonly been used in areas such as medical imaging, surveillance, and biometrics, that it has adopted a very sound reliability within the scientific community. It is understandable that forensic scientists have begun to use this method and adapted it to use on forensic evidence photography. Specifically, pattern recognition is highly relevant to this method due to the intricate detail needed to make some comparisons.

Zhang [13] released an article analyzing the use of image fusion technology, combined with software integration, in feature extraction and image enhancement in material evidence photography. This research dealt with a variety of evidence such as tool mark impressions, handwriting impressions, and fingerprints deposited on curved surfaces. Figure 1 below is an image of a fingerprint on a curved surface. The print was imaged under two different lighting conditions, (A) and (B), and the two images were then merged to create the composite image (C). The research showed how fusing two lower quality images together with different information contained in each can result in a final image containing more information. 


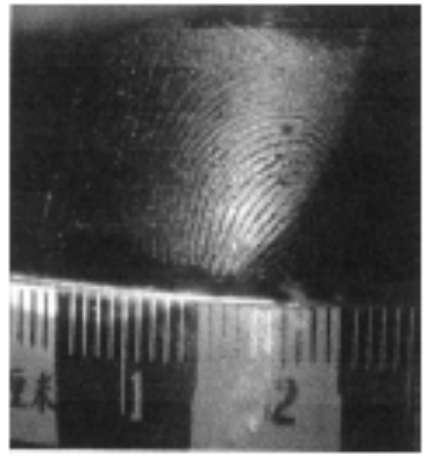

(A)

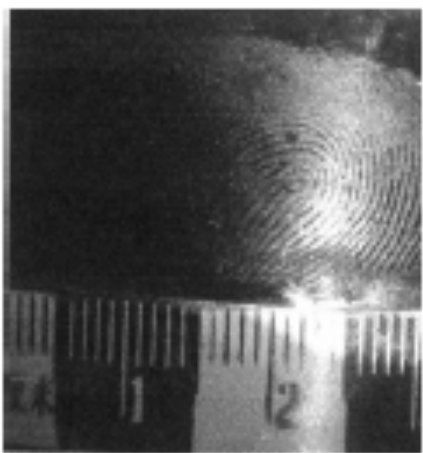

(B)

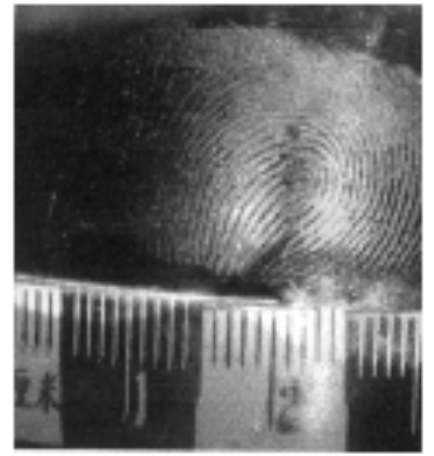

(C)

Figure 1 (A) and (B) show a fingerprint on a curved surface with lighting at two different angles. Image (C) is the merged image of (A) and (B) [13]

This article explores the use of pixel-level fusion, which is stated as 'the mainstream method' and the method that Photoshop uses to perform image fusion. Zhang [13] reported that Photoshop is a commonly used program to enhance material evidence images, discussed the validity of the method of image fusion using Photoshop, and concluded that the use of image fusion technology can be effective in the process of material evidence photography. Zhang stated that the method of image fusion can effectively solve any material evidence photograph problems relating 'to a certain extent.' [13] The statement "to a certain extent" implies that image fusion cannot make up for all evidence photography problems, and may not be able to help in cases of very low quality or missing detail.

Ross, S. Shah, and J. Shah [7] performed research on image mosaicing for fingerprints. The goal of their research was to take the information of two or more fingerprint impressions and create composite information, resulting in a more complete final image. They discussed two ways to combine the images; blending the impressions into a single mosaic or integrating the feature sets. Figure 2 shows two fingerprints (A) and (B) that were combined using image mosaicing to create the final image $(C)$, which encompasses more information than the two individual prints [7]. 


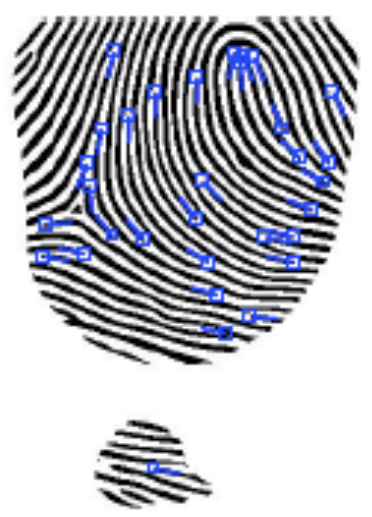

(a)

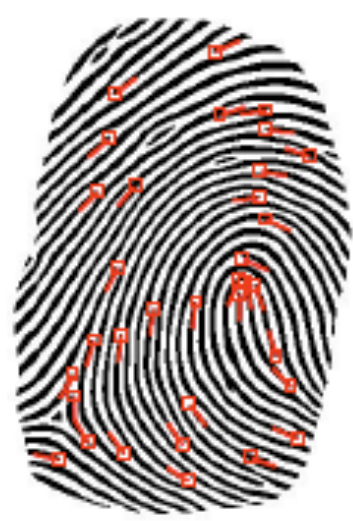

(b)

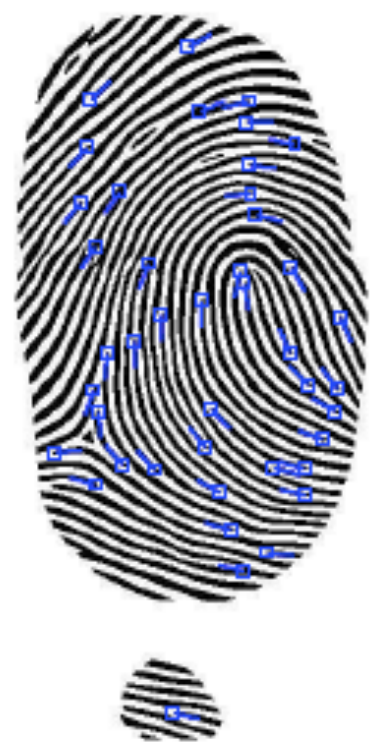

(c)

Figure 2 (A) and (B) are partial prints, image (C) is the final print after image mosaicing was done on (A) and (B)

Although Ross, S. Shah, and J. Shah [7] used Thin Plate Splines to create a composite, while this research utilized the Photoshop Auto-Blend algorithm, the goal of their study was similar; merge fingerprint impressions in order to obtain a better quality image, and obtain better match scores.

Joshitha and Selin [3] discussed image fusion using principal component analysis (PCA) for palm print recognition. The study focused on the use of PCA to fuse multiple images of the same palm print in order to obtain a full image of the print, and subsequently performing feature extraction to look at minutia, density map, and principal line map. This research showed that image fusion could create a higher quality composite image containing greater detail. They were able to determine that the matching accuracy was significantly improved through image fusion [3].

Research was not found which specifically involves fusing fingerprints that were processed using various physical or chemical techniques and imaged under multiple wavelengths and filters. 


\section{METHODOLOGY}

\subsection{Materials}

- $\quad$ Nikon ${ }^{\circledR} \mathrm{D} 7100^{\mathrm{TM}}$

- Nikon ${ }^{\circledR}$ Nikkor $60 \mathrm{~mm} \mathrm{f/2.8} \mathrm{Lens}$

- Neenah Exact Index cardstock 8.5 x 11 in.

- Fisherbrand 75 x 50 x $1 \mathrm{~mm}$ microscope slides

- Plastic page protectors

- Air Science USA fuming chamber

- Cyanoacrylate glue

- Diazafluorenone (DFO), ninhydrin reagent, zinc chloride reagent

- Basic red 28, basic yellow 40, rhodamine 6G, and MBD dye stains

- Sirchie black fingerprint powder

- Alternative Light Source

- Orange and green band-pass filters

- Adobe Photoshop CC 2014 Photo Editing Software

- AFIX Tracker

- NIST Fingerprint Image Quality software

\subsection{Methods}

\subsubsection{Fingerprint deposition}

There were a total of 328 prints taken from one subject. The prints were deposited on four different substrates; glass (99), plastic (136), cardboard (26), and white paper (67). Each print was deposited from the same subjects left thumb to eliminate the variable of different friction ridge patterns. The prints were deposited with added sebaceous material to keep the deposits consistent; the subjects' finger was rubbed against her forehead to add some of the oils present on the forehead. The addition of sebaceous material to the finger prior to deposition was 
necessary due to not enough oils being present on the finger. This was especially true when deposition occurred on paper and cardboard samples.

Processing of prints deposited on both porous and non-porous surfaces was done immediately to avoid saturation of the print into the porous substrate or the possibility of degradation due to light or other environmental conditions.

The prints were deposited on Neenah Exact Index cardstock 8.5 x 11 in. for the paper samples. They were deposited along the outer edge of the paper about 1 inch apart, and then immediately processed via either DFO, ninhydrin, or zinc chloride techniques. After processing was complete the prints were numbered. The glass samples were deposited on Fisherbrand $75 \mathrm{x}$ $50 \times 1 \mathrm{~mm}$ microscope slides. Two to three prints were deposited on each slide, and then numbered after fuming with cyanoacrylate. The prints deposited on plastic were on plastic page protectors, and then numbered after fuming with cyanoacrylate. The cardboard samples were deposited on the inside of a cardboard box to avoid overlays of areas that had been touched and were processed immediately with DFO, ninhydrin, or zinc chloride.

\subsubsection{Processing Techniques}

Detection of each print began with optical techniques. Optical detection techniques have the advantage of being non-destructive, therefore preceding any other physical processing techniques. The prints were first analyzed via illumination with white light. Any friction ridge detail visible was to be photographed. Detail was unable to be photographed for any of the fingerprints viewed under oblique illumination because no detail was visible without processing. Analysis was then done using absorption and/or luminescence, depending on the substrate and processing technique. Varying wavelengths and filters were used to illuminate the prints based on the processing technique that was used.

\subsubsection{DFO}

DFO was used to develop a total of 58 latent prints on paper (32) and cardboard (26). The reagent produces a pale purple color upon reaction with the amino acids in a fingerprint. DFO is a popular technique because the developed marks show a strong luminescence and the process is very simple and rapid. The sample was first sprayed with the reagent until saturated and allowed to air dry. The sample was then heated for 40 minutes at $100{ }^{\circ} \mathrm{C}$ with ambient humidity. Once removed from the heat source, the fingerprint was viewed under multiple wavelengths ranging from $450 \mathrm{~nm}$ to $530 \mathrm{~nm}$ with orange goggles. The use of this reagent allows further processing to be done using Ninhydrin [8]. Images were captured for the DFO developed prints at $470 \mathrm{~nm}$ with an orange bandpass filter.

\subsubsection{Ninhydrin}

Ninhydrin was another reagent used to develop 61 total latent prints on paper (35) and cardboard (26). The chemical compound 2,2-Dihydroxyindane-1,3-dione reacts with the amino acids that are present in a fingerprint due to the eccrine component to create a dark purple coloration known as Ruhemann's Purple. The sample was sprayed until completely saturated by the reagent, allowed to air dry and heated to $80^{\circ} \mathrm{C}$ and $65 \%$ humidity for 40 minutes. The prints 
were viewed under white light, with no goggles, and under white light with green goggles. Images were captured under white light with no filter, and under white light with a green bandpass filter. The latent prints that were previously processed with DFO were also subsequently processed with ninhydrin.

\subsubsection{Zinc Chloride}

Zinc chloride was used to further process the prints that were processed using ninhydrin on the paper samples, including the post-DFO ninhydrin treatment. Ninhydrin treatment does not interfere with further treatment by zinc chloride [9]. The aqueous reagent changes the purple color of the ridges that were a result of the ninhydrin to an orange/red color. The advantage of using this technique as a post-ninhydrin treatment is that it fluoresces under wavelengths from 490-505 $\mathrm{nm}$ and may bring out more friction ridge detail. The samples were sprayed with zinc chloride, allowed to dry, and heated to $80^{\circ} \mathrm{C}$, at $65 \%$ humidity for 40 minutes. The prints were viewed at $490 \mathrm{~nm}$ with orange goggles. Images were captured at $490 \mathrm{~nm}$ with an orange bandpass filter.

\subsubsection{Cyanoacrylate Fuming}

Fingerprints deposited on the non-porous substrates (glass and plastic) were fumed with cyanoacrylate. A total of 235 prints were fumed. The samples were placed into the Air Science USA fuming chamber with a heat source, superglue, and a water source for humidity. The chamber was set at $80^{\circ} \mathrm{C}$ with humidity at $65 \%$. The cyanoacrylate polymerized on the friction ridges to create white ridges with more contrast. After latent prints were fumed with cyanoacrylate, they were dye-stained with either basic yellow 40 (18 glass, 0 plastic), basic red 28 (33 glass, 40 plastic), MBD. (16 glass, 46 plastic), and rhodamine 6G (32 glass, 50 plastic). Each dye staining process required the prints to be submerged in the reagent for 5-10 seconds, allowed to dry, rinsed with distilled water, and allowed to air dry again. Each dye stain was used on both substrates, however the basic yellow 40 on the plastic substrate did not develop correctly, and due to being completely out of the reagent with a small time frame left to obtain images, it was determined that the number of images using other dye-stains were sufficient for the aim of the study, and the basic yellow 40 dye-stained prints on plastic were not a necessity to analyze the method. These prints were numbered 100-119, and were eliminated from the study.

Table 1. List of dye stains used after fuming, wavelengths, and filters

\begin{tabular}{|l|l|}
\hline Dye Stain & Wavelength/filter \\
\hline Basic Yellow 40 & $385,450,485 \mathrm{~nm}$, orange filter \\
\hline Basic Red 28 & $470,500,550 \mathrm{~nm}$, orange filter \\
\hline Rhodamine 6G & $500,515,540 \mathrm{~nm}$, orange filter \\
\hline MBD & $415,450 \mathrm{~nm}$, orange filter \\
\hline
\end{tabular}




\subsubsection{Dusting using black powder}

The only samples that were dusted with black powder were the prints deposited on glass, fumed with cyanoacrylate, and dye stained with basic red 28. After dusting the prints and photographing them, it was obvious that the prints had become degraded and had a significant loss in quality just by observation. Once observing this, it was decided that no other fingerprints would be dusted due to this subsequent processing worsening the quality of the print. The black powder seemed to not only stick to the friction ridges but to the background of the print. This may have been due to any extra reagent still present on the substrate.

\subsubsection{Sequence of Processing Techniques}

Processing techniques for any forensic evidence, whether it is fibers, drugs, hairs, or fingerprints, starts with the non-destructive methods first, and may be followed with processes that will help to enhance the quality of the fingerprint. Figure 3 shows the sequence of how the prints were processed. This was adapted from Champod's (2004) suggested sequence of processing techniques, which was used as a guideline for how the prints were processed [1].

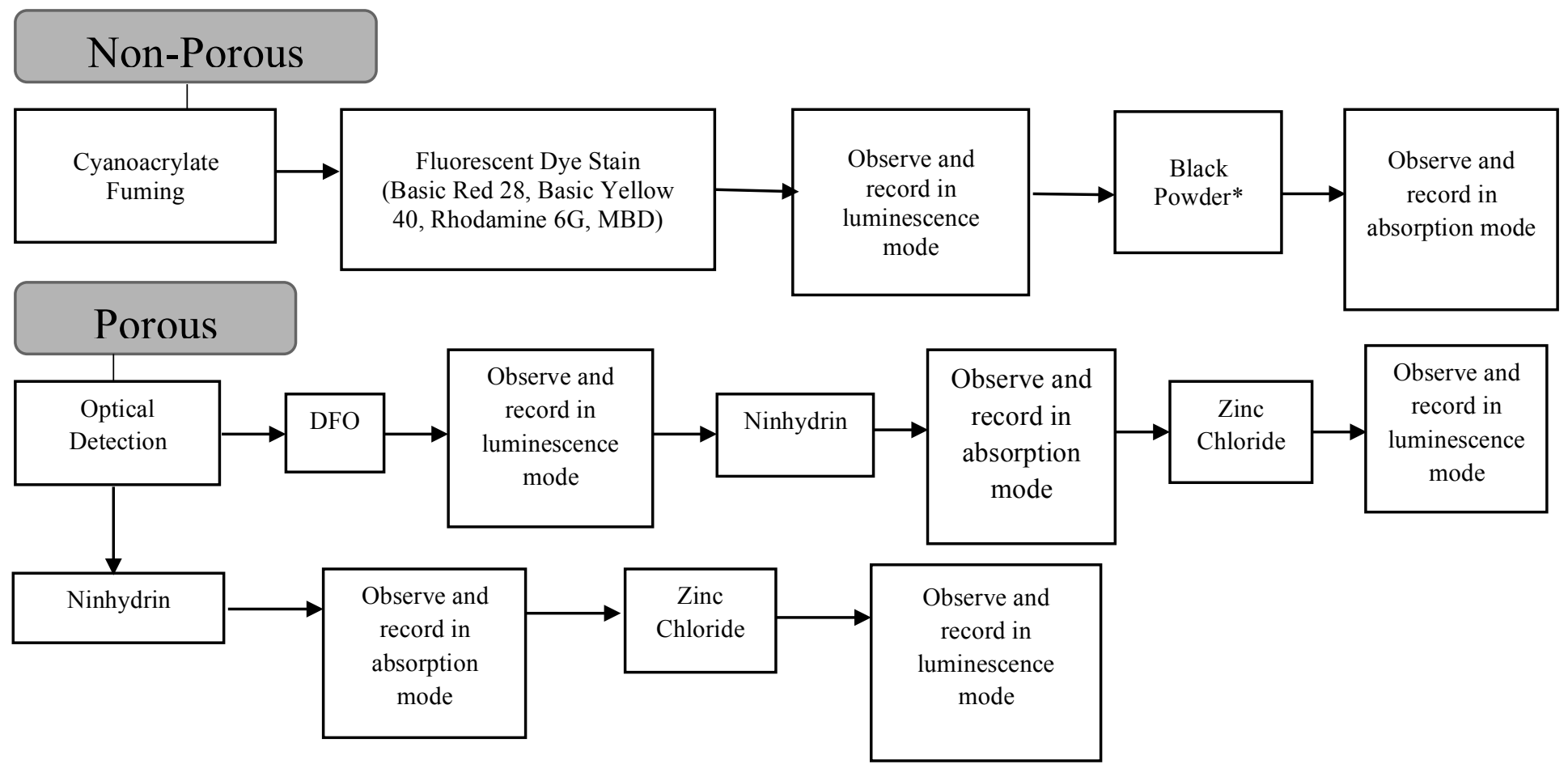

Figure 3. Flow chart showing the sequence of processing techniques

*Only performed on prints deposited on glass, fumed with CA, and dye stained with basic red 28 


\subsubsection{Digital Image Processing and Forensics}

The Scientific Working Group on Friction Ridge Analysis, Study and Technology (SWGFAST) presents standards for friction ridge impression digital imaging for latents or tenprints. A latent that is being used as an item of evidence must be documented according to the SWGFAST guidelines. Also, image integrity must be maintained by keeping an image of the original fingerprint and any enhancements will be saved as separate images [10]. All original images were kept, along with all image enhancements saved separately for this study.

\subsubsection{Image Contrast Adjustment}

The contrast for each original image was adjusted using Photoshop CC 2014. This process was done by adjusting the histogram of each image to obtain the highest amount of contrast possible. The shadows, midtones, and highlights were adjusted by using the levels adjustment function to change the tonal range of the image and achieve higher contrast prior to merging the individual fingerprints. Images that had too low of a tonal range, therefore resulting in less contrast, where given a larger range between 0 and 255 . The quality of the contrast was measured during this step by simply observing the print and the contrast between the friction ridges and the background, and by looking at the tonal range and histogram of each image.

Prior to performing image fusion on all samples, it was decided based on the first few samples done that the image contrast would be adjusted in order to give the best possible scenario. Without adjusting the contrast, the fused images contained very little information from the other images, and were mostly composed of one image. The contrast was adjusted in all images in order to eliminate that as a variable of image quality.

\subsubsection{Digital Image Registration Using Photoshop Auto-Align}

Digital image registration is the process of converting images of different data sets into one coordinate system. This process is used to align images that have different magnification, rotation, field of view, scale, translation, etc. It is also known as image alignment, and is essential in many image analysis processes, including image fusion [14]. One of the images of interest is the reference image, while the other image(s) are the target image(s). The target image(s) are spatially registered to align with the reference image. There are two types of image registration: area-based and feature-based [14]. In this study, feature-based registration was done by utilizing the Auto-Align command on Photoshop CC 2014. Feature-based registration uses fixed points in an image (line intersections, corners, edges, areas of high curvature, region features, etc.) and establishes a correspondence between these points. The Auto-Align command on Photoshop CC 2014 automatically aligns layers based on similar content in different layers. Once this correspondence between different layers is established, a transformation is done to map the target image to the reference image. Photoshop automatically chooses a reference layer based on the images uploaded by the user, and the matching content overlays itself [13].

Photoshop allows the user to register the images in the same step as merging the image, which will be discussed further in the next section. First, through the File menu, Scripts $>$ Load Files Into Stack was selected. Browse was then selected, and multiple RGB images of the sample 
print were highlighted and opened. The Automatically Align Source Images box was checked. This option uses the Auto-Align feature prior to stacking the images, which eliminates performing this action in a separate step. After all images loaded, each image was selected and cropped to adjust the aligned images and cut the edges.

The specific algorithm that Adobe uses to perform feature-based registration is unable to be released to the public. Since it is unknown what the algorithm that Adobe uses for this function is, a brief overview of possible feature-based algorithms will be discussed; canny-edge detector and detectors based on Laplacian [14]. These two algorithms are specifically used to establish correspondence between images by detecting edges.

\subsubsection{Canny Edge Detector}

One possible feature-based algorithm that Adobe may utilize for establishing correspondence is the canny edge detector. This algorithm applies a Gaussian filter to smooth the image and eliminate noise, finds the intensity gradients of the image, applies non-maximum suppression to get rid of spurious response to edge detection, applies a threshold to determine edges, and finalizes the edges by detecting and suppressing weak edges that are not connected to strong edges [4].

\subsubsection{Laplacian of Gaussian}

This algorithm uses a Gaussian kernel to convolve an input image at a certain scale, giving a scale-space representation. The scale-space representation scales the input image to the target image in order to complete registration. The Laplacian operator is applied and the result is computed. The Laplacian performs edge detection by highlighting regions of rapid intensity change [19]. After a correspondence is made, the images were rotated by the program to create an alignment based on the edges that were detected. Registration was performed between multiple images of one fingerprint, for all samples. The prints that were deposited on paper and cardboard were unable to be successfully registered; therefore they were also unable to be fused together. After attempting with each image and having reoccurring failure, it was decided to eliminate these samples from the sample set. This will be discussed further in section 4.5.

\subsubsection{Digital Image Merging Using Photoshop Auto-Blend}

Each individual image contains pertinent information. Information from multiple images can be combined to create a single image containing both sets of information. This composite image will provide more comprehensive information for analysis [13]. In this study, the AutoBlend Layers feature on Adobe Photoshop CC 2014 was used to combine multiple images of the same fingerprint. This function applies layer masks to each layer to mask over- or under-exposed areas, or content differences, and create a composite image [13]. Once the images were registered and aligned with one another as outlined in the previous section, they were merged on Photoshop. Under the Edit menu, Auto-Blend Layers was selected, and then Stack Images. This process resulted in a blended image of all chosen layers. This blended image was merged into a single composite image, eliminating the separate layers, by selecting Merge Layers from the Layer menu. Figures 4 and 6 below show an example of four images of one fingerprint, and Figures 5 and 7 show their composite images, respectively, once layers were aligned, cropped, and merged. The individual layers and final merged image were each converted to grayscale 
before being saved as a separate JPEG since the NFIQ program used for analysis required all images to be in JPEG format and grayscale. Table 2 gives the total number of images taken for each processing technique and the merged images.

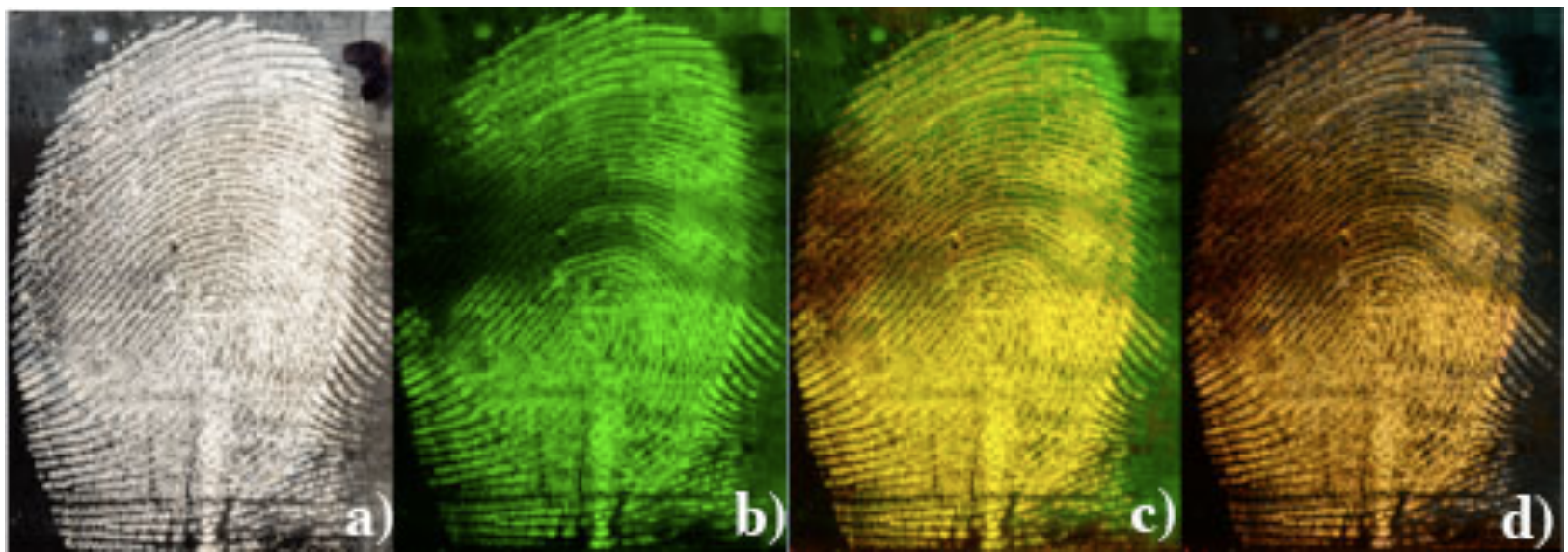

Figure 4. Individual images of print \#172 before merging. Deposited on glass and photographed under four different conditions; a) fumed with cyanoacrylate, b) dye-stained with Rhodamine $6 \mathrm{G}$ at $540 \mathrm{~nm}$, c) dye-stained with Rhodamine $6 \mathrm{G}$ at $515 \mathrm{~nm}$,d) dye-stained with Rhodamine $6 \mathrm{G}$ at $500 \mathrm{~nm}$

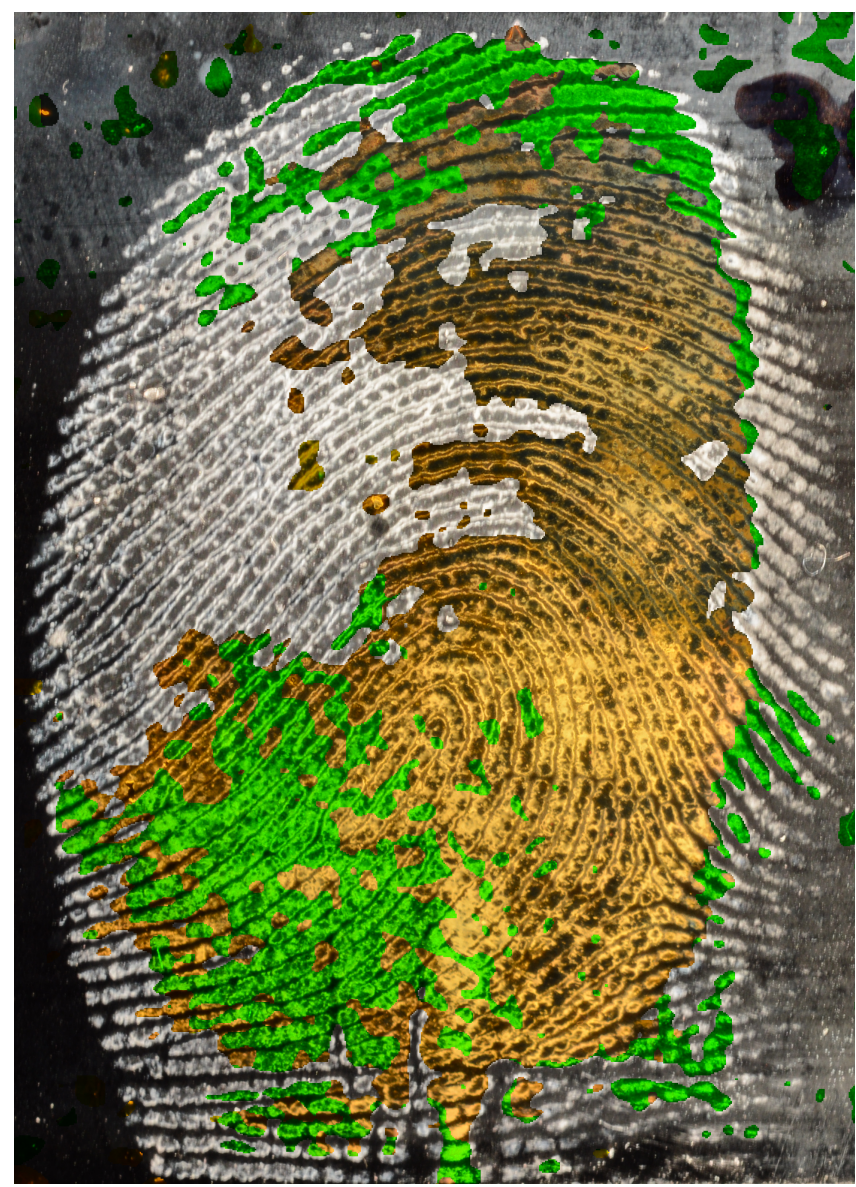

Figure 5. Merged image of print \#172 


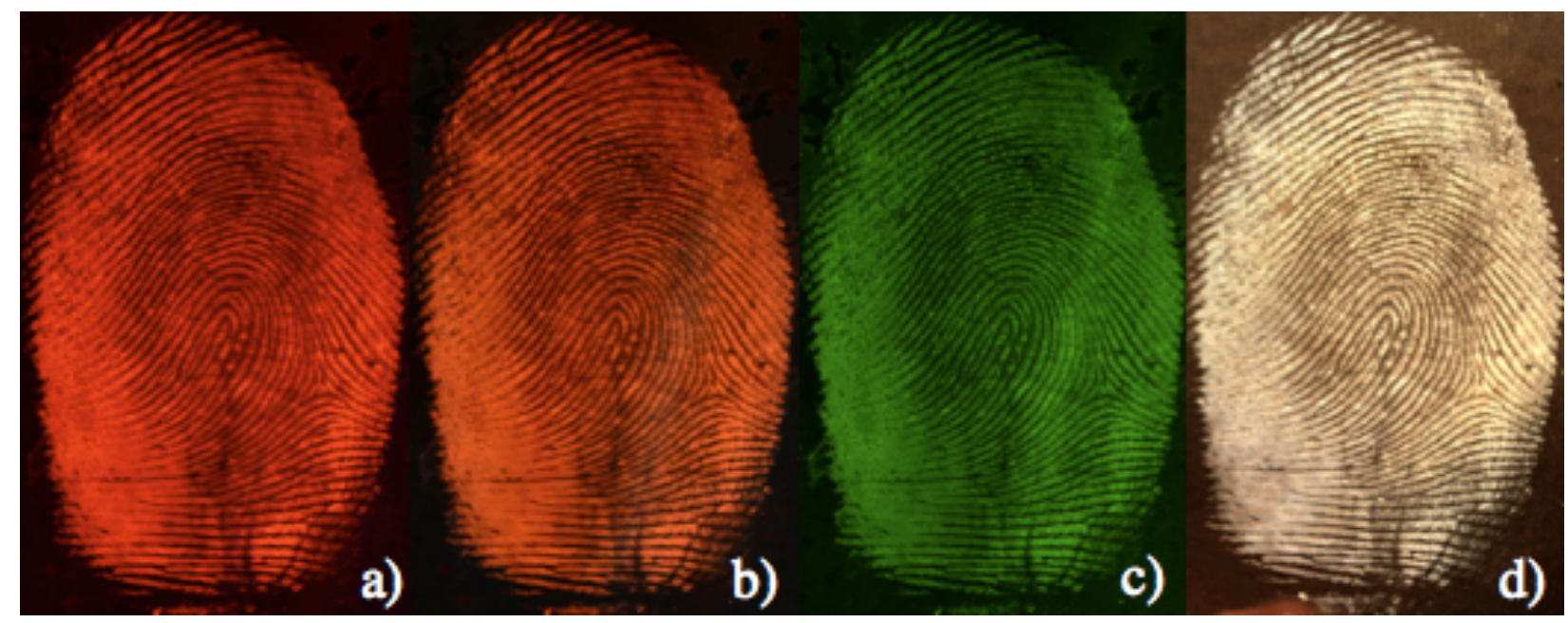

Figure 6. Individual images of print \#16 before merging. Deposited on plastic and photographed under four different conditions; a) dye-stained with Basic Red 28 at 470nm, b) dye-stained with Basic Red 28 at 500nm, c) dyestained with Basic Red at 550nm, d) fumed with cyanoacrylate

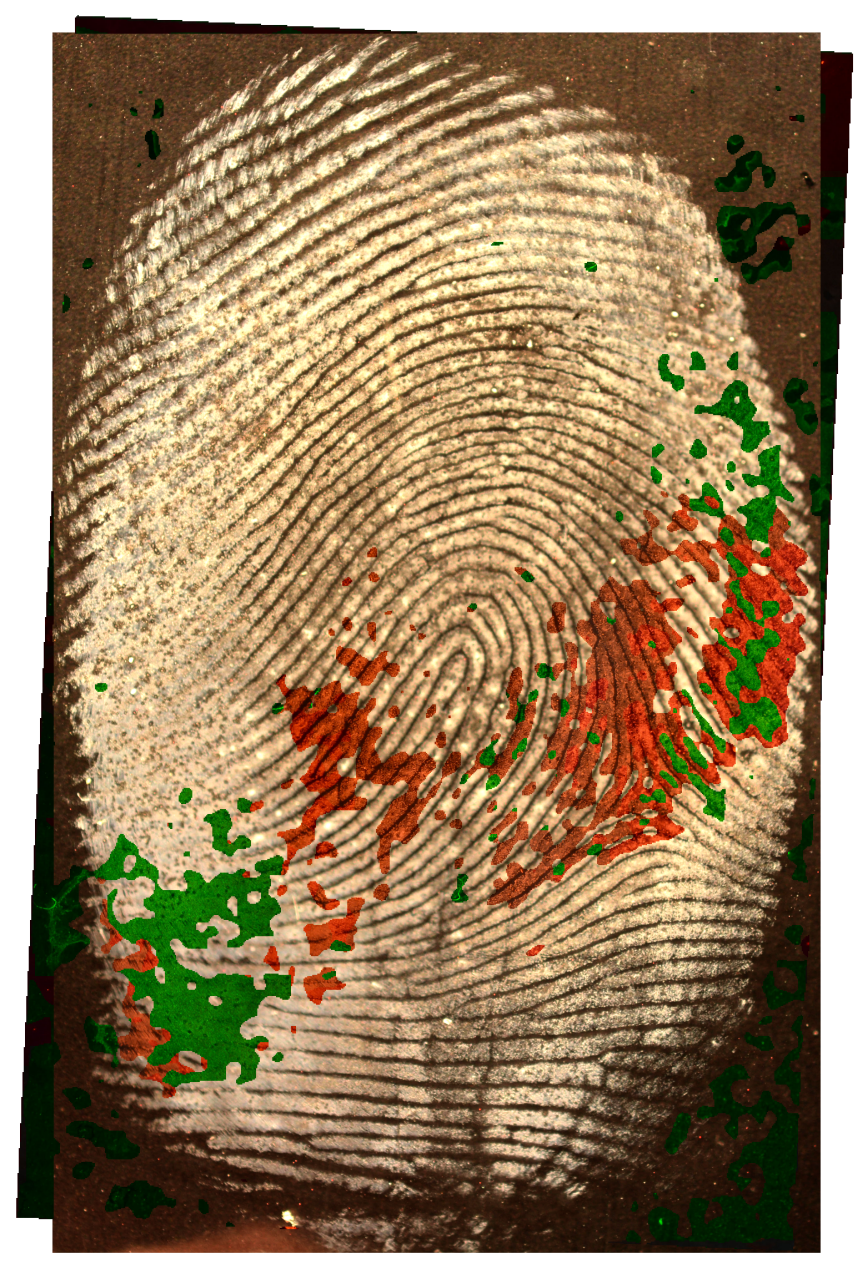

Figure 7. Merged image of print \#16 
Table 2. The total number of images for each process and merged images

\begin{tabular}{|ccc|}
\hline Substrate & Processing Method & Total Images \\
\hline Glass & Cyano & 98 \\
\hline Glass & Basic Red 28 & 99 \\
\hline Glass & Basic Yellow 40 & 54 \\
\hline Glass & Rhodamine 6G & 96 \\
\hline Glass & MBD & 16 \\
\hline Glass & Merged & 99 \\
\hline Plastic & Cyano & 113 \\
\hline Plastic & Basic Red 28 & 118 \\
\hline Plastic & MBD & 91 \\
\hline Plastic & Rhodamine 6G & 90 \\
\hline Plastic & Merged & 115 \\
\hline
\end{tabular}

\subsubsection{NIST Fingerprint Image Quality (NFIQ)}

After each image was converted to grayscale and saved as a JPEG, they were all placed into a folder within the NFIQ program that would be set as the directory for the script that was entered into Linux. The NFIQ algorithm will only take an input image that is in ANSI/NIST or NIST IHEAD format or is compressed. The input images can be compressed using baseline JPEG or lossless JPEG, which was the case for this study. NFIQ assesses image quality by computing a feature vector using the quality image map and minutiae quality statistics produced by the MINDTCT minutia detection algorithm (Figure 8) [5].

The quality image map generated by the MINDTCT package measures the quality of regions of the print by detecting regions of low contrast, low ridge flow, and high curvature. These three conditions represent unstable areas in which minutiae detection is unreliable. The direction map, low contrast map, low flow map, and high curve map mark blocks of the fingerprint that are unreliable. The information from these individual maps is combined into one general map containing five levels of quality from 0 to 4 . A score of 0 quality is regarded as the background and lowest quality, while a score of 4 is the highest quality [5]. The unstable areas are flagged when the score is lower than a 2 . The quality is determined based on its proximity to blocks that were flagged in the maps.

The minutia quality is then determined by assessing the location of the minutia points within the quality map. The algorithm also takes into account pixel intensity statistics within the immediate neighborhood of the minutia. The minutia quality are rated as 0.5 or better, 0.6 or better, 0.75 or better, 0.8 and better, and 0.9 and better. Minutiae that have a quality lower than 0.5 are unreliable. 
NFIQ combines the image quality map and the minutia quality assessment to create an 11dimensional feature vector. Table 3 below shows the feature vector description [5].

Table 3. Feature vector description of MINDTCT algorithm [5]

\begin{tabular}{|c|c|c|}
\hline & NAME & DESCRIPTION \\
\hline 1 & foreground & $\begin{array}{l}\text { number of blocks that are quality } 1 \text { or better; i.e. foreground }=\sum_{i=1}^{4} U_{i} \\
\text { where } U_{i} \text { is number of blocks with quality } i\end{array}$ \\
\hline 2 & total \#of minutia & number of total minutiae found in the fingerprint \\
\hline 3 & $\min 05$ & number of minutiae that have quality 0.5 or better \\
\hline 4 & $\min 06$ & number of minutiae that have quality 0.6 or better \\
\hline 5 & $\min 075$ & number of minutiae that have quality 0.75 or better \\
\hline 6 & $\min 08$ & number of minutiae that have quality 0.8 or better \\
\hline 7 & $\min 09$ & number of minutiae that have quality 0.9 or better \\
\hline 8 & quality zone 1 & percentage of the foreground blocks of quality map with quality $=1$ \\
\hline 9 & quality zone 2 & percentage of the foreground blocks of quality map with quality $=2$ \\
\hline 10 & quality zone 3 & percentage of the foreground blocks of quality map with quality $=3$ \\
\hline 11 & quality zone 4 & percentage of the foreground blocks of quality map with quality $=4$ \\
\hline
\end{tabular}

The feature vector is used to input a Multi-Layer Perceptron neural network classifier. The output activation level of the neural network is used to determine the prints image quality score as an integer from 1 to 5 [5]. Figures 8 and 9 show fingerprint images and their NFIQ scores. Figure 8 is a print with an NFIQ score of 5, and figure 9 is a print with an NFIQ score of 1.

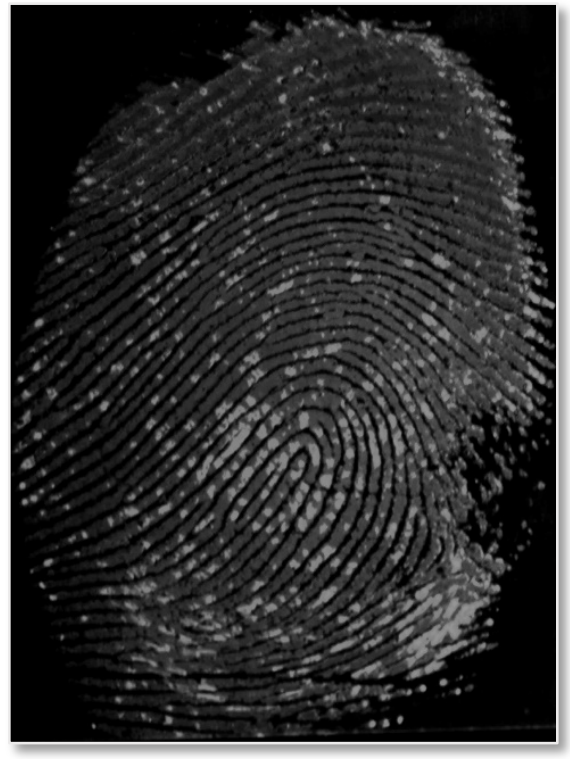

Figure 8. FP \#159 stained with BR28, at 470nm

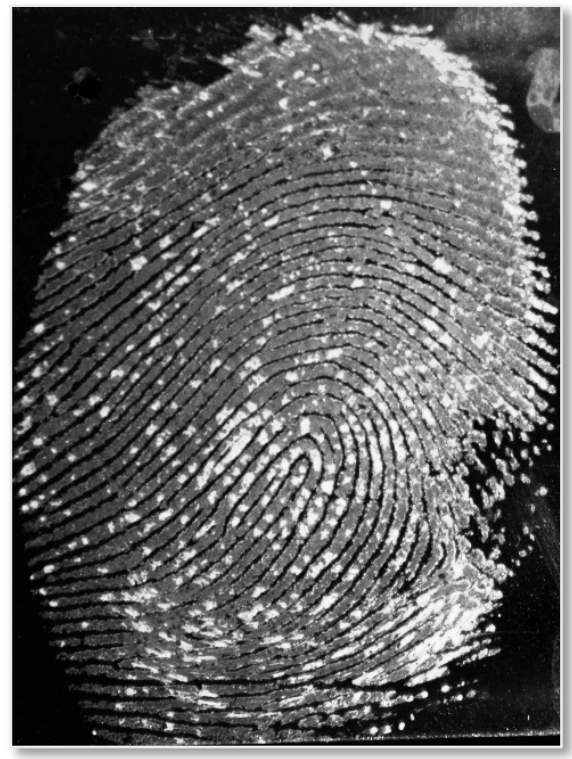

Figure 9. FP \#159 stained with BR28, at 550nm 


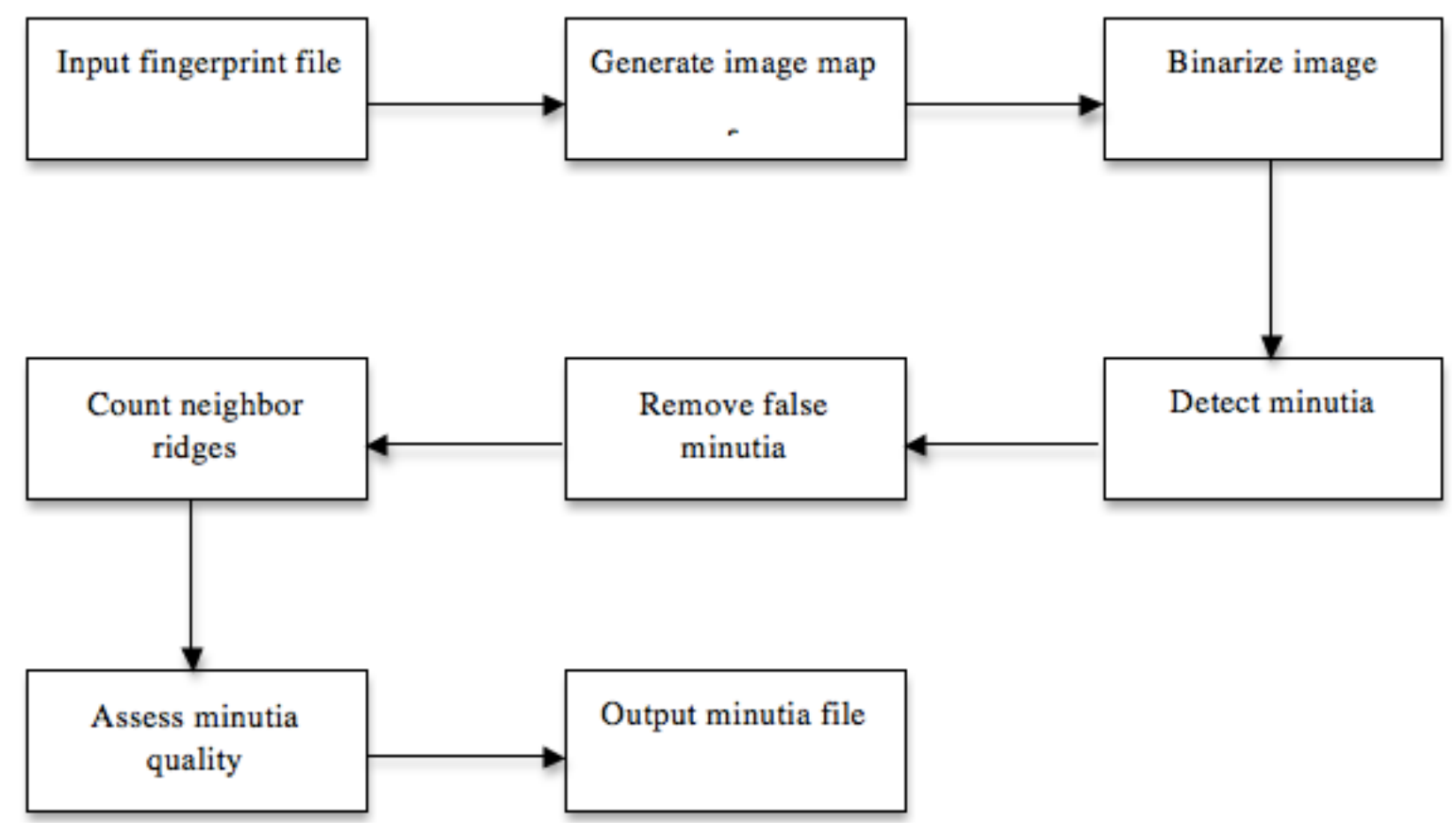

Figure 10. MINDTCT minutia detection process [5]

The commands to run NFIQ were entered into Linux and produced a quality score of an integer from 1 to 5 for each image next to the image file name in a separate text file. A score of 1 indicated the highest quality, and a score of 5 indicated the lowest quality [18]. The NFIQ source code was available for download through public domain and is under no license requirements.

\subsubsection{Bandey Scale}

All images were randomized and renamed by a peer in order to minimize subjectivity when rating each image using the Bandey scale. The five point scale (table 4) was created by Bandey to give a score from 0 to 4 that rates the amount of development of the print based on the examiner [17]. The purpose of utilizing the Bandey scale as an aspect of this study was to introduce a third type of image quality scoring system that is based on the examiner. This scoring method has the advantage of showing the significance of the merging based on what the examiner is viewing, which is importance since this is how an identification is performed. 
Table 4. Bandey fingerprint quality grading scheme [17]

\begin{tabular}{|l|l|}
\hline Grade & Description \\
\hline 0 & No development \\
\hline 1 & No continuous ridges; all discontinuous or dotty \\
\hline 2 & $\begin{array}{l}\text { One third of the mark comprised of continuous ridges; remainder show no } \\
\text { development or dotty }\end{array}$ \\
\hline 3 & $\begin{array}{l}\text { Two thirds of the mark comprised of continuous ridges; remainder either show } \\
\text { no development or dotty }\end{array}$ \\
\hline 4 & Full development; whole mark comprised of continuous ridges \\
\hline
\end{tabular}

Figures 11 and 12 show fingerprint images that were scored using the Bandey scale. Figure 11 was scored as a 4, and figure 12 was scored as a 1 . No fingerprints in this study were rated as a 0.

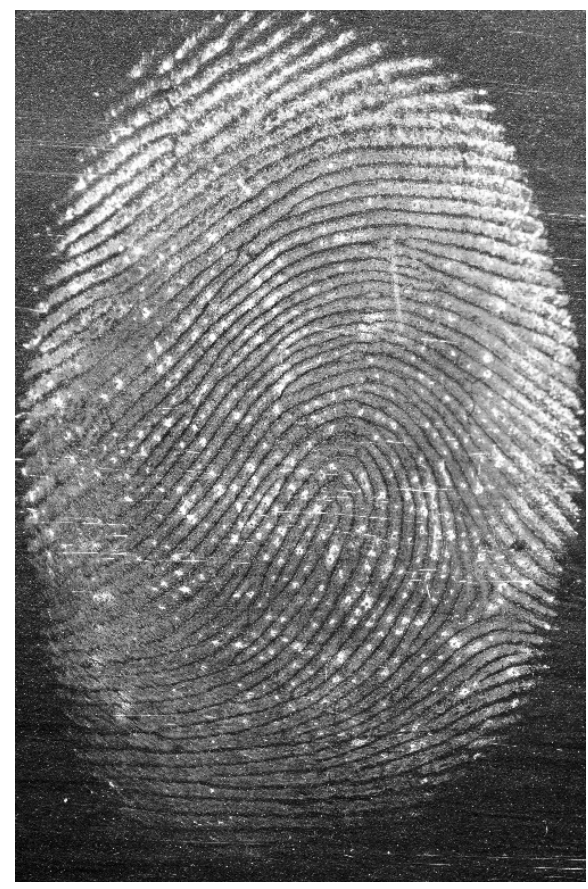

Figure 11. FP \#10 CA fumed

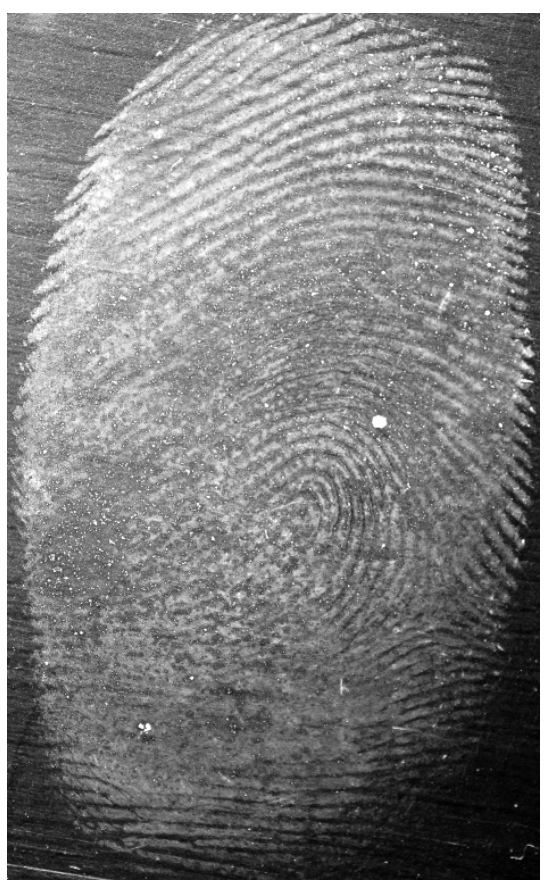

Figure 12. FP \#80 CA fumed 


\subsubsection{AFIX}

Fingerprint identification is typically performed using an automated matching system. AFIX Tracker, which is a fingerprint, palmprint, and biometric identification system, is the first automated fingerprint identification system that is PC-based [15]. AFIX uses a minutia matching algorithm which first registers the images by translation, rotation, and scaling as needed. After registration is performed, minutia pairs are counted between both fingerprints. Two minutia are determined to correspond if they are located within a bounding box. The matching of minutia is used to then create the match score [16].

Each image was loaded into AFIX as a latent file at 1000 PPI, along with a rolled tenprint from the subject that was scanned at 500 PPI. The minutia were manually marked on all prints, then a search was ran for each print against all tenprints in the database. The database used was the Crime Scene Lab database that is utilized by West Virginia University. The search was set to show the top 20 matches for each latent fingerprint. Once each print was searched against the database, the match score, number of lines, and false non-matches were recorded for each latent.

The three scoring methods were chosen due to the different aspects of quality they each analyze. NFIQ specifically looks at image quality by assessing contrast in the image and the quality of the minutia. The Bandey scale determines quality by the examiner's analysis of which image is clearer for identification. The AFIX match scores give information about the quality of the image by identifying and counting minutia. Analyzing the images using these three scoring methods was important in order to cover the different ways that the quality of a fingerprint can be determined.

\section{RESULTS AND DISCUSSION}

\subsection{NFIQ}

The data represented in tables 5 and 6 show that the average NFIQ score for all of the merged samples was 2.8, while the average NFIQ score for all of the original images was 3.1. The average NFIQ score for the merged samples was lower than the original samples by 0.3 . There were a higher percentage of merged images than original images with a score of 1 , and a higher percentage of original images than merged images with a score of 5 (Figure 13). There were 122 prints where the merged image NFIQ score was greater than the average score of the original images for that print, and 92 where the average score of the original images was greater than or the same as the merged. Therefore, $57 \%$ of merged images had a higher NFIQ score than the average of their original images. Section 4.4 will discuss the improvement in quality more in depth. 
Table 5. NFIQ scores and average score of all merged fingerprints NFIQ of Merged (All Samples)

\begin{tabular}{cc}
\hline Score & Frequency \\
\hline 1 & 64 \\
2 & 39 \\
3 & 34 \\
4 & 26 \\
5 & 51 \\
\hline Average Score & $\mathbf{2 . 8}$
\end{tabular}

Table 6. NFIQ scores and average score of all original fingerprints

NFIQ of Originals (All Samples)

\begin{tabular}{cc}
\hline Score & Frequency \\
\hline 1 & 220 \\
2 & 94 \\
3 & 91 \\
4 & 113 \\
5 & 257 \\
\hline Average Score & $\mathbf{3 . 1}$
\end{tabular}




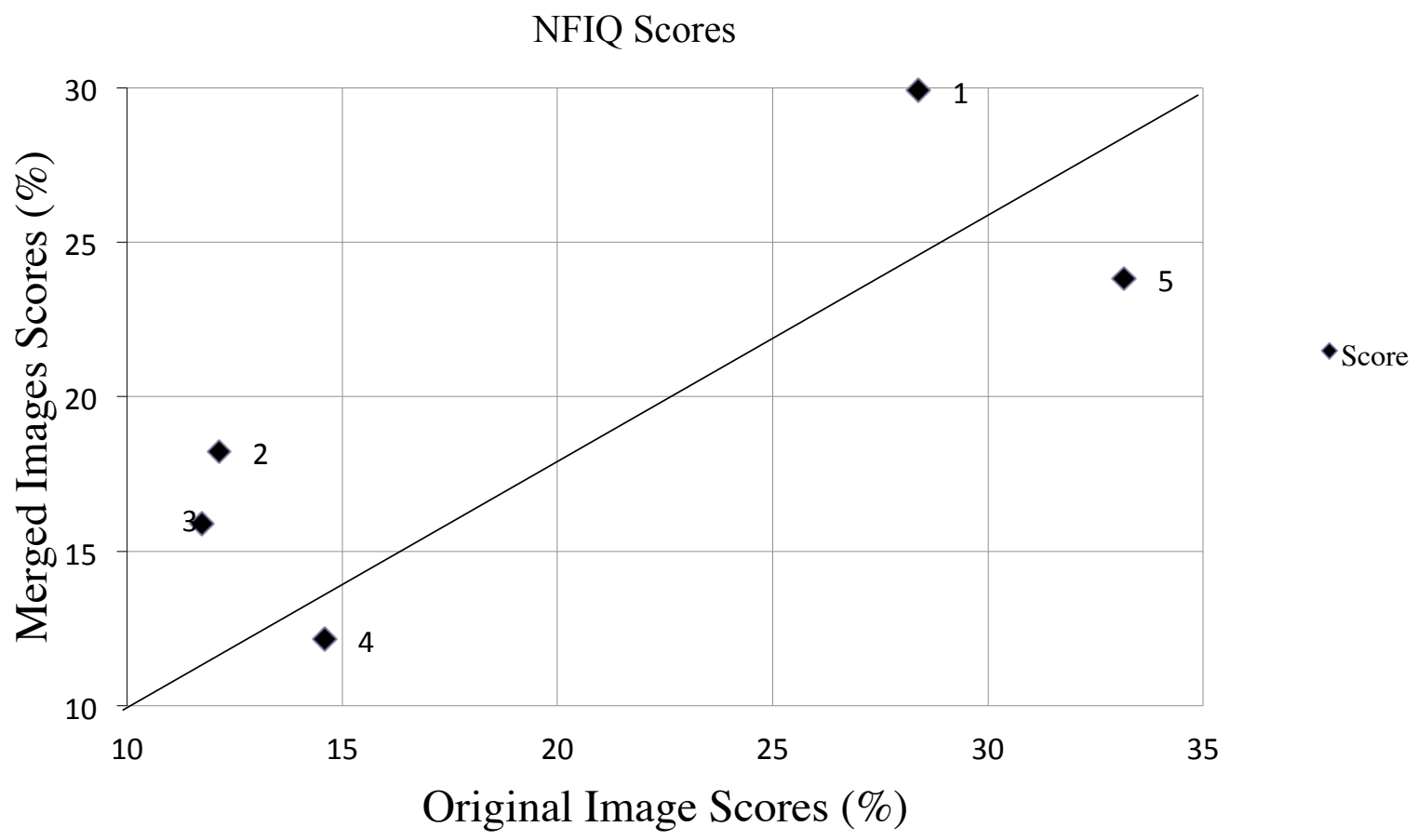

Figure 13. Percentages of each score from 1 (highest quality) to 5 (lowest quality) in original images vs. merged images

\subsection{Bandey Scale}

The data represented in tables 7 and 8 shows the Bandey scale scores of all merged and all original samples. The average score for all merged images and all original images based on the Bandey scale is 3.4 , meaning there was a 0.0 difference between the average scores. When comparing the percentage of merged samples with a score of 4 to the percentage of original samples with a score of 4 , there is a small amount of difference, but a higher percentage of the original images have a score of 4 . There are more merged images than originals with a score of 3. Scores 0,1 , and 2 represent little to no ridge detail and are a very low percentage of the scores for the merged and the originals. There were 100 prints where the merged image Bandey score was greater than the average score of the original images for that print, and 114 where the average score of the original images was greater than or the same as the merged. Forty-seven percent of merged images had a greater Bandey score than the average of their originals. 
Table 7. Bandey scale scores and average score of all merged images

\section{Bandey Scale of Merged (All Samples)}

\begin{tabular}{cc}
\hline Score & Frequency \\
\hline 0 & 0 \\
1 & 2 \\
2 & 15 \\
3 & 97 \\
4 & 100 \\
\hline Average Score & $\mathbf{3 . 4}$
\end{tabular}

Table 8. Bandey scale scores and average score of all original images

\section{Bandey Scale of Originals (All Samples)}

\begin{tabular}{cc}
\hline Score & Frequency \\
\hline 0 & 0 \\
1 & 4 \\
2 & 54 \\
3 & 318 \\
4 & 399 \\
\hline Average Scort & $\mathbf{3 . 4}$
\end{tabular}

\section{Bandey Scores}

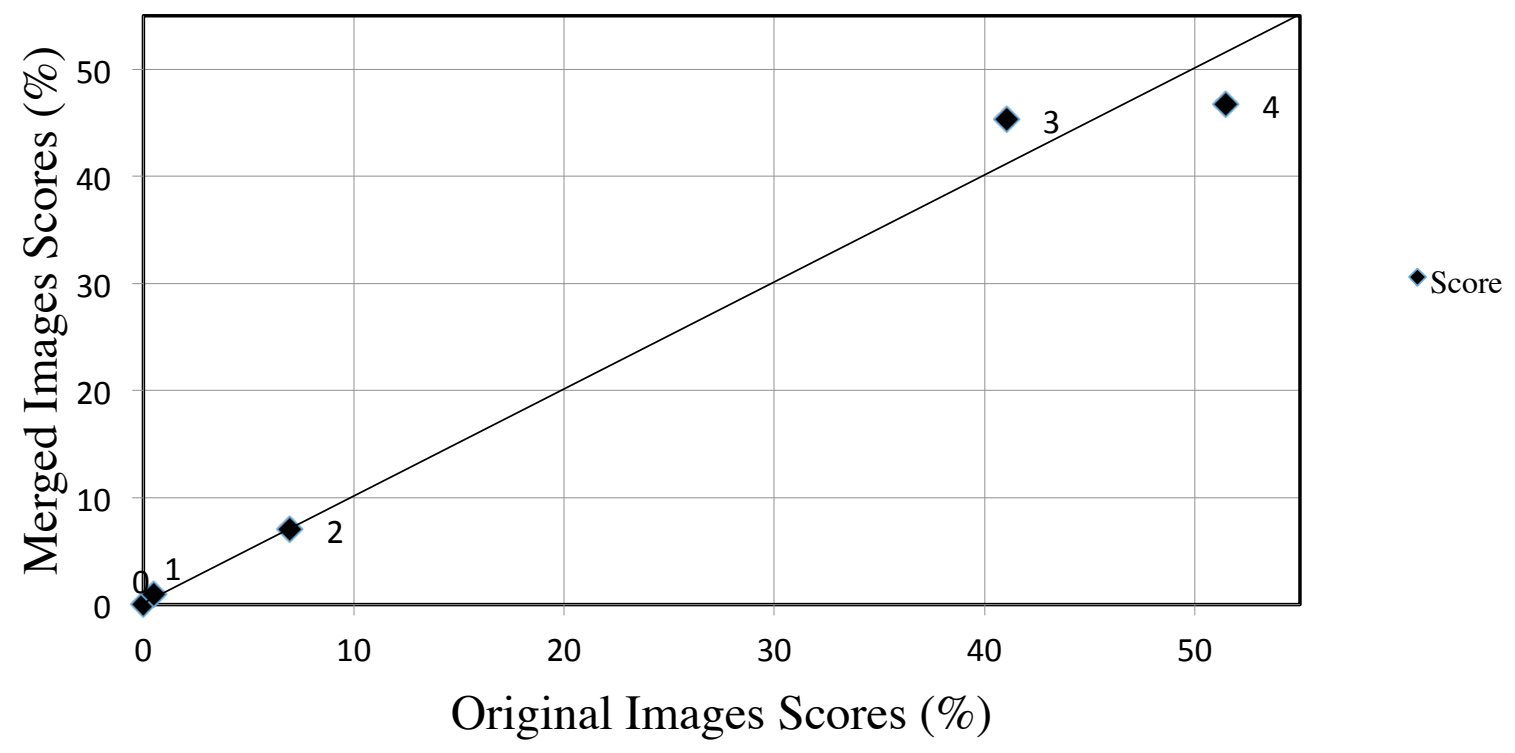

Figure 14. Percentages of each score from 0 (lowest quality) to 4 (highest quality) in original images vs. merged images 
The results from the Bandey scale showed that there was very little distinction between images rated a 3 or a 4, but there were little to no images rated a 2 or below (Figure 14). Also, since both merged and original images had an average score of 3.4, it is difficult to determine using this scale if the merged images were of better quality.

\subsection{AFIX}

Average match scores, the average percentage of lines drawn between matching prints, number of matches, and number of non-matches were computed and recorded for each substrate and processing technique (Table 9). Refer back to table 2 for a list of total number of images for each substrate and process; the total matches compared with the amount of images inputted into AFIX for comparison show the percentage of true matches made (Table 10).

Table 9. Average match scores, average percent of lines drawn, number of matches, and number of non-matches for each processing technique

\begin{tabular}{llcccc}
\hline Substrate & Process & Average Match Score & Average Lines Drawn (\%) & Matches & Non-Matches \\
\hline Glass & Cyano & 438908 & 43 & 73 & 25 \\
Glass & Basic Red 28 & 423281 & 40 & 76 & 23 \\
Glass & Basic Yellow 40 & 243426 & 39 & 37 & 17 \\
Glass & Rhodamine 6G & 366740 & 47 & 21 & 75 \\
Glass & MBD & 415742 & 42 & 10 & 6 \\
Glass & Merged & 364050 & 39 & 70 & 28 \\
Plastic & Cyano & 1604899 & 62 & 103 & 9 \\
Plastic & Basic Red 28 & 1834425 & 58 & 112 & 5 \\
Plastic & MBD & 522405 & 54 & 83 & 6 \\
Plastic & Rhodamine 6G & 1325115 & 61 & 78 & 8 \\
Plastic & Merged & 1279411 & 58 & 106 & 9 \\
\hline
\end{tabular}

Table 10. Percentage of true matches made by AFIX

\begin{tabular}{llc} 
Substrate & Process & \% Matches \\
\hline Glass & Cyano & 74 \\
Glass & Basic Red 28 & 77 \\
Glass & Basic Yellow 40 & 69 \\
Glass & Rhodamine 6G & 78 \\
Glass & MBD & 63 \\
Glass & Merged & 71 \\
Plastic & Cyano & 91 \\
Plastic & Basic Red 28 & 95 \\
Plastic & MBD & 91 \\
Plastic & Rhodamine 6G & 87 \\
Plastic & Merged & 92 \\
\hline
\end{tabular}


The merged samples on glass had a higher percentage of true matches than the MBD and basic yellow 40 images, but was lower than the cyanoacrylate, basic red 28, and rhodamine $6 \mathrm{G}$. The merged samples on plastic had a higher percentage of true matches than all original samples but the basic red 28. The graph in figure 15 gives a visual of the average match scores for each processing technique. The graph shows that there were significantly higher match scores for all prints that were deposited on the plastic substrates. It also shows that the average score for the merged plastic images were only higher than the prints processed with cyanoacrylate and then dye-stained with rhodamine 6G. The fingerprints deposited on glass show less range between average match scores. The average match score for the merged images is however higher than the basic yellow 40 dye-stained prints, but close or lower than the rest of the dye-stained prints. There were 80 prints where the merged image match score was greater than the average score of the original images for that print, and 134 where the average score of the original images was greater than or the same as the merged image.

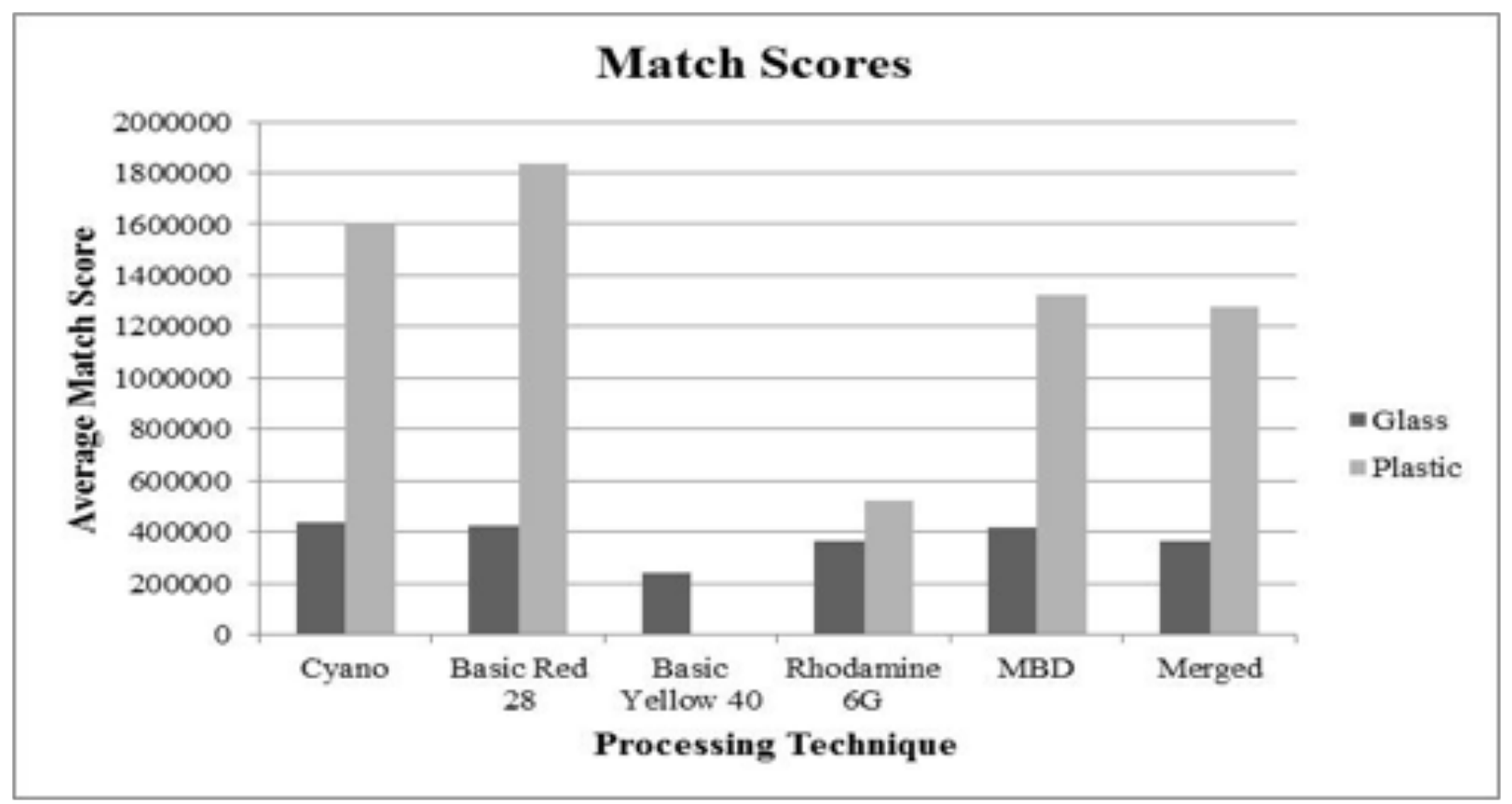

Figure 15. Average match scores for each processing technique and substrate

There were 80 prints where the merged image match score was greater than the average score of the original images for that print, and 134 where the average score of the original images was greater than or the same as the merged image. The results from the AFIX match scores showed that merging did improve some of the images. 


\subsection{Quality Improvement}

There were a large number of images where the quality of the merged image improved and was greater than the quality of the original image based on the NFIQ quality score and the match score from AFIX. However, the number of images that showed no improvement was slightly higher. The Bandey scale scores showed that there were very few merged images with improved quality and a high number of images where there was no improvement by merging. When looking at the fingerprints, 26 of the 214 prints were fully improved based on their NFIQ scores. The term "fully improved" implies that all original images were of lower quality than the final merged image; therefore the merged image would be the better image to use for comparison and identification. In comparison, there were 69 prints out of 214 where the merged image showed no improvement over any of the original images taken of that fingerprint prior to merging. This means that merging the images to obtain a better quality image was unsuccessful for those fingerprints. According to the Bandey scale, only 6 prints were full improved, and 102 prints showed no improvement. AFIX again shows similar results to the NFIQ scores; 32 prints were fully improved and 58 prints showed no improvement when merged (Table 11). The table also shows the individual images that had a lower quality than the merged image for that fingerprint. There were 329 out of 774 images that had a lower NFIQ score than the merged image of that same fingerprint, 199 images that had a lower Bandey scale score, and 349 images that had a lower match score. Although this is important data to consider, ideally the merged image would be of better quality than all of the individual images of that fingerprint rather than some of the images.

Table 11. NFIQ, Bandey, and AFIX results showing percentage of improvement in images and prints.

\begin{tabular}{lccc}
\hline & NFIQ & Bandey & AFIX \\
\hline Images with improved quality & 329 & 199 & 349 \\
Images with no improvement & 445 & 575 & 417 \\
Total Images & 774 & 774 & 774 \\
Percent Improvement & $42.5 \%$ & $25.7 \%$ & $45.1 \%$ \\
Prints with improved quality & 26 & 6 & 32 \\
Prints with no improvement & 69 & 102 & 58 \\
Total prints & $214 *$ & $214 *$ & $214^{*}$ \\
Percent Improvement & $12.1 \%$ & $2.8 \%$ & $15.0 \%$ \\
\hline
\end{tabular}

* Remaining prints not accounted for had one or more originals images whose quality was less than the merged image, but did not have all original images quality improved

Section 4.1 showed the average scores for all merged versus all original images. They were then broken down into their substrate and processing technique in this section. For the glass substrate, the average NFIQ score for the merged images was 2.9, which is lower than the average scores of the originals for all other processes for glass. The average NFIQ score for the plastic merged images was 2.7, which is again lower than all other average scores for that substrate. Remember that for the NFIQ scale, the lower the number indicates a higher quality. 
The Bandey results were less conclusive; the average merged image score for glass was 3.4 , which was slightly lower than the cyanoacrylate, basic red 28, and basic yellow 40 at 3.5 each. The average was the same for rhodamine $6 \mathrm{G}$ and the merged. For the plastic samples, the average score for the original images of all process was 3.4, and the score for the merged was 3.3. Therefore, the Bandey results showed a small difference in quality, but indicated less quality in the merged images than the originals.

Table 12. NFIQ and Bandey scale scores and average score of glass, cyano

$\begin{aligned} & \text { Glass Cyano } \\
& \text { NFIQ }\end{aligned}$
\begin{tabular}{cc|cc} 
Score & Frequency & Score & Frequency \\
\hline 1 & 27 & 0 & 0 \\
2 & 17 & 1 & 0 \\
3 & 11 & 2 & 9 \\
4 & 17 & 3 & 32 \\
5 & 26 & 4 & 57 \\
\hline Average Score & 3.0 & Average Score & 3.5
\end{tabular}

Table 13. NFIQ and Bandey scale scores and average score of glass, basic red 28

Glass Basic Red 28

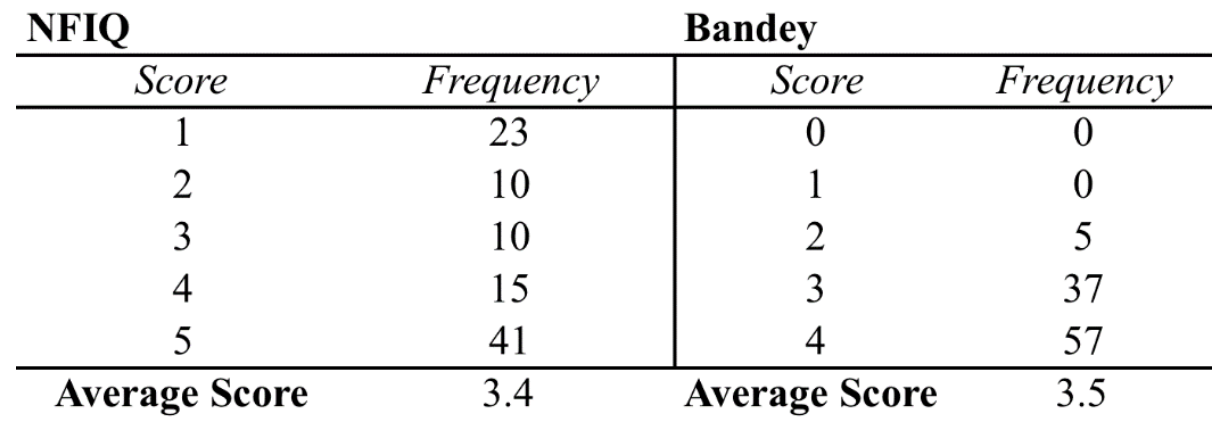

Table 14. NFIQ and Bandey scale scores and average score of glass, basic yellow 40

Glass Basic Yellow 40

NFIQ

\section{Bandey}

\begin{tabular}{cc|cc}
\hline Score & Frequency & Score & Frequency \\
\hline 1 & 16 & 0 & 0 \\
2 & 6 & 1 & 0 \\
3 & 7 & 2 & 5 \\
4 & 11 & 3 & 17 \\
5 & 14 & 4 & 32 \\
\hline Average Score & 3.0 & Average Score & 3.5
\end{tabular}


Table 15. NFIQ and Bandey scale scores and average score of glass, MBD Glass MBD

NFIQ Bandey

\begin{tabular}{cc|cc}
\hline Score & Frequency & Score & Frequency \\
\hline 1 & 4 & 0 & 0 \\
2 & 3 & 1 & 0 \\
3 & 1 & 2 & 2 \\
4 & 3 & 3 & 5 \\
5 & 5 & 4 & 9 \\
\hline Average Score & 3.1 & Average Score & 3.4
\end{tabular}

Table 16. NFIQ and Bandey scale scores and average score of glass, rhodamine 6G Glass Rhodamine 6G

\begin{tabular}{ccc|cc} 
NFIQ & \multicolumn{4}{c}{ Bandey } \\
\hline Score & Frequency & Score & Frequency \\
\hline & 1 & 19 & 0 & 0 \\
2 & 11 & 1 & 0 \\
3 & 17 & 2 & 7 \\
4 & 19 & 3 & 42 \\
5 & 30 & 4 & 47 \\
\hline
\end{tabular}

\begin{tabular}{llll}
\hline Average Score & 3.3 & Average Score & 3.4
\end{tabular}

Table 17. NFIQ and Bandey scale scores and average score of glass, merged Glass Merged

\begin{tabular}{cc|cc}
\multicolumn{4}{c}{ Bandey } \\
\hline Score & Frequency & Score & Frequency \\
\hline 1 & 28 & 0 & 0 \\
2 & 17 & 1 & 1 \\
3 & 14 & 2 & 6 \\
4 & 15 & 3 & 41 \\
5 & 25 & 4 & 51 \\
\hline Average Score & 2.9 & Average Score & 3.4
\end{tabular}


Table 18. NFIQ and Bandey scale scores and average score of plastic, cyano Plastic Cyano

\begin{tabular}{cc|cc} 
NFIQ & \multicolumn{3}{c}{ Bandey } \\
\hline Score & Frequency & Score & Frequency \\
\hline 1 & 30 & 0 & 0 \\
2 & 17 & 1 & 1 \\
3 & 17 & 2 & 10 \\
4 & 13 & 3 & 43 \\
5 & 31 & 4 & 59 \\
\hline Average Score & 3.0 & Average Score & 3.4
\end{tabular}

Table 19. NFIQ and Bandey scale scores and average score of plastic, basic red 28

Plastic Basic Red 28

\begin{tabular}{cc|cc}
\multicolumn{4}{c}{ Bandey } \\
\hline Score & Frequency & Score & Frequency \\
\hline 1 & 37 & 0 & 0 \\
2 & 11 & 1 & 0 \\
3 & 10 & 2 & 10 \\
4 & 14 & 3 & 55 \\
5 & 46 & 4 & 53 \\
\hline Average Score & 3.2 & Average Score & 3.4
\end{tabular}

Table 20. NFIQ and Bandey scale scores and average score of plastic, MBD

Plastic MBD

\begin{tabular}{cc|cc} 
NFIQ & \multicolumn{3}{c}{ Bandey } \\
\hline Score & Frequency & Score & Frequency \\
\hline 1 & 34 & 0 & 0 \\
2 & 11 & 1 & 2 \\
3 & 6 & 2 & 5 \\
4 & 15 & 3 & 41 \\
5 & 25 & 4 & 43 \\
\hline Average Score & 2.8 & Average Score & 3.4
\end{tabular}


Table 21. NFIQ and Bandey scale scores and average score of plastic, rhodamine 6G

Plastic Rhodamine 6G

\begin{tabular}{cc|cc}
\multicolumn{4}{c}{ Bandey } \\
\hline Score & Frequency & Score & Frequency \\
\hline 1 & 30 & 0 & 0 \\
2 & 8 & 1 & 1 \\
3 & 7 & 2 & 1 \\
4 & 6 & 3 & 46 \\
5 & 39 & 4 & 42 \\
\hline Average Score & 3.2 & Average Score & 3.4
\end{tabular}

Table 22. NFIQ and Bandey scale scores and average score of plastic, merged Plastic Merged

\begin{tabular}{cc|cc} 
NFIQ & \multicolumn{3}{c}{ Bandey } \\
\hline Score & Frequency & Score & Frequency \\
\hline 1 & 36 & 0 & 0 \\
2 & 22 & 1 & 1 \\
3 & 20 & 2 & 9 \\
4 & 11 & 3 & 56 \\
5 & 26 & 4 & 49 \\
\hline Average Score & 2.7 & Average Score & 3.3
\end{tabular}




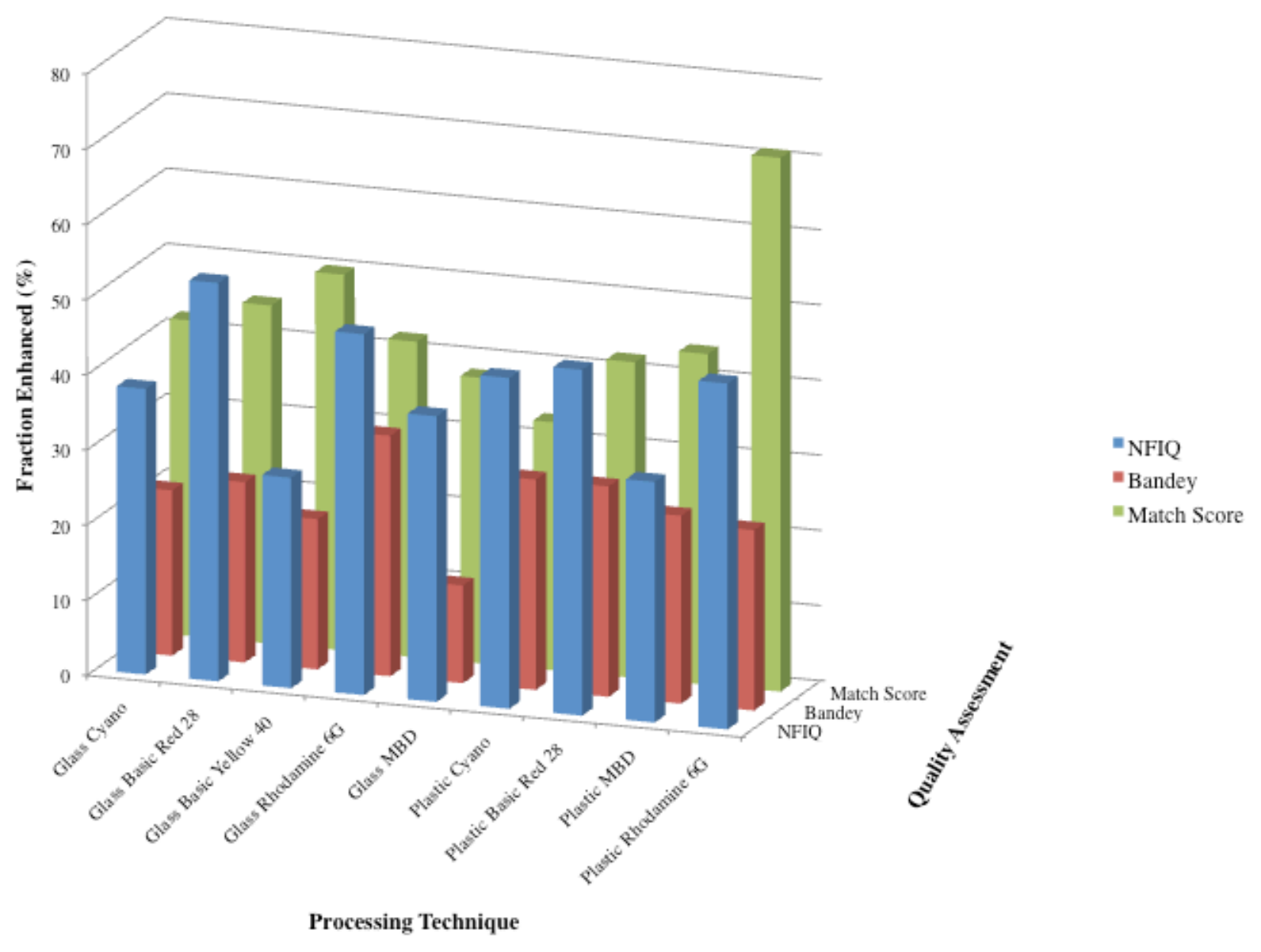

Figure 16. 3D bar graph showing the fraction of images that were improved by merging

Figure 16 shows the fraction of images that were improved. The chart is broken down by each processing method and the three quality assessment methods. Each bar indicates the percentage of these images of each processing method where the merged image was of greater quality than the individual images. It is consistent throughout the different variables that the NFIQ and AFIX (match score) quality assessments showed a greater percentage of images that were improved when compared to the Bandey scores. This could, as previously discussed, be due to the automated programs having the ability to notice a higher level of detail and more accurately rate the quality of an image.

\subsection{Chi-square Test}

The chi-square test was performed on the sets of data for the NFIQ scores and the Bandey scores to determine the significance of the scores generated. The goal of the study was to determine if merging of the images created a final image of better quality. Since there were images where the quality was increased by merging, the chi-square test will show whether there 
is statistical significance to the results. Ultimately, it is important to determine if the higher scores of the merged images was due specifically to the merging or a result of chance. The chisquare test produced $\mathrm{p}$-values which determine statistical significance. If the set of data has a pvalue of greater than 0.05 , the results are not statistically significant. If the set of data has a pvalue of less than 0.05 , the results are considered statistically significant, with a confidence level of $95 \%$ or higher. Tables 23 and 24 show the chi-square results for each scoring method. The results are broken down into the different processing techniques on both glass and plastic. The pvalues were calculated for the actual individual image and merged image scores versus the expected individual and merged image scores to determine if the difference is significant, therefore that the merging is what created the higher quality score. Chi-square was chosen to analyze the data due to the categorical nature of the NFIQ and Bandey scores.

Table 23. Chi-square results for NFIQ scores

\begin{tabular}{cccc} 
Substrate & $\begin{array}{c}\text { Scoring } \\
\text { Method }\end{array}$ & $\begin{array}{c}\text { Processing } \\
\text { Technique }\end{array}$ & p-value \\
\hline Glass & NFIQ & R6G & 0.38226949 \\
Glass & NFIQ & MBD & 0.90451039 \\
Glass & NFIQ & BY40 & 0.8306395 \\
Glass & NFIQ & BR28 & 0.144004627 \\
Glass & NFIQ & Cyano & 0.971752481 \\
Plastic & NFIQ & Cyano & 0.75973047 \\
Plastic & NFIQ & BR28 & 0.01181183 \\
Plastic & NFIQ & MBD & 0.05568353 \\
Plastic & NFIQ & R6G & 0.00566486 \\
\hline
\end{tabular}


Table 24. Chi-square results for Bandey scores

\begin{tabular}{cccc} 
Substrate & $\begin{array}{c}\text { Scoring } \\
\text { Method }\end{array}$ & $\begin{array}{c}\text { Processing } \\
\text { Technique }\end{array}$ & p-value \\
\hline Glass & Bandey & R6G & 0.88443484 \\
Glass & Bandey & MBD & 0.8415516 \\
Glass & Bandey & BY40 & 0.6552575 \\
Glass & Bandey & BR28 & 0.781807749 \\
Glass & Bandey & Cyano & 0.53019083 \\
Plastic & Bandey & Cyano & 0.61477481 \\
Plastic & Bandey & BR28 & 0.88136855 \\
Plastic & Bandey & MBD & 0.84243668 \\
Plastic & Bandey & R6G & 0.29313414 \\
\hline
\end{tabular}

There were two p-values generated that were under 0.05 for the NFIQ scores: Basic Red 28 and Rhodamine $6 \mathrm{G}$ on plastic substrate. The plastic MDB stained images had a p-value of about 0.06, which is the lowest p-value that does not fall into the desired confidence level.

Otherwise, the p-values for the majority of the samples are considerably high. The Bandey score results yielded no $\mathrm{p}$-values equal to or less than 0.05 . This shows that the merging may not have been the cause of the increased scores in the merged samples. Other factors could have caused a higher score, such as chance, or the possibility of a majority of the merged image being from one highly scored individual image of that fingerprint.

\subsection{Analysis of Variance}

Analysis of Variance (ANOVA) was performed on the data from the AFIX match scores. ANOVA is similar to chi-square; the test analyzes the statistical significance of the results to determine if the difference in the scores is a matter of chance or a result of the merging of images. Since the AFIX match score data is not categorical, this method of data analysis was chosen rather than the chi-square analysis. Table 25 shows the ANOVA results for the AFIX match scores. The variance between the original images and merged images was measured to give a p-value, similar to the chi-square analysis. A p-value of less than 0.05 indicated that there is statistical significance to the difference between the original and merged images, while a higher $\mathrm{p}$-value indicated that there is no statistical significance. 
Table 25. ANOVA results for AFIX match scores

\begin{tabular}{|cccc|}
\hline Substrate & Scoring Method & Processing Technique & p-value \\
\hline Glass & AFIX & BR28 & 0.287517 \\
\hline Glass & AFIX & Cyano & 0.237732 \\
\hline Glass & AFIX & BY40 & 0.048759 \\
\hline Glass & AFIX & R6G & 0.965876 \\
\hline Glass & AFIX & MBD & 0.644709 \\
\hline Plastic & AFIX & BR28 & 0.034532 \\
\hline Plastic & AFIX & Cyano & 0.2002 \\
\hline Plastic & AFIX & MBD & 0.000136 \\
\hline Plastic & AFIX & R6G & 0.844397 \\
\hline
\end{tabular}

The p-value was less than 0.05 for three of the AFIX match scores. Again, these high p-values for most of the samples indicatse that the increased scores of the merged images may have been due to chance, and not as a result of the merging.

\subsection{Justification for Elimination of Cardboard and Paper Samples}

The cardboard and paper latent print samples were discarded due to unsuccessful image registration and image fusion. The images would not register correctly; therefore image fusion did not create a composite image, but created one that could not be used in any case for analysis. Since Photoshop uses a feature-based algorithm to perform image registration, it is possible that the cardboard and paper latent prints did not have sufficient detail to allow the program to perform registration. Although the examiner could easily see the ridges, the Photoshop algorithm needed more defined friction ridge detail. This is a very important note to make when discussing this research. Based on this observation, it appears that the images that are being used must have enough detail for the algorithm to detect the features and edges that are needed to register the image.

\subsection{Spurious Minutiae}

The possibility of spurious minutia when conducting this experiment was of concern when merging the images on Photoshop. An examiner may allow for exclusion if spurious minutia are mistaken for real minutia, therefore they would have to take extra precaution to be sure to avoid false exclusion or identification due to spurious minutia. In order to avoid this 
possible affect, the prints were examined after fusion to ensure that the process of fusing the images together created no spurious minutia.

\subsection{Examiners' Subjectivity}

Subjectivity was reduced as much as possible during this study. Programs with limited to no examiner input were chosen to assess the quality of the images in order to eliminate the quality being determined only by the examiner. Quality scores were assigned by NFIQ, which requires no human input, only loading the files into the folder within the program.

One way of eliminating bias is to perform a "blind" analysis. This is a practice that is accepted and expected within the forensic science community and is done in order to avoid subjectivity of the examiner when performing a comparison or identification. This is especially important in fingerprint analysis. The Bandey scale scores were assigned to images after the images were randomized, and renamed by a peer. This created the ability of the prints to be scored without the knowledge of which were the merged or original images, or which images were of the same fingerprint.

AFIX requires the examiner to manually mark minutia on each print. Although there is an option to auto-extract features, which was not done in this study, auto-extraction of features often marks spurious minutia and requires the examiner to manually alter the minutia.

\section{CONCLUSION}

This study was intended to determine whether or not the commonly used method of image fusion in multiple fields of study such as biometrics, surveillance, and medical imaging had the ability to improve the latent fingerprint identification process. Since image fusion is becoming increasingly popular in the forensics field, now is the time to determine how to implement this method into fingerprint processing to improve the quality of the images that examiners are using to make identifications.

Image fusion for increasing quality of latent fingerprints images is a method that shows small benefits for the examiner. Only $12.1 \%$ of the fingerprints were improved by merging based on the NFIQ scale, therefore it may be unnecessary for the examiner to merge the images, when at least one or more of the original images in $87.9 \%$ of the prints was of better or the same quality as the merged image. The Bandey scale test results showed that the examiner is unable to consider $2^{\text {nd }}$ level detail as well as an automated system using a feature-based algorithm, because only $2.8 \%$ of the prints were considered to be improved upon merging. Considering this, the examiner would likely not notice a significant difference between the merged image and the original image quality. AFIX showed the highest percentage of improvement at $15.0 \%$.

There should be considerable judgment used as to whether performing the image fusion will be useful. In order to judge this, the examiner could take multiple images of the print under different wavelengths and filters, and then examine the images for the quality of the friction 
ridge detail. If there is an area of one image (A) of noticeably bad quality, but another image (B) where that same area shows more friction ridge detail, then the examiner may choose to merge the images together to create the composite image $(C)$. However, unless one area of $A$ is of better quality than the same area in B, the examiner may find it unnecessary to merge the images and simply use image B for analysis.

This study has given a better understanding of the process of image fusion for latent fingerprints, shown that only images of a certain quality can actually be merged, and that there seems to be very little variability between the quality of the merged images and the original images.

\subsection{Future Research}

Further research could be conducted using various other substrates, including those with curved edges, backgrounds with multiple colors, rough surfaces, etc. This study delved into the basic method to determine if image fusion would work effectively using Photoshop, create an image without spurious minutia, create an image of better quality, and be suitable for the examiner to perform an identification. Since we know that the method works, extensive research could be done on a multitude of substrates that create less quality in latent fingerprints and show less friction ridge detail.

Another possible addition to this study could be to look at the specific areas of the print that are being merged, and if the Photoshop algorithm is replacing the area of low quality with an area of definite better quality. This could be done by performing a quality assessment on sections of the fingerprints before and after merging, and evaluating the sections that were chosen to be merged into one image.

Determining a measurement of the amount of contrast or detail needed for Photoshop to be able to register and merge the images would be a very useful study. Efficiency and quality are both pertinent to performing analysis, but in order for the examiner to be efficient they must know if a certain image has too low of quality to be merged prior to putting the time and effort into doing so.

\subsection{Field Application in Forensics}

This method would be applicable to examiners whom have a latent fingerprint of questionable quality. If the print can be processed using a) multiple techniques, b) under multiple wavelengths, or c) under various filters to obtain multiple images of the same print, then the examiner could perform image fusion. Photoshop is an easily accessible program, is quick, efficient, and user-friendly. It would not take a considerable amount of time for an examiner to merge the images, nor would it be difficult to set up and perform.

It would be beneficial for examiners to understand the process of image fusion and that it can be done to increase quality of a latent fingerprint image. 


\section{REFERENCES}

[1] Champod, C., et al. Fingerprint and other Ridge Skin Impressions. International Forensic Science and Investigation Series. 2004.

[2] Exline, D. et al. Forensic applications of chemical imaging: latent fingerprint detection using visible absorption and luminescence. J Forensic Sci, Vol. 48 (5). pp. 1047-1053. Sept. 2003.

[3] Joshitha, N., Selin, M. Image Fusing Using PCA in Multifeature Based Palmprint

Recognition. International Journal of Soft Computing and Engineering, Vol. 2 (2). pp. 226-230.

May 2012.

[4] Moeslund, T. Canny Edge Detection, pp. 1-7. March 2009.

http://www.cse.iitd.ernet.in/ pkalra/cs1783/canny.pdf (Accessed 10/22/15)

[5] NIST. Fingerprint Image Quality, pp. 1-69. Aug. 2004.

http://www.nist.gov/customcf/get_pdf.cfm?pub_id=905710 (Accessed 10/22/15)

[6] Payne, G., et al. A further study to investigate the detection and enhancement of latent fingerprints using visible absorption and luminescence chemical imaging. Forensic Science International, Vol. 150 (1), pp. 33-51, May 2005.

[7] Ross, A., Shah, S., Shah, J., Image Versus Feature Mosaicing: A Case Study in Fingerprints. Proc. Of SPIE Conference on Biometric Technology for Human Identification III, pp. 620208-1 -620208-12, April 2006.

[8] Sirchie Products. Technical Information: DFO.

http://www.sirchie.com/Assets/Manuals/pdf/UPD/DFO_TI02-28ENG-REV6E.pdf (Accessed 9/16/2013)

[9] Sirchie Products. Technical Information: Ninhydrin. http://www.sirchie.com/Assets/Manuals/pdf/UPD/NSI609_TI11-631ENG.pdf (Accessed 9/16/2013)

[10] SWGFAST. Scientific Working Group on Friction Ridge Analysis, Study and Technology. Standard for Friction Ridge Impression Digital Imaging (Latent/Tenprint). http://www.swgfast.org/documents/imaging/121124_Standard_Imaging_RevisedDRAFT_2.0.pdf (Accessed 9/16/2013)

[11] Wang, Z., Ziou, D., Armenakis, C., Li, D., and Li, Q., A comparative analysis of image fusion methods, IEEE Trans. Geosci. Remote Sens. Vol. 43 (6), pp. 81-84, June 2005.

[12] Yamashita, B., French, M., Latent Print Development. The Fingerprint Sourcebook. 2010. 
[13] Zhang, H., Research on the Application of Image Fusion in Material Evidence Photography. Department of Criminal Scientific Technology, IEEE. 2010. DOI:

10.1109/ICMULT.2010.5631114.

[14] Zitova, B., Flusser, J., Image Registration Methods: A Survey. Image and Visiton Computing. Vol. 21, pp. 977-1000. June 2003.

[15] AFIX Technologies. http://www .afix.net/index.html\#6 (Accessed 10/22/15)

[16] Bazen, A., Gerez, S. Fingerprint Matching by Thin-plate Spline Modelling of Elastic Deformations. Pattern Recognition. Vol. 36. pp. 1859-1867. 2003.

[17] Bandey HL. Fingerprint development and imaging newsletter: the powders process, study 1. Sandridge: Police Scientific Development Branch, Home Office. Report No.:54/04. 2004.

[18] Tabassi, E. NIST Fingerprint Image Quality and Relation to PIV. http://biometrics.nist.gov/cs_links/standard/archived/workshops/workshop1/presentations/Tabass i-Image-Quality.pdf (Accessed 1/12/2014)

[19] Laplacian/Laplacian of Gaussian. http://homepages.inf.ed.ac.uk/rbf/HIPR2/log.htm (Accessed 10/30/15) 


\section{APPENDIX A}

\section{Camera Settings}

\begin{tabular}{|c|c|c|c|c|c|c|c|}
\hline $\begin{array}{c}\text { FP } \\
\#\end{array}$ & Type & $\begin{array}{c}\text { Substrat } \\
\mathrm{e}\end{array}$ & Development & f number & $\begin{array}{c}\text { Exposure } \\
\text { time }\end{array}$ & Focal Length & Wavelength \\
\hline 137 & $\mathrm{O}$ & Glass & Cyano & 4 & $1 / 6$ & 60 & white \\
\hline 138 & $\mathrm{O}$ & Glass & Cyano & 4 & $1 / 2$ & 60 & white \\
\hline 139 & $\mathrm{O}$ & Glass & Cyano & 4 & $1 / 2$ & 60 & white \\
\hline 140 & $\mathrm{O}$ & Glass & Cyano & 4 & $1 / 5$ & 60 & white \\
\hline 141 & $\mathrm{O}$ & Glass & Cyano & 4 & $1 / 5$ & 60 & white \\
\hline 142 & $\mathrm{O}$ & Glass & Cyano & 4 & $1 / 5$ & 60 & white \\
\hline 143 & $\mathrm{O}$ & Glass & Cyano & 4 & $1 / 5$ & 60 & white \\
\hline 144 & $\mathrm{O}$ & Glass & Cyano & 4 & $1 / 5$ & 60 & white \\
\hline 145 & $\mathrm{O}$ & Glass & Cyano & 4 & $1 / 5$ & 60 & white \\
\hline 146 & $\mathrm{O}$ & Glass & Cyano & 4 & $1 / 5$ & 60 & white \\
\hline 147 & $\mathrm{O}$ & Glass & Cyano & 4 & $1 / 5$ & 60 & white \\
\hline 148 & $\mathrm{O}$ & Glass & Cyano & 11 & $1 / 25$ & 60 & white \\
\hline 149 & $\mathrm{O}$ & Glass & Cyano & 4 & $1 / 5$ & 60 & white \\
\hline 150 & $\mathrm{O}$ & Glass & Cyano & 4 & $1 / 5$ & 60 & white \\
\hline 151 & $\mathrm{O}$ & Glass & Cyano & 11 & $1 / 25$ & 60 & white \\
\hline 152 & $\mathrm{O}$ & Glass & Cyano & 4 & $1 / 4$ & 60 & white \\
\hline 153 & $\mathrm{O}$ & Glass & Cyano & 4 & $1 / 4$ & 60 & white \\
\hline 154 & $\mathrm{O}$ & Glass & Cyano & 25 & $2 / 5$ & 60 & white \\
\hline 155 & $\mathrm{O}$ & Glass & Cyano & 20 & $2 / 5$ & 60 & white \\
\hline 156 & $\mathrm{O}$ & Glass & Cyano & 32 & $2 / 5$ & 60 & white \\
\hline 157 & $\mathrm{O}$ & Glass & Cyano & 22 & $2 / 5$ & 60 & white \\
\hline 158 & $\mathrm{O}$ & Glass & Cyano & 25 & $2 / 5$ & 60 & white \\
\hline 159 & $\mathrm{O}$ & Glass & Cyano & 32 & $2 / 5$ & 60 & white \\
\hline 160 & $\mathrm{O}$ & Glass & Cyano & 22 & $2 / 5$ & 60 & white \\
\hline 161 & $\mathrm{O}$ & Glass & Cyano & 0.4 & 20 & 60 & white \\
\hline 162 & $\mathrm{O}$ & Glass & Cyano & 25 & $2 / 5$ & 60 & white \\
\hline 163 & $\mathrm{O}$ & Glass & Cyano & 25 & $2 / 5$ & 60 & white \\
\hline 164 & $\mathrm{O}$ & Glass & Cyano & 24 & $2 / 5$ & 60 & white \\
\hline 165 & $\mathrm{O}$ & Glass & Cyano & 32 & $2 / 5$ & 60 & white \\
\hline 166 & $\mathrm{O}$ & Glass & Cyano & 22 & $2 / 5$ & 60 & white \\
\hline 167 & $\mathrm{O}$ & Glass & Cyano & 29 & $2 / 5$ & 60 & white \\
\hline 168 & $\mathrm{O}$ & Glass & Cyano & 40 & $2 / 5$ & 60 & white \\
\hline 169 & $\mathrm{O}$ & Glass & Cyano & 13 & $1 / 20$ & 60 & white \\
\hline 170 & $\mathrm{O}$ & Glass & Cyano & 18 & $1 / 20$ & 60 & white \\
\hline 171 & $\mathrm{O}$ & Glass & Cyano & 14 & $1 / 20$ & 60 & white \\
\hline 172 & $\mathrm{O}$ & Glass & Cyano & 16 & $1 / 20$ & 60 & white \\
\hline 173 & $\mathrm{O}$ & Glass & Cyano & 20 & $1 / 20$ & 60 & white \\
\hline 174 & $\mathrm{O}$ & Glass & Cyano & 20 & $1 / 20$ & 60 & white \\
\hline 175 & $\mathrm{O}$ & Glass & Cyano & 18 & $1 / 20$ & 60 & white \\
\hline 176 & $\mathrm{O}$ & Glass & Cyano & 9 & $1 / 20$ & 60 & white \\
\hline 177 & $\mathrm{O}$ & Glass & Cyano & 8 & $1 / 20$ & 60 & white \\
\hline 178 & $\mathrm{O}$ & Glass & Cyano & 10 & $1 / 20$ & 60 & white \\
\hline 179 & $\mathrm{O}$ & Glass & Cyano & 13 & $1 / 20$ & 60 & white \\
\hline 180 & $\mathrm{O}$ & Glass & Cyano & 11 & $1 / 20$ & 60 & white \\
\hline 181 & $\mathrm{O}$ & Glass & Cyano & 11 & $1 / 20$ & 60 & white \\
\hline 182 & $\mathrm{O}$ & Glass & Cyano & 8 & $1 / 20$ & 60 & white \\
\hline
\end{tabular}




\begin{tabular}{|c|c|c|c|c|c|c|c|}
\hline 183 & $\mathrm{O}$ & Glass & Cyano & 8 & $1 / 20$ & 60 & white \\
\hline 184 & $\mathrm{O}$ & Glass & Cyano & 10 & $1 / 20$ & 60 & white \\
\hline 185 & $\mathrm{O}$ & Glass & Cyano & 10 & $1 / 20$ & 60 & white \\
\hline 186 & $\mathrm{O}$ & Glass & Cyano & 8 & $1 / 20$ & 60 & white \\
\hline 187 & $\mathrm{O}$ & Glass & Cyano & 11 & $1 / 20$ & 60 & white \\
\hline 188 & $\mathrm{O}$ & Glass & Cyano & 9 & $1 / 20$ & 60 & white \\
\hline 189 & $\mathrm{O}$ & Glass & Cyano & 10 & $1 / 20$ & 60 & white \\
\hline 190 & $\mathrm{O}$ & Glass & Cyano & 13 & $1 / 20$ & 60 & white \\
\hline 191 & $\mathrm{O}$ & Glass & Cyano & 9 & $1 / 20$ & 60 & white \\
\hline 192 & $\mathrm{O}$ & Glass & Cyano & 9 & $1 / 20$ & 60 & white \\
\hline 193 & $\mathrm{O}$ & Glass & Cyano & 11 & $1 / 20$ & 60 & white \\
\hline 194 & $\mathrm{O}$ & Glass & Cyano & 13 & $1 / 20$ & 60 & white \\
\hline 195 & $\mathrm{O}$ & Glass & Cyano & 16 & $1 / 20$ & 60 & white \\
\hline 196 & $\mathrm{O}$ & Glass & Cyano & 18 & $1 / 20$ & 60 & white \\
\hline 197 & $\mathrm{O}$ & Glass & Cyano & 9 & $1 / 20$ & 60 & white \\
\hline 198 & $\mathrm{O}$ & Glass & Cyano & 10 & $1 / 20$ & 60 & white \\
\hline 199 & $\mathrm{O}$ & Glass & Cyano & 14 & $1 / 20$ & 60 & white \\
\hline 200 & $\mathrm{O}$ & Glass & Cyano & 16 & $1 / 20$ & 60 & white \\
\hline 201 & $\mathrm{O}$ & Glass & Cyano & 16 & $1 / 20$ & 60 & white \\
\hline 202 & $\mathrm{O}$ & Glass & Cyano & 14 & 2 & 60 & white \\
\hline 203 & $\mathrm{O}$ & Glass & Cyano & 9 & 2 & 60 & white \\
\hline 204 & $\mathrm{O}$ & Glass & Cyano & 7.1 & $13 / 10$ & 60 & white \\
\hline 205 & $\mathrm{O}$ & Glass & Cyano & 4 & $1 / 5$ & 60 & white \\
\hline 207 & $\mathrm{O}$ & Glass & Cyano & 4 & $1 / 5$ & 60 & white \\
\hline 208 & $\mathrm{O}$ & Glass & Cyano & 4 & $1 / 5$ & 60 & white \\
\hline 209 & $\mathrm{O}$ & Glass & Cyano & 4 & $1 / 5$ & 60 & white \\
\hline 210 & $\mathrm{O}$ & Glass & Cyano & 4 & $1 / 5$ & 60 & white \\
\hline 211 & $\mathrm{O}$ & Glass & Cyano & 4 & $1 / 5$ & 60 & white \\
\hline 212 & $\mathrm{O}$ & Glass & Cyano & 4 & $1 / 5$ & 60 & white \\
\hline 213 & $\mathrm{O}$ & Glass & Cyano & 4 & $1 / 5$ & 60 & white \\
\hline 214 & $\mathrm{O}$ & Glass & Cyano & 4 & $1 / 5$ & 60 & white \\
\hline 215 & $\mathrm{O}$ & Glass & Cyano & 4 & $1 / 5$ & 60 & white \\
\hline 216 & $\mathrm{O}$ & Glass & Cyano & 4 & $1 / 5$ & 60 & white \\
\hline 217 & $\mathrm{O}$ & Glass & Cyano & 4.5 & $1 / 4$ & 60 & white \\
\hline 218 & $\mathrm{O}$ & Glass & Cyano & 4 & $1 / 4$ & 60 & white \\
\hline 219 & $\mathrm{O}$ & Glass & Cyano & 4 & $1 / 4$ & 60 & white \\
\hline 220 & $\mathrm{O}$ & Glass & Cyano & 32 & $1 / 10$ & 60 & white \\
\hline 221 & $\mathrm{O}$ & Glass & Cyano & 32 & $1 / 10$ & 60 & white \\
\hline 222 & $\mathrm{O}$ & Glass & Cyano & 29 & $1 / 10$ & 60 & white \\
\hline 223 & $\mathrm{O}$ & Glass & Cyano & 29 & $1 / 10$ & 60 & white \\
\hline 224 & $\mathrm{O}$ & Glass & Cyano & 29 & $1 / 10$ & 60 & white \\
\hline 225 & $\mathrm{O}$ & Glass & Cyano & 29 & $1 / 10$ & 60 & white \\
\hline 226 & $\mathrm{O}$ & Glass & Cyano & 29 & $1 / 10$ & 60 & white \\
\hline 227 & $\mathrm{O}$ & Glass & Cyano & 25 & $1 / 10$ & 60 & white \\
\hline 228 & $\mathrm{O}$ & Glass & Cyano & 29 & $1 / 10$ & 60 & white \\
\hline 229 & $\mathrm{O}$ & Glass & Cyano & 20 & $1 / 25$ & 60 & white \\
\hline 230 & $\mathrm{O}$ & Glass & Cyano & 18 & $1 / 25$ & 60 & white \\
\hline 231 & $\mathrm{O}$ & Glass & Cyano & 16 & $1 / 25$ & 60 & white \\
\hline 232 & $\mathrm{O}$ & Glass & Cyano & 22 & $1 / 25$ & 60 & white \\
\hline 233 & $\mathrm{O}$ & Glass & Cyano & 18 & $1 / 25$ & 60 & white \\
\hline 234 & $\mathrm{O}$ & Glass & Cyano & 16 & $1 / 25$ & 60 & white \\
\hline 235 & $\mathrm{O}$ & Glass & Cyano & 13 & $1 / 25$ & 60 & white \\
\hline
\end{tabular}




\begin{tabular}{|c|c|c|c|c|c|c|c|}
\hline 137 & $\mathrm{O}$ & Glass & Cyano + Basic Red 28 & 4 & $21 / 2$ & 60 & 470 \\
\hline 137 & $\mathrm{O}$ & Glass & Cyano + Basic Red 28 & 9 & $21 / 2$ & 60 & 550 \\
\hline 137 & $\mathrm{O}$ & Glass & Cyano + Basic Red 28 & 11 & $.1 / 13$ & 60 & white \\
\hline 138 & $\mathrm{O}$ & Glass & Cyano + Basic Red 28 & 4 & $21 / 2$ & 60 & 470 \\
\hline 138 & $\mathrm{O}$ & Glass & Cyano + Basic Red 28 & 4 & $21 / 2$ & 60 & 550 \\
\hline 138 & $\mathrm{O}$ & Glass & Cyano + Basic Red 28 & 9 & $.1 / 25$ & 60 & white \\
\hline 139 & $\mathrm{O}$ & Glass & Cyano + Basic Red 28 & 4 & $21 / 2$ & 60 & 470 \\
\hline 139 & $\mathrm{O}$ & Glass & Cyano + Basic Red 28 & 5.6 & $10 / 13$ & 60 & 550 \\
\hline 139 & $\mathrm{O}$ & Glass & Cyano + Basic Red 28 & 8 & $1 / 25$ & 60 & white \\
\hline 140 & $\mathrm{O}$ & Glass & Cyano + Basic Red 28 & 4 & $10 / 13$ & 60 & 470 \\
\hline 140 & $\mathrm{O}$ & Glass & Cyano + Basic Red 28 & 4.5 & $10 / 13$ & 60 & 550 \\
\hline 140 & $\mathrm{O}$ & Glass & Cyano + Basic Red 28 & 8 & $1 / 25$ & 60 & white \\
\hline 141 & $\mathrm{O}$ & Glass & Cyano + Basic Red 28 & 4 & $10 / 13$ & 60 & 470 \\
\hline 141 & $\mathrm{O}$ & Glass & Cyano + Basic Red 28 & 4.5 & $10 / 13$ & 60 & 550 \\
\hline 141 & $\mathrm{O}$ & Glass & Cyano + Basic Red 28 & 8 & $1 / 25$ & 60 & white \\
\hline 142 & $\mathrm{O}$ & Glass & Cyano + Basic Red 28 & 4 & $10 / 13$ & 60 & white \\
\hline 142 & $\mathrm{O}$ & Glass & Cyano + Basic Red 28 & 4.5 & $10 / 13$ & 60 & 470 \\
\hline 142 & $\mathrm{O}$ & Glass & Cyano + Basic Red 28 & 7.1 & $1 / 25$ & 60 & 550 \\
\hline 143 & $\mathrm{O}$ & Glass & Cyano + Basic Red 28 & 4 & $10 / 13$ & 60 & 470 \\
\hline 143 & $\mathrm{O}$ & Glass & Cyano + Basic Red 28 & 4.5 & $10 / 13$ & 60 & 550 \\
\hline 143 & $\mathrm{O}$ & Glass & Cyano + Basic Red 28 & 8 & $1 / 25$ & 60 & white \\
\hline 144 & $\mathrm{O}$ & Glass & Cyano + Basic Red 28 & 4 & $10 / 13$ & 60 & 470 \\
\hline 144 & $\mathrm{O}$ & Glass & Cyano + Basic Red 28 & 4.5 & $10 / 13$ & 60 & 550 \\
\hline 144 & $\mathrm{O}$ & Glass & Cyano + Basic Red 28 & 8 & $1 / 25$ & 60 & white \\
\hline 145 & $\mathrm{O}$ & Glass & Cyano + Basic Red 28 & 4 & $10 / 13$ & 60 & 470 \\
\hline 145 & $\mathrm{O}$ & Glass & Cyano + Basic Red 28 & 5 & $10 / 13$ & 60 & 550 \\
\hline 145 & $\mathrm{O}$ & Glass & Cyano + Basic Red 28 & 10 & $1 / 25$ & 60 & white \\
\hline 146 & $\mathrm{O}$ & Glass & Cyano + Basic Red 28 & 4 & $10 / 13$ & 60 & white \\
\hline 146 & $\mathrm{O}$ & Glass & Cyano + Basic Red 28 & 5 & $10 / 13$ & 60 & 470 \\
\hline 146 & $\mathrm{O}$ & Glass & Cyano + Basic Red 28 & 11 & $1 / 25$ & 60 & 550 \\
\hline 147 & $\mathrm{O}$ & Glass & Cyano + Basic Red 28 & 4 & $10 / 13$ & 60 & 470 \\
\hline 147 & $\mathrm{O}$ & Glass & Cyano + Basic Red 28 & 4.5 & $10 / 13$ & 60 & 550 \\
\hline 147 & $\mathrm{O}$ & Glass & Cyano + Basic Red 28 & 11 & $1 / 25$ & 60 & white \\
\hline 148 & $\mathrm{O}$ & Glass & Cyano + Basic Red 28 & 4 & $10 / 13$ & 60 & 470 \\
\hline 148 & $\mathrm{O}$ & Glass & Cyano + Basic Red 28 & 4 & 2 & 60 & 550 \\
\hline 148 & $\mathrm{O}$ & Glass & Cyano + Basic Red 28 & 5 & $10 / 13$ & 60 & white \\
\hline 149 & $\mathrm{O}$ & Glass & Cyano + Basic Red 28 & 4.5 & $10 / 13$ & 60 & white \\
\hline 149 & $\mathrm{O}$ & Glass & Cyano + Basic Red 28 & 4 & 2 & 60 & 470 \\
\hline 149 & $\mathrm{O}$ & Glass & Cyano + Basic Red 28 & 4 & $10 / 13$ & 60 & 550 \\
\hline 150 & $\mathrm{O}$ & Glass & Cyano + Basic Red 28 & 4 & $10 / 13$ & 60 & 470 \\
\hline 150 & $\mathrm{O}$ & Glass & Cyano + Basic Red 28 & 4 & 2 & 60 & 485 \\
\hline 150 & $\mathrm{O}$ & Glass & Cyano + Basic Red 28 & 5 & $10 / 13$ & 60 & 550 \\
\hline 150 & $\mathrm{O}$ & Glass & Cyano + Basic Red 28 & 11 & $.1 / 25$ & 60 & white \\
\hline 151 & $\mathrm{O}$ & Glass & Cyano + Basic Red 28 & 4 & $10 / 13$ & 60 & 470 \\
\hline 151 & $\mathrm{O}$ & Glass & Cyano + Basic Red 28 & 4.5 & $10 / 13$ & 60 & 550 \\
\hline 152 & $\mathrm{O}$ & Glass & Cyano + Basic Red 28 & 4 & $10 / 13$ & 60 & 470 \\
\hline 152 & $\mathrm{O}$ & Glass & Cyano + Basic Red 28 & 4 & $10 / 13$ & 60 & 550 \\
\hline 152 & $\mathrm{O}$ & Glass & Cyano + Basic Red 28 & 11 & $1 / 25$ & 60 & white \\
\hline 153 & $\mathrm{O}$ & Glass & Cyano + Basic Red 28 & 4 & $10 / 13$ & 60 & 470 \\
\hline 153 & $\mathrm{O}$ & Glass & Cyano + Basic Red 28 & 4 & $10 / 13$ & 60 & 550 \\
\hline 153 & $\mathrm{O}$ & Glass & Cyano + Basic Red 28 & 10 & $1 / 25$ & 60 & white \\
\hline 154 & $\mathrm{O}$ & Glass & Cyano + Basic Red 28 & 4 & $10 / 13$ & 60 & 470 \\
\hline
\end{tabular}




\begin{tabular}{|c|c|c|c|c|c|c|c|}
\hline 154 & $\mathrm{O}$ & Glass & Cyano + Basic Red 28 & 4 & $10 / 13$ & 60 & 550 \\
\hline 154 & $\mathrm{O}$ & Glass & Cyano + Basic Red 28 & 10 & $1 / 25$ & 60 & white \\
\hline 155 & $\mathrm{O}$ & Glass & Cyano + Basic Red 28 & 4 & $10 / 13$ & 60 & 470 \\
\hline 155 & $\mathrm{O}$ & Glass & Cyano + Basic Red 28 & 4 & $10 / 13$ & 60 & 550 \\
\hline 155 & $\mathrm{O}$ & Glass & Cyano + Basic Red 28 & 10 & $1 / 25$ & 60 & white \\
\hline 156 & $\mathrm{O}$ & Glass & Cyano + Basic Red 28 & 4 & $10 / 13$ & 60 & 470 \\
\hline 156 & $\mathrm{O}$ & Glass & Cyano + Basic Red 28 & 4.5 & $10 / 13$ & 60 & 550 \\
\hline 156 & $\mathrm{O}$ & Glass & Cyano + Basic Red 28 & 11 & $1 / 25$ & 60 & white \\
\hline 157 & $\mathrm{O}$ & Glass & Cyano + Basic Red 28 & 4 & $10 / 13$ & 60 & 470 \\
\hline 157 & $\mathrm{O}$ & Glass & Cyano + Basic Red 28 & 4 & $10 / 13$ & 60 & 550 \\
\hline 157 & $\mathrm{O}$ & Glass & Cyano + Basic Red 28 & 11 & $1 / 25$ & 60 & white \\
\hline 158 & $\mathrm{O}$ & Glass & Cyano + Basic Red 28 & 4 & $10 / 13$ & 60 & 470 \\
\hline 158 & $\mathrm{O}$ & Glass & Cyano + Basic Red 28 & 4 & $10 / 13$ & 60 & 550 \\
\hline 158 & $\mathrm{O}$ & Glass & Cyano + Basic Red 28 & 10 & $1 / 25$ & 60 & white \\
\hline 159 & $\mathrm{O}$ & Glass & Cyano + Basic Red 28 & 4 & $10 / 13$ & 60 & 470 \\
\hline 159 & $\mathrm{O}$ & Glass & Cyano + Basic Red 28 & 4 & $10 / 13$ & 60 & 550 \\
\hline 159 & $\mathrm{O}$ & Glass & Cyano + Basic Red 28 & 11 & $1 / 25$ & 60 & white \\
\hline 160 & $\mathrm{O}$ & Glass & Cyano + Basic Red 28 & 4 & $10 / 13$ & 60 & white \\
\hline 160 & $\mathrm{O}$ & Glass & Cyano + Basic Red 28 & 4 & $10 / 13$ & 60 & 470 \\
\hline 160 & $\mathrm{O}$ & Glass & Cyano + Basic Red 28 & 10 & $1 / 25$ & 60 & 550 \\
\hline 161 & $\mathrm{O}$ & Glass & Cyano + Basic Red 28 & 4 & $10 / 13$ & 60 & 470 \\
\hline 161 & $\mathrm{O}$ & Glass & Cyano + Basic Red 28 & 4 & $10 / 13$ & 60 & 550 \\
\hline 161 & $\mathrm{O}$ & Glass & Cyano + Basic Red 28 & 10 & $1 / 25$ & 60 & white \\
\hline 162 & $\mathrm{O}$ & Glass & Cyano + Basic Red 28 & 4 & $10 / 13$ & 60 & 470 \\
\hline 162 & $\mathrm{O}$ & Glass & Cyano + Basic Red 28 & 4.5 & $10 / 13$ & 60 & 550 \\
\hline 162 & $\mathrm{O}$ & Glass & Cyano + Basic Red 28 & 11 & $1 / 25$ & 60 & white \\
\hline 163 & $\mathrm{O}$ & Glass & Cyano + Basic Red 28 & 4 & $10 / 13$ & 60 & 470 \\
\hline 163 & $\mathrm{O}$ & Glass & Cyano + Basic Red 28 & 4 & $10 / 13$ & 60 & 550 \\
\hline 163 & $\mathrm{O}$ & Glass & Cyano + Basic Red 28 & 10 & $1 / 25$ & 60 & white \\
\hline 164 & $\mathrm{O}$ & Glass & Cyano + Basic Red 28 & 4 & $10 / 13$ & 60 & 470 \\
\hline 164 & $\mathrm{O}$ & Glass & Cyano + Basic Red 28 & 4 & $10 / 13$ & 60 & 550 \\
\hline 164 & $\mathrm{O}$ & Glass & Cyano + Basic Red 28 & 11 & $1 / 25$ & 60 & white \\
\hline 165 & $\mathrm{O}$ & Glass & Cyano + Basic Red 28 & 4 & $10 / 13$ & 60 & 470 \\
\hline 165 & $\mathrm{O}$ & Glass & Cyano + Basic Red 28 & 4 & $10 / 13$ & 60 & 550 \\
\hline 165 & $\mathrm{O}$ & Glass & Cyano + Basic Red 28 & 11 & $1 / 25$ & 60 & white \\
\hline 166 & $\mathrm{O}$ & Glass & Cyano + Basic Red 28 & 4 & $10 / 13$ & 60 & 470 \\
\hline 166 & $\mathrm{O}$ & Glass & Cyano + Basic Red 28 & 5 & $10 / 13$ & 60 & 550 \\
\hline 166 & $\mathrm{O}$ & Glass & Cyano + Basic Red 28 & 11 & $1 / 25$ & 60 & white \\
\hline 167 & $\mathrm{O}$ & Glass & Cyano + Basic Red 28 & 4 & $10 / 13$ & 60 & 470 \\
\hline 167 & $\mathrm{O}$ & Glass & Cyano + Basic Red 28 & 4.5 & $10 / 13$ & 60 & 550 \\
\hline 167 & $\mathrm{O}$ & Glass & Cyano + Basic Red 28 & 11 & $1 / 25$ & 60 & white \\
\hline 168 & $\mathrm{O}$ & Glass & Cyano + Basic Red 28 & 4 & $10 / 13$ & 60 & 470 \\
\hline 168 & $\mathrm{O}$ & Glass & Cyano + Basic Red 28 & 5 & $10 / 13$ & 60 & 550 \\
\hline 168 & $\mathrm{O}$ & Glass & Cyano + Basic Red 28 & 11 & $1 / 25$ & 60 & white \\
\hline 169 & $\mathrm{O}$ & Glass & Cyano + Basic Red 28 & 4 & $10 / 13$ & 60 & 470 \\
\hline 169 & $\mathrm{O}$ & Glass & Cyano + Basic Red 28 & 5.6 & $10 / 13$ & 60 & 550 \\
\hline 169 & $\mathrm{O}$ & Glass & Cyano + Basic Red 28 & 11 & $1 / 25$ & 60 & white \\
\hline 202 & $\mathrm{O}$ & Glass & Cyano + Basic Yellow 40 & 7.1 & 13 & 60 & 385 \\
\hline 202 & $\mathrm{O}$ & Glass & Cyano + Basic Yellow 40 & 4 & 3 & 60 & 450 \\
\hline 202 & $\mathrm{O}$ & Glass & Cyano + Basic Yellow 40 & 4.5 & 13 & 60 & 485 \\
\hline 203 & $\mathrm{O}$ & Glass & Cyano + Basic Yellow 40 & 8 & 13 & 60 & 385 \\
\hline 203 & $\mathrm{O}$ & Glass & Cyano + Basic Yellow 40 & 4 & 3 & 60 & 450 \\
\hline
\end{tabular}




\begin{tabular}{|c|c|c|c|c|c|c|c|}
\hline 203 & $\mathrm{O}$ & Glass & Cyano + Basic Yellow 40 & 4 & 13 & 60 & 485 \\
\hline 204 & $\mathrm{O}$ & Glass & Cyano + Basic Yellow 40 & 6.3 & 10 & 60 & 385 \\
\hline 204 & $\mathrm{O}$ & Glass & Cyano + Basic Yellow 40 & 4 & 3 & 60 & 450 \\
\hline 204 & $\mathrm{O}$ & Glass & Cyano + Basic Yellow 40 & 4 & 10 & 60 & 485 \\
\hline 205 & $\mathrm{O}$ & Glass & Cyano + Basic Yellow 40 & 5.6 & 10 & 60 & 385 \\
\hline 205 & $\mathrm{O}$ & Glass & Cyano + Basic Yellow 40 & 4.5 & 8 & 60 & 450 \\
\hline 205 & $\mathrm{O}$ & Glass & Cyano + Basic Yellow 40 & 4 & 10 & 60 & 485 \\
\hline 206 & $\mathrm{O}$ & Glass & Cyano + Basic Yellow 40 & 5 & 10 & 60 & 385 \\
\hline 206 & $\mathrm{O}$ & Glass & Cyano + Basic Yellow 40 & 5 & 8 & 60 & 450 \\
\hline 206 & $\mathrm{O}$ & Glass & Cyano + Basic Yellow 40 & 4 & 10 & 60 & 485 \\
\hline 207 & $\mathrm{O}$ & Glass & Cyano + Basic Yellow 40 & 5 & 10 & 60 & 385 \\
\hline 207 & $\mathrm{O}$ & Glass & Cyano + Basic Yellow 40 & 4 & 8 & 60 & 450 \\
\hline 207 & $\mathrm{O}$ & Glass & Cyano + Basic Yellow 40 & 4 & 10 & 60 & 485 \\
\hline 208 & $\mathrm{O}$ & Glass & Cyano + Basic Yellow 40 & 5.6 & 10 & 60 & 385 \\
\hline 208 & $\mathrm{O}$ & Glass & Cyano + Basic Yellow 40 & 4 & 8 & 60 & 450 \\
\hline 208 & $\mathrm{O}$ & Glass & Cyano + Basic Yellow 40 & 4 & 10 & 60 & 485 \\
\hline 209 & $\mathrm{O}$ & Glass & Cyano + Basic Yellow 40 & 5 & 10 & 60 & 385 \\
\hline 209 & $\mathrm{O}$ & Glass & Cyano + Basic Yellow 40 & 4 & 8 & 60 & 450 \\
\hline 209 & $\mathrm{O}$ & Glass & Cyano + Basic Yellow 40 & 4 & 10 & 60 & 485 \\
\hline 210 & $\mathrm{O}$ & Glass & Cyano + Basic Yellow 40 & 4.5 & 10 & 60 & 385 \\
\hline 210 & $\mathrm{O}$ & Glass & Cyano + Basic Yellow 40 & 4 & 8 & 60 & 450 \\
\hline 210 & $\mathrm{O}$ & Glass & Cyano + Basic Yellow 40 & 4 & 10 & 60 & 485 \\
\hline 211 & $\mathrm{O}$ & Glass & Cyano + Basic Yellow 40 & 5 & 10 & 60 & 385 \\
\hline 211 & $\mathrm{O}$ & Glass & Cyano + Basic Yellow 40 & 4 & 8 & 60 & 450 \\
\hline 211 & $\mathrm{O}$ & Glass & Cyano + Basic Yellow 40 & 4 & 10 & 60 & 485 \\
\hline 212 & $\mathrm{O}$ & Glass & Cyano + Basic Yellow 40 & 4.5 & 10 & 60 & 385 \\
\hline 212 & $\mathrm{O}$ & Glass & Cyano + Basic Yellow 40 & 4 & 8 & 60 & 450 \\
\hline 212 & $\mathrm{O}$ & Glass & Cyano + Basic Yellow 40 & 4 & 10 & 60 & 485 \\
\hline 213 & $\mathrm{O}$ & Glass & Cyano + Basic Yellow 40 & 5 & 10 & 60 & 385 \\
\hline 213 & $\mathrm{O}$ & Glass & Cyano + Basic Yellow 40 & 4 & 8 & 60 & 450 \\
\hline 213 & $\mathrm{O}$ & Glass & Cyano + Basic Yellow 40 & 4 & 10 & 60 & 485 \\
\hline 214 & $\mathrm{O}$ & Glass & Cyano + Basic Yellow 40 & 5 & 10 & 60 & 385 \\
\hline 214 & $\mathrm{O}$ & Glass & Cyano + Basic Yellow 40 & 4 & 8 & 60 & 450 \\
\hline 214 & $\mathrm{O}$ & Glass & Cyano + Basic Yellow 40 & 4 & 10 & 60 & 485 \\
\hline 215 & $\mathrm{O}$ & Glass & Cyano + Basic Yellow 40 & 5 & 10 & 60 & 385 \\
\hline 215 & $\mathrm{O}$ & Glass & Cyano + Basic Yellow 40 & 4 & 8 & 60 & 450 \\
\hline 215 & $\mathrm{O}$ & Glass & Cyano + Basic Yellow 40 & 4 & 10 & 60 & 485 \\
\hline 216 & $\mathrm{O}$ & Glass & Cyano + Basic Yellow 40 & 5 & 10 & 60 & 385 \\
\hline 216 & $\mathrm{O}$ & Glass & Cyano + Basic Yellow 40 & 4 & 8 & 60 & 450 \\
\hline 216 & $\mathrm{O}$ & Glass & Cyano + Basic Yellow 40 & 4 & 10 & 60 & 485 \\
\hline 217 & $\mathrm{O}$ & Glass & Cyano + Basic Yellow 40 & 9 & 10 & 60 & 385 \\
\hline 217 & $\mathrm{O}$ & Glass & Cyano + Basic Yellow 40 & 5 & 8 & 60 & 450 \\
\hline 217 & $\mathrm{O}$ & Glass & Cyano + Basic Yellow 40 & 4.5 & 10 & 60 & 485 \\
\hline 218 & $\mathrm{O}$ & Glass & Cyano + Basic Yellow 40 & 9 & 10 & 60 & 385 \\
\hline 218 & $\mathrm{O}$ & Glass & Cyano + Basic Yellow 40 & 5 & 8 & 60 & 450 \\
\hline 218 & $\mathrm{O}$ & Glass & Cyano + Basic Yellow 40 & 4 & 10 & 60 & 485 \\
\hline 219 & $\mathrm{O}$ & Glass & Cyano + Basic Yellow 40 & 8 & 10 & 60 & 385 \\
\hline 219 & $\mathrm{O}$ & Glass & Cyano + Basic Yellow 40 & 4.5 & 8 & 60 & 450 \\
\hline 219 & $\mathrm{O}$ & Glass & Cyano + Basic Yellow 40 & 4 & 10 & 60 & 485 \\
\hline 220 & $\mathrm{O}$ & Glass & Cyano + MBD & 4 & 6 & 60 & 415 \\
\hline 221 & $\mathrm{O}$ & Glass & Cyano + MBD & 4 & 6 & 60 & 415 \\
\hline 222 & $\mathrm{O}$ & Glass & Cyano + MBD & 4 & 6 & 60 & 415 \\
\hline
\end{tabular}




\begin{tabular}{|c|c|c|c|c|c|c|c|}
\hline 223 & $\mathrm{O}$ & Glass & Cyano + MBD & 4 & 6 & 60 & 415 \\
\hline 224 & $\mathrm{O}$ & Glass & Cyano + MBD & 4 & 6 & 60 & 415 \\
\hline 225 & $\mathrm{O}$ & Glass & Cyano + MBD & 4 & 6 & 60 & 415 \\
\hline 226 & $\mathrm{O}$ & Glass & Cyano + MBD & 4 & 6 & 60 & 415 \\
\hline 227 & $\mathrm{O}$ & Glass & Cyano + MBD & 4 & 6 & 60 & 415 \\
\hline 228 & $\mathrm{O}$ & Glass & Cyano + MBD & 4 & 6 & 60 & 415 \\
\hline 229 & $\mathrm{O}$ & Glass & Cyano + MBD & 4 & 6 & 60 & 415 \\
\hline 230 & $\mathrm{O}$ & Glass & Cyano + MBD & 4 & 6 & 60 & 415 \\
\hline 231 & $\mathrm{O}$ & Glass & Cyano + MBD & 4 & 6 & 60 & 415 \\
\hline 232 & $\mathrm{O}$ & Glass & Cyano + MBD & 4 & 6 & 60 & 415 \\
\hline 233 & $\mathrm{O}$ & Glass & Cyano + MBD & 4 & 6 & 60 & 415 \\
\hline 234 & $\mathrm{O}$ & Glass & Cyano + MBD & 4 & 6 & 60 & 415 \\
\hline 235 & $\mathrm{O}$ & Glass & Cyano + MBD & 4 & 6 & 60 & 415 \\
\hline 170 & $\mathrm{O}$ & Glass & Cyano + Rhodamine $6 \mathrm{G}$ & 4 & 13 & 60 & 500 \\
\hline 170 & $\mathrm{O}$ & Glass & Cyano + Rhodamine 6G & 5.6 & 13 & 60 & 515 \\
\hline 170 & $\mathrm{O}$ & Glass & Cyano + Rhodamine $6 \mathrm{G}$ & 13 & 13 & 60 & 540 \\
\hline 171 & $\mathrm{O}$ & Glass & Cyano + Rhodamine $6 \mathrm{G}$ & 4 & 13 & 60 & 500 \\
\hline 171 & $\mathrm{O}$ & Glass & Cyano + Rhodamine $6 \mathrm{G}$ & 5 & 13 & 60 & 515 \\
\hline 171 & $\mathrm{O}$ & Glass & Cyano + Rhodamine $6 \mathrm{G}$ & 18 & 13 & 60 & 540 \\
\hline 172 & $\mathrm{O}$ & Glass & Cyano + Rhodamine $6 \mathrm{G}$ & 4 & 4 & 60 & 500 \\
\hline 172 & $\mathrm{O}$ & Glass & Cyano + Rhodamine 6G & 4 & 4 & 60 & 515 \\
\hline 172 & $\mathrm{O}$ & Glass & Cyano + Rhodamine $6 \mathrm{G}$ & 25 & 13 & 60 & 540 \\
\hline 173 & $\mathrm{O}$ & Glass & Cyano + Rhodamine $6 \mathrm{G}$ & 4 & 13 & 60 & 500 \\
\hline 173 & $\mathrm{O}$ & Glass & Cyano + Rhodamine $6 \mathrm{G}$ & 5.6 & 13 & 60 & 515 \\
\hline 173 & $\mathrm{O}$ & Glass & Cyano + Rhodamine $6 \mathrm{G}$ & 13 & 13 & 60 & 540 \\
\hline 174 & $\mathrm{O}$ & Glass & Cyano + Rhodamine $6 \mathrm{G}$ & 4 & 13 & 60 & 500 \\
\hline 174 & $\mathrm{O}$ & Glass & Cyano + Rhodamine 6G & 4.5 & 13 & 60 & 515 \\
\hline 174 & $\mathrm{O}$ & Glass & Cyano + Rhodamine $6 \mathrm{G}$ & 11 & 13 & 60 & 540 \\
\hline 175 & $\mathrm{O}$ & Glass & Cyano + Rhodamine 6G & 4 & 13 & 60 & 500 \\
\hline 175 & $\mathrm{O}$ & Glass & Cyano + Rhodamine 6G & 5 & 13 & 60 & 515 \\
\hline 175 & $\mathrm{O}$ & Glass & Cyano + Rhodamine 6G & 11 & 13 & 60 & 540 \\
\hline 176 & $\mathrm{O}$ & Glass & Cyano + Rhodamine $6 \mathrm{G}$ & 4 & 13 & 60 & 500 \\
\hline 176 & $\mathrm{O}$ & Glass & Cyano + Rhodamine 6G & 4 & 13 & 60 & 515 \\
\hline 176 & $\mathrm{O}$ & Glass & Cyano + Rhodamine $6 \mathrm{G}$ & 4.5 & 13 & 60 & 540 \\
\hline 177 & $\mathrm{O}$ & Glass & Cyano + Rhodamine 6G & 4 & 13 & 60 & 500 \\
\hline 177 & $\mathrm{O}$ & Glass & Cyano + Rhodamine 6G & 4 & 13 & 60 & 515 \\
\hline 177 & $\mathrm{O}$ & Glass & Cyano + Rhodamine 6G & 4 & 13 & 60 & 540 \\
\hline 178 & $\mathrm{O}$ & Glass & Cyano + Rhodamine $6 \mathrm{G}$ & 4 & 13 & 60 & 500 \\
\hline 178 & $\mathrm{O}$ & Glass & Cyano + Rhodamine $6 \mathrm{G}$ & 4 & 13 & 60 & 515 \\
\hline 178 & $\mathrm{O}$ & Glass & Cyano + Rhodamine $6 \mathrm{G}$ & 4 & 13 & 60 & 540 \\
\hline 179 & $\mathrm{O}$ & Glass & Cyano + Rhodamine 6G & 4 & 13 & 60 & 500 \\
\hline 179 & $\mathrm{O}$ & Glass & Cyano + Rhodamine 6G & 4 & 13 & 60 & 515 \\
\hline 179 & $\mathrm{O}$ & Glass & Cyano + Rhodamine 6G & 5 & 13 & 60 & 540 \\
\hline 180 & $\mathrm{O}$ & Glass & Cyano + Rhodamine $6 \mathrm{G}$ & 4 & 13 & 60 & 500 \\
\hline 180 & $\mathrm{O}$ & Glass & Cyano + Rhodamine 6G & 4 & 13 & 60 & 515 \\
\hline 180 & $\mathrm{O}$ & Glass & Cyano + Rhodamine $6 \mathrm{G}$ & 4 & 13 & 60 & 540 \\
\hline 181 & $\mathrm{O}$ & Glass & Cyano + Rhodamine $6 \mathrm{G}$ & 4 & 13 & 60 & 500 \\
\hline 181 & $\mathrm{O}$ & Glass & Cyano + Rhodamine 6G & 4 & 13 & 60 & 515 \\
\hline 181 & $\mathrm{O}$ & Glass & Cyano + Rhodamine 6G & 4 & 13 & 60 & 540 \\
\hline 182 & $\mathrm{O}$ & Glass & Cyano + Rhodamine 6G & 4 & 13 & 60 & 500 \\
\hline 182 & $\mathrm{O}$ & Glass & Cyano + Rhodamine 6G & 5 & 13 & 60 & 515 \\
\hline 182 & $\mathrm{O}$ & Glass & Cyano + Rhodamine 6G & 9 & 13 & 60 & 540 \\
\hline
\end{tabular}




\begin{tabular}{|c|c|c|c|c|c|c|c|}
\hline 183 & $\mathrm{O}$ & Glass & Cyano + Rhodamine $6 \mathrm{G}$ & 4.5 & 13 & 60 & 500 \\
\hline 183 & $\mathrm{O}$ & Glass & Cyano + Rhodamine 6G & 4 & 13 & 60 & 515 \\
\hline 183 & $\mathrm{O}$ & Glass & Cyano + Rhodamine 6G & 6.3 & 13 & 60 & 540 \\
\hline 184 & $\mathrm{O}$ & Glass & Cyano + Rhodamine 6G & 4 & 13 & 60 & 500 \\
\hline 184 & $\mathrm{O}$ & Glass & Cyano + Rhodamine 6G & 4 & 13 & 60 & 515 \\
\hline 184 & $\mathrm{O}$ & Glass & Cyano + Rhodamine 6G & 6.3 & 13 & 60 & 540 \\
\hline 185 & $\mathrm{O}$ & Glass & Cyano + Rhodamine $6 \mathrm{G}$ & 4 & 13 & 60 & 500 \\
\hline 185 & $\mathrm{O}$ & Glass & Cyano + Rhodamine 6G & 5.6 & 13 & 60 & 515 \\
\hline 185 & $\mathrm{O}$ & Glass & Cyano + Rhodamine 6G & 10 & 13 & 60 & 540 \\
\hline 186 & $\mathrm{O}$ & Glass & Cyano + Rhodamine 6G & 4 & 13 & 60 & 500 \\
\hline 186 & $\mathrm{O}$ & Glass & Cyano + Rhodamine 6G & 4.5 & 13 & 60 & 515 \\
\hline 186 & $\mathrm{O}$ & Glass & Cyano + Rhodamine 6G & 7.1 & 13 & 60 & 540 \\
\hline 187 & $\mathrm{O}$ & Glass & Cyano + Rhodamine 6G & 4 & 13 & 60 & 500 \\
\hline 187 & $\mathrm{O}$ & Glass & Cyano + Rhodamine 6G & 5 & 13 & 60 & 515 \\
\hline 187 & $\mathrm{O}$ & Glass & Cyano + Rhodamine $6 \mathrm{G}$ & 9 & 13 & 60 & 540 \\
\hline 188 & $\mathrm{O}$ & Glass & Cyano + Rhodamine 6G & 4 & 13 & 60 & 500 \\
\hline 188 & $\mathrm{O}$ & Glass & Cyano + Rhodamine 6G & 4 & 13 & 60 & 515 \\
\hline 188 & $\mathrm{O}$ & Glass & Cyano + Rhodamine 6G & 8 & 13 & 60 & 540 \\
\hline 189 & $\mathrm{O}$ & Glass & Cyano + Rhodamine 6G & 4.5 & 13 & 60 & 500 \\
\hline 189 & $\mathrm{O}$ & Glass & Cyano + Rhodamine $6 \mathrm{G}$ & 4 & 13 & 60 & 515 \\
\hline 189 & $\mathrm{O}$ & Glass & Cyano + Rhodamine 6G & 6.3 & 13 & 60 & 540 \\
\hline 190 & $\mathrm{O}$ & Glass & Cyano + Rhodamine 6G & 4 & 13 & 60 & 500 \\
\hline 190 & $\mathrm{O}$ & Glass & Cyano + Rhodamine $6 \mathrm{G}$ & 4.5 & 13 & 60 & 515 \\
\hline 190 & $\mathrm{O}$ & Glass & Cyano + Rhodamine 6G & 7.1 & 13 & 60 & 540 \\
\hline 191 & $\mathrm{O}$ & Glass & Cyano + Rhodamine $6 \mathrm{G}$ & 4 & 13 & 60 & 500 \\
\hline 191 & $\mathrm{O}$ & Glass & Cyano + Rhodamine $6 \mathrm{G}$ & 5.6 & 13 & 60 & 515 \\
\hline 191 & $\mathrm{O}$ & Glass & Cyano + Rhodamine $6 \mathrm{G}$ & 10 & 13 & 60 & 540 \\
\hline 192 & $\mathrm{O}$ & Glass & Cyano + Rhodamine 6G & 4 & 13 & 60 & 500 \\
\hline 192 & $\mathrm{O}$ & Glass & Cyano + Rhodamine $6 \mathrm{G}$ & 5 & 13 & 60 & 515 \\
\hline 192 & $\mathrm{O}$ & Glass & Cyano + Rhodamine 6G & 7.1 & 13 & 60 & 540 \\
\hline 193 & $\mathrm{O}$ & Glass & Cyano + Rhodamine 6G & 4 & 13 & 60 & 500 \\
\hline 193 & $\mathrm{O}$ & Glass & Cyano + Rhodamine 6G & 5.6 & 13 & 60 & 515 \\
\hline 193 & $\mathrm{O}$ & Glass & Cyano + Rhodamine 6G & 5 & 13 & 60 & 540 \\
\hline 194 & $\mathrm{O}$ & Glass & Cyano + Rhodamine 6G & 4 & 13 & 60 & 500 \\
\hline 194 & $\mathrm{O}$ & Glass & Cyano + Rhodamine 6G & 5 & 13 & 60 & 515 \\
\hline 194 & $\mathrm{O}$ & Glass & Cyano + Rhodamine 6G & 11 & 13 & 60 & 540 \\
\hline 195 & $\mathrm{O}$ & Glass & Cyano + Rhodamine 6G & 4.5 & 13 & 60 & 500 \\
\hline 195 & $\mathrm{O}$ & Glass & Cyano + Rhodamine $6 \mathrm{G}$ & 5.6 & 13 & 60 & 515 \\
\hline 195 & $\mathrm{O}$ & Glass & Cyano + Rhodamine 6G & 16 & 13 & 60 & 540 \\
\hline 196 & $\mathrm{O}$ & Glass & Cyano + Rhodamine $6 \mathrm{G}$ & 5 & 13 & 60 & 500 \\
\hline 196 & $\mathrm{O}$ & Glass & Cyano + Rhodamine $6 \mathrm{G}$ & 11 & 13 & 60 & 515 \\
\hline 196 & $\mathrm{O}$ & Glass & Cyano + Rhodamine 6G & 25 & 13 & 60 & 540 \\
\hline 197 & $\mathrm{O}$ & Glass & Cyano + Rhodamine 6G & 4 & 13 & 60 & 500 \\
\hline 197 & $\mathrm{O}$ & Glass & Cyano + Rhodamine $6 \mathrm{G}$ & 4.5 & 13 & 60 & 515 \\
\hline 197 & $\mathrm{O}$ & Glass & Cyano + Rhodamine 6G & 7.1 & 13 & 60 & 540 \\
\hline 198 & $\mathrm{O}$ & Glass & Cyano + Rhodamine 6G & 4 & 13 & 60 & 500 \\
\hline 198 & $\mathrm{O}$ & Glass & Cyano + Rhodamine $6 \mathrm{G}$ & 4.5 & 13 & 60 & 515 \\
\hline 198 & $\mathrm{O}$ & Glass & Cyano + Rhodamine 6G & 9 & 13 & 60 & 540 \\
\hline 199 & $\mathrm{O}$ & Glass & Cyano + Rhodamine 6G & 4 & 13 & 60 & 500 \\
\hline 199 & $\mathrm{O}$ & Glass & Cyano + Rhodamine 6G & 4 & 13 & 60 & 515 \\
\hline 199 & $\mathrm{O}$ & Glass & Cyano + Rhodamine 6G & 9 & 13 & 60 & 540 \\
\hline 200 & $\mathrm{O}$ & Glass & Cyano + Rhodamine $6 \mathrm{G}$ & 5 & 13 & 60 & 500 \\
\hline
\end{tabular}




\begin{tabular}{|c|c|c|c|c|c|c|c|}
\hline 200 & $\mathrm{O}$ & Glass & Cyano + Rhodamine 6G & 8 & 13 & 60 & 515 \\
\hline 200 & $\mathrm{O}$ & Glass & Cyano + Rhodamine 6G & 20 & 13 & 60 & 540 \\
\hline 201 & $\mathrm{O}$ & Glass & Cyano + Rhodamine 6G & 5 & 13 & 60 & 500 \\
\hline 201 & $\mathrm{O}$ & Glass & Cyano + Rhodamine 6G & 9 & 13 & 60 & 515 \\
\hline 201 & $\mathrm{O}$ & Glass & Cyano + Rhodamine 6G & 22 & 13 & 60 & 540 \\
\hline 137 & $\mathrm{M}$ & Glass & Merged & N/A & N/A & N/A & N/A \\
\hline 138 & $\mathrm{M}$ & Glass & Merged & N/A & N/A & N/A & N/A \\
\hline 139 & $\mathrm{M}$ & Glass & Merged & N/A & N/A & N/A & N/A \\
\hline 140 & $\mathrm{M}$ & Glass & Merged & N/A & N/A & N/A & N/A \\
\hline 141 & $\mathrm{M}$ & Glass & Merged & N/A & N/A & N/A & N/A \\
\hline 142 & $\mathrm{M}$ & Glass & Merged & N/A & N/A & N/A & $\mathrm{N} / \mathrm{A}$ \\
\hline 143 & $\mathrm{M}$ & Glass & Merged & N/A & N/A & N/A & N/A \\
\hline 144 & $\mathrm{M}$ & Glass & Merged & N/A & N/A & N/A & N/A \\
\hline 145 & $\mathrm{M}$ & Glass & Merged & N/A & N/A & N/A & $\mathrm{N} / \mathrm{A}$ \\
\hline 146 & $\mathrm{M}$ & Glass & Merged & N/A & N/A & N/A & N/A \\
\hline 147 & $\mathrm{M}$ & Glass & Merged & N/A & N/A & N/A & N/A \\
\hline 148 & $\mathrm{M}$ & Glass & Merged & N/A & N/A & N/A & N/A \\
\hline 149 & $\mathrm{M}$ & Glass & Merged & N/A & N/A & N/A & N/A \\
\hline 150 & $\mathrm{M}$ & Glass & Merged & N/A & N/A & N/A & N/A \\
\hline 151 & $\mathrm{M}$ & Glass & Merged & N/A & N/A & N/A & N/A \\
\hline 152 & $\mathrm{M}$ & Glass & Merged & N/A & N/A & N/A & N/A \\
\hline 153 & $\mathrm{M}$ & Glass & Merged & N/A & N/A & N/A & N/A \\
\hline 154 & $\mathrm{M}$ & Glass & Merged & N/A & N/A & N/A & N/A \\
\hline 155 & $\mathrm{M}$ & Glass & Merged & N/A & N/A & N/A & N/A \\
\hline 156 & $\mathrm{M}$ & Glass & Merged & N/A & N/A & N/A & N/A \\
\hline 157 & $\mathrm{M}$ & Glass & Merged & N/A & N/A & N/A & N/A \\
\hline 158 & $M$ & Glass & Merged & N/A & N/A & N/A & N/A \\
\hline 159 & $M$ & Glass & Merged & N/A & N/A & N/A & N/A \\
\hline 160 & $\mathrm{M}$ & Glass & Merged & N/A & N/A & N/A & N/A \\
\hline 161 & M & Glass & Merged & N/A & N/A & N/A & $\mathrm{N} / \mathrm{A}$ \\
\hline 162 & M & Glass & Merged & N/A & N/A & N/A & N/A \\
\hline 163 & M & Glass & Merged & N/A & N/A & N/A & N/A \\
\hline 164 & $\mathrm{M}$ & Glass & Merged & N/A & $\mathrm{N} / \mathrm{A}$ & N/A & $\mathrm{N} / \mathrm{A}$ \\
\hline 165 & $\mathrm{M}$ & Glass & Merged & N/A & N/A & N/A & $\mathrm{N} / \mathrm{A}$ \\
\hline 166 & $\mathrm{M}$ & Glass & Merged & N/A & N/A & N/A & N/A \\
\hline 167 & $\mathrm{M}$ & Glass & Merged & N/A & N/A & N/A & N/A \\
\hline 168 & $\mathrm{M}$ & Glass & Merged & N/A & N/A & N/A & N/A \\
\hline 169 & $\mathrm{M}$ & Glass & Merged & N/A & N/A & N/A & N/A \\
\hline 170 & M & Glass & Merged & N/A & N/A & N/A & N/A \\
\hline 171 & M & Glass & Merged & N/A & N/A & N/A & N/A \\
\hline 172 & $\mathrm{M}$ & Glass & Merged & N/A & N/A & N/A & N/A \\
\hline 173 & $\mathrm{M}$ & Glass & Merged & N/A & N/A & N/A & N/A \\
\hline 174 & $\mathrm{M}$ & Glass & Merged & N/A & N/A & N/A & N/A \\
\hline 175 & $\mathrm{M}$ & Glass & Merged & N/A & N/A & N/A & N/A \\
\hline 176 & $M$ & Glass & Merged & N/A & N/A & N/A & N/A \\
\hline 177 & $M$ & Glass & Merged & N/A & N/A & N/A & N/A \\
\hline 178 & $\mathrm{M}$ & Glass & Merged & N/A & N/A & N/A & N/A \\
\hline 179 & $\mathrm{M}$ & Glass & Merged & N/A & N/A & N/A & N/A \\
\hline 180 & $\mathrm{M}$ & Glass & Merged & N/A & N/A & N/A & N/A \\
\hline 181 & M & Glass & Merged & N/A & N/A & N/A & N/A \\
\hline 182 & $\mathrm{M}$ & Glass & Merged & N/A & N/A & N/A & N/A \\
\hline 183 & $\mathrm{M}$ & Glass & Merged & N/A & N/A & N/A & N/A \\
\hline
\end{tabular}




\begin{tabular}{|c|c|c|c|c|c|c|c|}
\hline 184 & $\mathrm{M}$ & Glass & Merged & N/A & N/A & N/A & N/A \\
\hline 185 & $\mathrm{M}$ & Glass & Merged & N/A & N/A & N/A & N/A \\
\hline 186 & $\mathrm{M}$ & Glass & Merged & N/A & N/A & N/A & N/A \\
\hline 187 & $\mathrm{M}$ & Glass & Merged & N/A & N/A & N/A & N/A \\
\hline 188 & $\mathrm{M}$ & Glass & Merged & N/A & N/A & N/A & N/A \\
\hline 189 & M & Glass & Merged & N/A & N/A & N/A & N/A \\
\hline 190 & $\mathrm{M}$ & Glass & Merged & N/A & N/A & N/A & $\mathrm{N} / \mathrm{A}$ \\
\hline 191 & $\mathrm{M}$ & Glass & Merged & N/A & N/A & N/A & N/A \\
\hline 192 & $\mathrm{M}$ & Glass & Merged & N/A & N/A & N/A & N/A \\
\hline 193 & $\mathrm{M}$ & Glass & Merged & N/A & N/A & N/A & N/A \\
\hline 194 & $\mathrm{M}$ & Glass & Merged & N/A & N/A & N/A & $\mathrm{N} / \mathrm{A}$ \\
\hline 195 & $\mathrm{M}$ & Glass & Merged & N/A & N/A & N/A & N/A \\
\hline 196 & $\mathrm{M}$ & Glass & Merged & N/A & N/A & N/A & N/A \\
\hline 197 & $\mathrm{M}$ & Glass & Merged & N/A & N/A & N/A & N/A \\
\hline 198 & $\mathrm{M}$ & Glass & Merged & N/A & N/A & N/A & N/A \\
\hline 199 & $\mathrm{M}$ & Glass & Merged & N/A & N/A & N/A & N/A \\
\hline 200 & $\mathrm{M}$ & Glass & Merged & N/A & N/A & N/A & N/A \\
\hline 201 & $\mathrm{M}$ & Glass & Merged & N/A & N/A & N/A & N/A \\
\hline 202 & $\mathrm{M}$ & Glass & Merged & N/A & N/A & N/A & $\mathrm{N} / \mathrm{A}$ \\
\hline 203 & $\mathrm{M}$ & Glass & Merged & N/A & N/A & N/A & N/A \\
\hline 204 & $\mathrm{M}$ & Glass & Merged & N/A & N/A & N/A & N/A \\
\hline 205 & $\mathrm{M}$ & Glass & Merged & N/A & N/A & N/A & N/A \\
\hline 206 & $\mathrm{M}$ & Glass & Merged & N/A & N/A & N/A & $\mathrm{N} / \mathrm{A}$ \\
\hline 207 & $\mathrm{M}$ & Glass & Merged & N/A & N/A & N/A & N/A \\
\hline 208 & $\mathrm{M}$ & Glass & Merged & N/A & N/A & N/A & N/A \\
\hline 209 & $\mathrm{M}$ & Glass & Merged & N/A & N/A & N/A & N/A \\
\hline 210 & $\mathrm{M}$ & Glass & Merged & N/A & N/A & N/A & $\mathrm{N} / \mathrm{A}$ \\
\hline 211 & $\mathrm{M}$ & Glass & Merged & N/A & N/A & N/A & N/A \\
\hline 212 & $\mathrm{M}$ & Glass & Merged & N/A & N/A & N/A & $\mathrm{N} / \mathrm{A}$ \\
\hline 213 & $\mathrm{M}$ & Glass & Merged & N/A & N/A & N/A & N/A \\
\hline 214 & $\mathrm{M}$ & Glass & Merged & N/A & N/A & N/A & N/A \\
\hline 215 & $\mathrm{M}$ & Glass & Merged & N/A & N/A & N/A & N/A \\
\hline 216 & $\mathrm{M}$ & Glass & Merged & N/A & N/A & N/A & N/A \\
\hline 217 & $\mathrm{M}$ & Glass & Merged & N/A & N/A & N/A & N/A \\
\hline 218 & $\mathrm{M}$ & Glass & Merged & N/A & N/A & N/A & N/A \\
\hline 219 & $\mathrm{M}$ & Glass & Merged & N/A & N/A & N/A & N/A \\
\hline 220 & $\mathrm{M}$ & Glass & Merged & N/A & N/A & N/A & $\mathrm{N} / \mathrm{A}$ \\
\hline 221 & $\mathrm{M}$ & Glass & Merged & N/A & N/A & N/A & $\mathrm{N} / \mathrm{A}$ \\
\hline 222 & $\mathrm{M}$ & Glass & Merged & N/A & N/A & N/A & N/A \\
\hline 223 & $\mathrm{M}$ & Glass & Merged & N/A & N/A & N/A & N/A \\
\hline 224 & $\mathrm{M}$ & Glass & Merged & N/A & N/A & N/A & $\mathrm{N} / \mathrm{A}$ \\
\hline 225 & $\mathrm{M}$ & Glass & Merged & N/A & N/A & N/A & N/A \\
\hline 226 & $\mathrm{M}$ & Glass & Merged & N/A & N/A & N/A & N/A \\
\hline 227 & $\mathrm{M}$ & Glass & Merged & N/A & N/A & N/A & N/A \\
\hline 228 & $\mathrm{M}$ & Glass & Merged & N/A & N/A & N/A & N/A \\
\hline 229 & $\mathrm{M}$ & Glass & Merged & N/A & N/A & N/A & $\mathrm{N} / \mathrm{A}$ \\
\hline 230 & $\mathrm{M}$ & Glass & Merged & N/A & N/A & N/A & N/A \\
\hline 231 & $\mathrm{M}$ & Glass & Merged & N/A & N/A & N/A & N/A \\
\hline 232 & $\mathrm{M}$ & Glass & Merged & N/A & N/A & N/A & N/A \\
\hline 233 & $\mathrm{M}$ & Glass & Merged & N/A & N/A & N/A & N/A \\
\hline 234 & $\mathrm{M}$ & Glass & Merged & N/A & N/A & N/A & N/A \\
\hline 235 & $\mathrm{M}$ & Glass & Merged & N/A & N/A & N/A & $\mathrm{N} / \mathrm{A}$ \\
\hline
\end{tabular}




\begin{tabular}{|c|c|c|c|c|c|c|c|}
\hline $\begin{array}{c}\text { FP } \\
\#\end{array}$ & $\begin{array}{c}\text { Typ } \\
\text { e }\end{array}$ & Substrate & Development & f number & Exposure time & Focal Length & Wavelength \\
\hline 1 & $\mathrm{O}$ & Plastic & Cyano & 10 & $1 / 125$ & 60 & white \\
\hline 10 & $\mathrm{O}$ & Plastic & Cyano & 8 & $1 / 200$ & 60 & white \\
\hline 11 & $\mathrm{O}$ & Plastic & Cyano & 8 & $1 / 200$ & 60 & white \\
\hline 12 & $\mathrm{O}$ & Plastic & Cyano & 8 & $1 / 200$ & 60 & white \\
\hline 120 & $\mathrm{O}$ & Plastic & Cyano & 9 & $1 / 160$ & 60 & white \\
\hline 121 & $\mathrm{O}$ & Plastic & Cyano & 9 & $1 / 160$ & 60 & white \\
\hline 122 & $\mathrm{O}$ & Plastic & Cyano & 8 & $1 / 160$ & 60 & white \\
\hline 123 & $\mathrm{O}$ & Plastic & Cyano & 8 & $1 / 160$ & 60 & white \\
\hline 124 & $\mathrm{O}$ & Plastic & Cyano & 8 & $1 / 160$ & 60 & white \\
\hline 125 & $\mathrm{O}$ & Plastic & Cyano & 8 & $1 / 160$ & 60 & white \\
\hline 126 & $\mathrm{O}$ & Plastic & Cyano & 8 & $1 / 160$ & 60 & white \\
\hline 127 & $\mathrm{O}$ & Plastic & Cyano & 7.1 & $1 / 160$ & 60 & white \\
\hline 128 & $\mathrm{O}$ & Plastic & Cyano & 8 & $1 / 160$ & 60 & white \\
\hline 129 & $\mathrm{O}$ & Plastic & Cyano & 8 & $1 / 160$ & 60 & white \\
\hline 13 & $\mathrm{O}$ & Plastic & Cyano & 8 & $1 / 200$ & 60 & white \\
\hline 130 & $\mathrm{O}$ & Plastic & Cyano & 9 & $1 / 160$ & 60 & white \\
\hline 131 & $\mathrm{O}$ & Plastic & Cyano & 9 & $1 / 160$ & 60 & white \\
\hline 132 & $\mathrm{O}$ & Plastic & Cyano & 9 & $1 / 160$ & 60 & white \\
\hline 133 & $\mathrm{O}$ & Plastic & Cyano & 9 & $1 / 160$ & 60 & white \\
\hline 134 & $\mathrm{O}$ & Plastic & Cyano & 9 & $1 / 160$ & 60 & white \\
\hline 135 & $\mathrm{O}$ & Plastic & Cyano & 9 & $1 / 160$ & 60 & white \\
\hline 136 & $\mathrm{O}$ & Plastic & Cyano & 9 & $1 / 160$ & 60 & white \\
\hline 15 & $\mathrm{O}$ & Plastic & Cyano & 8 & $1 / 200$ & 60 & white \\
\hline 16 & $\mathrm{O}$ & Plastic & Cyano & 8 & $1 / 200$ & 60 & white \\
\hline 17 & $\mathrm{O}$ & Plastic & Cyano & 8 & $1 / 200$ & 60 & white \\
\hline 18 & $\mathrm{O}$ & Plastic & Cyano & 7.1 & $1 / 200$ & 60 & white \\
\hline 19 & $\mathrm{O}$ & Plastic & Cyano & 8 & $1 / 200$ & 60 & white \\
\hline 2 & $\mathrm{O}$ & Plastic & Cyano & 9 & $1 / 125$ & 60 & white \\
\hline 20 & $\mathrm{O}$ & Plastic & Cyano & 8 & $1 / 200$ & 60 & white \\
\hline 21 & $\mathrm{O}$ & Plastic & Cyano & 8 & $1 / 200$ & 60 & white \\
\hline 22 & $\mathrm{O}$ & Plastic & Cyano & 8 & $1 / 200$ & 60 & white \\
\hline 23 & $\mathrm{O}$ & Plastic & Cyano & 5 & $1 / 320$ & 60 & white \\
\hline 24 & $\mathrm{O}$ & Plastic & Cyano & 5.6 & $1 / 320$ & 60 & white \\
\hline 26 & $\mathrm{O}$ & Plastic & Cyano & 5.6 & $1 / 320$ & 60 & white \\
\hline 27 & $\mathrm{O}$ & Plastic & Cyano & 5.6 & $1 / 320$ & 60 & white \\
\hline 28 & $\mathrm{O}$ & Plastic & Cyano & 5 & $1 / 400$ & 60 & white \\
\hline 29 & $\mathrm{O}$ & Plastic & Cyano & 5 & $1 / 400$ & 60 & white \\
\hline 3 & $\mathrm{O}$ & Plastic & Cyano & 7.1 & $1 / 200$ & 60 & white \\
\hline 30 & $\mathrm{O}$ & Plastic & Cyano & 5 & $1 / 400$ & 60 & white \\
\hline 31 & $\mathrm{O}$ & Plastic & Cyano & 5 & $1 / 400$ & 60 & white \\
\hline 32 & $\mathrm{O}$ & Plastic & Cyano & 9 & $1 / 125$ & 60 & white \\
\hline 33 & $\mathrm{O}$ & Plastic & Cyano & 9 & $1 / 125$ & 60 & white \\
\hline 34 & $\mathrm{O}$ & Plastic & Cyano & 9 & $1 / 125$ & 60 & white \\
\hline 35 & $\mathrm{O}$ & Plastic & Cyano & 10 & $1 / 125$ & 60 & white \\
\hline 36 & $\mathrm{O}$ & Plastic & Cyano & 9 & $1 / 125$ & 60 & white \\
\hline 38 & $\mathrm{O}$ & Plastic & Cyano & 8 & $1 / 125$ & 60 & white \\
\hline
\end{tabular}




\begin{tabular}{|c|c|c|c|c|c|c|c|}
\hline 39 & $\mathrm{O}$ & Plastic & Cyano & 9 & $1 / 125$ & 60 & white \\
\hline 4 & $\mathrm{O}$ & Plastic & Cyano & 8 & $1 / 200$ & 60 & white \\
\hline 40 & $\mathrm{O}$ & Plastic & Cyano & 9 & $1 / 125$ & 60 & white \\
\hline 41 & $\mathrm{O}$ & Plastic & Cyano & 45 & $1 / 5$ & 60 & white \\
\hline 42 & $\mathrm{O}$ & Plastic & Cyano & 40 & $1 / 5$ & 60 & white \\
\hline 43 & $\mathrm{O}$ & Plastic & Cyano & 40 & $1 / 5$ & 60 & white \\
\hline 44 & $\mathrm{O}$ & Plastic & Cyano & 40 & $1 / 5$ & 60 & white \\
\hline 45 & $\mathrm{O}$ & Plastic & Cyano & 40 & $1 / 5$ & 60 & white \\
\hline 46 & $\mathrm{O}$ & Plastic & Cyano & 45 & $1 / 5$ & 60 & white \\
\hline 47 & $\mathrm{O}$ & Plastic & Cyano & 45 & $1 / 5$ & 60 & white \\
\hline 48 & $\mathrm{O}$ & Plastic & Cyano & 45 & $1 / 5$ & 60 & white \\
\hline 5 & $\mathrm{O}$ & Plastic & Cyano & 8 & $1 / 200$ & 60 & white \\
\hline 50 & $\mathrm{O}$ & Plastic & Cyano & 45 & $1 / 3$ & 60 & white \\
\hline 51 & $\mathrm{O}$ & Plastic & Cyano & 45 & $1 / 3$ & 60 & white \\
\hline 52 & $\mathrm{O}$ & Plastic & Cyano & 45 & $1 / 3$ & 60 & white \\
\hline 53 & $\mathrm{O}$ & Plastic & Cyano & 45 & $1 / 3$ & 60 & white \\
\hline 54 & $\mathrm{O}$ & Plastic & Cyano & 45 & $1 / 3$ & 60 & white \\
\hline 55 & $\mathrm{O}$ & Plastic & Cyano & 45 & $1 / 3$ & 60 & white \\
\hline 56 & $\mathrm{O}$ & Plastic & Cyano & 45 & $1 / 3$ & 60 & white \\
\hline 57 & $\mathrm{O}$ & Plastic & Cyano & 45 & $1 / 3$ & 60 & white \\
\hline 58 & $\mathrm{O}$ & Plastic & Cyano & 45 & $1 / 3$ & 60 & white \\
\hline 59 & $\mathrm{O}$ & Plastic & Cyano & 45 & $1 / 3$ & 60 & white \\
\hline 6 & $\mathrm{O}$ & Plastic & Cyano & 8 & $1 / 200$ & 60 & white \\
\hline 60 & $\mathrm{O}$ & Plastic & Cyano & 45 & $1 / 3$ & 60 & white \\
\hline 61 & $\mathrm{O}$ & Plastic & Cyano & 8 & $1 / 160$ & 60 & white \\
\hline 62 & $\mathrm{O}$ & Plastic & Cyano & 7.1 & $1 / 160$ & 60 & white \\
\hline 63 & $\mathrm{O}$ & Plastic & Cyano & 7.1 & $1 / 160$ & 60 & white \\
\hline 64 & $\mathrm{O}$ & Plastic & Cyano & 7.1 & $1 / 160$ & 60 & white \\
\hline 65 & $\mathrm{O}$ & Plastic & Cyano & 7.1 & $1 / 160$ & 60 & white \\
\hline 66 & $\mathrm{O}$ & Plastic & Cyano & 7.1 & $1 / 160$ & 60 & white \\
\hline 67 & $\mathrm{O}$ & Plastic & Cyano & 7.1 & $1 / 160$ & 60 & white \\
\hline 68 & $\mathrm{O}$ & Plastic & Cyano & 7.1 & $1 / 160$ & 60 & white \\
\hline 69 & $\mathrm{O}$ & Plastic & Cyano & 8 & $1 / 160$ & 60 & white \\
\hline 7 & $\mathrm{O}$ & Plastic & Cyano & 7.1 & $1 / 200$ & 60 & white \\
\hline 70 & $\mathrm{O}$ & Plastic & Cyano & 8 & $1 / 160$ & 60 & white \\
\hline 71 & $\mathrm{O}$ & Plastic & Cyano & 8 & $1 / 160$ & 60 & white \\
\hline 72 & $\mathrm{O}$ & Plastic & Cyano & 8 & $1 / 160$ & 60 & white \\
\hline 73 & $\mathrm{O}$ & Plastic & Cyano & 7.1 & $1 / 160$ & 60 & white \\
\hline 74 & $\mathrm{O}$ & Plastic & Cyano & 7.1 & $1 / 160$ & 60 & white \\
\hline 75 & $\mathrm{O}$ & Plastic & Cyano & 8 & $1 / 160$ & 60 & white \\
\hline 76 & $\mathrm{O}$ & Plastic & Cyano & 8 & $1 / 160$ & 60 & white \\
\hline 77 & $\mathrm{O}$ & Plastic & Cyano & 8 & $1 / 160$ & 60 & white \\
\hline 78 & $\mathrm{O}$ & Plastic & Cyano & 8 & $1 / 160$ & 60 & white \\
\hline 79 & $\mathrm{O}$ & Plastic & Cyano & 8 & $1 / 160$ & 60 & white \\
\hline 8 & $\mathrm{O}$ & Plastic & Cyano & 8 & $1 / 200$ & 60 & white \\
\hline 80 & $\mathrm{O}$ & Plastic & Cyano & 8 & $1 / 160$ & 60 & white \\
\hline 81 & $\mathrm{O}$ & Plastic & Cyano & 7.1 & $1 / 160$ & 60 & white \\
\hline 82 & $\mathrm{O}$ & Plastic & Cyano & 7.1 & $1 / 160$ & 60 & white \\
\hline 83 & $\mathrm{O}$ & Plastic & Cyano & 7.1 & $1 / 160$ & 60 & white \\
\hline 84 & $\mathrm{O}$ & Plastic & Cyano & 8 & $1 / 160$ & 60 & white \\
\hline 85 & $\mathrm{O}$ & Plastic & Cyano & 7.1 & $1 / 160$ & 60 & white \\
\hline 86 & $\mathrm{O}$ & Plastic & Cyano & 7.1 & $1 / 160$ & 60 & white \\
\hline
\end{tabular}




\begin{tabular}{|c|c|c|c|c|c|c|c|}
\hline 87 & $\mathrm{O}$ & Plastic & Cyano & 8 & $1 / 160$ & 60 & white \\
\hline 88 & $\mathrm{O}$ & Plastic & Cyano & 8 & $1 / 160$ & 60 & white \\
\hline 89 & $\mathrm{O}$ & Plastic & Cyano & 9 & $1 / 160$ & 60 & white \\
\hline 9 & $\mathrm{O}$ & Plastic & Cyano & 8 & $1 / 200$ & 60 & white \\
\hline 90 & $\mathrm{O}$ & Plastic & Cyano & 9 & $1 / 160$ & 60 & white \\
\hline 91 & $\mathrm{O}$ & Plastic & Cyano & 9 & $1 / 160$ & 60 & white \\
\hline 92 & $\mathrm{O}$ & Plastic & Cyano & 7.1 & $1 / 160$ & 60 & white \\
\hline 93 & $\mathrm{O}$ & Plastic & Cyano & 8 & $1 / 160$ & 60 & white \\
\hline 94 & $\mathrm{O}$ & Plastic & Cyano & 8 & $1 / 160$ & 60 & white \\
\hline 95 & $\mathrm{O}$ & Plastic & Cyano & 8 & $1 / 160$ & 60 & white \\
\hline 96 & $\mathrm{O}$ & Plastic & Cyano & 9 & $1 / 160$ & 60 & white \\
\hline 97 & $\mathrm{O}$ & Plastic & Cyano & 8 & $1 / 160$ & 60 & white \\
\hline 98 & $\mathrm{O}$ & Plastic & Cyano & 8 & $1 / 160$ & 60 & white \\
\hline 99 & $\mathrm{O}$ & Plastic & Cyano & 9 & $1 / 160$ & 60 & white \\
\hline 1 & $\mathrm{O}$ & Plastic & Cyano + Basic Red 28 & 4 & 8 & 60 & 470 \\
\hline 1 & $\mathrm{O}$ & Plastic & Cyano + Basic Red 28 & 4 & 8 & 60 & 500 \\
\hline 1 & $\mathrm{O}$ & Plastic & Cyano + Basic Red 28 & 14 & 8 & 60 & 550 \\
\hline 10 & $\mathrm{O}$ & Plastic & Cyano + Basic Red 28 & 4 & 6 & 60 & 470 \\
\hline 10 & $\mathrm{O}$ & Plastic & Cyano + Basic Red 28 & 4 & 6 & 60 & 500 \\
\hline 10 & $\mathrm{O}$ & Plastic & Cyano + Basic Red 28 & 13 & 6 & 60 & 550 \\
\hline 11 & $\mathrm{O}$ & Plastic & Cyano + Basic Red 28 & 4 & 6 & 60 & 470 \\
\hline 11 & $\mathrm{O}$ & Plastic & Cyano + Basic Red 28 & 4 & 6 & 60 & 500 \\
\hline 11 & $\mathrm{O}$ & Plastic & Cyano + Basic Red 28 & 14 & 6 & 60 & 550 \\
\hline 12 & $\mathrm{O}$ & Plastic & Cyano + Basic Red 28 & 4 & 6 & 60 & 470 \\
\hline 12 & $\mathrm{O}$ & Plastic & Cyano + Basic Red 28 & 4 & 6 & 60 & 500 \\
\hline 12 & $\mathrm{O}$ & Plastic & Cyano + Basic Red 28 & 14 & 6 & 60 & 550 \\
\hline 13 & $\mathrm{O}$ & Plastic & Cyano + Basic Red 28 & 4 & 6 & 60 & 470 \\
\hline 13 & $\mathrm{O}$ & Plastic & Cyano + Basic Red 28 & 4 & 6 & 60 & 500 \\
\hline 13 & $\mathrm{O}$ & Plastic & Cyano + Basic Red 28 & 14 & 6 & 60 & 550 \\
\hline 14 & $\mathrm{O}$ & Plastic & Cyano + Basic Red 28 & 4 & 6 & 60 & 500 \\
\hline 14 & $\mathrm{O}$ & Plastic & Cyano + Basic Red 28 & 13 & 6 & 60 & 550 \\
\hline 14 & $\mathrm{O}$ & Plastic & Cyano + Basic Red 28 & 8 & $1 / 200$ & 60 & white \\
\hline 14 & $\mathrm{O}$ & Plastic & Cyano + Basic Red 28 & 4 & 6 & 60 & 470 \\
\hline 15 & $\mathrm{O}$ & Plastic & Cyano + Basic Red 28 & 4 & 4 & 60 & 470 \\
\hline 15 & $\mathrm{O}$ & Plastic & Cyano + Basic Red 28 & 4 & 4 & 60 & 500 \\
\hline 15 & $\mathrm{O}$ & Plastic & Cyano + Basic Red 28 & 11 & 4 & 60 & 550 \\
\hline 16 & $\mathrm{O}$ & Plastic & Cyano + Basic Red 28 & 4 & 4 & 60 & 470 \\
\hline 16 & $\mathrm{O}$ & Plastic & Cyano + Basic Red 28 & 4 & 4 & 60 & 500 \\
\hline 16 & $\mathrm{O}$ & Plastic & Cyano + Basic Red 28 & 14 & 4 & 60 & 550 \\
\hline 17 & $\mathrm{O}$ & Plastic & Cyano + Basic Red 28 & 4 & 4 & 60 & 470 \\
\hline 17 & $\mathrm{O}$ & Plastic & Cyano + Basic Red 28 & 4 & 4 & 60 & 500 \\
\hline 17 & $\mathrm{O}$ & Plastic & Cyano + Basic Red 28 & 11 & 4 & 60 & 550 \\
\hline 18 & $\mathrm{O}$ & Plastic & Cyano + Basic Red 28 & 4 & 4 & 60 & 470 \\
\hline 18 & $\mathrm{O}$ & Plastic & Cyano + Basic Red 28 & 4 & 4 & 60 & 500 \\
\hline 18 & $\mathrm{O}$ & Plastic & Cyano + Basic Red 28 & 10 & 4 & 60 & 550 \\
\hline 19 & $\mathrm{O}$ & Plastic & Cyano + Basic Red 28 & 4 & 4 & 60 & 470 \\
\hline 19 & $\mathrm{O}$ & Plastic & Cyano + Basic Red 28 & 4 & 4 & 60 & 500 \\
\hline 19 & $\mathrm{O}$ & Plastic & Cyano + Basic Red 28 & 9 & 4 & 60 & 550 \\
\hline 2 & $\mathrm{O}$ & Plastic & Cyano + Basic Red 28 & 4 & 8 & 60 & 470 \\
\hline 2 & $\mathrm{O}$ & Plastic & Cyano + Basic Red 28 & 4 & 8 & 60 & 500 \\
\hline 2 & $\mathrm{O}$ & Plastic & Cyano + Basic Red 28 & 14 & 8 & 60 & 550 \\
\hline 20 & $\mathrm{O}$ & Plastic & Cyano + Basic Red 28 & 4 & 4 & 60 & 470 \\
\hline
\end{tabular}




\begin{tabular}{|c|c|c|c|c|c|c|c|}
\hline 20 & $\mathrm{O}$ & Plastic & Cyano + Basic Red 28 & 4 & 4 & 60 & 500 \\
\hline 20 & $\mathrm{O}$ & Plastic & Cyano + Basic Red 28 & 10 & 4 & 60 & 550 \\
\hline 21 & $\mathrm{O}$ & Plastic & Cyano + Basic Red 28 & 4 & 4 & 60 & 470 \\
\hline 21 & $\mathrm{O}$ & Plastic & Cyano + Basic Red 28 & 4 & 4 & 60 & 500 \\
\hline 21 & $\mathrm{O}$ & Plastic & Cyano + Basic Red 28 & 9 & 4 & 60 & 550 \\
\hline 22 & $\mathrm{O}$ & Plastic & Cyano + Basic Red 28 & 4 & 4 & 60 & 470 \\
\hline 22 & $\mathrm{O}$ & Plastic & Cyano + Basic Red 28 & 4 & 4 & 60 & 500 \\
\hline 22 & $\mathrm{O}$ & Plastic & Cyano + Basic Red 28 & 11 & 4 & 60 & 550 \\
\hline 23 & $\mathrm{O}$ & Plastic & Cyano + Basic Red 28 & 4 & 6 & 60 & 470 \\
\hline 23 & $\mathrm{O}$ & Plastic & Cyano + Basic Red 28 & 4 & 6 & 60 & 500 \\
\hline 23 & $\mathrm{O}$ & Plastic & Cyano + Basic Red 28 & 4 & $5 / 8$ & 60 & 550 \\
\hline 24 & $\mathrm{O}$ & Plastic & Cyano + Basic Red 28 & 4 & 10 & 60 & 470 \\
\hline 24 & $\mathrm{O}$ & Plastic & Cyano + Basic Red 28 & 4 & 10 & 60 & 500 \\
\hline 24 & $\mathrm{O}$ & Plastic & Cyano + Basic Red 28 & 14 & 10 & 60 & 550 \\
\hline 25 & $\mathrm{O}$ & Plastic & Cyano + Basic Red 28 & 4 & 10 & 60 & 470 \\
\hline 25 & $\mathrm{O}$ & Plastic & Cyano + Basic Red 28 & 4 & 10 & 60 & 500 \\
\hline 25 & $\mathrm{O}$ & Plastic & Cyano + Basic Red 28 & 16 & 10 & 60 & 550 \\
\hline 26 & $\mathrm{O}$ & Plastic & Cyano + Basic Red 28 & 4 & 10 & 60 & 470 \\
\hline 26 & $\mathrm{O}$ & Plastic & Cyano + Basic Red 28 & 4 & 10 & 60 & 500 \\
\hline 26 & $\mathrm{O}$ & Plastic & Cyano + Basic Red 28 & 14 & 10 & 60 & 550 \\
\hline 27 & $\mathrm{O}$ & Plastic & Cyano + Basic Red 28 & 4 & 10 & 60 & 470 \\
\hline 27 & $\mathrm{O}$ & Plastic & Cyano + Basic Red 28 & 4 & 10 & 60 & 500 \\
\hline 27 & $\mathrm{O}$ & Plastic & Cyano + Basic Red 28 & 13 & 10 & 60 & 550 \\
\hline 28 & $\mathrm{O}$ & Plastic & Cyano + Basic Red 28 & 4 & 10 & 60 & 470 \\
\hline 28 & $\mathrm{O}$ & Plastic & Cyano + Basic Red 28 & 4 & 10 & 60 & 500 \\
\hline 28 & $\mathrm{O}$ & Plastic & Cyano + Basic Red 28 & 11 & 10 & 60 & 550 \\
\hline 29 & $\mathrm{O}$ & Plastic & Cyano + Basic Red 28 & 4 & 6 & 60 & 470 \\
\hline 29 & $\mathrm{O}$ & Plastic & Cyano + Basic Red 28 & 4 & 6 & 60 & 500 \\
\hline 29 & $\mathrm{O}$ & Plastic & Cyano + Basic Red 28 & 11 & 10 & 60 & 550 \\
\hline 3 & $\mathrm{O}$ & Plastic & Cyano + Basic Red 28 & 4 & 8 & 60 & 470 \\
\hline 3 & $\mathrm{O}$ & Plastic & Cyano + Basic Red 28 & 4 & 8 & 60 & 500 \\
\hline 3 & $\mathrm{O}$ & Plastic & Cyano + Basic Red 28 & 13 & 8 & 60 & 550 \\
\hline 30 & $\mathrm{O}$ & Plastic & Cyano + Basic Red 28 & 4 & 6 & 60 & 470 \\
\hline 30 & $\mathrm{O}$ & Plastic & Cyano + Basic Red 28 & 4 & 6 & 60 & 500 \\
\hline 30 & $\mathrm{O}$ & Plastic & Cyano + Basic Red 28 & 11 & 6 & 60 & 550 \\
\hline 31 & $\mathrm{O}$ & Plastic & Cyano + Basic Red 28 & 4 & 6 & 60 & 470 \\
\hline 31 & $\mathrm{O}$ & Plastic & Cyano + Basic Red 28 & 4 & 6 & 60 & 500 \\
\hline 31 & $\mathrm{O}$ & Plastic & Cyano + Basic Red 28 & 10 & 6 & 60 & 550 \\
\hline 32 & $\mathrm{O}$ & Plastic & Cyano + Basic Red 28 & 4 & 6 & 60 & 470 \\
\hline 32 & $\mathrm{O}$ & Plastic & Cyano + Basic Red 28 & 4 & 6 & 60 & 500 \\
\hline 32 & $\mathrm{O}$ & Plastic & Cyano + Basic Red 28 & 11 & 6 & 60 & 550 \\
\hline 33 & $\mathrm{O}$ & Plastic & Cyano + Basic Red 28 & 4 & 6 & 60 & 470 \\
\hline 33 & $\mathrm{O}$ & Plastic & Cyano + Basic Red 28 & 4 & 6 & 60 & 500 \\
\hline 33 & $\mathrm{O}$ & Plastic & Cyano + Basic Red 28 & 10 & 6 & 60 & 550 \\
\hline 34 & $\underline{O}$ & Plastic & Cyano + Basic Red 28 & 4 & 6 & 60 & 470 \\
\hline 34 & $\overline{\mathrm{O}}$ & Plastic & Cyano + Basic Red 28 & 4 & 6 & 60 & 500 \\
\hline 34 & $\mathrm{O}$ & Plastic & Cyano + Basic Red 28 & 13 & 6 & 60 & 550 \\
\hline 35 & $\mathrm{O}$ & Plastic & Cyano + Basic Red 28 & 4 & 6 & 60 & 470 \\
\hline 35 & $\mathrm{O}$ & Plastic & Cyano + Basic Red 28 & 4 & 6 & 60 & 500 \\
\hline 35 & $\mathrm{O}$ & Plastic & Cyano + Basic Red 28 & 13 & 6 & 60 & 550 \\
\hline 36 & $\mathrm{O}$ & Plastic & Cyano + Basic Red 28 & 4 & 6 & 60 & 470 \\
\hline 36 & $\mathrm{O}$ & Plastic & Cyano + Basic Red 28 & 4 & 6 & 60 & 500 \\
\hline
\end{tabular}




\begin{tabular}{|c|c|c|c|c|c|c|c|}
\hline 36 & $\mathrm{O}$ & Plastic & Cyano + Basic Red 28 & 9 & 6 & 60 & 550 \\
\hline 38 & $\mathrm{O}$ & Plastic & Cyano + Basic Red 28 & 4 & 6 & 60 & 470 \\
\hline 38 & $\mathrm{O}$ & Plastic & Cyano + Basic Red 28 & 4 & 6 & 60 & 500 \\
\hline 38 & $\mathrm{O}$ & Plastic & Cyano + Basic Red 28 & 9 & 6 & 60 & 550 \\
\hline 39 & $\mathrm{O}$ & Plastic & Cyano + Basic Red 28 & 4 & 6 & 60 & 470 \\
\hline 39 & $\mathrm{O}$ & Plastic & Cyano + Basic Red 28 & 4 & 6 & 60 & 500 \\
\hline 39 & $\mathrm{O}$ & Plastic & Cyano + Basic Red 28 & 10 & 6 & 60 & 550 \\
\hline 4 & $\mathrm{O}$ & Plastic & Cyano + Basic Red 28 & 4 & 8 & 60 & 470 \\
\hline 4 & $\mathrm{O}$ & Plastic & Cyano + Basic Red 28 & 4 & 8 & 60 & 500 \\
\hline 4 & $\mathrm{O}$ & Plastic & Cyano + Basic Red 28 & 14 & 8 & 60 & 550 \\
\hline 40 & $\mathrm{O}$ & Plastic & Cyano + Basic Red 28 & 4 & 6 & 60 & 470 \\
\hline 40 & $\mathrm{O}$ & Plastic & Cyano + Basic Red 28 & 4 & 6 & 60 & 500 \\
\hline 40 & $\mathrm{O}$ & Plastic & Cyano + Basic Red 28 & 11 & 6 & 60 & 550 \\
\hline 5 & $\mathrm{O}$ & Plastic & Cyano + Basic Red 28 & 4 & 6 & 60 & 470 \\
\hline 5 & $\mathrm{O}$ & Plastic & Cyano + Basic Red 28 & 4 & 6 & 60 & 500 \\
\hline 5 & $\mathrm{O}$ & Plastic & Cyano + Basic Red 28 & 14 & 6 & 60 & 550 \\
\hline 6 & $\mathrm{O}$ & Plastic & Cyano + Basic Red 28 & 4 & 6 & 60 & 470 \\
\hline 6 & $\mathrm{O}$ & Plastic & Cyano + Basic Red 28 & 4 & 6 & 60 & 500 \\
\hline 6 & $\mathrm{O}$ & Plastic & Cyano + Basic Red 28 & 14 & 6 & 60 & 550 \\
\hline 7 & $\mathrm{O}$ & Plastic & Cyano + Basic Red 28 & 4 & 6 & 60 & 470 \\
\hline 7 & $\mathrm{O}$ & Plastic & Cyano + Basic Red 28 & 4 & 6 & 60 & 500 \\
\hline 7 & $\mathrm{O}$ & Plastic & Cyano + Basic Red 28 & 13 & 6 & 60 & 550 \\
\hline 8 & $\mathrm{O}$ & Plastic & Cyano + Basic Red 28 & 4 & 6 & 60 & 470 \\
\hline 8 & $\mathrm{O}$ & Plastic & Cyano + Basic Red 28 & 4 & 6 & 60 & 500 \\
\hline 8 & $\mathrm{O}$ & Plastic & Cyano + Basic Red 28 & 11 & 6 & 60 & 550 \\
\hline 9 & $\mathrm{O}$ & Plastic & Cyano + Basic Red 28 & 4 & 6 & 60 & 470 \\
\hline 9 & $\mathrm{O}$ & Plastic & Cyano + Basic Red 28 & 4 & 6 & 60 & 500 \\
\hline 9 & $\mathrm{O}$ & Plastic & Cyano + Basic Red 28 & 10 & 6 & 60 & 550 \\
\hline 41 & $\mathrm{O}$ & Plastic & Cyano + MBD & 4 & 13 & 60 & 415 \\
\hline 41 & $\mathrm{O}$ & Plastic & Cyano + MBD & 5 & 20 & 60 & 450 \\
\hline 42 & $\mathrm{O}$ & Plastic & Cyano + MBD & 5 & 20 & 60 & 415 \\
\hline 42 & $\mathrm{O}$ & Plastic & Cyano + MBD & 5 & 20 & 60 & 450 \\
\hline 43 & $\mathrm{O}$ & Plastic & Cyano + MBD & 5 & 20 & 60 & 415 \\
\hline 43 & $\mathrm{O}$ & Plastic & Cyano + MBD & 5 & 20 & 60 & 450 \\
\hline 44 & $\mathrm{O}$ & Plastic & Cyano + MBD & 5 & 20 & 60 & 415 \\
\hline 44 & $\mathrm{O}$ & Plastic & Cyano + MBD & 5 & 20 & 60 & 450 \\
\hline 45 & $\mathrm{O}$ & Plastic & Cyano + MBD & 5 & 20 & 60 & 415 \\
\hline 45 & $\mathrm{O}$ & Plastic & Cyano + MBD & 5 & 20 & 60 & 450 \\
\hline 46 & $\mathrm{O}$ & Plastic & Cyano + MBD & 5 & 20 & 60 & 415 \\
\hline 46 & $\mathrm{O}$ & Plastic & Cyano + MBD & 5 & 20 & 60 & 450 \\
\hline 47 & $\mathrm{O}$ & Plastic & Cyano + MBD & 5 & 20 & 60 & 415 \\
\hline 47 & $\mathrm{O}$ & Plastic & Cyano + MBD & 5 & 20 & 60 & 450 \\
\hline 48 & $\mathrm{O}$ & Plastic & Cyano + MBD & 5 & 20 & 60 & 415 \\
\hline 48 & $\mathrm{O}$ & Plastic & Cyano + MBD & 5 & 20 & 60 & 450 \\
\hline 49 & $\mathrm{O}$ & Plastic & Cyano + MBD & 5 & 20 & 60 & 415 \\
\hline 49 & $\mathrm{O}$ & Plastic & Cyano + MBD & 5 & 20 & 60 & 450 \\
\hline 50 & $\mathrm{O}$ & Plastic & Cyano + MBD & 5 & 20 & 60 & 415 \\
\hline 50 & $\mathrm{O}$ & Plastic & Cyano + MBD & 5 & 20 & 60 & 450 \\
\hline 51 & $\mathrm{O}$ & Plastic & Cyano + MBD & 5 & 20 & 60 & 415 \\
\hline 51 & $\mathrm{O}$ & Plastic & Cyano + MBD & 5 & 20 & 60 & 450 \\
\hline 52 & $\mathrm{O}$ & Plastic & Cyano + MBD & 5 & 20 & 60 & 415 \\
\hline 52 & $\mathrm{O}$ & Plastic & Cyano + MBD & 5 & 20 & 60 & 450 \\
\hline
\end{tabular}




\begin{tabular}{|c|c|c|c|c|c|c|c|}
\hline 53 & $\mathrm{O}$ & Plastic & Cyano + MBD & 5 & 20 & 60 & 415 \\
\hline 53 & $\mathrm{O}$ & Plastic & Cyano + MBD & 5 & 20 & 60 & 450 \\
\hline 54 & $\mathrm{O}$ & Plastic & Cyano + MBD & 5 & 20 & 60 & 415 \\
\hline 54 & $\mathrm{O}$ & Plastic & Cyano + MBD & 5 & 20 & 60 & 450 \\
\hline 55 & $\mathrm{O}$ & Plastic & Cyano + MBD & 5 & 20 & 60 & 415 \\
\hline 55 & $\mathrm{O}$ & Plastic & Cyano + MBD & 5 & 20 & 60 & 450 \\
\hline 56 & $\mathrm{O}$ & Plastic & Cyano + MBD & 5 & 20 & 60 & 415 \\
\hline 56 & $\mathrm{O}$ & Plastic & Cyano + MBD & 5 & 20 & 60 & 450 \\
\hline 57 & $\mathrm{O}$ & Plastic & Cyano + MBD & 5 & 20 & 60 & 415 \\
\hline 57 & $\mathrm{O}$ & Plastic & Cyano + MBD & 5 & 20 & 60 & 450 \\
\hline 58 & $\mathrm{O}$ & Plastic & Cyano + MBD & 5 & 20 & 60 & 415 \\
\hline 58 & $\mathrm{O}$ & Plastic & Cyano + MBD & 5 & 20 & 60 & 450 \\
\hline 59 & $\mathrm{O}$ & Plastic & Cyano + MBD & 5 & 20 & 60 & 415 \\
\hline 59 & $\mathrm{O}$ & Plastic & Cyano + MBD & 5 & 20 & 60 & 450 \\
\hline 60 & $\mathrm{O}$ & Plastic & Cyano + MBD & 5 & 20 & 60 & 415 \\
\hline 60 & $\mathrm{O}$ & Plastic & Cyano + MBD & 5 & 20 & 60 & 450 \\
\hline 61 & $\mathrm{O}$ & Plastic & Cyano + MBD & 5 & 20 & 60 & 415 \\
\hline 61 & $\mathrm{O}$ & Plastic & Cyano + MBD & 5 & 20 & 60 & 450 \\
\hline 62 & $\mathrm{O}$ & Plastic & Cyano + MBD & 5 & 20 & 60 & 415 \\
\hline 62 & $\mathrm{O}$ & Plastic & Cyano + MBD & 5 & 20 & 60 & 450 \\
\hline 63 & $\mathrm{O}$ & Plastic & Cyano + MBD & 5 & 20 & 60 & 415 \\
\hline 63 & $\mathrm{O}$ & Plastic & Cyano + MBD & 5 & 20 & 60 & 450 \\
\hline 64 & $\mathrm{O}$ & Plastic & Cyano + MBD & 5 & 20 & 60 & 415 \\
\hline 64 & $\mathrm{O}$ & Plastic & Cyano + MBD & 5 & 20 & 60 & 450 \\
\hline 65 & $\mathrm{O}$ & Plastic & Cyano + MBD & 5 & 20 & 60 & 415 \\
\hline 65 & $\mathrm{O}$ & Plastic & Cyano + MBD & 5 & 20 & 60 & 450 \\
\hline 66 & $\mathrm{O}$ & Plastic & Cyano + MBD & 5 & 20 & 60 & 415 \\
\hline 66 & $\mathrm{O}$ & Plastic & Cyano + MBD & 5 & 20 & 60 & 450 \\
\hline 67 & $\mathrm{O}$ & Plastic & Cyano + MBD & 5 & 20 & 60 & 415 \\
\hline 67 & $\mathrm{O}$ & Plastic & Cyano + MBD & 5 & 20 & 60 & 450 \\
\hline 68 & $\mathrm{O}$ & Plastic & Cyano + MBD & 5 & 20 & 60 & 415 \\
\hline 68 & $\mathrm{O}$ & Plastic & Cyano + MBD & 5 & 20 & 60 & 450 \\
\hline 69 & $\mathrm{O}$ & Plastic & Cyano + MBD & 5 & 20 & 60 & 415 \\
\hline 69 & $\mathrm{O}$ & Plastic & Cyano + MBD & 5 & 20 & 60 & 450 \\
\hline 70 & $\mathrm{O}$ & Plastic & Cyano + MBD & 5 & 20 & 60 & 415 \\
\hline 70 & $\mathrm{O}$ & Plastic & Cyano + MBD & 5 & 20 & 60 & 450 \\
\hline 71 & $\mathrm{O}$ & Plastic & Cyano + MBD & 5 & 20 & 60 & 415 \\
\hline 71 & $\mathrm{O}$ & Plastic & Cyano + MBD & 5 & 20 & 60 & 450 \\
\hline 72 & $\mathrm{O}$ & Plastic & Cyano + MBD & 5 & 20 & 60 & 415 \\
\hline 72 & $\mathrm{O}$ & Plastic & Cyano + MBD & 5 & 20 & 60 & 450 \\
\hline 73 & $\mathrm{O}$ & Plastic & Cyano + MBD & 5 & 20 & 60 & 415 \\
\hline 73 & $\mathrm{O}$ & Plastic & Cyano + MBD & 5 & 20 & 60 & 450 \\
\hline 74 & $\mathrm{O}$ & Plastic & Cyano + MBD & 5 & 20 & 60 & 415 \\
\hline 74 & $\mathrm{O}$ & Plastic & Cyano + MBD & 5 & 20 & 60 & 450 \\
\hline 75 & $\mathrm{O}$ & Plastic & Cyano + MBD & 5 & 20 & 60 & 415 \\
\hline 75 & $\mathrm{O}$ & Plastic & Cyano + MBD & 5 & 20 & 60 & 450 \\
\hline 76 & $\mathrm{O}$ & Plastic & Cyano + MBD & 5 & 20 & 60 & 415 \\
\hline 76 & $\mathrm{O}$ & Plastic & Cyano + MBD & 5 & 20 & 60 & 450 \\
\hline 77 & $\mathrm{O}$ & Plastic & Cyano + MBD & 5 & 20 & 60 & 415 \\
\hline 77 & $\mathrm{O}$ & Plastic & Cyano + MBD & 5 & 20 & 60 & 450 \\
\hline 78 & $\mathrm{O}$ & Plastic & Cyano + MBD & 5 & 20 & 60 & 415 \\
\hline 78 & $\mathrm{O}$ & Plastic & Cyano + MBD & 5 & 20 & 60 & 450 \\
\hline
\end{tabular}




\begin{tabular}{|c|c|c|c|c|c|c|c|}
\hline 79 & $\mathrm{O}$ & Plastic & Cyano + MBD & 5 & 20 & 60 & 415 \\
\hline 79 & $\mathrm{O}$ & Plastic & Cyano + MBD & 5 & 20 & 60 & 450 \\
\hline 80 & $\mathrm{O}$ & Plastic & Cyano + MBD & 5 & 20 & 60 & 415 \\
\hline 80 & $\mathrm{O}$ & Plastic & Cyano + MBD & 5 & 20 & 60 & 450 \\
\hline 81 & $\mathrm{O}$ & Plastic & Cyano + MBD & 5 & 20 & 60 & 415 \\
\hline 81 & $\mathrm{O}$ & Plastic & Cyano + MBD & 5 & 20 & 60 & 450 \\
\hline 82 & $\mathrm{O}$ & Plastic & Cyano + MBD & 5 & 20 & 60 & 415 \\
\hline 82 & $\mathrm{O}$ & Plastic & Cyano + MBD & 5 & 20 & 60 & 450 \\
\hline 83 & $\mathrm{O}$ & Plastic & Cyano + MBD & 5 & 20 & 60 & 415 \\
\hline 83 & $\mathrm{O}$ & Plastic & Cyano + MBD & 5 & 20 & 60 & 450 \\
\hline 84 & $\mathrm{O}$ & Plastic & Cyano + MBD & 5 & 20 & 60 & 415 \\
\hline 84 & $\mathrm{O}$ & Plastic & Cyano + MBD & 5 & 20 & 60 & 450 \\
\hline 85 & $\mathrm{O}$ & Plastic & Cyano + MBD & 5 & 20 & 60 & 415 \\
\hline 85 & $\mathrm{O}$ & Plastic & Cyano + MBD & 5 & 20 & 60 & 450 \\
\hline 86 & $\mathrm{O}$ & Plastic & Cyano + MBD & 5 & 20 & 60 & 415 \\
\hline 120 & $\mathrm{O}$ & Plastic & Cyano + Rhodamine 6G & 14 & 13 & 60 & 500 \\
\hline 120 & $\mathrm{O}$ & Plastic & Cyano + Rhodamine 6G & 14 & 13 & 60 & 515 \\
\hline 120 & $\mathrm{O}$ & Plastic & Cyano + Rhodamine 6G & 14 & 13 & 60 & 540 \\
\hline 121 & $\mathrm{O}$ & Plastic & Cyano + Rhodamine 6G & 14 & 13 & 60 & 500 \\
\hline 121 & $\mathrm{O}$ & Plastic & Cyano + Rhodamine 6G & 14 & 8 & 60 & 515 \\
\hline 121 & $\mathrm{O}$ & Plastic & Cyano + Rhodamine 6G & 14 & 8 & 60 & 540 \\
\hline 122 & $\mathrm{O}$ & Plastic & Cyano + Rhodamine 6G & 14 & 13 & 60 & 500 \\
\hline 122 & $\mathrm{O}$ & Plastic & Cyano + Rhodamine 6G & 14 & 13 & 60 & 515 \\
\hline 122 & $\mathrm{O}$ & Plastic & Cyano + Rhodamine 6G & 14 & 13 & 60 & 540 \\
\hline 123 & $\mathrm{O}$ & Plastic & Cyano + Rhodamine 6G & 14 & 13 & 60 & 500 \\
\hline 123 & $\mathrm{O}$ & Plastic & Cyano + Rhodamine $6 \mathrm{G}$ & 14 & 13 & 60 & 515 \\
\hline 123 & $\mathrm{O}$ & Plastic & Cyano + Rhodamine 6G & 14 & 13 & 60 & 540 \\
\hline 124 & $\mathrm{O}$ & Plastic & Cyano + Rhodamine $6 \mathrm{G}$ & 14 & 13 & 60 & 500 \\
\hline 124 & $\mathrm{O}$ & Plastic & Cyano + Rhodamine 6G & 14 & 13 & 60 & 515 \\
\hline 124 & $\mathrm{O}$ & Plastic & Cyano + Rhodamine 6G & 14 & 13 & 60 & 540 \\
\hline 125 & $\mathrm{O}$ & Plastic & Cyano + Rhodamine 6G & 14 & 13 & 60 & 500 \\
\hline 125 & $\mathrm{O}$ & Plastic & Cyano + Rhodamine 6G & 14 & 13 & 60 & 515 \\
\hline 125 & $\mathrm{O}$ & Plastic & Cyano + Rhodamine 6G & 14 & 13 & 60 & 540 \\
\hline 126 & $\mathrm{O}$ & Plastic & Cyano + Rhodamine 6G & 6.3 & 15 & 60 & 500 \\
\hline 126 & $\mathrm{O}$ & Plastic & Cyano + Rhodamine 6G & 16 & 13 & 60 & 515 \\
\hline 126 & $\mathrm{O}$ & Plastic & Cyano + Rhodamine 6G & 16 & 13 & 60 & 540 \\
\hline 127 & $\mathrm{O}$ & Plastic & Cyano + Rhodamine 6G & 14 & 15 & 60 & 500 \\
\hline 127 & $\mathrm{O}$ & Plastic & Cyano + Rhodamine 6G & 14 & 15 & 60 & 515 \\
\hline 127 & $\mathrm{O}$ & Plastic & Cyano + Rhodamine 6G & 14 & 15 & 60 & 540 \\
\hline 128 & $\mathrm{O}$ & Plastic & Cyano + Rhodamine 6G & 14 & 15 & 60 & 500 \\
\hline 128 & $\mathrm{O}$ & Plastic & Cyano + Rhodamine 6G & 14 & 15 & 60 & 515 \\
\hline 128 & $\mathrm{O}$ & Plastic & Cyano + Rhodamine 6G & 14 & 15 & 60 & 540 \\
\hline 129 & $\mathrm{O}$ & Plastic & Cyano + Rhodamine 6G & 14 & 15 & 60 & 500 \\
\hline 129 & $\mathrm{O}$ & Plastic & Cyano + Rhodamine 6G & 14 & 15 & 60 & 515 \\
\hline 129 & $\mathrm{O}$ & Plastic & Cyano + Rhodamine $6 \mathrm{G}$ & 14 & 15 & 60 & 540 \\
\hline 130 & $\mathrm{O}$ & Plastic & Cyano + Rhodamine $6 \mathrm{G}$ & 14 & 15 & 60 & 500 \\
\hline 130 & $\mathrm{O}$ & Plastic & Cyano + Rhodamine 6G & 14 & 15 & 60 & 515 \\
\hline 130 & $\mathrm{O}$ & Plastic & Cyano + Rhodamine 6G & 14 & 15 & 60 & 540 \\
\hline 131 & $\mathrm{O}$ & Plastic & Cyano + Rhodamine 6G & 14 & 15 & 60 & 500 \\
\hline 131 & $\mathrm{O}$ & Plastic & Cyano + Rhodamine 6G & 14 & 15 & 60 & 515 \\
\hline 131 & $\mathrm{O}$ & Plastic & Cyano + Rhodamine 6G & 14 & 15 & 60 & 540 \\
\hline 132 & $\mathrm{O}$ & Plastic & Cyano + Rhodamine 6G & 4.5 & 13 & 60 & 500 \\
\hline
\end{tabular}




\begin{tabular}{|c|c|c|c|c|c|c|c|}
\hline 132 & $\mathrm{O}$ & Plastic & Cyano + Rhodamine 6G & 14 & 15 & 60 & 515 \\
\hline 132 & $\mathrm{O}$ & Plastic & Cyano + Rhodamine 6G & 14 & 15 & 60 & 540 \\
\hline 133 & $\mathrm{O}$ & Plastic & Cyano + Rhodamine 6G & 4.5 & 13 & 60 & 500 \\
\hline 133 & $\mathrm{O}$ & Plastic & Cyano + Rhodamine 6G & 13 & 13 & 60 & 515 \\
\hline 133 & $\mathrm{O}$ & Plastic & Cyano + Rhodamine 6G & 13 & $21 / 2$ & 60 & 540 \\
\hline 134 & $\mathrm{O}$ & Plastic & Cyano + Rhodamine 6G & 14 & 15 & 60 & 500 \\
\hline 134 & $\mathrm{O}$ & Plastic & Cyano + Rhodamine 6G & 14 & 4 & 60 & 515 \\
\hline 134 & $\mathrm{O}$ & Plastic & Cyano + Rhodamine 6G & 14 & 4 & 60 & 540 \\
\hline 135 & $\mathrm{O}$ & Plastic & Cyano + Rhodamine 6G & 14 & 15 & 60 & 500 \\
\hline 135 & $\mathrm{O}$ & Plastic & Cyano + Rhodamine 6G & 14 & 15 & 60 & 515 \\
\hline 135 & $\mathrm{O}$ & Plastic & Cyano + Rhodamine 6G & 14 & 4 & 60 & 540 \\
\hline 136 & $\mathrm{O}$ & Plastic & Cyano + Rhodamine 6G & 6.3 & 15 & 60 & 500 \\
\hline 136 & $\mathrm{O}$ & Plastic & Cyano + Rhodamine 6G & 14 & 13 & 60 & 515 \\
\hline 136 & $\mathrm{O}$ & Plastic & Cyano + Rhodamine 6G & 14 & 4 & 60 & 540 \\
\hline 87 & $\mathrm{O}$ & Plastic & Cyano + Rhodamine 6G & 4 & 13 & 60 & 500 \\
\hline 87 & $\mathrm{O}$ & Plastic & Cyano + Rhodamine 6G & 9 & 13 & 60 & 515 \\
\hline 87 & $\mathrm{O}$ & Plastic & Cyano + Rhodamine 6G & 29 & 13 & 60 & 540 \\
\hline 88 & $\mathrm{O}$ & Plastic & Cyano + Rhodamine 6G & 4 & 13 & 60 & 500 \\
\hline 88 & $\mathrm{O}$ & Plastic & Cyano + Rhodamine 6G & 7.1 & 13 & 60 & 515 \\
\hline 88 & $\mathrm{O}$ & Plastic & Cyano + Rhodamine 6G & 25 & 13 & 60 & 540 \\
\hline 89 & $\mathrm{O}$ & Plastic & Cyano + Rhodamine 6G & 4 & 13 & 60 & 500 \\
\hline 89 & $\mathrm{O}$ & Plastic & Cyano + Rhodamine 6G & 8 & 13 & 60 & 515 \\
\hline 89 & $\mathrm{O}$ & Plastic & Cyano + Rhodamine 6G & 29 & 13 & 60 & 540 \\
\hline 90 & $\mathrm{O}$ & Plastic & Cyano + Rhodamine 6G & 4 & 13 & 60 & 500 \\
\hline 90 & $\mathrm{O}$ & Plastic & Cyano + Rhodamine 6G & 6.3 & 13 & 60 & 515 \\
\hline 90 & $\mathrm{O}$ & Plastic & Cyano + Rhodamine 6G & 22 & 13 & 60 & 540 \\
\hline 91 & $\mathrm{O}$ & Plastic & Cyano + Rhodamine $6 \mathrm{G}$ & 4.5 & 13 & 60 & 500 \\
\hline 91 & $\mathrm{O}$ & Plastic & Cyano + Rhodamine 6G & 10 & 13 & 60 & 515 \\
\hline 91 & $\mathrm{O}$ & Plastic & Cyano + Rhodamine 6G & 25 & 13 & 60 & 540 \\
\hline 92 & $\mathrm{O}$ & Plastic & Cyano + Rhodamine 6G & 4 & 13 & 60 & 500 \\
\hline 92 & $\mathrm{O}$ & Plastic & Cyano + Rhodamine 6G & 10 & 13 & 60 & 515 \\
\hline 92 & $\mathrm{O}$ & Plastic & Cyano + Rhodamine 6G & 18 & 13 & 60 & 540 \\
\hline 93 & $\mathrm{O}$ & Plastic & Cyano + Rhodamine 6G & 4 & 13 & 60 & 500 \\
\hline 93 & $\mathrm{O}$ & Plastic & Cyano + Rhodamine 6G & 5 & 13 & 60 & 60 \\
\hline 93 & $\mathrm{O}$ & Plastic & Cyano + Rhodamine 6G & 16 & 13 & 60 & 540 \\
\hline 94 & $\mathrm{O}$ & Plastic & Cyano + Rhodamine 6G & 4 & 13 & 60 & 500 \\
\hline 94 & $\mathrm{O}$ & Plastic & Cyano + Rhodamine 6G & 5.6 & 13 & 60 & 515 \\
\hline 94 & $\mathrm{O}$ & Plastic & Cyano + Rhodamine 6G & 20 & 13 & 60 & 540 \\
\hline 95 & $\mathrm{O}$ & Plastic & Cyano + Rhodamine 6G & 4.5 & 13 & 60 & 500 \\
\hline 95 & $\mathrm{O}$ & Plastic & Cyano + Rhodamine $6 \mathrm{G}$ & 11 & 13 & 60 & 515 \\
\hline 95 & $\mathrm{O}$ & Plastic & Cyano + Rhodamine 6G & 29 & 13 & 60 & 540 \\
\hline 96 & $\mathrm{O}$ & Plastic & Cyano + Rhodamine 6G & 4 & 13 & 60 & 500 \\
\hline 96 & $\mathrm{O}$ & Plastic & Cyano + Rhodamine 6G & 7.1 & 13 & 60 & 515 \\
\hline 96 & $\mathrm{O}$ & Plastic & Cyano + Rhodamine 6G & 25 & 13 & 60 & 540 \\
\hline 97 & $\mathrm{O}$ & Plastic & Cyano + Rhodamine 6G & 4 & 13 & 60 & 500 \\
\hline 97 & $\mathrm{O}$ & Plastic & Cyano + Rhodamine 6G & 5.6 & 13 & 60 & 515 \\
\hline 97 & $\mathrm{O}$ & Plastic & Cyano + Rhodamine 6G & 20 & 13 & 60 & 540 \\
\hline 98 & $\mathrm{O}$ & Plastic & Cyano + Rhodamine 6G & 4.5 & 13 & 60 & 500 \\
\hline 98 & $\mathrm{O}$ & Plastic & Cyano + Rhodamine 6G & 11 & 13 & 60 & 515 \\
\hline 98 & $\mathrm{O}$ & Plastic & Cyano + Rhodamine 6G & 29 & 13 & 60 & 540 \\
\hline 99 & $\mathrm{O}$ & Plastic & Cyano + Rhodamine 6G & 4 & 13 & 60 & 500 \\
\hline 99 & $\mathrm{O}$ & Plastic & Cyano + Rhodamine 6G & 10 & 13 & 60 & 515 \\
\hline
\end{tabular}




\begin{tabular}{|c|c|c|c|c|c|c|c|}
\hline 99 & $\mathrm{O}$ & Plastic & Cyano + Rhodamine 6G & 25 & 13 & 60 & 540 \\
\hline 1 & $\mathrm{M}$ & Plastic & Merged & N/A & N/A & N/A & N/A \\
\hline 10 & M & Plastic & Merged & N/A & N/A & N/A & N/A \\
\hline 11 & $\mathrm{M}$ & Plastic & Merged & N/A & N/A & N/A & N/A \\
\hline 12 & M & Plastic & Merged & N/A & N/A & N/A & N/A \\
\hline 120 & M & Plastic & Merged & N/A & N/A & N/A & N/A \\
\hline 121 & $\mathrm{M}$ & Plastic & Merged & N/A & N/A & N/A & N/A \\
\hline 122 & $\mathrm{M}$ & Plastic & Merged & N/A & N/A & N/A & N/A \\
\hline 123 & M & Plastic & Merged & N/A & N/A & N/A & N/A \\
\hline 124 & $M$ & Plastic & Merged & N/A & N/A & N/A & N/A \\
\hline 125 & M & Plastic & Merged & N/A & N/A & N/A & N/A \\
\hline 126 & M & Plastic & Merged & N/A & N/A & N/A & N/A \\
\hline 127 & M & Plastic & Merged & N/A & N/A & N/A & N/A \\
\hline 128 & $\mathrm{M}$ & Plastic & Merged & N/A & N/A & N/A & $\mathrm{N} / \mathrm{A}$ \\
\hline 129 & M & Plastic & Merged & N/A & N/A & N/A & N/A \\
\hline 13 & M & Plastic & Merged & N/A & N/A & N/A & N/A \\
\hline 130 & $\mathrm{M}$ & Plastic & Merged & N/A & N/A & N/A & N/A \\
\hline 131 & M & Plastic & Merged & N/A & N/A & N/A & N/A \\
\hline 132 & $\mathrm{M}$ & Plastic & Merged & N/A & N/A & N/A & N/A \\
\hline 133 & M & Plastic & Merged & N/A & N/A & N/A & N/A \\
\hline 134 & $\mathrm{M}$ & Plastic & Merged & N/A & N/A & N/A & N/A \\
\hline 135 & $\mathrm{M}$ & Plastic & Merged & N/A & N/A & N/A & N/A \\
\hline 136 & M & Plastic & Merged & N/A & N/A & N/A & N/A \\
\hline 14 & $\mathrm{M}$ & Plastic & Merged & N/A & N/A & N/A & N/A \\
\hline 15 & $\mathrm{M}$ & Plastic & Merged & N/A & N/A & N/A & $\mathrm{N} / \mathrm{A}$ \\
\hline 16 & $\mathrm{M}$ & Plastic & Merged & N/A & N/A & N/A & N/A \\
\hline 17 & $\mathrm{M}$ & Plastic & Merged & N/A & N/A & N/A & N/A \\
\hline 18 & $\mathrm{M}$ & Plastic & Merged & N/A & N/A & N/A & N/A \\
\hline 19 & $\mathrm{M}$ & Plastic & Merged & N/A & N/A & N/A & N/A \\
\hline 2 & M & Plastic & Merged & N/A & N/A & N/A & N/A \\
\hline 20 & M & Plastic & Merged & N/A & N/A & N/A & N/A \\
\hline 21 & M & Plastic & Merged & N/A & N/A & N/A & N/A \\
\hline 22 & M & Plastic & Merged & N/A & N/A & N/A & N/A \\
\hline 23 & M & Plastic & Merged & N/A & N/A & N/A & N/A \\
\hline 24 & $\mathrm{M}$ & Plastic & Merged & N/A & N/A & N/A & $\mathrm{N} / \mathrm{A}$ \\
\hline 25 & $\mathrm{M}$ & Plastic & Merged & N/A & $\mathrm{N} / \mathrm{A}$ & N/A & N/A \\
\hline 26 & $\mathrm{M}$ & Plastic & Merged & N/A & N/A & N/A & N/A \\
\hline 27 & M & Plastic & Merged & N/A & N/A & N/A & N/A \\
\hline 28 & $\mathrm{M}$ & Plastic & Merged & N/A & N/A & N/A & $\mathrm{N} / \mathrm{A}$ \\
\hline 29 & M & Plastic & Merged & N/A & N/A & N/A & N/A \\
\hline 3 & M & Plastic & Merged & N/A & $\mathrm{N} / \mathrm{A}$ & N/A & $\mathrm{N} / \mathrm{A}$ \\
\hline 30 & M & Plastic & Merged & N/A & N/A & N/A & N/A \\
\hline 31 & M & Plastic & Merged & N/A & N/A & N/A & N/A \\
\hline 32 & $\mathrm{M}$ & Plastic & Merged & N/A & N/A & N/A & N/A \\
\hline 33 & $\mathrm{M}$ & Plastic & Merged & N/A & N/A & N/A & N/A \\
\hline 34 & $M$ & Plastic & Merged & N/A & N/A & N/A & N/A \\
\hline 35 & $\mathrm{M}$ & Plastic & Merged & N/A & N/A & N/A & N/A \\
\hline 36 & $\mathrm{M}$ & Plastic & Merged & N/A & N/A & N/A & N/A \\
\hline 38 & $\mathrm{M}$ & Plastic & Merged & N/A & N/A & N/A & N/A \\
\hline 39 & $M$ & Plastic & Merged & N/A & N/A & N/A & $\mathrm{N} / \mathrm{A}$ \\
\hline 4 & M & Plastic & Merged & N/A & N/A & N/A & N/A \\
\hline 40 & M & Plastic & Merged & N/A & N/A & N/A & N/A \\
\hline
\end{tabular}




\begin{tabular}{|c|c|c|c|c|c|c|c|}
\hline 41 & M & Plastic & Merged & N/A & N/A & N/A & $\mathrm{N} / \mathrm{A}$ \\
\hline 42 & $\mathrm{M}$ & Plastic & Merged & N/A & N/A & N/A & N/A \\
\hline 43 & $\mathrm{M}$ & Plastic & Merged & N/A & N/A & N/A & N/A \\
\hline 44 & $\mathrm{M}$ & Plastic & Merged & N/A & N/A & N/A & N/A \\
\hline 45 & $M$ & Plastic & Merged & N/A & N/A & N/A & N/A \\
\hline 46 & $\mathrm{M}$ & Plastic & Merged & N/A & N/A & N/A & N/A \\
\hline 47 & $\mathrm{M}$ & Plastic & Merged & N/A & N/A & N/A & N/A \\
\hline 48 & M & Plastic & Merged & N/A & N/A & N/A & N/A \\
\hline 49 & M & Plastic & Merged & N/A & N/A & N/A & N/A \\
\hline 5 & M & Plastic & Merged & N/A & N/A & N/A & N/A \\
\hline 50 & M & Plastic & Merged & N/A & N/A & N/A & N/A \\
\hline 51 & $\mathrm{M}$ & Plastic & Merged & N/A & N/A & N/A & N/A \\
\hline 52 & $\mathrm{M}$ & Plastic & Merged & N/A & N/A & N/A & N/A \\
\hline 53 & M & Plastic & Merged & N/A & N/A & N/A & $\mathrm{N} / \mathrm{A}$ \\
\hline 54 & $\mathrm{M}$ & Plastic & Merged & N/A & N/A & N/A & N/A \\
\hline 55 & $\mathrm{M}$ & Plastic & Merged & N/A & N/A & N/A & N/A \\
\hline 56 & $\mathrm{M}$ & Plastic & Merged & N/A & N/A & N/A & N/A \\
\hline 57 & $\mathrm{M}$ & Plastic & Merged & N/A & N/A & N/A & N/A \\
\hline 58 & M & Plastic & Merged & N/A & N/A & N/A & $\mathrm{N} / \mathrm{A}$ \\
\hline 59 & $\mathrm{M}$ & Plastic & Merged & N/A & N/A & N/A & N/A \\
\hline 6 & $\mathrm{M}$ & Plastic & Merged & N/A & N/A & N/A & N/A \\
\hline 60 & $M$ & Plastic & Merged & N/A & N/A & N/A & N/A \\
\hline 61 & $\mathrm{M}$ & Plastic & Merged & N/A & N/A & N/A & N/A \\
\hline 62 & M & Plastic & Merged & N/A & N/A & N/A & N/A \\
\hline 63 & $\mathrm{M}$ & Plastic & Merged & N/A & N/A & N/A & N/A \\
\hline 64 & $\mathrm{M}$ & Plastic & Merged & N/A & N/A & N/A & N/A \\
\hline 65 & M & Plastic & Merged & N/A & N/A & N/A & N/A \\
\hline 66 & M & Plastic & Merged & N/A & N/A & N/A & $\mathrm{N} / \mathrm{A}$ \\
\hline 67 & $\mathrm{M}$ & Plastic & Merged & N/A & N/A & N/A & N/A \\
\hline 68 & $\mathrm{M}$ & Plastic & Merged & N/A & N/A & N/A & N/A \\
\hline 69 & $\mathrm{M}$ & Plastic & Merged & N/A & N/A & N/A & N/A \\
\hline 7 & $M$ & Plastic & Merged & N/A & N/A & N/A & N/A \\
\hline 70 & M & Plastic & Merged & N/A & N/A & N/A & N/A \\
\hline 71 & M & Plastic & Merged & N/A & N/A & N/A & N/A \\
\hline 72 & $\mathrm{M}$ & Plastic & Merged & N/A & N/A & N/A & N/A \\
\hline 73 & $\mathrm{M}$ & Plastic & Merged & N/A & N/A & N/A & $\mathrm{N} / \mathrm{A}$ \\
\hline 74 & $\mathrm{M}$ & Plastic & Merged & N/A & N/A & N/A & N/A \\
\hline 75 & $\mathrm{M}$ & Plastic & Merged & N/A & N/A & N/A & N/A \\
\hline 76 & $\mathrm{M}$ & Plastic & Merged & N/A & N/A & N/A & N/A \\
\hline 77 & $\mathrm{M}$ & Plastic & Merged & N/A & N/A & N/A & N/A \\
\hline 78 & $\mathrm{M}$ & Plastic & Merged & N/A & N/A & N/A & N/A \\
\hline 79 & M & Plastic & Merged & N/A & N/A & N/A & N/A \\
\hline 8 & $\mathrm{M}$ & Plastic & Merged & N/A & N/A & N/A & N/A \\
\hline 80 & $\mathrm{M}$ & Plastic & Merged & N/A & N/A & N/A & N/A \\
\hline 81 & $\mathrm{M}$ & Plastic & Merged & N/A & N/A & N/A & $\mathrm{N} / \mathrm{A}$ \\
\hline 82 & M & Plastic & Merged & N/A & N/A & N/A & N/A \\
\hline 83 & $\mathrm{M}$ & Plastic & Merged & N/A & N/A & N/A & N/A \\
\hline 84 & $\mathrm{M}$ & Plastic & Merged & N/A & N/A & N/A & N/A \\
\hline 85 & $M$ & Plastic & Merged & N/A & N/A & N/A & N/A \\
\hline 86 & $\mathrm{M}$ & Plastic & Merged & N/A & N/A & N/A & N/A \\
\hline 87 & $\mathrm{M}$ & Plastic & Merged & N/A & N/A & N/A & N/A \\
\hline 88 & $\mathrm{M}$ & Plastic & Merged & N/A & N/A & N/A & N/A \\
\hline
\end{tabular}




\begin{tabular}{|c|c|c|c|c|c|c|c|}
\hline 89 & $\mathrm{M}$ & Plastic & Merged & N/A & N/A & N/A & N/A \\
\hline 9 & $\mathrm{M}$ & Plastic & Merged & N/A & N/A & N/A & N/A \\
\hline 90 & $\mathrm{M}$ & Plastic & Merged & N/A & $\mathrm{N} / \mathrm{A}$ & N/A & N/A \\
\hline 91 & $\mathrm{M}$ & Plastic & Merged & N/A & $\mathrm{N} / \mathrm{A}$ & N/A & $\mathrm{N} / \mathrm{A}$ \\
\hline 92 & $\mathrm{M}$ & Plastic & Merged & N/A & N/A & N/A & $\mathrm{N} / \mathrm{A}$ \\
\hline 93 & $\mathrm{M}$ & Plastic & Merged & N/A & N/A & N/A & $\mathrm{N} / \mathrm{A}$ \\
\hline 94 & $\mathrm{M}$ & Plastic & Merged & N/A & N/A & N/A & N/A \\
\hline 95 & $\mathrm{M}$ & Plastic & Merged & N/A & N/A & N/A & N/A \\
\hline 96 & $\mathrm{M}$ & Plastic & Merged & N/A & N/A & N/A & $\mathrm{N} / \mathrm{A}$ \\
\hline 97 & $\mathrm{M}$ & Plastic & Merged & N/A & N/A & N/A & $\mathrm{N} / \mathrm{A}$ \\
\hline 98 & $\mathrm{M}$ & Plastic & Merged & N/A & $\mathrm{N} / \mathrm{A}$ & N/A & $\mathrm{N} / \mathrm{A}$ \\
\hline 99 & $\mathrm{M}$ & Plastic & Merged & N/A & N/A & N/A & $\mathrm{N} / \mathrm{A}$ \\
\hline
\end{tabular}




\section{APPENDIX B}

\section{Results}

\begin{tabular}{|c|c|c|c|c|c|c|c|c|c|}
\hline $\begin{array}{c}\text { FP } \\
\#\end{array}$ & $\begin{array}{c}\text { Typ } \\
\text { e }\end{array}$ & Substrate & Development & NFIQ & Bandey & Match & Match Score & Lines Drawn & Total Lines \\
\hline 1 & $\mathrm{O}$ & Plastic & Cyano & 5 & 4 & $\mathrm{Y}$ & 2970840 & 38 & 63 \\
\hline 1 & $\mathrm{O}$ & Plastic & Cyano + Basic Red 28 & 5 & 3 & $\mathrm{Y}$ & 164064 & 32 & 62 \\
\hline 1 & $\mathrm{O}$ & Plastic & Cyano + Basic Red 28 & 1 & 4 & $\mathrm{Y}$ & 3082720 & 39 & 62 \\
\hline 1 & $\mathrm{O}$ & Plastic & Cyano + Basic Red 28 & 1 & 4 & $\mathrm{Y}$ & 2900562 & 42 & 60 \\
\hline 1 & M & Plastic & Merged & 2 & 4 & $\mathrm{Y}$ & 1882287 & 33 & 53 \\
\hline 2 & $\mathrm{O}$ & Plastic & Cyano & 2 & 3 & $\mathrm{Y}$ & 1929642 & 39 & 50 \\
\hline 2 & $\mathrm{O}$ & Plastic & Cyano + Basic Red 28 & 3 & 4 & Y & 3229932 & 51 & 68 \\
\hline 2 & $\mathrm{O}$ & Plastic & Cyano + Basic Red 28 & 1 & 3 & $\mathrm{Y}$ & 2006818 & 38 & 63 \\
\hline 2 & $\mathrm{O}$ & Plastic & Cyano + Basic Red 28 & 5 & 4 & $\mathrm{Y}$ & 3522690 & 45 & 62 \\
\hline 2 & M & Plastic & Merged & 1 & 4 & $\mathrm{Y}$ & 2991240 & 40 & 58 \\
\hline 3 & $\mathrm{O}$ & Plastic & Cyano & 5 & 4 & $\mathrm{Y}$ & 2659316 & 38 & 58 \\
\hline 3 & $\mathrm{O}$ & Plastic & Cyano + Basic Red 28 & 5 & 3 & $\mathrm{Y}$ & 1569724 & 38 & 61 \\
\hline 3 & $\mathrm{O}$ & Plastic & Cyano + Basic Red 28 & 1 & 3 & $\mathrm{Y}$ & 3144288 & 42 & 64 \\
\hline 3 & $\mathrm{O}$ & Plastic & Cyano + Basic Red 28 & 3 & 4 & $\mathrm{Y}$ & 547338 & 22 & 60 \\
\hline 3 & $\mathrm{M}$ & Plastic & Merged & 3 & 4 & $\mathrm{Y}$ & 1115961 & 33 & 54 \\
\hline 4 & $\mathrm{O}$ & Plastic & Cyano & 4 & 4 & $\mathrm{Y}$ & 1921218 & 39 & 61 \\
\hline 4 & $\mathrm{O}$ & Plastic & Cyano + Basic Red 28 & 2 & 3 & $\mathrm{Y}$ & 1458310 & 35 & 68 \\
\hline 4 & $\mathrm{O}$ & Plastic & Cyano + Basic Red 28 & 2 & 3 & $\mathrm{Y}$ & 1644552 & 36 & 65 \\
\hline 4 & $\mathrm{O}$ & Plastic & Cyano + Basic Red 28 & 2 & 4 & $\mathrm{Y}$ & 2292802 & 41 & 67 \\
\hline 4 & $\mathrm{M}$ & Plastic & Merged & 2 & 4 & $\mathrm{Y}$ & 1736235 & 45 & 69 \\
\hline 5 & $\mathrm{O}$ & Plastic & Cyano & 5 & 2 & $\mathrm{Y}$ & 3462624 & 44 & 60 \\
\hline 5 & $\mathrm{O}$ & Plastic & Cyano + Basic Red 28 & 5 & 4 & $\mathrm{Y}$ & 1503166 & 38 & 65 \\
\hline 5 & $\mathrm{O}$ & Plastic & Cyano + Basic Red 28 & 5 & 3 & Y & 3316131 & 39 & 64 \\
\hline 5 & $\mathrm{O}$ & Plastic & Cyano + Basic Red 28 & 2 & 4 & Y & 2358765 & 43 & 63 \\
\hline 5 & $\mathrm{M}$ & Plastic & Merged & 1 & 4 & $\mathrm{Y}$ & 2273466 & 39 & 54 \\
\hline 6 & $\mathrm{O}$ & Plastic & Cyano & 5 & 4 & $\mathrm{Y}$ & 783224 & 26 & 46 \\
\hline 6 & $\mathrm{O}$ & Plastic & Cyano + Basic Red 28 & 4 & 4 & $\mathrm{Y}$ & 1140386 & 23 & 42 \\
\hline 6 & $\mathrm{O}$ & Plastic & Cyano + Basic Red 28 & 4 & 3 & $\mathrm{Y}$ & 864984 & 24 & 51 \\
\hline 6 & $\mathrm{O}$ & Plastic & Cyano + Basic Red 28 & 1 & 2 & $\mathrm{Y}$ & 703488 & 24 & 38 \\
\hline 6 & M & Plastic & Merged & 3 & 3 & $\mathrm{Y}$ & 1018348 & 23 & 35 \\
\hline 7 & $\mathrm{O}$ & Plastic & Cyano & 2 & 4 & $\mathrm{Y}$ & 902564 & 35 & 63 \\
\hline 7 & $\mathrm{O}$ & Plastic & Cyano + Basic Red 28 & 1 & 4 & $\mathrm{Y}$ & 1476840 & 31 & 63 \\
\hline 7 & $\mathrm{O}$ & Plastic & Cyano + Basic Red 28 & 5 & 4 & $\mathrm{Y}$ & 1395498 & 39 & 66 \\
\hline 7 & $\mathrm{O}$ & Plastic & Cyano + Basic Red 28 & 1 & 4 & $\mathrm{Y}$ & 841509 & 27 & 55 \\
\hline 7 & M & Plastic & Merged & 1 & 3 & $\mathrm{Y}$ & 492507 & 27 & 55 \\
\hline 8 & $\mathrm{O}$ & Plastic & Cyano & 2 & 4 & $\mathrm{Y}$ & 396960 & 24 & 52 \\
\hline 8 & $\mathrm{O}$ & Plastic & Cyano + Basic Red 28 & 5 & 3 & $\mathrm{Y}$ & 973420 & 34 & 66 \\
\hline 8 & $\mathrm{O}$ & Plastic & Cyano + Basic Red 28 & 3 & 3 & $\mathrm{Y}$ & 769098 & 33 & 63 \\
\hline 8 & $\mathrm{O}$ & Plastic & Cyano + Basic Red 28 & 5 & 2 & $\mathrm{Y}$ & 1767456 & 34 & 66 \\
\hline 8 & $\mathrm{M}$ & Plastic & Merged & 3 & 4 & $\mathrm{Y}$ & 790972 & 28 & 62 \\
\hline 9 & $\mathrm{O}$ & Plastic & Cyano & 5 & 3 & $\mathrm{Y}$ & 1000290 & 30 & 63 \\
\hline 9 & $\mathrm{O}$ & Plastic & Cyano + Basic Red 28 & 4 & 4 & $\mathrm{Y}$ & 802728 & 24 & 67 \\
\hline 9 & $\mathrm{O}$ & Plastic & Cyano + Basic Red 28 & 5 & 4 & Y & 936789 & 31 & 66 \\
\hline 9 & $\mathrm{O}$ & Plastic & Cyano + Basic Red 28 & 1 & 3 & $\mathrm{Y}$ & 1640296 & 34 & 66 \\
\hline 9 & $\mathrm{M}$ & Plastic & Merged & 2 & 4 & $\mathrm{Y}$ & 943530 & 35 & 63 \\
\hline 10 & $\mathrm{O}$ & Plastic & Cyano & 2 & 2 & Y & 7883128 & 58 & 74 \\
\hline
\end{tabular}




\begin{tabular}{|c|c|c|c|c|c|c|c|c|c|}
\hline 10 & $\mathrm{O}$ & Plastic & Cyano + Basic Red 28 & 5 & 4 & $\mathrm{Y}$ & 6957804 & 49 & 65 \\
\hline 10 & $\mathrm{O}$ & Plastic & Cyano + Basic Red 28 & 5 & 3 & $\mathrm{Y}$ & 6980113 & 59 & 75 \\
\hline 10 & $\mathrm{O}$ & Plastic & Cyano + Basic Red 28 & 1 & 3 & $\mathrm{Y}$ & 2172513 & 49 & 60 \\
\hline 10 & $\mathrm{M}$ & Plastic & Merged & 2 & 3 & $\mathrm{Y}$ & 8725035 & 55 & 65 \\
\hline 11 & $\mathrm{O}$ & Plastic & Cyano & 3 & 3 & $\mathrm{Y}$ & 6084673 & 49 & 63 \\
\hline 11 & $\mathrm{O}$ & Plastic & Cyano + Basic Red 28 & 1 & 3 & $\mathrm{Y}$ & 8689380 & 60 & 71 \\
\hline 11 & $\mathrm{O}$ & Plastic & Cyano + Basic Red 28 & 1 & 2 & $\mathrm{Y}$ & 7095093 & 61 & 75 \\
\hline 11 & $\mathrm{O}$ & Plastic & Cyano + Basic Red 28 & 1 & 4 & $\mathrm{Y}$ & 7161648 & 52 & 68 \\
\hline 11 & $\mathrm{M}$ & Plastic & Merged & 3 & 4 & $\mathrm{Y}$ & 5966892 & 54 & 68 \\
\hline 12 & $\mathrm{O}$ & Plastic & Cyano & 2 & 4 & $\mathrm{Y}$ & 9999999 & 65 & 75 \\
\hline 12 & $\mathrm{O}$ & Plastic & Cyano + Basic Red 28 & 5 & 3 & $\mathrm{Y}$ & 9999999 & 63 & 77 \\
\hline 12 & $\mathrm{O}$ & Plastic & Cyano + Basic Red 28 & 1 & 4 & $\mathrm{Y}$ & 9999999 & 66 & 77 \\
\hline 12 & $\mathrm{O}$ & Plastic & Cyano + Basic Red 28 & 1 & 3 & $\mathrm{Y}$ & 9588895 & 61 & 69 \\
\hline 12 & $\mathrm{M}$ & Plastic & Merged & 5 & 3 & $\mathrm{Y}$ & 9511059 & 61 & 73 \\
\hline 13 & $\mathrm{O}$ & Plastic & Cyano & 1 & 3 & $\mathrm{Y}$ & 2651465 & 35 & 63 \\
\hline 13 & $\mathrm{O}$ & Plastic & Cyano + Basic Red 28 & 4 & 3 & $\mathrm{Y}$ & 2144340 & 33 & 60 \\
\hline 13 & $\mathrm{O}$ & Plastic & Cyano + Basic Red 28 & 2 & 3 & $\mathrm{Y}$ & 2499276 & 39 & 60 \\
\hline 13 & $\mathrm{O}$ & Plastic & Cyano + Basic Red 28 & 1 & 4 & $\mathrm{Y}$ & 1557675 & 35 & 57 \\
\hline 13 & M & Plastic & Merged & 1 & 3 & Y & 2491812 & 38 & 60 \\
\hline 14 & $\mathrm{O}$ & Plastic & Cyano + Basic Red 28 & 4 & 4 & $\mathrm{Y}$ & 3910162 & 43 & 63 \\
\hline 14 & $\mathrm{O}$ & Plastic & Cyano + Basic Red 28 & 1 & 4 & $\mathrm{Y}$ & 1955918 & 34 & 51 \\
\hline 14 & $\mathrm{O}$ & Plastic & Cyano + Basic Red 28 & 4 & 3 & $\mathrm{Y}$ & 5386450 & 50 & 68 \\
\hline 14 & $\mathrm{O}$ & Plastic & Cyano + Basic Red 28 & 5 & 3 & $\mathrm{~N} / \mathrm{A}$ & N/A & $\mathrm{N} / \mathrm{A}$ & $\mathrm{N} / \mathrm{A}$ \\
\hline 14 & $\mathrm{M}$ & Plastic & Merged & 5 & 4 & $\mathrm{Y}$ & 3245600 & 40 & 62 \\
\hline 15 & $\mathrm{O}$ & Plastic & Cyano & 4 & 3 & $\mathrm{Y}$ & 2207275 & 35 & 59 \\
\hline 15 & $\mathrm{O}$ & Plastic & Cyano + Basic Red 28 & 3 & 4 & $\mathrm{Y}$ & 1543184 & 43 & 63 \\
\hline 15 & $\mathrm{O}$ & Plastic & Cyano + Basic Red 28 & 1 & 3 & $\mathrm{Y}$ & 3905354 & 46 & 67 \\
\hline 15 & $\mathrm{O}$ & Plastic & Cyano + Basic Red 28 & 1 & 4 & Y & 2087400 & 42 & 66 \\
\hline 15 & $\mathrm{M}$ & Plastic & Merged & 3 & 3 & $\mathrm{Y}$ & 2986944 & 47 & 69 \\
\hline 16 & $\mathrm{O}$ & Plastic & Cyano & 2 & 3 & $\mathrm{Y}$ & 2014722 & 43 & 64 \\
\hline 16 & $\mathrm{O}$ & Plastic & Cyano + Basic Red 28 & 1 & 3 & $\mathrm{Y}$ & 3038532 & 42 & 64 \\
\hline 16 & $\mathrm{O}$ & Plastic & Cyano + Basic Red 28 & 1 & 4 & $\mathrm{Y}$ & 1089616 & 40 & 62 \\
\hline 16 & $\mathrm{O}$ & Plastic & Cyano + Basic Red 28 & 1 & 4 & Y & 1882228 & 41 & 63 \\
\hline 16 & M & Plastic & Merged & 4 & 2 & $\mathrm{Y}$ & 569811 & 31 & 56 \\
\hline 17 & $\mathrm{O}$ & Plastic & Cyano & 1 & 4 & $\mathrm{Y}$ & 4305059 & 47 & 74 \\
\hline 17 & $\mathrm{O}$ & Plastic & Cyano + Basic Red 28 & 5 & 4 & $\mathrm{Y}$ & 3061036 & 44 & 73 \\
\hline 17 & $\mathrm{O}$ & Plastic & Cyano + Basic Red 28 & 2 & 4 & $\mathrm{Y}$ & 2738840 & 46 & 73 \\
\hline 17 & $\mathrm{O}$ & Plastic & Cyano + Basic Red 28 & 1 & 4 & $\mathrm{Y}$ & 3918768 & 42 & 70 \\
\hline 17 & $\mathrm{M}$ & Plastic & Merged & 2 & 3 & $\mathrm{Y}$ & 3020380 & 44 & 64 \\
\hline 18 & $\mathrm{O}$ & Plastic & Cyano & 3 & 3 & $\mathrm{Y}$ & 3657276 & 46 & 61 \\
\hline 18 & $\mathrm{O}$ & Plastic & Cyano + Basic Red 28 & 1 & 4 & Y & 3428392 & 44 & 66 \\
\hline 18 & $\mathrm{O}$ & Plastic & Cyano + Basic Red 28 & 5 & 3 & Y & 1741276 & 34 & 68 \\
\hline 18 & $\mathrm{O}$ & Plastic & Cyano + Basic Red 28 & 4 & 3 & $\mathrm{Y}$ & 4628928 & 48 & 70 \\
\hline 18 & M & Plastic & Merged & 1 & 3 & $\mathrm{Y}$ & 1852617 & 39 & 66 \\
\hline 19 & $\mathrm{O}$ & Plastic & Cyano & 1 & 4 & $\mathrm{Y}$ & 2965624 & 43 & 77 \\
\hline 19 & $\mathrm{O}$ & Plastic & Cyano + Basic Red 28 & 1 & 2 & Y & 1408225 & 34 & 73 \\
\hline 19 & $\mathrm{O}$ & Plastic & Cyano + Basic Red 28 & 5 & 3 & $\mathrm{Y}$ & 3373890 & 41 & 71 \\
\hline 19 & $\mathrm{O}$ & Plastic & Cyano + Basic Red 28 & 2 & 4 & $\mathrm{Y}$ & 2774112 & 44 & 69 \\
\hline 19 & $\mathrm{M}$ & Plastic & Merged & 1 & 3 & $\mathrm{Y}$ & 2938896 & 48 & 75 \\
\hline 20 & $\mathrm{O}$ & Plastic & Cyano & 1 & 4 & $\mathrm{Y}$ & 4715616 & 48 & 67 \\
\hline 20 & $\mathrm{O}$ & Plastic & Cyano + Basic Red 28 & 1 & 3 & $\mathrm{Y}$ & 1092204 & 27 & 66 \\
\hline 20 & $\mathrm{O}$ & Plastic & Cyano + Basic Red 28 & 1 & 4 & $\mathrm{Y}$ & 2870316 & 36 & 64 \\
\hline
\end{tabular}




\begin{tabular}{|c|c|c|c|c|c|c|c|c|c|}
\hline 20 & $\mathrm{O}$ & Plastic & Cyano + Basic Red 28 & 3 & 3 & Y & 3143736 & 36 & 61 \\
\hline 20 & $\mathrm{M}$ & Plastic & Merged & 3 & 3 & $\mathrm{Y}$ & 2924208 & 42 & 69 \\
\hline 21 & $\mathrm{O}$ & Plastic & Cyano & 5 & 4 & N/A & N/A & N/A & N/A \\
\hline 21 & $\mathrm{O}$ & Plastic & Cyano + Basic Red 28 & 5 & 4 & $\mathrm{Y}$ & 779085 & 27 & 51 \\
\hline 21 & $\mathrm{O}$ & Plastic & Cyano + Basic Red 28 & 2 & 4 & $\mathrm{Y}$ & 864786 & 26 & 59 \\
\hline 21 & $\mathrm{O}$ & Plastic & Cyano + Basic Red 28 & 1 & 4 & $\mathrm{Y}$ & 980397 & 27 & 52 \\
\hline 21 & $\mathrm{M}$ & Plastic & Merged & 5 & 1 & $\mathrm{Y}$ & 1339832 & 26 & 53 \\
\hline 22 & $\mathrm{O}$ & Plastic & Cyano & 1 & 4 & $\mathrm{Y}$ & 454087 & 17 & 49 \\
\hline 22 & $\mathrm{O}$ & Plastic & Cyano + Basic Red 28 & 5 & 2 & $\mathrm{Y}$ & 322684 & 17 & 43 \\
\hline 22 & $\mathrm{O}$ & Plastic & Cyano + Basic Red 28 & 5 & 3 & $\mathrm{Y}$ & 362253 & 17 & 47 \\
\hline 22 & $\mathrm{O}$ & Plastic & Cyano + Basic Red 28 & 4 & 3 & $\mathrm{Y}$ & 361267 & 17 & 41 \\
\hline 22 & $\mathrm{M}$ & Plastic & Merged & 4 & 3 & $\mathrm{Y}$ & 136268 & 11 & 29 \\
\hline 23 & $\mathrm{O}$ & Plastic & Cyano & 3 & 3 & $\mathrm{Y}$ & 331211 & 17 & 29 \\
\hline 23 & $\mathrm{O}$ & Plastic & Cyano + Basic Red 28 & 5 & 2 & $\mathrm{Y}$ & 195755 & 17 & 25 \\
\hline 23 & $\mathrm{O}$ & Plastic & Cyano + Basic Red 28 & 5 & 4 & $\mathrm{Y}$ & 273751 & 17 & 34 \\
\hline 23 & $\mathrm{O}$ & Plastic & Cyano + Basic Red 28 & 5 & 4 & $\mathrm{Y}$ & 66330 & 15 & 23 \\
\hline 23 & $\mathrm{M}$ & Plastic & Merged & 3 & 3 & $\mathrm{Y}$ & 190590 & 15 & 31 \\
\hline 24 & $\mathrm{O}$ & Plastic & Cyano & 3 & 4 & $\mathrm{Y}$ & 314944 & 14 & 36 \\
\hline 24 & $\mathrm{O}$ & Plastic & Cyano + Basic Red 28 & 5 & 3 & Y & 400707 & 17 & 36 \\
\hline 24 & $\mathrm{O}$ & Plastic & Cyano + Basic Red 28 & 4 & 3 & $\mathrm{Y}$ & 460150 & 25 & 47 \\
\hline 24 & $\mathrm{O}$ & Plastic & Cyano + Basic Red 28 & 5 & 4 & $\mathrm{Y}$ & 460150 & 25 & 47 \\
\hline 24 & M & Plastic & Merged & 4 & 3 & $\mathrm{Y}$ & 169510 & 11 & 41 \\
\hline 25 & $\mathrm{O}$ & Plastic & Cyano + Basic Red 28 & 5 & 4 & Y & 889200 & 25 & 40 \\
\hline 25 & $\mathrm{O}$ & Plastic & Cyano + Basic Red 28 & 3 & 4 & $\mathrm{Y}$ & 942084 & 26 & 42 \\
\hline 25 & $\mathrm{O}$ & Plastic & Cyano + Basic Red 28 & 5 & 4 & $\mathrm{Y}$ & 1155198 & 23 & 38 \\
\hline 25 & $\mathrm{M}$ & Plastic & Merged & 1 & 2 & $\mathrm{Y}$ & 819582 & 23 & 31 \\
\hline 26 & $\mathrm{O}$ & Plastic & Cyano & 1 & 3 & $\mathrm{Y}$ & 133653 & 13 & 23 \\
\hline 26 & $\mathrm{O}$ & Plastic & Cyano + Basic Red 28 & 5 & 3 & $\mathrm{Y}$ & 355623 & 17 & 37 \\
\hline 26 & $\mathrm{O}$ & Plastic & Cyano + Basic Red 28 & 4 & 3 & $\mathrm{~N}$ & 42481 & 12 & 32 \\
\hline 26 & $\mathrm{O}$ & Plastic & Cyano + Basic Red 28 & 3 & 4 & $\mathrm{Y}$ & 147248 & 16 & 29 \\
\hline 26 & $\mathrm{M}$ & Plastic & Merged & 4 & 3 & $\mathrm{Y}$ & 74460 & 12 & 31 \\
\hline 27 & $\mathrm{O}$ & Plastic & Cyano & 1 & 3 & $\mathrm{Y}$ & 591612 & 21 & 34 \\
\hline 27 & $\mathrm{O}$ & Plastic & Cyano + Basic Red 28 & 5 & 4 & Y & 1939112 & 28 & 43 \\
\hline 27 & $\mathrm{O}$ & Plastic & Cyano + Basic Red 28 & 5 & 3 & $\mathrm{Y}$ & 961925 & 25 & 37 \\
\hline 27 & $\mathrm{O}$ & Plastic & Cyano + Basic Red 28 & 5 & 3 & $\mathrm{Y}$ & 1248992 & 23 & 40 \\
\hline 27 & $\mathrm{M}$ & Plastic & Merged & 3 & 4 & $\mathrm{Y}$ & 187026 & 14 & 28 \\
\hline 28 & $\mathrm{O}$ & Plastic & Cyano & 3 & 4 & $\mathrm{Y}$ & 420399 & 21 & 32 \\
\hline 28 & $\mathrm{O}$ & Plastic & Cyano + Basic Red 28 & 4 & 3 & $\mathrm{Y}$ & 948304 & 28 & 55 \\
\hline 28 & $\mathrm{O}$ & Plastic & Cyano + Basic Red 28 & 2 & 3 & $\mathrm{Y}$ & 646350 & 25 & 51 \\
\hline 28 & $\mathrm{O}$ & Plastic & Cyano + Basic Red 28 & 1 & 4 & $\mathrm{Y}$ & 391457 & 19 & 37 \\
\hline 28 & $\mathrm{M}$ & Plastic & Merged & 3 & 2 & Y & 576035 & 23 & 43 \\
\hline 29 & $\mathrm{O}$ & Plastic & Cyano & 3 & 3 & Y & 941904 & 24 & 43 \\
\hline 29 & $\mathrm{O}$ & Plastic & Cyano + Basic Red 28 & 5 & 2 & $\mathrm{Y}$ & 815025 & 25 & 50 \\
\hline 29 & $\mathrm{O}$ & Plastic & Cyano + Basic Red 28 & 1 & 3 & $\mathrm{Y}$ & 932976 & 31 & 60 \\
\hline 29 & $\mathrm{O}$ & Plastic & Cyano + Basic Red 28 & 1 & 4 & Y & 473675 & 25 & 49 \\
\hline 29 & $\mathrm{M}$ & Plastic & Merged & 3 & 4 & $\mathrm{Y}$ & 1199421 & 31 & 50 \\
\hline 30 & $\mathrm{O}$ & Plastic & Cyano & 1 & 3 & $\mathrm{Y}$ & 2274228 & 33 & 49 \\
\hline 30 & $\mathrm{O}$ & Plastic & Cyano + Basic Red 28 & 4 & 3 & $\mathrm{Y}$ & 1557472 & 28 & 45 \\
\hline 30 & $\mathrm{O}$ & Plastic & Cyano + Basic Red 28 & 1 & 4 & $\mathrm{Y}$ & 1338744 & 33 & 49 \\
\hline 30 & $\mathrm{O}$ & Plastic & Cyano + Basic Red 28 & 1 & 3 & $\mathrm{Y}$ & 512350 & 25 & 41 \\
\hline 30 & $\mathrm{M}$ & Plastic & Merged & 1 & 3 & $\mathrm{Y}$ & 1044238 & 26 & 38 \\
\hline 31 & $\mathrm{O}$ & Plastic & Cyano & 4 & 2 & $\mathrm{Y}$ & 632385 & 23 & 43 \\
\hline
\end{tabular}




\begin{tabular}{|c|c|c|c|c|c|c|c|c|c|}
\hline 31 & $\mathrm{O}$ & Plastic & Cyano + Basic Red 28 & 2 & 4 & $\mathrm{Y}$ & 874940 & 22 & 44 \\
\hline 31 & $\mathrm{O}$ & Plastic & Cyano + Basic Red 28 & 5 & 4 & $\mathrm{Y}$ & 942550 & 25 & 39 \\
\hline 31 & $\mathrm{O}$ & Plastic & Cyano + Basic Red 28 & 1 & 4 & $\mathrm{Y}$ & 482724 & 22 & 42 \\
\hline 31 & $\mathrm{M}$ & Plastic & Merged & 1 & 4 & $\mathrm{Y}$ & 359908 & 21 & 44 \\
\hline 32 & $\mathrm{O}$ & Plastic & Cyano & 2 & 3 & $\mathrm{Y}$ & 576422 & 22 & 39 \\
\hline 32 & $\mathrm{O}$ & Plastic & Cyano + Basic Red 28 & 5 & 3 & $\mathrm{Y}$ & 522198 & 18 & 40 \\
\hline 32 & $\mathrm{O}$ & Plastic & Cyano + Basic Red 28 & 1 & 3 & $\mathrm{Y}$ & 1073203 & 23 & 40 \\
\hline 32 & $\mathrm{O}$ & Plastic & Cyano + Basic Red 28 & 5 & 3 & $\mathrm{Y}$ & 127326 & 28 & 43 \\
\hline 32 & $\mathrm{M}$ & Plastic & Merged & 3 & 3 & $\mathrm{Y}$ & 716900 & 20 & 41 \\
\hline 33 & $\mathrm{O}$ & Plastic & Cyano & 3 & 3 & $\mathrm{Y}$ & 1144665 & 27 & 47 \\
\hline 33 & $\mathrm{O}$ & Plastic & Cyano + Basic Red 28 & 5 & 3 & $\mathrm{Y}$ & 600006 & 22 & 47 \\
\hline 33 & $\mathrm{O}$ & Plastic & Cyano + Basic Red 28 & 1 & 4 & $\mathrm{Y}$ & 760750 & 25 & 47 \\
\hline 33 & $\mathrm{O}$ & Plastic & Cyano + Basic Red 28 & 5 & 3 & $\mathrm{Y}$ & 575302 & 29 & 46 \\
\hline 33 & $\mathrm{M}$ & Plastic & Merged & 2 & 4 & $\mathrm{Y}$ & 643377 & 21 & 48 \\
\hline 34 & $\mathrm{O}$ & Plastic & Cyano & 2 & 3 & $\mathrm{Y}$ & 194082 & 21 & 33 \\
\hline 34 & $O$ & Plastic & Cyano + Basic Red 28 & 3 & 4 & $N$ & 59640 & 10 & 37 \\
\hline 34 & $\overline{\mathrm{O}}$ & Plastic & Cyano + Basic Red 28 & 4 & 4 & $\bar{N}$ & N/A & $\mathrm{N} / \mathrm{A}$ & $\mathrm{N} / \mathrm{A}$ \\
\hline 34 & $\mathrm{O}$ & Plastic & Cyano + Basic Red 28 & 5 & 4 & $\mathrm{Y}$ & 177701 & 17 & 35 \\
\hline 34 & $\mathrm{M}$ & Plastic & Merged & 2 & 4 & $\mathrm{Y}$ & 86072 & 14 & 39 \\
\hline 35 & $\mathrm{O}$ & Plastic & Cyano & 1 & 4 & $\mathrm{Y}$ & 583065 & 21 & 33 \\
\hline 35 & $\mathrm{O}$ & Plastic & Cyano + Basic Red 28 & 5 & 3 & $\mathrm{Y}$ & 986742 & 27 & 44 \\
\hline 35 & $\mathrm{O}$ & Plastic & Cyano + Basic Red 28 & 1 & 3 & $\mathrm{Y}$ & 375564 & 21 & 41 \\
\hline 35 & $\mathrm{O}$ & Plastic & Cyano + Basic Red 28 & 5 & 3 & Y & 263130 & 14 & 25 \\
\hline 35 & $\mathrm{M}$ & Plastic & Merged & 1 & 4 & $\mathrm{Y}$ & 721680 & 24 & 35 \\
\hline 36 & $\mathrm{O}$ & Plastic & Cyano & 1 & 4 & $\mathrm{Y}$ & 71832 & 8 & 15 \\
\hline 36 & $\mathrm{O}$ & Plastic & Cyano + Basic Red 28 & 5 & 2 & $\mathrm{~N}$ & 53650 & 10 & 33 \\
\hline 36 & $\mathrm{O}$ & Plastic & Cyano + Basic Red 28 & 5 & 3 & $\mathrm{Y}$ & 218960 & 16 & 29 \\
\hline 36 & $\mathrm{O}$ & Plastic & Cyano + Basic Red 28 & 4 & 3 & $\mathrm{Y}$ & 189134 & 11 & 19 \\
\hline 36 & $\mathrm{M}$ & Plastic & Merged & 5 & 3 & $\mathrm{Y}$ & 28494 & 9 & 15 \\
\hline 38 & $\mathrm{O}$ & Plastic & Cyano & 3 & 2 & $\mathrm{Y}$ & 232144 & 16 & 24 \\
\hline 38 & $\mathrm{O}$ & Plastic & Cyano + Basic Red 28 & 5 & 4 & $\mathrm{Y}$ & 371450 & 19 & 30 \\
\hline 38 & $\mathrm{O}$ & Plastic & Cyano + Basic Red 28 & 5 & 2 & $\mathrm{Y}$ & 162225 & 15 & 26 \\
\hline 38 & $\mathrm{O}$ & Plastic & Cyano + Basic Red 28 & 3 & 3 & $\mathrm{Y}$ & 424740 & 15 & 29 \\
\hline 38 & $\mathrm{M}$ & Plastic & Merged & 3 & 3 & $\mathrm{Y}$ & 385630 & 14 & 27 \\
\hline 39 & $\mathrm{O}$ & Plastic & Cyano & 2 & 2 & $\mathrm{Y}$ & 46497 & 11 & 20 \\
\hline 39 & $\mathrm{O}$ & Plastic & Cyano + Basic Red 28 & 5 & 2 & $\mathrm{Y}$ & 26936 & 8 & 22 \\
\hline 39 & $\mathrm{O}$ & Plastic & Cyano + Basic Red 28 & 5 & 3 & $\mathrm{Y}$ & 15246 & 6 & 23 \\
\hline 39 & $\mathrm{O}$ & Plastic & Cyano + Basic Red 28 & 3 & 3 & $\mathrm{~N}$ & N/A & N/A & N/A \\
\hline 39 & $\mathrm{M}$ & Plastic & Merged & 1 & 3 & $\mathrm{Y}$ & 46752 & 8 & 19 \\
\hline 40 & $\mathrm{O}$ & Plastic & Cyano & 4 & 4 & $\mathrm{Y}$ & 329220 & 15 & 23 \\
\hline 40 & $\mathrm{O}$ & Plastic & Cyano + Basic Red 28 & 1 & 3 & Y & 291940 & 20 & 33 \\
\hline 40 & $\mathrm{O}$ & Plastic & Cyano + Basic Red 28 & 5 & 3 & $\mathrm{Y}$ & 461244 & 19 & 33 \\
\hline 40 & $\mathrm{O}$ & Plastic & Cyano + Basic Red 28 & 2 & 4 & $\mathrm{Y}$ & 216426 & 14 & 22 \\
\hline 40 & $\mathrm{M}$ & Plastic & Merged & 2 & 4 & $\mathrm{Y}$ & 259136 & 16 & 24 \\
\hline 41 & $\mathrm{O}$ & Plastic & Cyano & 3 & 4 & $\mathrm{Y}$ & 99270 & 15 & 26 \\
\hline 41 & $\mathrm{O}$ & Plastic & Cyano + MBD & 5 & 4 & $\mathrm{Y}$ & 71988 & 12 & 37 \\
\hline 41 & $\mathrm{O}$ & Plastic & Cyano + MBD & 5 & 3 & $\mathrm{Y}$ & 692199 & 27 & 48 \\
\hline 41 & $\mathrm{M}$ & Plastic & Merged & 2 & 3 & $\mathrm{Y}$ & 53452 & 14 & 40 \\
\hline 42 & $\mathrm{O}$ & Plastic & Cyano & 2 & 4 & $\mathrm{Y}$ & 880178 & 26 & 43 \\
\hline 42 & $\mathrm{O}$ & Plastic & Cyano + MBD & 3 & 4 & $\mathrm{~N} / \mathrm{A}$ & $\mathrm{N} / \mathrm{A}$ & $\mathrm{N} / \mathrm{A}$ & $\mathrm{N} / \mathrm{A}$ \\
\hline 42 & $\mathrm{O}$ & Plastic & Cyano + MBD & 1 & 4 & $\mathrm{Y}$ & 1233707 & 31 & 54 \\
\hline 42 & $\mathrm{M}$ & Plastic & Merged & 3 & 3 & $\mathrm{Y}$ & 758016 & 32 & 44 \\
\hline
\end{tabular}




\begin{tabular}{|c|c|c|c|c|c|c|c|c|c|}
\hline 43 & $\mathrm{O}$ & Plastic & Cyano & 5 & 4 & $\mathrm{Y}$ & 678546 & 23 & 34 \\
\hline 43 & $\mathrm{O}$ & Plastic & Cyano + MBD & 1 & 3 & $\mathrm{Y}$ & 1485520 & 31 & 50 \\
\hline 43 & $\mathrm{O}$ & Plastic & Cyano + MBD & 1 & 3 & $\mathrm{Y}$ & 1197450 & 30 & 52 \\
\hline 43 & $\mathrm{M}$ & Plastic & Merged & 5 & 3 & $\mathrm{Y}$ & 550900 & 27 & 50 \\
\hline 44 & $\mathrm{O}$ & Plastic & Cyano & 3 & 4 & $\mathrm{Y}$ & 613620 & 21 & 40 \\
\hline 44 & $\mathrm{O}$ & Plastic & Cyano + MBD & 3 & 4 & $\mathrm{Y}$ & 276858 & 18 & 43 \\
\hline 44 & $\mathrm{O}$ & Plastic & Cyano + MBD & 1 & 4 & $\mathrm{Y}$ & 914172 & 21 & 41 \\
\hline 44 & $\mathrm{M}$ & Plastic & Merged & 3 & 2 & $\mathrm{Y}$ & 465642 & 18 & 37 \\
\hline 45 & $\mathrm{O}$ & Plastic & Cyano & 1 & 3 & $\mathrm{Y}$ & 1275534 & 26 & 29 \\
\hline 45 & $\mathrm{O}$ & Plastic & Cyano + MBD & 4 & 3 & $\mathrm{~N}$ & 31196 & 10 & 17 \\
\hline 45 & $\mathrm{O}$ & Plastic & Cyano + MBD & 3 & 2 & $\mathrm{~N}$ & 24748 & 10 & 17 \\
\hline 45 & $\mathrm{M}$ & Plastic & Merged & 3 & 4 & $\mathrm{Y}$ & 115570 & 14 & 21 \\
\hline 46 & $\mathrm{O}$ & Plastic & Cyano & 1 & 4 & $\mathrm{Y}$ & 1834641 & 23 & 28 \\
\hline 46 & $\mathrm{O}$ & Plastic & Cyano + MBD & 4 & 4 & $\mathrm{Y}$ & 799124 & 29 & 43 \\
\hline 46 & $\mathrm{O}$ & Plastic & Cyano + MBD & 1 & 4 & $\mathrm{Y}$ & 978600 & 28 & 53 \\
\hline 46 & $\mathrm{M}$ & Plastic & Merged & 3 & 4 & $\mathrm{Y}$ & 625350 & 22 & 35 \\
\hline 47 & $\mathrm{O}$ & Plastic & Cyano & 1 & 4 & $\mathrm{Y}$ & 688857 & 17 & 20 \\
\hline 47 & $\mathrm{O}$ & Plastic & Cyano + MBD & 1 & 4 & $\mathrm{Y}$ & 1152819 & 27 & 39 \\
\hline 47 & $\mathrm{O}$ & Plastic & Cyano + MBD & 2 & 4 & $\mathrm{Y}$ & 340408 & 17 & 28 \\
\hline 47 & $\mathrm{M}$ & Plastic & Merged & 1 & 4 & $\mathrm{Y}$ & 433512 & 18 & 32 \\
\hline 48 & $\mathrm{O}$ & Plastic & Cyano & 5 & 2 & $\mathrm{Y}$ & 231350 & 14 & 15 \\
\hline 48 & $\mathrm{O}$ & Plastic & Cyano + MBD & 5 & 3 & $\mathrm{Y}$ & 538660 & 20 & 41 \\
\hline 48 & $\mathrm{O}$ & Plastic & Cyano + MBD & 2 & 3 & $\mathrm{Y}$ & 595608 & 24 & 44 \\
\hline 48 & $\mathrm{M}$ & Plastic & Merged & 4 & 4 & $\mathrm{Y}$ & 744150 & 25 & 44 \\
\hline 49 & $\mathrm{O}$ & Plastic & Cyano + MBD & 5 & 4 & $\mathrm{Y}$ & 854260 & 20 & 43 \\
\hline 49 & $\mathrm{O}$ & Plastic & Cyano + MBD & 2 & 4 & $\mathrm{Y}$ & 240312 & 17 & 42 \\
\hline 49 & $\mathrm{M}$ & Plastic & Merged & 2 & 4 & $\mathrm{Y}$ & 179445 & 15 & 40 \\
\hline 50 & $\mathrm{O}$ & Plastic & Cyano & 5 & 4 & $\mathrm{Y}$ & 980400 & 24 & 49 \\
\hline 50 & $\mathrm{O}$ & Plastic & Cyano + MBD & 1 & 4 & $\mathrm{Y}$ & 280425 & 25 & 42 \\
\hline 50 & $\mathrm{O}$ & Plastic & Cyano + MBD & 1 & 3 & $\mathrm{Y}$ & 461013 & 21 & 48 \\
\hline 50 & $\mathrm{M}$ & Plastic & Merged & 2 & 3 & $\mathrm{Y}$ & 312902 & 17 & 47 \\
\hline 51 & $\mathrm{O}$ & Plastic & Cyano & 5 & 3 & $\mathrm{~N}$ & 45840 & 15 & 33 \\
\hline 51 & $\mathrm{O}$ & Plastic & Cyano + MBD & 5 & 3 & $\mathrm{Y}$ & 338859 & 23 & 37 \\
\hline 51 & $\mathrm{O}$ & Plastic & Cyano + MBD & 4 & 4 & $\mathrm{Y}$ & 242280 & 20 & 36 \\
\hline 51 & $\mathrm{M}$ & Plastic & Merged & 5 & 3 & $\mathrm{~N}$ & 89925 & 15 & 30 \\
\hline 52 & $\mathrm{O}$ & Plastic & Cyano & 5 & 3 & $\mathrm{Y}$ & 741275 & 25 & 45 \\
\hline 52 & $\mathrm{O}$ & Plastic & Cyano + MBD & 4 & 3 & Y & 332080 & 20 & 28 \\
\hline 52 & $\mathrm{O}$ & Plastic & Cyano + MBD & 5 & 4 & $\mathrm{Y}$ & 751872 & 22 & 41 \\
\hline 52 & $\mathrm{M}$ & Plastic & Merged & 1 & 4 & $\mathrm{Y}$ & 43180 & 10 & 19 \\
\hline 53 & $\mathrm{O}$ & Plastic & Cyano & 5 & 3 & $\mathrm{Y}$ & 511537 & 19 & 24 \\
\hline 53 & $\mathrm{O}$ & Plastic & Cyano + MBD & 1 & 4 & $\mathrm{Y}$ & 187216 & 16 & 29 \\
\hline 53 & $\mathrm{O}$ & Plastic & Cyano + MBD & 1 & 4 & $\mathrm{Y}$ & 45264 & 12 & 25 \\
\hline 53 & $\mathrm{M}$ & Plastic & Merged & 1 & 2 & $\mathrm{Y}$ & 197574 & 13 & 30 \\
\hline 54 & $\mathrm{O}$ & Plastic & Cyano & 3 & 3 & $\mathrm{Y}$ & 783299 & 23 & 31 \\
\hline 54 & $\mathrm{O}$ & Plastic & Cyano + MBD & 1 & 3 & $\mathrm{Y}$ & 798570 & 30 & 39 \\
\hline 54 & $\mathrm{O}$ & Plastic & Cyano + MBD & 5 & 3 & $\mathrm{Y}$ & 1103808 & 32 & 44 \\
\hline 54 & $\mathrm{M}$ & Plastic & Merged & 1 & 4 & $\mathrm{Y}$ & 254353 & 19 & 35 \\
\hline 55 & $\mathrm{O}$ & Plastic & Cyano & 1 & 3 & $\mathrm{Y}$ & 234192 & 16 & 26 \\
\hline 55 & $\mathrm{O}$ & Plastic & Cyano + MBD & 4 & 3 & $\mathrm{Y}$ & 368067 & 17 & 33 \\
\hline 55 & $\mathrm{O}$ & Plastic & Cyano + MBD & 1 & 3 & $\mathrm{Y}$ & 845691 & 21 & 32 \\
\hline 55 & $\mathrm{M}$ & Plastic & Merged & 1 & 4 & $\mathrm{Y}$ & 1045488 & 24 & 35 \\
\hline 56 & $\mathrm{O}$ & Plastic & Cyano & 1 & 4 & $\mathrm{~N}$ & 37476 & 8 & 33 \\
\hline
\end{tabular}




\begin{tabular}{|c|c|c|c|c|c|c|c|c|c|}
\hline 56 & $\mathrm{O}$ & Plastic & Cyano + MBD & 1 & 2 & $\mathrm{Y}$ & 488088 & 24 & 55 \\
\hline 56 & $\mathrm{O}$ & Plastic & Cyano + MBD & 4 & 3 & $\mathrm{Y}$ & 275706 & 18 & 50 \\
\hline 56 & $\mathrm{M}$ & Plastic & Merged & 5 & 3 & $\mathrm{Y}$ & 1419806 & 34 & 54 \\
\hline 57 & $\mathrm{O}$ & Plastic & Cyano & 1 & 4 & $\mathrm{Y}$ & 50292 & 12 & 24 \\
\hline 57 & $\mathrm{O}$ & Plastic & Cyano + MBD & 1 & 2 & $\mathrm{Y}$ & 41040 & 15 & 27 \\
\hline 57 & $\mathrm{O}$ & Plastic & Cyano + MBD & 5 & 4 & $\mathrm{Y}$ & 46240 & 10 & 23 \\
\hline 57 & $\mathrm{M}$ & Plastic & Merged & 1 & 2 & $\mathrm{~N}$ & N/A & N/A & N/A \\
\hline 58 & $\mathrm{O}$ & Plastic & Cyano & 3 & 2 & $\mathrm{Y}$ & 765325 & 25 & 55 \\
\hline 58 & $\mathrm{O}$ & Plastic & Cyano + MBD & 1 & 4 & $\mathrm{Y}$ & 326485 & 17 & 47 \\
\hline 58 & $\mathrm{O}$ & Plastic & Cyano + MBD & 1 & 4 & $\mathrm{Y}$ & 259254 & 18 & 51 \\
\hline 58 & $\mathrm{M}$ & Plastic & Merged & 1 & 4 & $\mathrm{~N}$ & 38619 & 8 & 34 \\
\hline 59 & $\mathrm{O}$ & Plastic & Cyano & 5 & 3 & $\mathrm{Y}$ & 565240 & 26 & 60 \\
\hline 59 & $\mathrm{O}$ & Plastic & Cyano + MBD & 1 & 4 & $\mathrm{Y}$ & 897402 & 33 & 60 \\
\hline 59 & $\mathrm{O}$ & Plastic & Cyano + MBD & 4 & 3 & $\mathrm{Y}$ & 435952 & 22 & 61 \\
\hline 59 & $\mathrm{M}$ & Plastic & Merged & 2 & 3 & $\mathrm{Y}$ & 302192 & 22 & 59 \\
\hline 60 & $\mathrm{O}$ & Plastic & Cyano & 1 & 4 & $\mathrm{Y}$ & 977756 & 26 & 40 \\
\hline 60 & $\mathrm{O}$ & Plastic & Cyano + MBD & 5 & 4 & $\mathrm{Y}$ & 347544 & 27 & 35 \\
\hline 60 & $\mathrm{O}$ & Plastic & Cyano + MBD & 5 & 3 & $\mathrm{Y}$ & 98096 & 16 & 43 \\
\hline 60 & $\mathrm{M}$ & Plastic & Merged & 4 & 4 & $\mathrm{~N}$ & 51312 & 12 & 40 \\
\hline 61 & $\mathrm{O}$ & Plastic & Cyano & 5 & 3 & $\mathrm{~N}$ & N/A & N/A & N/A \\
\hline 61 & $\mathrm{O}$ & Plastic & Cyano + MBD & 5 & 4 & $\mathrm{~N}$ & N/A & N/A & N/A \\
\hline 61 & $\mathrm{O}$ & Plastic & Cyano + MBD & 2 & 4 & $\mathrm{~N}$ & N/A & N/A & N/A \\
\hline 61 & $\mathrm{M}$ & Plastic & Merged & 3 & 3 & $\mathrm{~N}$ & N/A & N/A & N/A \\
\hline 62 & $\mathrm{O}$ & Plastic & Cyano & 3 & 4 & $\mathrm{Y}$ & 318978 & 18 & 33 \\
\hline 62 & $\mathrm{O}$ & Plastic & Cyano + MBD & 3 & 3 & $\mathrm{Y}$ & 113796 & 18 & 31 \\
\hline 62 & $\mathrm{O}$ & Plastic & Cyano + MBD & 1 & 4 & $\mathrm{Y}$ & 47696 & 11 & 33 \\
\hline 62 & $\mathrm{M}$ & Plastic & Merged & 5 & 4 & $\mathrm{Y}$ & 214016 & 16 & 28 \\
\hline 63 & $\mathrm{O}$ & Plastic & Cyano & 1 & 4 & $\mathrm{Y}$ & 729014 & 26 & 37 \\
\hline 63 & $\mathrm{O}$ & Plastic & Cyano + MBD & 5 & 3 & $\mathrm{Y}$ & 520464 & 28 & 39 \\
\hline 63 & $\mathrm{O}$ & Plastic & Cyano + MBD & 5 & 3 & $\mathrm{Y}$ & 574636 & 19 & 46 \\
\hline 63 & $\mathrm{M}$ & Plastic & Merged & 5 & 3 & $\mathrm{~N}$ & 56804 & 11 & 32 \\
\hline 64 & $\mathrm{O}$ & Plastic & Cyano & 1 & 4 & $\mathrm{Y}$ & 484592 & 31 & 53 \\
\hline 64 & $\mathrm{O}$ & Plastic & Cyano + MBD & 4 & 3 & $\mathrm{Y}$ & 1789092 & 36 & 58 \\
\hline 64 & $\mathrm{O}$ & Plastic & Cyano + MBD & 5 & 4 & $\mathrm{Y}$ & 1998990 & 35 & 61 \\
\hline 64 & $\mathrm{M}$ & Plastic & Merged & 5 & 3 & $\mathrm{Y}$ & 1345281 & 29 & 55 \\
\hline 65 & $\mathrm{O}$ & Plastic & Cyano & 1 & 2 & $\mathrm{Y}$ & 508600 & 20 & 43 \\
\hline 65 & $\mathrm{O}$ & Plastic & Cyano + MBD & 2 & 4 & $\mathrm{Y}$ & 815764 & 23 & 54 \\
\hline 65 & $\mathrm{O}$ & Plastic & Cyano + MBD & 4 & 4 & $\mathrm{Y}$ & 844398 & 27 & 60 \\
\hline 65 & $\mathrm{M}$ & Plastic & Merged & 5 & 3 & $\mathrm{Y}$ & 1161545 & 35 & 51 \\
\hline 66 & $\mathrm{O}$ & Plastic & Cyano & 4 & 4 & $\mathrm{Y}$ & 1101246 & 29 & 49 \\
\hline 66 & $\mathrm{O}$ & Plastic & Cyano + MBD & 1 & 3 & $\mathrm{Y}$ & 1221840 & 30 & 48 \\
\hline 66 & $\mathrm{O}$ & Plastic & Cyano + MBD & 5 & 3 & $\mathrm{Y}$ & 954315 & 27 & 49 \\
\hline 66 & $\mathrm{M}$ & Plastic & Merged & 1 & 4 & $\mathrm{Y}$ & 2132889 & 33 & 43 \\
\hline 67 & $\mathrm{O}$ & Plastic & Cyano & 5 & 3 & $\mathrm{Y}$ & 249830 & 14 & 21 \\
\hline 67 & $\mathrm{O}$ & Plastic & Cyano + MBD & 1 & 4 & $\mathrm{Y}$ & 873356 & 22 & 37 \\
\hline 67 & $\mathrm{O}$ & Plastic & Cyano + MBD & 1 & 4 & $\mathrm{Y}$ & 452616 & 24 & 42 \\
\hline 67 & $\mathrm{M}$ & Plastic & Merged & 1 & 3 & $\mathrm{Y}$ & 494516 & 22 & 33 \\
\hline 68 & $\mathrm{O}$ & Plastic & Cyano & 5 & 4 & $\mathrm{~N}$ & N/A & N/A & N/A \\
\hline 68 & $\mathrm{O}$ & Plastic & Cyano + MBD & 2 & 3 & $\mathrm{Y}$ & 676894 & 13 & 47 \\
\hline 68 & $\mathrm{O}$ & Plastic & Cyano + MBD & 4 & 3 & $\mathrm{~N}$ & 510192 & 18 & 42 \\
\hline 68 & $\mathrm{M}$ & Plastic & Merged & 4 & 3 & $\mathrm{Y}$ & 591160 & 20 & 40 \\
\hline 69 & $\mathrm{O}$ & Plastic & Cyano & 1 & 4 & $\mathrm{Y}$ & 58392 & 12 & 19 \\
\hline
\end{tabular}




\begin{tabular}{|c|c|c|c|c|c|c|c|c|c|}
\hline 69 & $\mathrm{O}$ & Plastic & Cyano + MBD & 2 & 3 & $\mathrm{Y}$ & 44172 & 12 & 22 \\
\hline 69 & $\mathrm{O}$ & Plastic & Cyano + MBD & 5 & 4 & $\mathrm{Y}$ & 377944 & 4 & 22 \\
\hline 69 & $\mathrm{M}$ & Plastic & Merged & 4 & 3 & $\mathrm{Y}$ & 351356 & 17 & 25 \\
\hline 70 & $\mathrm{O}$ & Plastic & Cyano & 5 & 4 & $\mathrm{~N}$ & 272867 & 17 & 33 \\
\hline 70 & $\mathrm{O}$ & Plastic & Cyano + MBD & 4 & 3 & $\mathrm{Y}$ & 788000 & 25 & 46 \\
\hline 70 & $\mathrm{O}$ & Plastic & Cyano + MBD & 5 & 3 & $\mathrm{Y}$ & 139355 & 15 & 38 \\
\hline 70 & $\mathrm{M}$ & Plastic & Merged & 1 & 2 & $\mathrm{Y}$ & 226980 & 18 & 38 \\
\hline 71 & $\mathrm{O}$ & Plastic & Cyano & 2 & 3 & $\mathrm{Y}$ & 546720 & 17 & 28 \\
\hline 71 & $\mathrm{O}$ & Plastic & Cyano + MBD & 2 & 1 & $\mathrm{Y}$ & 203360 & 16 & 26 \\
\hline 71 & $\mathrm{O}$ & Plastic & Cyano + MBD & 2 & 4 & $\mathrm{Y}$ & 363375 & 17 & 34 \\
\hline 71 & $\mathrm{M}$ & Plastic & Merged & 5 & 4 & $\mathrm{Y}$ & 518610 & 15 & 24 \\
\hline 72 & $\mathrm{O}$ & Plastic & Cyano & 4 & 4 & $\mathrm{Y}$ & 948793 & 29 & 37 \\
\hline 72 & $\mathrm{O}$ & Plastic & Cyano + MBD & 5 & 3 & $\mathrm{Y}$ & 377568 & 23 & 40 \\
\hline 72 & $\mathrm{O}$ & Plastic & Cyano + MBD & 5 & 3 & $\mathrm{Y}$ & 1218425 & 25 & 31 \\
\hline 72 & $\mathrm{M}$ & Plastic & Merged & 1 & 4 & $\mathrm{Y}$ & 657279 & 21 & 32 \\
\hline 73 & $\mathrm{O}$ & Plastic & Cyano & 5 & 2 & $\mathrm{~N}$ & N/A & N/A & N/A \\
\hline 73 & $\mathrm{O}$ & Plastic & Cyano + MBD & 1 & 3 & $\mathrm{~N}$ & N/A & N/A & N/A \\
\hline 73 & $\mathrm{O}$ & Plastic & Cyano + MBD & 1 & 2 & $\mathrm{Y}$ & 39348 & 6 & 13 \\
\hline 73 & $\mathrm{M}$ & Plastic & Merged & 1 & 4 & $\mathrm{~N}$ & N/A & N/A & N/A \\
\hline 74 & $\mathrm{O}$ & Plastic & Cyano & 3 & 3 & $\mathrm{Y}$ & 1175916 & 28 & 43 \\
\hline 74 & $\mathrm{O}$ & Plastic & Cyano + MBD & 1 & 4 & $\mathrm{Y}$ & 45454 & 8 & 36 \\
\hline 74 & $\mathrm{O}$ & Plastic & Cyano + MBD & 5 & 4 & $\mathrm{Y}$ & 312648 & 21 & 36 \\
\hline 74 & $\mathrm{M}$ & Plastic & Merged & 2 & 4 & $\mathrm{Y}$ & 76275 & 15 & 30 \\
\hline 75 & $\mathrm{O}$ & Plastic & Cyano & 5 & 4 & $\mathrm{~N}$ & 37884 & 12 & 22 \\
\hline 75 & $\mathrm{O}$ & Plastic & Cyano + MBD & 1 & 4 & $\mathrm{Y}$ & 80514 & 14 & 21 \\
\hline 75 & $\mathrm{O}$ & Plastic & Cyano + MBD & 1 & 3 & $\mathrm{Y}$ & 55062 & 14 & 22 \\
\hline 75 & M & Plastic & Merged & 1 & 4 & $\mathrm{~N}$ & N/A & N/A & N/A \\
\hline 76 & $\mathrm{O}$ & Plastic & Cyano & 3 & 3 & $\mathrm{Y}$ & 417163 & 17 & 23 \\
\hline 76 & $\mathrm{O}$ & Plastic & Cyano + MBD & 1 & 4 & $\mathrm{Y}$ & 415837 & 17 & 31 \\
\hline 76 & $\mathrm{O}$ & Plastic & Cyano + MBD & 4 & 4 & $\mathrm{Y}$ & 189405 & 15 & 24 \\
\hline 76 & $\mathrm{M}$ & Plastic & Merged & 4 & 3 & $\mathrm{Y}$ & 625214 & 19 & 31 \\
\hline 77 & $\mathrm{O}$ & Plastic & Cyano & 3 & 3 & $\mathrm{Y}$ & 2440284 & 38 & 46 \\
\hline 77 & $\mathrm{O}$ & Plastic & Cyano + MBD & 1 & 3 & $\mathrm{Y}$ & 1445080 & 35 & 55 \\
\hline 77 & $\mathrm{O}$ & Plastic & Cyano + MBD & 3 & 3 & $\mathrm{Y}$ & 896396 & 31 & 58 \\
\hline 77 & $\mathrm{M}$ & Plastic & Merged & 5 & 3 & $\mathrm{Y}$ & 2046877 & 37 & 54 \\
\hline 78 & $\mathrm{O}$ & Plastic & Cyano & 3 & 3 & $\mathrm{~N}$ & N/A & N/A & N/A \\
\hline 78 & $\mathrm{O}$ & Plastic & Cyano + MBD & 4 & 3 & $\mathrm{Y}$ & 54390 & 10 & 12 \\
\hline 78 & $\mathrm{O}$ & Plastic & Cyano + MBD & 5 & 4 & N/A & N/A & N/A & N/A \\
\hline 78 & $\mathrm{M}$ & Plastic & Merged & 5 & 3 & $\mathrm{Y}$ & 56864 & 8 & 12 \\
\hline 79 & $\mathrm{O}$ & Plastic & Cyano & 3 & 4 & $\mathrm{Y}$ & 43230 & 11 & 20 \\
\hline 79 & $\mathrm{O}$ & Plastic & Cyano + MBD & 1 & 4 & $\mathrm{Y}$ & 755520 & 16 & 26 \\
\hline 79 & $\mathrm{O}$ & Plastic & Cyano + MBD & 1 & 3 & $\mathrm{Y}$ & 285810 & 21 & 32 \\
\hline 79 & $\mathrm{M}$ & Plastic & Merged & 3 & 3 & $\mathrm{Y}$ & 213018 & 13 & 30 \\
\hline 80 & $\mathrm{O}$ & Plastic & Cyano & 1 & 1 & $\mathrm{Y}$ & 14562 & 6 & 18 \\
\hline 80 & $\mathrm{O}$ & Plastic & Cyano + MBD & 4 & 2 & $\mathrm{Y}$ & 308057 & 17 & 29 \\
\hline 80 & $\mathrm{O}$ & Plastic & Cyano + MBD & 2 & 4 & $\mathrm{Y}$ & 143906 & 14 & 25 \\
\hline 80 & $\mathrm{M}$ & Plastic & Merged & 2 & 3 & $\mathrm{Y}$ & 127413 & 13 & 29 \\
\hline 81 & $\mathrm{O}$ & Plastic & Cyano & 1 & 4 & $\mathrm{Y}$ & 57830 & 10 & 18 \\
\hline 81 & $\mathrm{O}$ & Plastic & Cyano + MBD & 4 & 3 & $\mathrm{Y}$ & 252630 & 15 & 22 \\
\hline 81 & $\mathrm{O}$ & Plastic & Cyano + MBD & 1 & 4 & $\mathrm{Y}$ & 108800 & 10 & 14 \\
\hline 81 & $\mathrm{M}$ & Plastic & Merged & 5 & 3 & $\mathrm{Y}$ & 446112 & 18 & 23 \\
\hline 82 & $\mathrm{O}$ & Plastic & Cyano & 1 & 4 & $\mathrm{Y}$ & 4950880 & 20 & 32 \\
\hline
\end{tabular}




\begin{tabular}{|c|c|c|c|c|c|c|c|c|c|}
\hline 82 & $\mathrm{O}$ & Plastic & Cyano + MBD & 1 & 1 & $\mathrm{Y}$ & 375459 & 21 & 44 \\
\hline 82 & $\mathrm{O}$ & Plastic & Cyano + MBD & 5 & 3 & $\mathrm{Y}$ & 579176 & 26 & 44 \\
\hline 82 & $\mathrm{M}$ & Plastic & Merged & 5 & 3 & $\mathrm{Y}$ & 807709 & 19 & 27 \\
\hline 83 & $\mathrm{O}$ & Plastic & Cyano & 5 & 4 & $\mathrm{Y}$ & 1015680 & 30 & 47 \\
\hline 83 & $\mathrm{O}$ & Plastic & Cyano + MBD & 3 & 3 & $\mathrm{Y}$ & 792400 & 25 & 47 \\
\hline 83 & $\mathrm{O}$ & Plastic & Cyano + MBD & 2 & 4 & $\mathrm{Y}$ & 827232 & 24 & 44 \\
\hline 83 & $\mathrm{M}$ & Plastic & Merged & 5 & 3 & $\mathrm{Y}$ & 599780 & 20 & 43 \\
\hline 84 & $\mathrm{O}$ & Plastic & Cyano & 5 & 4 & $\mathrm{Y}$ & 744700 & 22 & 41 \\
\hline 84 & $\mathrm{O}$ & Plastic & Cyano + MBD & 1 & 4 & $\mathrm{Y}$ & 409222 & 19 & 39 \\
\hline 84 & $\mathrm{O}$ & Plastic & Cyano + MBD & 5 & 3 & $\mathrm{Y}$ & 608258 & 23 & 43 \\
\hline 84 & $\mathrm{M}$ & Plastic & Merged & 2 & 4 & $\mathrm{Y}$ & 196740 & 15 & 34 \\
\hline 85 & $\mathrm{O}$ & Plastic & Cyano & 4 & 4 & $\mathrm{Y}$ & 309552 & 16 & 29 \\
\hline 85 & $\mathrm{O}$ & Plastic & Cyano + MBD & 5 & 4 & $\mathrm{Y}$ & 159504 & 16 & 40 \\
\hline 85 & $\mathrm{O}$ & Plastic & Cyano + MBD & 5 & 3 & $\mathrm{Y}$ & 159860 & 10 & 23 \\
\hline 85 & $\mathrm{M}$ & Plastic & Merged & 1 & 3 & $\mathrm{Y}$ & 388580 & 20 & 42 \\
\hline 86 & $\mathrm{O}$ & Plastic & Cyano & 1 & 3 & $\mathrm{Y}$ & 3206440 & 40 & 73 \\
\hline 86 & $\mathrm{O}$ & Plastic & Cyano + MBD & 1 & 3 & $\mathrm{Y}$ & 322074 & 18 & 28 \\
\hline 86 & $\mathrm{M}$ & Plastic & Merged & 1 & 4 & $\mathrm{Y}$ & 664259 & 19 & 67 \\
\hline 87 & $\mathrm{O}$ & Plastic & Cyano & 2 & 3 & $\mathrm{Y}$ & 1462748 & 28 & 36 \\
\hline 87 & $\mathrm{O}$ & Plastic & Cyano + Rhodamine 6G & 5 & 4 & $\mathrm{Y}$ & 556358 & 22 & 30 \\
\hline 87 & $\mathrm{O}$ & Plastic & Cyano + Rhodamine 6G & 5 & 3 & $\mathrm{Y}$ & 271894 & 14 & 30 \\
\hline 87 & $\mathrm{O}$ & Plastic & Cyano + Rhodamine 6G & 1 & 4 & Y & 279633 & 17 & 25 \\
\hline 87 & $\mathrm{M}$ & Plastic & Merged & 1 & 2 & Y & 328263 & 16 & 38 \\
\hline 88 & $\mathrm{O}$ & Plastic & Cyano & 1 & 4 & $\mathrm{Y}$ & 1497300 & 42 & 65 \\
\hline 88 & $\mathrm{O}$ & Plastic & Cyano + Rhodamine $6 \mathrm{G}$ & 1 & 4 & $\mathrm{Y}$ & 1608353 & 37 & 63 \\
\hline 88 & $\mathrm{O}$ & Plastic & Cyano + Rhodamine 6G & 3 & 4 & $\mathrm{Y}$ & 1473654 & 39 & 62 \\
\hline 88 & $\mathrm{O}$ & Plastic & Cyano + Rhodamine 6G & 5 & 4 & $\mathrm{Y}$ & 1882650 & 35 & 52 \\
\hline 88 & $\mathrm{M}$ & Plastic & Merged & 1 & 3 & $\mathrm{Y}$ & 1865340 & 36 & 56 \\
\hline 89 & $\mathrm{O}$ & Plastic & Cyano & 5 & 3 & $\mathrm{Y}$ & 2124200 & 38 & 54 \\
\hline 89 & $\mathrm{O}$ & Plastic & Cyano + Rhodamine 6G & 2 & 3 & $\mathrm{Y}$ & 460377 & 27 & 46 \\
\hline 89 & $\mathrm{O}$ & Plastic & Cyano + Rhodamine 6G & 1 & 4 & $\mathrm{Y}$ & 1172195 & 23 & 48 \\
\hline 89 & $\mathrm{O}$ & Plastic & Cyano + Rhodamine 6G & 5 & 3 & $\mathrm{Y}$ & 980654 & 31 & 52 \\
\hline 89 & $\mathrm{M}$ & Plastic & Merged & 2 & 3 & $\mathrm{Y}$ & 1983934 & 43 & 57 \\
\hline 90 & $\mathrm{O}$ & Plastic & Cyano & 3 & 4 & $\mathrm{Y}$ & 1048850 & 25 & 48 \\
\hline 90 & $\mathrm{O}$ & Plastic & Cyano + Rhodamine $6 \mathrm{G}$ & 1 & 3 & $\mathrm{Y}$ & 159290 & 17 & 35 \\
\hline 90 & $\mathrm{O}$ & Plastic & Cyano + Rhodamine 6G & 1 & 3 & $\mathrm{Y}$ & 289125 & 15 & 39 \\
\hline 90 & $\mathrm{O}$ & Plastic & Cyano + Rhodamine $6 \mathrm{G}$ & 1 & 1 & $\mathrm{Y}$ & 192672 & 16 & 30 \\
\hline 90 & $\mathrm{M}$ & Plastic & Merged & 5 & 4 & $\mathrm{Y}$ & 1146912 & 24 & 48 \\
\hline 91 & $\mathrm{O}$ & Plastic & Cyano & 5 & 3 & $\mathrm{Y}$ & 2229897 & 29 & 47 \\
\hline 91 & $\mathrm{O}$ & Plastic & Cyano + Rhodamine 6G & 4 & 3 & $\mathrm{Y}$ & 198832 & 16 & 36 \\
\hline 91 & $\mathrm{O}$ & Plastic & Cyano + Rhodamine $6 \mathrm{G}$ & 5 & 4 & Y & 202635 & 15 & 39 \\
\hline 91 & $\mathrm{O}$ & Plastic & Cyano + Rhodamine 6G & 5 & 4 & Y & 319740 & 15 & 31 \\
\hline 91 & $\mathrm{M}$ & Plastic & Merged & 3 & 3 & $\mathrm{Y}$ & 623414 & 22 & 45 \\
\hline 92 & $\mathrm{O}$ & Plastic & Cyano & 3 & 3 & $\mathrm{Y}$ & 654040 & 20 & 31 \\
\hline 92 & $\mathrm{O}$ & Plastic & Cyano + Rhodamine $6 \mathrm{G}$ & 5 & 4 & $\mathrm{Y}$ & 452624 & 16 & 31 \\
\hline 92 & $\mathrm{O}$ & Plastic & Cyano + Rhodamine 6G & 2 & 3 & Y & 328600 & 20 & 31 \\
\hline 92 & $\mathrm{O}$ & Plastic & Cyano + Rhodamine 6G & 5 & 3 & $\mathrm{Y}$ & 283408 & 16 & 21 \\
\hline 92 & $\mathrm{M}$ & Plastic & Merged & 1 & 4 & $\mathrm{Y}$ & 1220525 & 25 & 36 \\
\hline 93 & $\mathrm{O}$ & Plastic & Cyano & 4 & 3 & $\mathrm{Y}$ & 409830 & 15 & 26 \\
\hline 93 & $\mathrm{O}$ & Plastic & Cyano + Rhodamine 6G & 5 & 3 & $\mathrm{~N} / \mathrm{A}$ & $\mathrm{N} / \mathrm{A}$ & $\mathrm{N} / \mathrm{A}$ & $\mathrm{N} / \mathrm{A}$ \\
\hline 93 & $\mathrm{O}$ & Plastic & Cyano + Rhodamine $6 \mathrm{G}$ & 1 & 2 & $\mathrm{~N} / \mathrm{A}$ & $\mathrm{N} / \mathrm{A}$ & $\mathrm{N} / \mathrm{A}$ & $\mathrm{N} / \mathrm{A}$ \\
\hline 93 & $\mathrm{O}$ & Plastic & Cyano + Rhodamine $6 \mathrm{G}$ & 5 & 4 & N/A & $\mathrm{N} / \mathrm{A}$ & $\mathrm{N} / \mathrm{A}$ & $\mathrm{N} / \mathrm{A}$ \\
\hline
\end{tabular}




\begin{tabular}{|c|c|c|c|c|c|c|c|c|c|}
\hline 93 & $\mathrm{M}$ & Plastic & Merged & 2 & 4 & $\mathrm{~N}$ & 10626 & 7 & 11 \\
\hline 94 & $\mathrm{O}$ & Plastic & Cyano & 2 & 3 & $\mathrm{Y}$ & 2564878 & 41 & 72 \\
\hline 94 & $\mathrm{O}$ & Plastic & Cyano + Rhodamine 6G & 3 & 3 & $\mathrm{Y}$ & 3164800 & 46 & 61 \\
\hline 94 & $\mathrm{O}$ & Plastic & Cyano + Rhodamine 6G & 5 & 4 & $\mathrm{Y}$ & 1996854 & 34 & 62 \\
\hline 94 & $\mathrm{O}$ & Plastic & Cyano + Rhodamine 6G & 2 & 4 & $\mathrm{Y}$ & 1793016 & 36 & 64 \\
\hline 94 & $\mathrm{M}$ & Plastic & Merged & 2 & 3 & $\mathrm{Y}$ & 3872127 & 53 & 70 \\
\hline 95 & $\mathrm{O}$ & Plastic & Cyano & 2 & 4 & $\mathrm{Y}$ & 719348 & 28 & 47 \\
\hline 95 & $\mathrm{O}$ & Plastic & Cyano + Rhodamine 6G & 1 & 3 & $\mathrm{Y}$ & 378325 & 25 & 38 \\
\hline 95 & $\mathrm{O}$ & Plastic & Cyano + Rhodamine 6G & 1 & 4 & $\mathrm{Y}$ & 1189725 & 25 & 41 \\
\hline 95 & $\mathrm{O}$ & Plastic & Cyano + Rhodamine 6G & 3 & 3 & $\mathrm{Y}$ & 1499524 & 26 & 34 \\
\hline 95 & $\mathrm{M}$ & Plastic & Merged & 2 & 4 & $\mathrm{Y}$ & 1133233 & 29 & 46 \\
\hline 96 & $\mathrm{O}$ & Plastic & Cyano & 5 & 4 & $\mathrm{Y}$ & 453992 & 22 & 35 \\
\hline 96 & $\mathrm{O}$ & Plastic & Cyano + Rhodamine 6G & 5 & 4 & N/A & N/A & N/A & N/A \\
\hline 96 & $\mathrm{O}$ & Plastic & Cyano + Rhodamine 6G & 5 & 3 & $\mathrm{~N}$ & N/A & N/A & N/A \\
\hline 96 & $\mathrm{O}$ & Plastic & Cyano + Rhodamine 6G & 5 & 4 & $\mathrm{~N}$ & N/A & N/A & N/A \\
\hline 96 & $\mathrm{M}$ & Plastic & Merged & 2 & 4 & $\mathrm{Y}$ & 201399 & 17 & 31 \\
\hline 97 & $\mathrm{O}$ & Plastic & Cyano & 5 & 4 & $\mathrm{Y}$ & 376125 & 25 & 49 \\
\hline 97 & $\mathrm{O}$ & Plastic & Cyano + Rhodamine 6G & 5 & 4 & $\mathrm{~N}$ & 125685 & 15 & 26 \\
\hline 97 & $\mathrm{O}$ & Plastic & Cyano + Rhodamine 6G & 5 & 4 & $\mathrm{Y}$ & 187410 & 15 & 25 \\
\hline 97 & $\mathrm{O}$ & Plastic & Cyano + Rhodamine 6G & 1 & 3 & $\mathrm{Y}$ & 128618 & 14 & 29 \\
\hline 97 & $\mathrm{M}$ & Plastic & Merged & 5 & 3 & $\mathrm{Y}$ & 197248 & 16 & 40 \\
\hline 98 & $\mathrm{O}$ & Plastic & Cyano & 1 & 2 & $\mathrm{Y}$ & 294538 & 19 & 32 \\
\hline 98 & $\mathrm{O}$ & Plastic & Cyano + Rhodamine 6G & 4 & 3 & $\mathrm{Y}$ & 203694 & 17 & 41 \\
\hline 98 & $\mathrm{O}$ & Plastic & Cyano + Rhodamine 6G & 1 & 4 & $\mathrm{Y}$ & 246780 & 18 & 40 \\
\hline 98 & $\mathrm{O}$ & Plastic & Cyano + Rhodamine 6G & 5 & 3 & $\mathrm{Y}$ & 159216 & 16 & 40 \\
\hline 98 & $\mathrm{M}$ & Plastic & Merged & 5 & 4 & $\mathrm{Y}$ & 203544 & 18 & 36 \\
\hline 99 & $\mathrm{O}$ & Plastic & Cyano & 3 & 3 & $\mathrm{~N}$ & 499882 & 23 & 38 \\
\hline 99 & $\mathrm{O}$ & Plastic & Cyano + Rhodamine 6G & 4 & 4 & $\mathrm{Y}$ & 276735 & 15 & 27 \\
\hline 99 & $\mathrm{O}$ & Plastic & Cyano + Rhodamine 6G & 5 & 4 & $\mathrm{Y}$ & 711774 & 18 & 35 \\
\hline 99 & $\mathrm{O}$ & Plastic & Cyano + Rhodamine 6G & 4 & 3 & $\mathrm{Y}$ & 238260 & 19 & 35 \\
\hline 99 & $\mathrm{M}$ & Plastic & Merged & 5 & 4 & $\mathrm{Y}$ & 461264 & 16 & 30 \\
\hline 120 & $\mathrm{O}$ & Plastic & Cyano & 4 & 4 & $\mathrm{Y}$ & 6877494 & 54 & 63 \\
\hline 120 & $\mathrm{O}$ & Plastic & Cyano + Rhodamine 6G & 1 & 3 & $\mathrm{~N}$ & N/A & $\mathrm{N} / \mathrm{A}$ & $\mathrm{N} / \mathrm{A}$ \\
\hline 120 & $\mathrm{O}$ & Plastic & Cyano + Rhodamine 6G & 5 & 4 & $\mathrm{Y}$ & 1075173 & 33 & 54 \\
\hline 120 & $\mathrm{O}$ & Plastic & Cyano + Rhodamine 6G & 3 & 3 & $\mathrm{Y}$ & 1373076 & 36 & 50 \\
\hline 120 & $\mathrm{M}$ & Plastic & Merged & 1 & 3 & $\mathrm{Y}$ & 3412510 & 46 & 58 \\
\hline 121 & $\mathrm{O}$ & Plastic & Cyano & 4 & 3 & $\mathrm{Y}$ & 6126840 & 54 & 69 \\
\hline 121 & $\mathrm{O}$ & Plastic & Cyano + Rhodamine 6G & 5 & 4 & $\mathrm{Y}$ & 2159157 & 39 & 51 \\
\hline 121 & $\mathrm{O}$ & Plastic & Cyano + Rhodamine 6G & 5 & 3 & $\mathrm{Y}$ & 4778960 & 47 & 64 \\
\hline 121 & $\mathrm{O}$ & Plastic & Cyano + Rhodamine 6G & 1 & 4 & $\mathrm{Y}$ & 3253624 & 44 & 61 \\
\hline 121 & $\mathrm{M}$ & Plastic & Merged & 1 & 4 & $\mathrm{Y}$ & 3926610 & 45 & 58 \\
\hline 122 & $\mathrm{O}$ & Plastic & Cyano & 4 & 4 & $\mathrm{Y}$ & 9802572 & 62 & 72 \\
\hline 122 & $\mathrm{O}$ & Plastic & Cyano + Rhodamine 6G & 5 & 3 & $\mathrm{Y}$ & 2460990 & 35 & 51 \\
\hline 122 & $\mathrm{O}$ & Plastic & Cyano + Rhodamine 6G & 1 & 4 & $\mathrm{Y}$ & 4453830 & 51 & 63 \\
\hline 122 & $\mathrm{O}$ & Plastic & Cyano + Rhodamine 6G & 1 & 4 & $\mathrm{Y}$ & 4965615 & 51 & 65 \\
\hline 122 & $\mathrm{M}$ & Plastic & Merged & 1 & 3 & $\mathrm{Y}$ & 9999999 & 63 & 78 \\
\hline 123 & $\mathrm{O}$ & Plastic & Cyano & 5 & 4 & $\mathrm{Y}$ & 6358688 & 56 & 71 \\
\hline 123 & $\mathrm{O}$ & Plastic & Cyano + Rhodamine 6G & 5 & 4 & $\mathrm{~N}$ & 255238 & 17 & 40 \\
\hline 123 & $\mathrm{O}$ & Plastic & Cyano + Rhodamine 6G & 5 & 4 & $\mathrm{Y}$ & 1969434 & 27 & 51 \\
\hline 123 & $\mathrm{O}$ & Plastic & Cyano + Rhodamine 6G & 1 & 4 & $\mathrm{Y}$ & 5815940 & 52 & 62 \\
\hline 123 & $\mathrm{M}$ & Plastic & Merged & 4 & 4 & $\mathrm{Y}$ & 3467142 & 49 & 61 \\
\hline 124 & $\mathrm{O}$ & Plastic & Cyano & 2 & 3 & $\mathrm{Y}$ & 1962741 & 33 & 58 \\
\hline
\end{tabular}




\begin{tabular}{|c|c|c|c|c|c|c|c|c|c|}
\hline 124 & $\mathrm{O}$ & Plastic & Cyano + Rhodamine 6G & 2 & 3 & $\mathrm{Y}$ & 769522 & 26 & 40 \\
\hline 124 & $\mathrm{O}$ & Plastic & Cyano + Rhodamine 6G & 1 & 4 & $\mathrm{Y}$ & 2411838 & 33 & 46 \\
\hline 124 & $\mathrm{O}$ & Plastic & Cyano + Rhodamine 6G & 3 & 3 & $\mathrm{Y}$ & 2585255 & 41 & 53 \\
\hline 124 & $\mathrm{M}$ & Plastic & Merged & 5 & 4 & $\mathrm{Y}$ & 492000 & 30 & 49 \\
\hline 125 & $\mathrm{O}$ & Plastic & Cyano & 3 & 3 & $\mathrm{Y}$ & 547620 & 30 & 52 \\
\hline 125 & $\mathrm{O}$ & Plastic & Cyano + Rhodamine 6G & 5 & 3 & $\mathrm{Y}$ & 154784 & 16 & 30 \\
\hline 125 & $\mathrm{O}$ & Plastic & Cyano + Rhodamine 6G & 5 & 3 & $\mathrm{~N}$ & N/A & N/A & N/A \\
\hline 125 & $\mathrm{O}$ & Plastic & Cyano + Rhodamine 6G & 2 & 3 & $\mathrm{~N}$ & 100512 & 16 & 32 \\
\hline 125 & $\mathrm{M}$ & Plastic & Merged & 4 & 3 & $\mathrm{Y}$ & 662920 & 20 & 36 \\
\hline 126 & $\mathrm{O}$ & Plastic & Cyano & 4 & 4 & $\mathrm{Y}$ & 3432518 & 43 & 60 \\
\hline 126 & $\mathrm{O}$ & Plastic & Cyano + Rhodamine 6G & 1 & 3 & $\mathrm{Y}$ & 3820421 & 43 & 56 \\
\hline 126 & $\mathrm{O}$ & Plastic & Cyano + Rhodamine 6G & 1 & 3 & $\mathrm{Y}$ & 1849392 & 27 & 35 \\
\hline 126 & $\mathrm{O}$ & Plastic & Cyano + Rhodamine 6G & 5 & 3 & $\mathrm{Y}$ & 1956782 & 37 & 48 \\
\hline 126 & $\mathrm{M}$ & Plastic & Merged & 3 & 3 & $\mathrm{Y}$ & 3223600 & 40 & 62 \\
\hline 127 & $\mathrm{O}$ & Plastic & Cyano & 1 & 3 & $\mathrm{Y}$ & 1144330 & 22 & 56 \\
\hline 127 & $\mathrm{O}$ & Plastic & Cyano + Rhodamine 6G & 5 & 3 & $\mathrm{Y}$ & 878725 & 25 & 36 \\
\hline 127 & $\mathrm{O}$ & Plastic & Cyano + Rhodamine 6G & 2 & 4 & $\mathrm{Y}$ & 999288 & 24 & 39 \\
\hline 127 & $\mathrm{O}$ & Plastic & Cyano + Rhodamine 6G & 3 & 3 & $\mathrm{Y}$ & 454938 & 22 & 33 \\
\hline 127 & $\mathrm{M}$ & Plastic & Merged & 5 & 3 & $\mathrm{Y}$ & 915095 & 29 & 54 \\
\hline 128 & $\mathrm{O}$ & Plastic & Cyano & 2 & 4 & $\mathrm{Y}$ & 3798144 & 42 & 60 \\
\hline 128 & $\mathrm{O}$ & Plastic & Cyano + Rhodamine 6G & 5 & 4 & $\mathrm{Y}$ & 257124 & 19 & 33 \\
\hline 128 & $\mathrm{O}$ & Plastic & Cyano + Rhodamine 6G & 5 & 3 & $\mathrm{Y}$ & 630683 & 23 & 38 \\
\hline 128 & $\mathrm{O}$ & Plastic & Cyano + Rhodamine 6G & 1 & 4 & $\mathrm{Y}$ & 1282873 & 29 & 42 \\
\hline 128 & $\mathrm{M}$ & Plastic & Merged & 5 & 4 & $\mathrm{Y}$ & 728620 & 20 & 32 \\
\hline 129 & $\mathrm{O}$ & Plastic & Cyano & 5 & 4 & $\mathrm{Y}$ & 3457079 & 41 & 51 \\
\hline 129 & $\mathrm{O}$ & Plastic & Cyano + Rhodamine 6G & 5 & 4 & $\mathrm{Y}$ & 4713236 & 44 & 48 \\
\hline 129 & $\mathrm{O}$ & Plastic & Cyano + Rhodamine 6G & 5 & 3 & $\mathrm{Y}$ & 3214440 & 40 & 47 \\
\hline 129 & $\mathrm{O}$ & Plastic & Cyano + Rhodamine 6G & 5 & 4 & $\mathrm{Y}$ & 2700445 & 37 & 47 \\
\hline 129 & $\mathrm{M}$ & Plastic & Merged & 1 & 4 & $\mathrm{Y}$ & 3757776 & 44 & 45 \\
\hline 130 & $\mathrm{O}$ & Plastic & Cyano & 5 & 4 & $\mathrm{Y}$ & 2078571 & 33 & 49 \\
\hline 130 & $\mathrm{O}$ & Plastic & Cyano + Rhodamine 6G & 1 & 3 & $\mathrm{Y}$ & 2080080 & 30 & 47 \\
\hline 130 & $\mathrm{O}$ & Plastic & Cyano + Rhodamine 6G & 1 & 4 & $\mathrm{Y}$ & 1891131 & 33 & 48 \\
\hline 130 & $\mathrm{O}$ & Plastic & Cyano + Rhodamine $6 \mathrm{G}$ & 1 & 3 & $\mathrm{Y}$ & 1330210 & 31 & 45 \\
\hline 130 & $\mathrm{M}$ & Plastic & Merged & 2 & 3 & $\mathrm{Y}$ & 1883343 & 31 & 45 \\
\hline 131 & $\mathrm{O}$ & Plastic & Cyano & 1 & 3 & $\mathrm{Y}$ & 1524570 & 30 & 46 \\
\hline 131 & $\mathrm{O}$ & Plastic & Cyano + Rhodamine 6G & 5 & 3 & $\mathrm{Y}$ & 794460 & 20 & 36 \\
\hline 131 & $\mathrm{O}$ & Plastic & Cyano + Rhodamine 6G & 5 & 3 & $\mathrm{Y}$ & 968968 & 22 & 40 \\
\hline 131 & $\mathrm{O}$ & Plastic & Cyano + Rhodamine 6G & 3 & 4 & $\mathrm{Y}$ & 836945 & 27 & 45 \\
\hline 131 & $\mathrm{M}$ & Plastic & Merged & 1 & 4 & $\mathrm{Y}$ & 1052942 & 22 & 44 \\
\hline 132 & $\mathrm{O}$ & Plastic & Cyano & 4 & 4 & $\mathrm{Y}$ & 366054 & 19 & 42 \\
\hline 132 & $\mathrm{O}$ & Plastic & Cyano + Rhodamine $6 \mathrm{G}$ & 2 & 3 & $\mathrm{Y}$ & 388269 & 21 & 53 \\
\hline 132 & $\mathrm{O}$ & Plastic & Cyano + Rhodamine 6G & 5 & 4 & $\mathrm{Y}$ & 506023 & 23 & 31 \\
\hline 132 & $\mathrm{O}$ & Plastic & Cyano + Rhodamine 6G & 4 & 3 & $\mathrm{Y}$ & 300504 & 19 & 37 \\
\hline 132 & $\mathrm{M}$ & Plastic & Merged & 1 & 3 & $\mathrm{Y}$ & 426456 & 24 & 44 \\
\hline 133 & $\mathrm{O}$ & Plastic & Cyano & 5 & 4 & $\mathrm{Y}$ & 544103 & 19 & 38 \\
\hline 133 & $\mathrm{O}$ & Plastic & Cyano + Rhodamine 6G & 5 & 3 & $\mathrm{~N}$ & N/A & N/A & $\mathrm{N} / \mathrm{A}$ \\
\hline 133 & $\mathrm{O}$ & Plastic & Cyano + Rhodamine 6G & 1 & 4 & $\mathrm{Y}$ & 100485 & 11 & 25 \\
\hline 133 & $\mathrm{O}$ & Plastic & Cyano + Rhodamine 6G & 1 & 3 & $\mathrm{Y}$ & 118720 & 14 & 24 \\
\hline 133 & $\mathrm{M}$ & Plastic & Merged & 5 & 3 & $\mathrm{Y}$ & 259726 & 17 & 33 \\
\hline 134 & $\mathrm{O}$ & Plastic & Cyano & 2 & 4 & $\mathrm{Y}$ & 2799664 & 49 & 72 \\
\hline 134 & $\mathrm{O}$ & Plastic & Cyano + Rhodamine $6 \mathrm{G}$ & 5 & 4 & $\mathrm{Y}$ & 326135 & 19 & 32 \\
\hline 134 & $\mathrm{O}$ & Plastic & Cyano + Rhodamine $6 \mathrm{G}$ & 1 & 3 & $\mathrm{Y}$ & 402200 & 25 & 31 \\
\hline
\end{tabular}




\begin{tabular}{|c|c|c|c|c|c|c|c|c|c|}
\hline 134 & $\mathrm{O}$ & Plastic & Cyano + Rhodamine 6G & 1 & 4 & $\mathrm{Y}$ & 545076 & 27 & 39 \\
\hline 134 & $\mathrm{M}$ & Plastic & Merged & 5 & 2 & $\mathrm{Y}$ & 1584448 & 38 & 58 \\
\hline 135 & $\mathrm{O}$ & Plastic & Cyano & 5 & 4 & $\mathrm{Y}$ & 2481320 & 34 & 62 \\
\hline 135 & $\mathrm{O}$ & Plastic & Cyano + Rhodamine 6G & 5 & 4 & $\mathrm{Y}$ & 1528227 & 27 & 55 \\
\hline 135 & $\mathrm{O}$ & Plastic & Cyano + Rhodamine 6G & 1 & 3 & $\mathrm{Y}$ & 1656116 & 28 & 61 \\
\hline 135 & $\mathrm{O}$ & Plastic & Cyano + Rhodamine 6G & 1 & 3 & $\mathrm{Y}$ & 2396352 & 32 & 63 \\
\hline 135 & $\mathrm{M}$ & Plastic & Merged & 2 & 3 & $\mathrm{Y}$ & 2158704 & 38 & 61 \\
\hline 136 & $\mathrm{O}$ & Plastic & Cyano & 5 & 3 & $\mathrm{Y}$ & 2127177 & 39 & 68 \\
\hline 136 & $\mathrm{O}$ & Plastic & Cyano + Rhodamine 6G & 4 & 3 & $\mathrm{Y}$ & 3216450 & 41 & 67 \\
\hline 136 & $\mathrm{O}$ & Plastic & Cyano + Rhodamine 6G & 1 & 4 & $\mathrm{Y}$ & 1699936 & 32 & 64 \\
\hline 136 & $\mathrm{O}$ & Plastic & Cyano + Rhodamine 6G & 2 & 3 & $\mathrm{Y}$ & 1493600 & 32 & 53 \\
\hline 136 & $\mathrm{M}$ & Plastic & Merged & 1 & 4 & $\mathrm{Y}$ & 2671536 & 42 & 75 \\
\hline 137 & $\mathrm{O}$ & Glass & Cyano & 4 & 4 & $\mathrm{~N}$ & N/A & N/A & N/A \\
\hline 137 & $\mathrm{O}$ & Glass & Cyano + Basic Red 28 & 5 & 4 & $\mathrm{~N}$ & N/A & N/A & N/A \\
\hline 137 & $\mathrm{O}$ & Glass & Cyano + Basic Red 28 & 3 & 4 & $\mathrm{Y}$ & 82719 & 13 & 43 \\
\hline 137 & $\mathrm{O}$ & Glass & Cyano + Basic Red 28 & 1 & 4 & $\mathrm{Y}$ & 123102 & 14 & 34 \\
\hline 137 & $\mathrm{M}$ & Glass & Merged & 2 & 1 & $\mathrm{~N}$ & N/A & N/A & N/A \\
\hline 138 & $\mathrm{O}$ & Glass & Cyano & 1 & 3 & $\mathrm{Y}$ & 67444 & 13 & 30 \\
\hline 138 & $\mathrm{O}$ & Glass & Cyano + Basic Red 28 & 3 & 4 & $\mathrm{~N}$ & N/A & N/A & N/A \\
\hline 138 & $\mathrm{O}$ & Glass & Cyano + Basic Red 28 & 1 & 4 & $\mathrm{~N}$ & N/A & N/A & N/A \\
\hline 138 & $\mathrm{O}$ & Glass & Cyano + Basic Red 28 & 4 & 3 & $\mathrm{Y}$ & 131220 & 15 & 42 \\
\hline 138 & $\mathrm{M}$ & Glass & Merged & 1 & 4 & $\mathrm{Y}$ & 191862 & 19 & 48 \\
\hline 139 & $\mathrm{O}$ & Glass & Cyano & 5 & 4 & $\mathrm{Y}$ & 101235 & 17 & 51 \\
\hline 139 & $\mathrm{O}$ & Glass & Cyano + Basic Red 28 & 1 & 3 & $\mathrm{~N}$ & $\mathrm{~N} / \mathrm{A}$ & $\mathrm{N} / \mathrm{A}$ & $\mathrm{N} / \mathrm{A}$ \\
\hline 139 & $\mathrm{O}$ & Glass & Cyano + Basic Red 28 & 1 & 4 & $\mathrm{Y}$ & 94425 & 15 & 40 \\
\hline 139 & $\mathrm{O}$ & Glass & Cyano + Basic Red 28 & 3 & 3 & $\mathrm{~N}$ & N/A & N/A & N/A \\
\hline 139 & M & Glass & Merged & 2 & 4 & $\mathrm{Y}$ & 51077 & 13 & 40 \\
\hline 140 & $\mathrm{O}$ & Glass & Cyano & 3 & 2 & $\mathrm{Y}$ & 64768 & 8 & 31 \\
\hline 140 & $\mathrm{O}$ & Glass & Cyano + Basic Red 28 & 4 & 3 & $\mathrm{~N}$ & N/A & N/A & $\mathrm{N} / \mathrm{A}$ \\
\hline 140 & $\mathrm{O}$ & Glass & Cyano + Basic Red 28 & 1 & 4 & $\mathrm{Y}$ & 115120 & 16 & 42 \\
\hline 140 & $\mathrm{O}$ & Glass & Cyano + Basic Red 28 & 4 & 4 & $\mathrm{Y}$ & 113595 & 15 & 42 \\
\hline 140 & $\mathrm{M}$ & Glass & Merged & 2 & 3 & $\mathrm{~N}$ & $\mathrm{~N} / \mathrm{A}$ & $\mathrm{N} / \mathrm{A}$ & $\mathrm{N} / \mathrm{A}$ \\
\hline 141 & $\mathrm{O}$ & Glass & Cyano & 2 & 4 & $\mathrm{~N}$ & $\mathrm{~N} / \mathrm{A}$ & N/A & $\mathrm{N} / \mathrm{A}$ \\
\hline 141 & $\mathrm{O}$ & Glass & Cyano + Basic Red 28 & 5 & 2 & $\mathrm{~N}$ & N/A & N/A & $\mathrm{N} / \mathrm{A}$ \\
\hline 141 & $\mathrm{O}$ & Glass & Cyano + Basic Red 28 & 3 & 4 & $\mathrm{Y}$ & 83160 & 11 & 49 \\
\hline 141 & $\mathrm{O}$ & Glass & Cyano + Basic Red 28 & 1 & 4 & $\mathrm{~N}$ & 62835 & 15 & 49 \\
\hline 141 & $M$ & Glass & Merged & 1 & 3 & $\mathrm{Y}$ & 82815 & 15 & 45 \\
\hline 142 & $\mathrm{O}$ & Glass & Cyano & 1 & 3 & $\mathrm{Y}$ & 1233981 & 27 & 39 \\
\hline 142 & $\mathrm{O}$ & Glass & Cyano + Basic Red 28 & 5 & 4 & $\mathrm{Y}$ & 700425 & 33 & 43 \\
\hline 142 & $\mathrm{O}$ & Glass & Cyano + Basic Red 28 & 5 & 4 & $\mathrm{Y}$ & 1130942 & 31 & 41 \\
\hline 142 & $\mathrm{O}$ & Glass & Cyano + Basic Red 28 & 1 & 4 & $\mathrm{Y}$ & 454572 & 27 & 43 \\
\hline 142 & $\mathrm{M}$ & Glass & Merged & 1 & 4 & $\mathrm{Y}$ & 1446048 & 32 & 41 \\
\hline 143 & $\mathrm{O}$ & Glass & Cyano & 2 & 4 & $\mathrm{~N}$ & 41382 & 11 & 34 \\
\hline 143 & $\mathrm{O}$ & Glass & Cyano + Basic Red 28 & 4 & 3 & $\mathrm{Y}$ & 181441 & 13 & 47 \\
\hline 143 & $\mathrm{O}$ & Glass & Cyano + Basic Red 28 & 1 & 4 & $\mathrm{Y}$ & 84370 & 11 & 48 \\
\hline 143 & $\mathrm{O}$ & Glass & Cyano + Basic Red 28 & 2 & 3 & $\mathrm{~N}$ & $\mathrm{~N} / \mathrm{A}$ & N/A & $\mathrm{N} / \mathrm{A}$ \\
\hline 143 & $\mathrm{M}$ & Glass & Merged & 3 & 3 & $\mathrm{Y}$ & 58707 & 11 & 38 \\
\hline 144 & $\mathrm{O}$ & Glass & Cyano & 5 & 4 & $\mathrm{Y}$ & 95863 & 17 & 36 \\
\hline 144 & $\mathrm{O}$ & Glass & Cyano + Basic Red 28 & 2 & 4 & $\mathrm{~N}$ & 39127 & 11 & 43 \\
\hline 144 & $\mathrm{O}$ & Glass & Cyano + Basic Red 28 & 2 & 4 & $\mathrm{Y}$ & 268656 & 12 & 44 \\
\hline 144 & $\mathrm{O}$ & Glass & Cyano + Basic Red 28 & 2 & 3 & $\mathrm{Y}$ & 93119 & 13 & 39 \\
\hline 144 & $\mathrm{M}$ & Glass & Merged & 1 & 4 & $\mathrm{Y}$ & 37770 & 10 & 31 \\
\hline
\end{tabular}




\begin{tabular}{|c|c|c|c|c|c|c|c|c|c|}
\hline 145 & $\mathrm{O}$ & Glass & Cyano & 1 & 4 & $\mathrm{~N}$ & 30074 & 11 & 33 \\
\hline 145 & $\mathrm{O}$ & Glass & Cyano + Basic Red 28 & 5 & 4 & $\mathrm{~N}$ & N/A & N/A & N/A \\
\hline 145 & $\mathrm{O}$ & Glass & Cyano + Basic Red 28 & 5 & 4 & $\mathrm{Y}$ & 295108 & 22 & 48 \\
\hline 145 & $\mathrm{O}$ & Glass & Cyano + Basic Red 28 & 4 & 2 & $\mathrm{Y}$ & 58430 & 10 & 41 \\
\hline 145 & M & Glass & Merged & 3 & 4 & $\mathrm{Y}$ & 89712 & 14 & 44 \\
\hline 146 & $\mathrm{O}$ & Glass & Cyano & 4 & 4 & $\mathrm{Y}$ & 586700 & 20 & 46 \\
\hline 146 & $\mathrm{O}$ & Glass & Cyano + Basic Red 28 & 5 & 4 & $\mathrm{Y}$ & 669922 & 22 & 46 \\
\hline 146 & $\mathrm{O}$ & Glass & Cyano + Basic Red 28 & 2 & 3 & $\mathrm{Y}$ & 378735 & 21 & 55 \\
\hline 146 & $\mathrm{O}$ & Glass & Cyano + Basic Red 28 & 2 & 3 & $\mathrm{Y}$ & 475250 & 25 & 53 \\
\hline 146 & $\mathrm{M}$ & Glass & Merged & 3 & 4 & $\mathrm{Y}$ & 637924 & 28 & 52 \\
\hline 147 & $\mathrm{O}$ & Glass & Cyano & 1 & 3 & $\mathrm{Y}$ & 211701 & 17 & 53 \\
\hline 147 & $\mathrm{O}$ & Glass & Cyano + Basic Red 28 & 5 & 3 & $\mathrm{Y}$ & 366344 & 22 & 53 \\
\hline 147 & $\mathrm{O}$ & Glass & Cyano + Basic Red 28 & 5 & 4 & $\mathrm{Y}$ & 1070336 & 32 & 56 \\
\hline 147 & $\mathrm{O}$ & Glass & Cyano + Basic Red 28 & 1 & 3 & $\mathrm{Y}$ & 399968 & 15 & 59 \\
\hline 147 & $\mathrm{M}$ & Glass & Merged & 1 & 3 & $\mathrm{Y}$ & 408768 & 24 & 57 \\
\hline 148 & $\mathrm{O}$ & Glass & Cyano & 2 & 2 & $\mathrm{Y}$ & 346736 & 26 & 54 \\
\hline 148 & $\mathrm{O}$ & Glass & Cyano + Basic Red 28 & 4 & 4 & $\mathrm{Y}$ & 728838 & 27 & 60 \\
\hline 148 & $\mathrm{O}$ & Glass & Cyano + Basic Red 28 & 5 & 4 & $\mathrm{Y}$ & 972475 & 35 & 59 \\
\hline 148 & $\mathrm{O}$ & Glass & Cyano + Basic Red 28 & 4 & 3 & $\mathrm{Y}$ & 346786 & 22 & 53 \\
\hline 148 & $\mathrm{M}$ & Glass & Merged & 5 & 4 & $\mathrm{Y}$ & 307608 & 21 & 55 \\
\hline 149 & $\mathrm{O}$ & Glass & Cyano & 4 & 4 & $\mathrm{Y}$ & 1296800 & 32 & 59 \\
\hline 149 & $\mathrm{O}$ & Glass & Cyano + Basic Red 28 & 1 & 3 & $\mathrm{Y}$ & 524016 & 24 & 62 \\
\hline 149 & $\mathrm{O}$ & Glass & Cyano + Basic Red 28 & 5 & 3 & $\mathrm{Y}$ & 820204 & 28 & 56 \\
\hline 149 & $\mathrm{O}$ & Glass & Cyano + Basic Red 28 & 5 & 4 & $\mathrm{Y}$ & 562764 & 23 & 57 \\
\hline 149 & $\mathrm{M}$ & Glass & Merged & 4 & 3 & $\mathrm{Y}$ & 68757 & 13 & 46 \\
\hline 150 & $\mathrm{O}$ & Glass & Cyano & 1 & 3 & $\mathrm{Y}$ & 329023 & 19 & 58 \\
\hline 150 & $\mathrm{O}$ & Glass & Cyano + Basic Red 28 & 5 & 3 & $\mathrm{Y}$ & 645030 & 27 & 59 \\
\hline 150 & $\mathrm{O}$ & Glass & Cyano + Basic Red 28 & 5 & 3 & $\mathrm{Y}$ & 380673 & 23 & 57 \\
\hline 150 & $\mathrm{O}$ & Glass & Cyano + Basic Red 28 & 1 & 4 & $\mathrm{Y}$ & 708630 & 25 & 62 \\
\hline 150 & $\mathrm{O}$ & Glass & Cyano + Basic Red 28 & 5 & 4 & $\mathrm{Y}$ & 721008 & 24 & 61 \\
\hline 150 & $\mathrm{M}$ & Glass & Merged & 3 & 3 & $\mathrm{Y}$ & 393652 & 28 & 60 \\
\hline 151 & $\mathrm{O}$ & Glass & Cyano & 5 & 4 & $\mathrm{Y}$ & 410020 & 19 & 39 \\
\hline 151 & $\mathrm{O}$ & Glass & Cyano + Basic Red 28 & 5 & 3 & $\mathrm{Y}$ & 689568 & 24 & 45 \\
\hline 151 & $\mathrm{O}$ & Glass & Cyano + Basic Red 28 & 5 & 4 & $\mathrm{Y}$ & 692050 & 25 & 53 \\
\hline 151 & M & Glass & Merged & 5 & 4 & $\mathrm{Y}$ & 488950 & 22 & 51 \\
\hline 152 & $\mathrm{O}$ & Glass & Cyano & 2 & 4 & $\mathrm{Y}$ & 404092 & 26 & 47 \\
\hline 152 & $\mathrm{O}$ & Glass & Cyano + Basic Red 28 & 5 & 3 & $\mathrm{Y}$ & 447668 & 26 & 46 \\
\hline 152 & $\mathrm{O}$ & Glass & Cyano + Basic Red 28 & 1 & 4 & $\mathrm{Y}$ & 472600 & 25 & 54 \\
\hline 152 & $\mathrm{O}$ & Glass & Cyano + Basic Red 28 & 1 & 3 & $\mathrm{Y}$ & 458514 & 21 & 48 \\
\hline 152 & $\mathrm{M}$ & Glass & Merged & 1 & 4 & $\mathrm{Y}$ & 385871 & 23 & 42 \\
\hline 153 & $\mathrm{O}$ & Glass & Cyano & 5 & 4 & $\mathrm{Y}$ & 63908 & 13 & 46 \\
\hline 153 & $\mathrm{O}$ & Glass & Cyano + Basic Red 28 & 5 & 3 & $\mathrm{~N}$ & $\mathrm{~N} / \mathrm{A}$ & $\mathrm{N} / \mathrm{A}$ & $\mathrm{N} / \mathrm{A}$ \\
\hline 153 & $\mathrm{O}$ & Glass & Cyano + Basic Red 28 & 5 & 4 & $\mathrm{~N}$ & 92036 & 14 & 55 \\
\hline 153 & $\mathrm{O}$ & Glass & Cyano + Basic Red 28 & 3 & 3 & $\mathrm{Y}$ & 57918 & 14 & 55 \\
\hline 153 & $\mathrm{M}$ & Glass & Merged & 1 & 3 & $\mathrm{~N}$ & 46981 & 11 & 56 \\
\hline 154 & $\mathrm{O}$ & Glass & Cyano & 5 & 4 & $\mathrm{Y}$ & 332325 & 25 & 52 \\
\hline 154 & $\mathrm{O}$ & Glass & Cyano + Basic Red 28 & 5 & 3 & $\mathrm{Y}$ & 1700480 & 32 & 50 \\
\hline 154 & $\mathrm{O}$ & Glass & Cyano + Basic Red 28 & 5 & 4 & $\mathrm{Y}$ & 1599708 & 33 & 55 \\
\hline 154 & $\mathrm{O}$ & Glass & Cyano + Basic Red 28 & 4 & 3 & $\mathrm{Y}$ & 292201 & 19 & 50 \\
\hline 154 & $\mathrm{M}$ & Glass & Merged & 5 & 4 & $\mathrm{Y}$ & 1283040 & 30 & 54 \\
\hline 155 & $\mathrm{O}$ & Glass & Cyano & 3 & 3 & $\mathrm{Y}$ & 879240 & 34 & 57 \\
\hline 155 & $\mathrm{O}$ & Glass & Cyano + Basic Red 28 & 5 & 4 & $\mathrm{Y}$ & 446952 & 22 & 55 \\
\hline
\end{tabular}




\begin{tabular}{|c|c|c|c|c|c|c|c|c|c|}
\hline 155 & $\mathrm{O}$ & Glass & Cyano + Basic Red 28 & 5 & 4 & $\mathrm{Y}$ & 466284 & 21 & 58 \\
\hline 155 & $\mathrm{O}$ & Glass & Cyano + Basic Red 28 & 4 & 4 & $\mathrm{Y}$ & 504609 & 21 & 51 \\
\hline 155 & $\mathrm{M}$ & Glass & Merged & 1 & 3 & $\mathrm{Y}$ & 569400 & 24 & 55 \\
\hline 156 & $\mathrm{O}$ & Glass & Cyano & 5 & 2 & $\mathrm{Y}$ & 515788 & 26 & 54 \\
\hline 156 & $\mathrm{O}$ & Glass & Cyano + Basic Red 28 & 5 & 4 & $\mathrm{Y}$ & 126405 & 15 & 50 \\
\hline 156 & $\mathrm{O}$ & Glass & Cyano + Basic Red 28 & 5 & 4 & $\mathrm{Y}$ & 208164 & 19 & 52 \\
\hline 156 & $\mathrm{O}$ & Glass & Cyano + Basic Red 28 & 1 & 4 & $\mathrm{Y}$ & 137880 & 20 & 50 \\
\hline 156 & $\mathrm{M}$ & Glass & Merged & 1 & 4 & $\mathrm{Y}$ & 187188 & 19 & 48 \\
\hline 157 & $\mathrm{O}$ & Glass & Cyano & 1 & 4 & $\mathrm{Y}$ & 118807 & 13 & 40 \\
\hline 157 & $\mathrm{O}$ & Glass & Cyano + Basic Red 28 & 5 & 4 & $\mathrm{Y}$ & 71862 & 14 & 46 \\
\hline 157 & $\mathrm{O}$ & Glass & Cyano + Basic Red 28 & 4 & 4 & $\mathrm{~N}$ & 60330 & 6 & 43 \\
\hline 157 & $\mathrm{O}$ & Glass & Cyano + Basic Red 28 & 1 & 3 & $\mathrm{~N}$ & N/A & N/A & N/A \\
\hline 157 & M & Glass & Merged & 1 & 2 & $\mathrm{~N}$ & 62460 & 10 & 45 \\
\hline 158 & $\mathrm{O}$ & Glass & Cyano & 4 & 3 & $\mathrm{Y}$ & 744540 & 30 & 55 \\
\hline 158 & $\mathrm{O}$ & Glass & Cyano + Basic Red 28 & 5 & 4 & $\mathrm{Y}$ & 339411 & 23 & 54 \\
\hline 158 & $\mathrm{O}$ & Glass & Cyano + Basic Red 28 & 2 & 3 & $\mathrm{Y}$ & 128928 & 16 & 53 \\
\hline 158 & $\mathrm{O}$ & Glass & Cyano + Basic Red 28 & 4 & 3 & $\mathrm{Y}$ & 101040 & 15 & 50 \\
\hline 158 & $\mathrm{M}$ & Glass & Merged & 3 & 3 & $\mathrm{Y}$ & 289199 & 19 & 51 \\
\hline 159 & $\mathrm{O}$ & Glass & Cyano & 5 & 4 & $\mathrm{Y}$ & 1163650 & 25 & 51 \\
\hline 159 & $\mathrm{O}$ & Glass & Cyano + Basic Red 28 & 5 & 4 & $\mathrm{Y}$ & 345296 & 14 & 49 \\
\hline 159 & $\mathrm{O}$ & Glass & Cyano + Basic Red 28 & 1 & 4 & $\mathrm{Y}$ & 285192 & 24 & 47 \\
\hline 159 & $\mathrm{O}$ & Glass & Cyano + Basic Red 28 & 3 & 3 & $\mathrm{Y}$ & 299418 & 21 & 44 \\
\hline 159 & $\mathrm{M}$ & Glass & Merged & 1 & 4 & $\mathrm{Y}$ & 243348 & 21 & 46 \\
\hline 160 & $\mathrm{O}$ & Glass & Cyano & 3 & 4 & $\mathrm{~N}$ & N/A & N/A & N/A \\
\hline 160 & $\mathrm{O}$ & Glass & Cyano + Basic Red 28 & 3 & 3 & $\mathrm{~N}$ & N/A & N/A & N/A \\
\hline 160 & $\mathrm{O}$ & Glass & Cyano + Basic Red 28 & 5 & 4 & $\mathrm{~N}$ & N/A & N/A & N/A \\
\hline 160 & $\mathrm{O}$ & Glass & Cyano + Basic Red 28 & 3 & 3 & $\mathrm{~N}$ & N/A & N/A & $\mathrm{N} / \mathrm{A}$ \\
\hline 160 & $\mathrm{M}$ & Glass & Merged & 3 & 4 & $\mathrm{~N}$ & 32983 & 6 & 50 \\
\hline 161 & $\mathrm{O}$ & Glass & Cyano & 2 & 4 & $\mathrm{~N}$ & 60630 & 15 & 50 \\
\hline 161 & $\mathrm{O}$ & Glass & Cyano + Basic Red 28 & 5 & 3 & $\mathrm{~N}$ & N/A & N/A & N/A \\
\hline 161 & $\mathrm{O}$ & Glass & Cyano + Basic Red 28 & 5 & 3 & $\mathrm{Y}$ & 111202 & 14 & 51 \\
\hline 161 & $\mathrm{O}$ & Glass & Cyano + Basic Red 28 & 4 & 4 & $\mathrm{~N}$ & 51160 & 10 & 44 \\
\hline 161 & M & Glass & Merged & 1 & 3 & $\mathrm{~N}$ & 66274 & 13 & 47 \\
\hline 162 & $\mathrm{O}$ & Glass & Cyano & 4 & 4 & $\mathrm{Y}$ & 163240 & 14 & 48 \\
\hline 162 & $\mathrm{O}$ & Glass & Cyano + Basic Red 28 & 5 & 3 & $\mathrm{Y}$ & 152677 & 17 & 54 \\
\hline 162 & $\mathrm{O}$ & Glass & Cyano + Basic Red 28 & 2 & 4 & $\mathrm{Y}$ & 339045 & 21 & 54 \\
\hline 162 & $\mathrm{O}$ & Glass & Cyano + Basic Red 28 & 1 & 4 & $\mathrm{Y}$ & 91168 & 11 & 44 \\
\hline 162 & $\mathrm{M}$ & Glass & Merged & 1 & 4 & $\mathrm{Y}$ & 197049 & 19 & 57 \\
\hline 163 & $\mathrm{O}$ & Glass & Cyano & 1 & 4 & $\mathrm{Y}$ & 615725 & 25 & 52 \\
\hline 163 & $\mathrm{O}$ & Glass & Cyano + Basic Red 28 & 5 & 4 & $\mathrm{Y}$ & 736668 & 27 & 56 \\
\hline 163 & $\mathrm{O}$ & Glass & Cyano + Basic Red 28 & 2 & 3 & $\mathrm{Y}$ & 672917 & 31 & 53 \\
\hline 163 & $\mathrm{O}$ & Glass & Cyano + Basic Red 28 & 4 & 4 & $\mathrm{Y}$ & 71907 & 11 & 46 \\
\hline 163 & $\mathrm{M}$ & Glass & Merged & 5 & 4 & $\mathrm{Y}$ & 216104 & 17 & 61 \\
\hline 164 & $\mathrm{O}$ & Glass & Cyano & 2 & 3 & $\mathrm{Y}$ & 863164 & 31 & 63 \\
\hline 164 & $\mathrm{O}$ & Glass & Cyano + Basic Red 28 & 5 & 2 & $\mathrm{Y}$ & 846750 & 30 & 63 \\
\hline 164 & $\mathrm{O}$ & Glass & Cyano + Basic Red 28 & 1 & 4 & $\mathrm{Y}$ & 202900 & 20 & 65 \\
\hline 164 & $\mathrm{O}$ & Glass & Cyano + Basic Red 28 & 4 & 2 & $\mathrm{~N}$ & 68376 & 12 & 57 \\
\hline 164 & $\mathrm{M}$ & Glass & Merged & 2 & 4 & $\mathrm{Y}$ & 1239480 & 39 & 62 \\
\hline 165 & $\mathrm{O}$ & Glass & Cyano & 1 & 4 & $\mathrm{Y}$ & 91924 & 14 & 51 \\
\hline 165 & $\mathrm{O}$ & Glass & Cyano + Basic Red 28 & 5 & 4 & $\mathrm{Y}$ & 387046 & 22 & 46 \\
\hline 165 & $\mathrm{O}$ & Glass & Cyano + Basic Red 28 & 1 & 4 & $\mathrm{Y}$ & 153670 & 22 & 46 \\
\hline 165 & $\mathrm{O}$ & Glass & Cyano + Basic Red 28 & 1 & 2 & $\mathrm{Y}$ & 109905 & 17 & 45 \\
\hline
\end{tabular}




\begin{tabular}{|c|c|c|c|c|c|c|c|c|c|}
\hline 165 & M & Glass & Merged & 1 & 2 & $\mathrm{Y}$ & 729089 & 31 & 60 \\
\hline 166 & $\mathrm{O}$ & Glass & Cyano & 4 & 3 & $\mathrm{Y}$ & 497574 & 22 & 61 \\
\hline 166 & $\mathrm{O}$ & Glass & Cyano + Basic Red 28 & 5 & 3 & $\mathrm{Y}$ & 709205 & 23 & 58 \\
\hline 166 & $\mathrm{O}$ & Glass & Cyano + Basic Red 28 & 1 & 3 & $\mathrm{Y}$ & 580814 & 26 & 65 \\
\hline 166 & $\mathrm{O}$ & Glass & Cyano + Basic Red 28 & 3 & 3 & $\mathrm{Y}$ & 735180 & 30 & 65 \\
\hline 166 & $\mathrm{M}$ & Glass & Merged & 5 & 3 & $\mathrm{Y}$ & 732312 & 28 & 63 \\
\hline 167 & $\mathrm{O}$ & Glass & Cyano & 1 & 3 & $\mathrm{Y}$ & 777800 & 25 & 63 \\
\hline 167 & $\mathrm{O}$ & Glass & Cyano + Basic Red 28 & 5 & 4 & $\mathrm{Y}$ & 1695078 & 33 & 56 \\
\hline 167 & $\mathrm{O}$ & Glass & Cyano + Basic Red 28 & 1 & 4 & $\mathrm{Y}$ & 979200 & 36 & 65 \\
\hline 167 & $\mathrm{O}$ & Glass & Cyano + Basic Red 28 & 2 & 4 & $\mathrm{Y}$ & 797720 & 28 & 61 \\
\hline 167 & $\mathrm{M}$ & Glass & Merged & 4 & 3 & $\mathrm{Y}$ & 586386 & 27 & 53 \\
\hline 168 & $\mathrm{O}$ & Glass & Cyano & 5 & 3 & $\mathrm{Y}$ & 333909 & 27 & 70 \\
\hline 168 & $\mathrm{O}$ & Glass & Cyano + Basic Red 28 & 5 & 4 & $\mathrm{Y}$ & 878130 & 30 & 65 \\
\hline 168 & $\mathrm{O}$ & Glass & Cyano + Basic Red 28 & 1 & 3 & $\mathrm{Y}$ & 454974 & 26 & 69 \\
\hline 168 & $\mathrm{O}$ & Glass & Cyano + Basic Red 28 & 3 & 4 & $\mathrm{~N}$ & 294740 & 20 & 67 \\
\hline 168 & $\mathrm{M}$ & Glass & Merged & 4 & 4 & $\mathrm{Y}$ & 955885 & 31 & 68 \\
\hline 169 & $\mathrm{O}$ & Glass & Cyano & 4 & 2 & $\mathrm{Y}$ & 282055 & 19 & 55 \\
\hline 169 & $\mathrm{O}$ & Glass & Cyano + Basic Red 28 & 5 & 4 & $\mathrm{Y}$ & 288686 & 19 & 53 \\
\hline 169 & $\mathrm{O}$ & Glass & Cyano + Basic Red 28 & 5 & 4 & $\mathrm{Y}$ & 188272 & 16 & 54 \\
\hline 169 & $\mathrm{O}$ & Glass & Cyano + Basic Red 28 & 4 & 4 & $\mathrm{~N}$ & 50325 & 11 & 52 \\
\hline 169 & $\mathrm{M}$ & Glass & Merged & 5 & 3 & $\mathrm{Y}$ & 61110 & 14 & 40 \\
\hline 170 & $\mathrm{O}$ & Glass & Cyano & 5 & 3 & $\mathrm{Y}$ & 103701 & 13 & 46 \\
\hline 170 & $\mathrm{O}$ & Glass & Cyano + Rhodamine 6G & 5 & 3 & $\mathrm{~N}$ & N/A & N/A & N/A \\
\hline 170 & $\mathrm{O}$ & Glass & Cyano + Rhodamine 6G & 4 & 4 & $\mathrm{~N}$ & N/A & N/A & $\mathrm{N} / \mathrm{A}$ \\
\hline 170 & $\mathrm{O}$ & Glass & Cyano + Rhodamine 6G & 1 & 2 & $\mathrm{Y}$ & 40095 & 11 & 36 \\
\hline 170 & $\mathrm{M}$ & Glass & Merged & 1 & 3 & $\mathrm{Y}$ & 267360 & 20 & 40 \\
\hline 171 & $\mathrm{O}$ & Glass & Cyano & 3 & 3 & $\mathrm{Y}$ & 183362 & 17 & 44 \\
\hline 171 & $\mathrm{O}$ & Glass & Cyano + Rhodamine 6G & 1 & 4 & $\mathrm{~N}$ & N/A & N/A & N/A \\
\hline 171 & $\mathrm{O}$ & Glass & Cyano + Rhodamine 6G & 1 & 3 & $\mathrm{~N}$ & 44544 & 5 & 44 \\
\hline 171 & $\mathrm{O}$ & Glass & Cyano + Rhodamine 6G & 1 & 3 & $\mathrm{~N}$ & N/A & N/A & N/A \\
\hline 171 & $\mathrm{M}$ & Glass & Merged & 4 & 4 & $\mathrm{Y}$ & 423177 & 23 & 44 \\
\hline 172 & $\mathrm{O}$ & Glass & Cyano & 5 & 4 & $\mathrm{~N}$ & N/A & $\mathrm{N} / \mathrm{A}$ & $\mathrm{N} / \mathrm{A}$ \\
\hline 172 & $\mathrm{O}$ & Glass & Cyano + Rhodamine $6 \mathrm{G}$ & 5 & 4 & $\mathrm{Y}$ & 88005 & 15 & 42 \\
\hline 172 & $\mathrm{O}$ & Glass & Cyano + Rhodamine 6G & 2 & 4 & $\mathrm{Y}$ & 257166 & 21 & 47 \\
\hline 172 & $\mathrm{O}$ & Glass & Cyano + Rhodamine 6G & 5 & 3 & $\mathrm{~N}$ & N/A & N/A & $\mathrm{N} / \mathrm{A}$ \\
\hline 172 & M & Glass & Merged & 1 & 4 & $\mathrm{~N}$ & 44132 & 4 & 44 \\
\hline 173 & $\mathrm{O}$ & Glass & Cyano & 1 & 3 & $\mathrm{Y}$ & 73381 & 11 & 47 \\
\hline 173 & $\mathrm{O}$ & Glass & Cyano + Rhodamine 6G & 4 & 3 & $\mathrm{Y}$ & 111969 & 13 & 49 \\
\hline 173 & $\mathrm{O}$ & Glass & Cyano + Rhodamine 6G & 1 & 3 & $\mathrm{Y}$ & 244928 & 16 & 47 \\
\hline 173 & $\mathrm{O}$ & Glass & Cyano + Rhodamine 6G & 2 & 4 & $\mathrm{Y}$ & 56340 & 12 & 40 \\
\hline 173 & $\mathrm{M}$ & Glass & Merged & 4 & 4 & $\mathrm{~N}$ & 42708 & 12 & 48 \\
\hline 174 & $\mathrm{O}$ & Glass & Cyano & 5 & 2 & $\mathrm{~N}$ & N/A & $\mathrm{N} / \mathrm{A}$ & $\mathrm{N} / \mathrm{A}$ \\
\hline 174 & $\mathrm{O}$ & Glass & Cyano + Rhodamine 6G & 4 & 4 & $\mathrm{~N}$ & N/A & N/A & N/A \\
\hline 174 & $\mathrm{O}$ & Glass & Cyano + Rhodamine 6G & 2 & 4 & $\mathrm{~N}$ & N/A & $\mathrm{N} / \mathrm{A}$ & $\mathrm{N} / \mathrm{A}$ \\
\hline 174 & $\mathrm{O}$ & Glass & Cyano + Rhodamine 6G & 4 & 3 & $\mathrm{Y}$ & 76750 & 10 & 38 \\
\hline 174 & $\mathrm{M}$ & Glass & Merged & 5 & 4 & $\mathrm{~N}$ & N/A & N/A & $\mathrm{N} / \mathrm{A}$ \\
\hline 175 & $\mathrm{O}$ & Glass & Cyano & 3 & 4 & $\mathrm{Y}$ & 185215 & 17 & 41 \\
\hline 175 & $\mathrm{O}$ & Glass & Cyano + Rhodamine 6G & 5 & 3 & $\mathrm{Y}$ & 74664 & 12 & 42 \\
\hline 175 & $\mathrm{O}$ & Glass & Cyano + Rhodamine 6G & 2 & 3 & $\mathrm{Y}$ & 280200 & 15 & 40 \\
\hline 175 & $\mathrm{O}$ & Glass & Cyano + Rhodamine 6G & 2 & 4 & $\mathrm{Y}$ & 151424 & 14 & 41 \\
\hline 175 & $\mathrm{M}$ & Glass & Merged & 2 & 4 & $\mathrm{Y}$ & 300945 & 15 & 46 \\
\hline 176 & $\mathrm{O}$ & Glass & Cyano & 5 & 3 & $\mathrm{Y}$ & 166680 & 10 & 37 \\
\hline
\end{tabular}




\begin{tabular}{|c|c|c|c|c|c|c|c|c|c|}
\hline 176 & $\mathrm{O}$ & Glass & Cyano + Rhodamine 6G & 4 & 2 & $\mathrm{Y}$ & 262700 & 20 & 50 \\
\hline 176 & $\mathrm{O}$ & Glass & Cyano + Rhodamine 6G & 2 & 3 & $\mathrm{Y}$ & 258592 & 16 & 46 \\
\hline 176 & $\mathrm{O}$ & Glass & Cyano + Rhodamine 6G & 5 & 4 & $\mathrm{Y}$ & 86190 & 13 & 42 \\
\hline 176 & $\mathrm{M}$ & Glass & Merged & 2 & 3 & $\mathrm{~N}$ & 43870 & 10 & 39 \\
\hline 177 & $\mathrm{O}$ & Glass & Cyano & 4 & 4 & $\mathrm{Y}$ & 693273 & 21 & 53 \\
\hline 177 & $\mathrm{O}$ & Glass & Cyano + Rhodamine 6G & 5 & 2 & $\mathrm{Y}$ & 382060 & 20 & 50 \\
\hline 177 & $\mathrm{O}$ & Glass & Cyano + Rhodamine $6 \mathrm{G}$ & 5 & 3 & $\mathrm{Y}$ & 177660 & 12 & 45 \\
\hline 177 & $\mathrm{O}$ & Glass & Cyano + Rhodamine 6G & 5 & 4 & $\mathrm{Y}$ & 167705 & 17 & 40 \\
\hline 177 & $\mathrm{M}$ & Glass & Merged & 2 & 4 & $\mathrm{Y}$ & 341700 & 20 & 54 \\
\hline 178 & $\mathrm{O}$ & Glass & Cyano & 5 & 4 & $\mathrm{Y}$ & 681025 & 24 & 63 \\
\hline 178 & $\mathrm{O}$ & Glass & Cyano + Rhodamine 6G & 5 & 4 & $\mathrm{Y}$ & 525132 & 29 & 64 \\
\hline 178 & $\mathrm{O}$ & Glass & Cyano + Rhodamine 6G & 4 & 3 & $\mathrm{Y}$ & 110143 & 17 & 57 \\
\hline 178 & $\mathrm{O}$ & Glass & Cyano + Rhodamine 6G & 4 & 3 & $\mathrm{Y}$ & 953440 & 32 & 67 \\
\hline 178 & M & Glass & Merged & 5 & 3 & $\mathrm{Y}$ & 339100 & 20 & 51 \\
\hline 179 & $\mathrm{O}$ & Glass & Cyano & 1 & 4 & $\mathrm{Y}$ & 609000 & 25 & 60 \\
\hline 179 & $\mathrm{O}$ & Glass & Cyano + Rhodamine 6G & 5 & 4 & $\mathrm{Y}$ & 390540 & 23 & 50 \\
\hline 179 & $\mathrm{O}$ & Glass & Cyano + Rhodamine 6G & 3 & 3 & $\mathrm{Y}$ & 421392 & 24 & 54 \\
\hline 179 & $\mathrm{O}$ & Glass & Cyano + Rhodamine 6G & 3 & 3 & $\mathrm{Y}$ & 190145 & 17 & 55 \\
\hline 179 & M & Glass & Merged & 1 & 4 & $\mathrm{Y}$ & 554591 & 19 & 56 \\
\hline 180 & $\mathrm{O}$ & Glass & Cyano & 5 & 4 & $\mathrm{Y}$ & 1574055 & 35 & 55 \\
\hline 180 & $\mathrm{O}$ & Glass & Cyano + Rhodamine 6G & 4 & 4 & $\mathrm{Y}$ & 120992 & 16 & 38 \\
\hline 180 & $\mathrm{O}$ & Glass & Cyano + Rhodamine 6G & 5 & 2 & $\mathrm{Y}$ & 104992 & 17 & 46 \\
\hline 180 & $\mathrm{O}$ & Glass & Cyano + Rhodamine 6G & 3 & 4 & $\mathrm{Y}$ & 682695 & 27 & 51 \\
\hline 180 & M & Glass & Merged & 1 & 4 & $\mathrm{Y}$ & 412872 & 24 & 57 \\
\hline 181 & $\mathrm{O}$ & Glass & Cyano & 5 & 4 & $\mathrm{Y}$ & 1417868 & 29 & 53 \\
\hline 181 & $\mathrm{O}$ & Glass & Cyano + Rhodamine 6G & 2 & 4 & $\mathrm{Y}$ & 1050120 & 24 & 43 \\
\hline 181 & $\mathrm{O}$ & Glass & Cyano + Rhodamine 6G & 3 & 3 & $\mathrm{Y}$ & 1096275 & 25 & 35 \\
\hline 181 & $\mathrm{O}$ & Glass & Cyano + Rhodamine 6G & 5 & 4 & $\mathrm{Y}$ & 590018 & 26 & 43 \\
\hline 181 & $\mathrm{M}$ & Glass & Merged & 2 & 3 & $\mathrm{Y}$ & 1225709 & 31 & 54 \\
\hline 182 & $\mathrm{O}$ & Glass & Cyano & 5 & 4 & $\mathrm{Y}$ & 98604 & 12 & 40 \\
\hline 182 & $\mathrm{O}$ & Glass & Cyano + Rhodamine 6G & 4 & 2 & $\mathrm{Y}$ & 72886 & 11 & 36 \\
\hline 182 & $\mathrm{O}$ & Glass & Cyano + Rhodamine 6G & 3 & 3 & $\mathrm{Y}$ & 104868 & 12 & 40 \\
\hline 182 & $\mathrm{O}$ & Glass & Cyano + Rhodamine 6G & 3 & 3 & $\mathrm{Y}$ & 98737 & 14 & 44 \\
\hline 182 & M & Glass & Merged & 2 & 3 & $\mathrm{~N}$ & N/A & N/A & N/A \\
\hline 183 & $\mathrm{O}$ & Glass & Cyano & 3 & 4 & $\mathrm{~N}$ & 31004 & 5 & 30 \\
\hline 183 & $\mathrm{O}$ & Glass & Cyano + Rhodamine 6G & 1 & 4 & $\mathrm{Y}$ & 74136 & 12 & 35 \\
\hline 183 & $\mathrm{O}$ & Glass & Cyano + Rhodamine 6G & 3 & 4 & $\mathrm{Y}$ & 74760 & 12 & 37 \\
\hline 183 & $\mathrm{O}$ & Glass & Cyano + Rhodamine 6G & 4 & 4 & $\mathrm{Y}$ & 307350 & 18 & 38 \\
\hline 183 & $\mathrm{M}$ & Glass & Merged & 5 & 3 & $\mathrm{~N}$ & N/A & N/A & N/A \\
\hline 184 & $\mathrm{O}$ & Glass & Cyano & 1 & 4 & $\mathrm{~N}$ & N/A & $\mathrm{N} / \mathrm{A}$ & N/A \\
\hline 184 & $\mathrm{O}$ & Glass & Cyano + Rhodamine 6G & 5 & 4 & $\mathrm{Y}$ & 872620 & 28 & 52 \\
\hline 184 & $\mathrm{O}$ & Glass & Cyano + Rhodamine 6G & 4 & 4 & $\mathrm{Y}$ & 312256 & 28 & 51 \\
\hline 184 & $\mathrm{O}$ & Glass & Cyano + Rhodamine 6G & 4 & 3 & $\mathrm{Y}$ & 420680 & 26 & 54 \\
\hline 184 & M & Glass & Merged & 2 & 3 & $\mathrm{Y}$ & 81168 & 12 & 38 \\
\hline 185 & $\mathrm{O}$ & Glass & Cyano & 2 & 4 & $\mathrm{~N}$ & N/A & N/A & N/A \\
\hline 185 & $\mathrm{O}$ & Glass & Cyano + Rhodamine 6G & 5 & 4 & $\mathrm{Y}$ & 281898 & 18 & 33 \\
\hline 185 & $\mathrm{O}$ & Glass & Cyano + Rhodamine 6G & 2 & 3 & $\mathrm{Y}$ & 116415 & 15 & 30 \\
\hline 185 & $\mathrm{O}$ & Glass & Cyano + Rhodamine 6G & 4 & 3 & $\mathrm{~N}$ & 10248 & 4 & 19 \\
\hline 185 & $\mathrm{M}$ & Glass & Merged & 4 & 4 & $\mathrm{~N}$ & N/A & $\mathrm{N} / \mathrm{A}$ & $\mathrm{N} / \mathrm{A}$ \\
\hline 186 & $\mathrm{O}$ & Glass & Cyano & 2 & 4 & $\mathrm{Y}$ & 44625 & 15 & 38 \\
\hline 186 & $\mathrm{O}$ & Glass & Cyano + Rhodamine $6 \mathrm{G}$ & 5 & 3 & $\mathrm{~N}$ & 45266 & 13 & 53 \\
\hline 186 & $\mathrm{O}$ & Glass & Cyano + Rhodamine 6G & 3 & 3 & $\mathrm{Y}$ & 160939 & 17 & 52 \\
\hline
\end{tabular}




\begin{tabular}{|c|c|c|c|c|c|c|c|c|c|}
\hline 186 & $\mathrm{O}$ & Glass & Cyano + Rhodamine $6 \mathrm{G}$ & 5 & 4 & $\mathrm{Y}$ & 101403 & 19 & 55 \\
\hline 186 & $\mathrm{M}$ & Glass & Merged & 3 & 4 & N/A & N/A & N/A & N/A \\
\hline 187 & $\mathrm{O}$ & Glass & Cyano & 5 & 4 & $\mathrm{~N}$ & N/A & N/A & N/A \\
\hline 187 & $\mathrm{O}$ & Glass & Cyano + Rhodamine 6G & 4 & 4 & $\mathrm{Y}$ & 64590 & 10 & 38 \\
\hline 187 & $\mathrm{O}$ & Glass & Cyano + Rhodamine 6G & 5 & 3 & $\mathrm{~N}$ & N/A & N/A & N/A \\
\hline 187 & $\mathrm{O}$ & Glass & Cyano + Rhodamine 6G & 3 & 3 & $\mathrm{Y}$ & 108200 & 10 & 36 \\
\hline 187 & $\mathrm{M}$ & Glass & Merged & 4 & 4 & $\mathrm{~N}$ & 45090 & 15 & 45 \\
\hline 188 & $\mathrm{O}$ & Glass & Cyano & 2 & 2 & $\mathrm{~N}$ & $\mathrm{~N} / \mathrm{A}$ & $\mathrm{N} / \mathrm{A}$ & $\mathrm{N} / \mathrm{A}$ \\
\hline 188 & $\mathrm{O}$ & Glass & Cyano + Rhodamine 6G & 3 & 3 & $\mathrm{~N}$ & N/A & N/A & N/A \\
\hline 188 & $\mathrm{O}$ & Glass & Cyano + Rhodamine 6G & 3 & 4 & $\mathrm{~N}$ & 7400 & 5 & 20 \\
\hline 188 & $\mathrm{O}$ & Glass & Cyano + Rhodamine 6G & 5 & 4 & $\mathrm{~N}$ & 25920 & 8 & 22 \\
\hline 188 & $\mathrm{M}$ & Glass & Merged & 2 & 3 & $\mathrm{Y}$ & 15757 & 7 & 27 \\
\hline 189 & $\mathrm{O}$ & Glass & Cyano & 3 & 3 & $\mathrm{~N}$ & 69887 & 17 & 54 \\
\hline 189 & $\mathrm{O}$ & Glass & Cyano + Rhodamine 6G & 1 & 4 & $\mathrm{Y}$ & 599844 & 28 & 55 \\
\hline 189 & $\mathrm{O}$ & Glass & Cyano + Rhodamine 6G & 5 & 4 & $\mathrm{Y}$ & 497097 & 26 & 54 \\
\hline 189 & $\mathrm{O}$ & Glass & Cyano + Rhodamine 6G & 3 & 4 & $\mathrm{Y}$ & 646775 & 25 & 48 \\
\hline 189 & $\mathrm{M}$ & Glass & Merged & 4 & 4 & $\mathrm{Y}$ & 278649 & 21 & 48 \\
\hline 190 & $\mathrm{O}$ & Glass & Cyano & 1 & 4 & $\mathrm{Y}$ & 1339380 & 35 & 56 \\
\hline 190 & $\mathrm{O}$ & Glass & Cyano + Rhodamine 6G & 3 & 3 & $\mathrm{Y}$ & 1232152 & 29 & 49 \\
\hline 190 & $\mathrm{O}$ & Glass & Cyano + Rhodamine 6G & 1 & 4 & $\mathrm{Y}$ & 652500 & 25 & 49 \\
\hline 190 & $\mathrm{O}$ & Glass & Cyano + Rhodamine 6G & 5 & 3 & $\mathrm{Y}$ & 361077 & 23 & 53 \\
\hline 190 & $\mathrm{M}$ & Glass & Merged & 1 & 4 & $\mathrm{Y}$ & 982731 & 31 & 59 \\
\hline 191 & $\mathrm{O}$ & Glass & Cyano & 4 & 3 & $\mathrm{~N}$ & N/A & N/A & N/A \\
\hline 191 & $\mathrm{O}$ & Glass & Cyano + Rhodamine 6G & 1 & 3 & $\mathrm{Y}$ & 527525 & 25 & 51 \\
\hline 191 & $\mathrm{O}$ & Glass & Cyano + Rhodamine 6G & 5 & 3 & $\mathrm{Y}$ & 1124730 & 30 & 53 \\
\hline 191 & $\mathrm{O}$ & Glass & Cyano + Rhodamine 6G & 3 & 3 & $\mathrm{Y}$ & 345805 & 23 & 54 \\
\hline 191 & M & Glass & Merged & 5 & 3 & $\mathrm{~N}$ & N/A & N/A & $\mathrm{N} / \mathrm{A}$ \\
\hline 192 & $\mathrm{O}$ & Glass & Cyano & 2 & 3 & $\mathrm{Y}$ & 1347964 & 34 & 56 \\
\hline 192 & $\mathrm{O}$ & Glass & Cyano + Rhodamine 6G & 5 & 4 & $\mathrm{Y}$ & 2791444 & 41 & 61 \\
\hline 192 & $\mathrm{O}$ & Glass & Cyano + Rhodamine 6G & 5 & 4 & $\mathrm{Y}$ & 1097827 & 37 & 63 \\
\hline 192 & $\mathrm{O}$ & Glass & Cyano + Rhodamine 6G & 5 & 4 & $\mathrm{Y}$ & 869006 & 34 & 62 \\
\hline 192 & $\mathrm{M}$ & Glass & Merged & 5 & 3 & Y & 1077020 & 35 & 62 \\
\hline 193 & $\mathrm{O}$ & Glass & Cyano & 2 & 4 & Y & 256305 & 21 & 50 \\
\hline 193 & $\mathrm{O}$ & Glass & Cyano + Rhodamine 6G & 1 & 4 & Y & 181203 & 19 & 62 \\
\hline 193 & $\mathrm{O}$ & Glass & Cyano + Rhodamine 6G & 1 & 4 & $\mathrm{Y}$ & 310152 & 24 & 64 \\
\hline 193 & $\mathrm{O}$ & Glass & Cyano + Rhodamine 6G & 1 & 4 & $\mathrm{Y}$ & 260326 & 22 & 55 \\
\hline 193 & $\mathrm{M}$ & Glass & Merged & 3 & 3 & $\mathrm{Y}$ & 86282 & 14 & 54 \\
\hline 194 & $\mathrm{O}$ & Glass & Cyano & 2 & 3 & $\mathrm{~N}$ & N/A & N/A & N/A \\
\hline 194 & $\mathrm{O}$ & Glass & Cyano + Rhodamine 6G & 1 & 4 & $\mathrm{Y}$ & 34012 & 11 & 27 \\
\hline 194 & $\mathrm{O}$ & Glass & Cyano + Rhodamine 6G & 3 & 4 & $\mathrm{Y}$ & 46530 & 10 & 28 \\
\hline 194 & $\mathrm{O}$ & Glass & Cyano + Rhodamine 6G & 4 & 4 & $\mathrm{Y}$ & 52056 & 12 & 30 \\
\hline 194 & M & Glass & Merged & 1 & 3 & $\mathrm{~N}$ & N/A & N/A & N/A \\
\hline 195 & $\mathrm{O}$ & Glass & Cyano & 3 & 3 & $\mathrm{~N}$ & N/A & N/A & N/A \\
\hline 195 & $\mathrm{O}$ & Glass & Cyano + Rhodamine 6G & 2 & 3 & $\mathrm{~N}$ & 14016 & 6 & 26 \\
\hline 195 & $\mathrm{O}$ & Glass & Cyano + Rhodamine 6G & 1 & 3 & $\mathrm{~N}$ & N/A & N/A & N/A \\
\hline 195 & $\mathrm{O}$ & Glass & Cyano + Rhodamine 6G & 1 & 4 & $\mathrm{~N}$ & N/A & N/A & $\mathrm{N} / \mathrm{A}$ \\
\hline 195 & $\mathrm{M}$ & Glass & Merged & 1 & 4 & $\mathrm{~N}$ & 25208 & 8 & 37 \\
\hline 196 & $\mathrm{O}$ & Glass & Cyano & 4 & 4 & $\mathrm{~N}$ & 22020 & 10 & 24 \\
\hline 196 & $\mathrm{O}$ & Glass & Cyano + Rhodamine 6G & 5 & 3 & $\mathrm{Y}$ & 267789 & 23 & 35 \\
\hline 196 & $\mathrm{O}$ & Glass & Cyano + Rhodamine 6G & 1 & 4 & $\mathrm{Y}$ & 131145 & 15 & 33 \\
\hline 196 & $\mathrm{O}$ & Glass & Cyano + Rhodamine $6 \mathrm{G}$ & 5 & 3 & $\mathrm{Y}$ & 267060 & 20 & 37 \\
\hline 196 & $\mathrm{M}$ & Glass & Merged & 2 & 3 & $\mathrm{Y}$ & 327348 & 18 & 38 \\
\hline
\end{tabular}




\begin{tabular}{|c|c|c|c|c|c|c|c|c|c|}
\hline 197 & $\mathrm{O}$ & Glass & Cyano & 2 & 4 & $\mathrm{~N}$ & 18276 & 12 & 25 \\
\hline 197 & $\mathrm{O}$ & Glass & Cyano + Rhodamine 6G & 3 & 4 & $\mathrm{Y}$ & 53131 & 13 & 25 \\
\hline 197 & $\mathrm{O}$ & Glass & Cyano + Rhodamine 6G & 2 & 3 & $\mathrm{Y}$ & 78160 & 16 & 28 \\
\hline 197 & $\mathrm{O}$ & Glass & Cyano + Rhodamine 6G & 5 & 4 & $\mathrm{~N}$ & N/A & N/A & N/A \\
\hline 197 & $\mathrm{M}$ & Glass & Merged & 4 & 3 & $\mathrm{~N}$ & N/A & N/A & N/A \\
\hline 198 & $\mathrm{O}$ & Glass & Cyano & 1 & 4 & $\mathrm{Y}$ & 321678 & 23 & 45 \\
\hline 198 & $\mathrm{O}$ & Glass & Cyano + Rhodamine 6G & 1 & 3 & $\mathrm{Y}$ & 94934 & 14 & 49 \\
\hline 198 & $\mathrm{O}$ & Glass & Cyano + Rhodamine 6G & 5 & 4 & $\mathrm{Y}$ & 188850 & 25 & 54 \\
\hline 198 & $\mathrm{O}$ & Glass & Cyano + Rhodamine 6G & 2 & 4 & $\mathrm{Y}$ & 187304 & 15 & 53 \\
\hline 198 & $\mathrm{M}$ & Glass & Merged & 5 & 4 & $\mathrm{Y}$ & 311809 & 19 & 49 \\
\hline 199 & $\mathrm{O}$ & Glass & Cyano & 4 & 4 & $\mathrm{Y}$ & 1093965 & 27 & 40 \\
\hline 199 & $\mathrm{O}$ & Glass & Cyano + Rhodamine 6G & 5 & 2 & $\mathrm{Y}$ & 447746 & 17 & 29 \\
\hline 199 & $\mathrm{O}$ & Glass & Cyano + Rhodamine 6G & 1 & 3 & $\mathrm{Y}$ & 667359 & 21 & 34 \\
\hline 199 & $\mathrm{O}$ & Glass & Cyano + Rhodamine 6G & 4 & 3 & $\mathrm{Y}$ & 1659987 & 27 & 40 \\
\hline 199 & $\mathrm{M}$ & Glass & Merged & 3 & 4 & $\mathrm{Y}$ & 795674 & 22 & 41 \\
\hline 200 & $\mathrm{O}$ & Glass & Cyano & 1 & 3 & $\mathrm{~N}$ & $\mathrm{~N} / \mathrm{A}$ & N/A & N/A \\
\hline 200 & $\mathrm{O}$ & Glass & Cyano + Rhodamine 6G & 5 & 3 & $\mathrm{~N}$ & $\mathrm{~N} / \mathrm{A}$ & $\mathrm{N} / \mathrm{A}$ & N/A \\
\hline 200 & $\mathrm{O}$ & Glass & Cyano + Rhodamine $6 \mathrm{G}$ & 4 & 4 & $\mathrm{~N}$ & $\mathrm{~N} / \mathrm{A}$ & $\mathrm{N} / \mathrm{A}$ & N/A \\
\hline 200 & $\mathrm{O}$ & Glass & Cyano + Rhodamine 6G & 1 & 4 & $\mathrm{~N}$ & 38943 & 9 & 44 \\
\hline 200 & $\mathrm{M}$ & Glass & Merged & 5 & 3 & $\mathrm{~N}$ & N/A & N/A & N/A \\
\hline 201 & $\mathrm{O}$ & Glass & Cyano & 1 & 2 & $\mathrm{Y}$ & 1887080 & 38 & 65 \\
\hline 201 & $\mathrm{O}$ & Glass & Cyano + Rhodamine 6G & 3 & 3 & $\mathrm{Y}$ & 1581255 & 39 & 65 \\
\hline 201 & $\mathrm{O}$ & Glass & Cyano + Rhodamine 6G & 4 & 2 & $\mathrm{Y}$ & 199650 & 22 & 52 \\
\hline 201 & $\mathrm{O}$ & Glass & Cyano + Rhodamine $6 \mathrm{G}$ & 4 & 3 & $\mathrm{Y}$ & 307832 & 28 & 57 \\
\hline 201 & $\mathrm{M}$ & Glass & Merged & 1 & 3 & $\mathrm{Y}$ & 586385 & 23 & 61 \\
\hline 202 & $\mathrm{O}$ & Glass & Cyano & 4 & 3 & $\mathrm{Y}$ & 89610 & 15 & 49 \\
\hline 202 & $\mathrm{O}$ & Glass & Cyano + Basic Yellow 40 & 1 & 4 & $\mathrm{Y}$ & 323610 & 23 & 51 \\
\hline 202 & $\mathrm{O}$ & Glass & Cyano + Basic Yellow 40 & 4 & 3 & $\mathrm{~N}$ & 41119 & 13 & 43 \\
\hline 202 & $\mathrm{O}$ & Glass & Cyano + Basic Yellow 40 & 5 & 4 & $\mathrm{Y}$ & 92412 & 18 & 52 \\
\hline 202 & $\mathrm{M}$ & Glass & Merged & 5 & 4 & $\mathrm{Y}$ & 219300 & 17 & 52 \\
\hline 203 & $\mathrm{O}$ & Glass & Cyano & 5 & 3 & $\mathrm{Y}$ & 98804 & 17 & 40 \\
\hline 203 & $\mathrm{O}$ & Glass & Cyano + Basic Yellow 40 & 2 & 4 & $\mathrm{~N}$ & 75950 & 14 & 45 \\
\hline 203 & $\mathrm{O}$ & Glass & Cyano + Basic Yellow 40 & 2 & 4 & $\mathrm{~N}$ & $\mathrm{~N} / \mathrm{A}$ & $\mathrm{N} / \mathrm{A}$ & N/A \\
\hline 203 & $\mathrm{O}$ & Glass & Cyano + Basic Yellow 40 & 1 & 3 & $\mathrm{Y}$ & 169760 & 16 & 41 \\
\hline 203 & $\mathrm{M}$ & Glass & Merged & 5 & 3 & $\mathrm{Y}$ & 117844 & 17 & 34 \\
\hline 204 & $\mathrm{O}$ & Glass & Cyano & 1 & 4 & $\mathrm{Y}$ & 438560 & 20 & 52 \\
\hline 204 & $\mathrm{O}$ & Glass & Cyano + Basic Yellow 40 & 3 & 3 & $\mathrm{Y}$ & 316954 & 22 & 56 \\
\hline 204 & $\mathrm{O}$ & Glass & Cyano + Basic Yellow 40 & 1 & 2 & $\mathrm{Y}$ & 94945 & 17 & 54 \\
\hline 204 & $\mathrm{O}$ & Glass & Cyano + Basic Yellow 40 & 1 & 4 & $\mathrm{Y}$ & 130543 & 17 & 55 \\
\hline 204 & $\mathrm{M}$ & Glass & Merged & 1 & 3 & $\mathrm{Y}$ & 304656 & 22 & 56 \\
\hline 205 & $\mathrm{O}$ & Glass & Cyano & 1 & 4 & $\mathrm{Y}$ & 164646 & 18 & 50 \\
\hline 205 & $\mathrm{O}$ & Glass & Cyano + Basic Yellow 40 & 1 & 4 & $\mathrm{~N}$ & $\mathrm{~N} / \mathrm{A}$ & $\mathrm{N} / \mathrm{A}$ & N/A \\
\hline 205 & $\mathrm{O}$ & Glass & Cyano + Basic Yellow 40 & 4 & 4 & $\mathrm{Y}$ & 158382 & 14 & 37 \\
\hline 205 & $\mathrm{O}$ & Glass & Cyano + Basic Yellow 40 & 1 & 3 & $\mathrm{~N}$ & 188976 & 16 & 47 \\
\hline 205 & M & Glass & Merged & 4 & 4 & $\mathrm{Y}$ & 82030 & 13 & 45 \\
\hline 206 & $\mathrm{O}$ & Glass & Cyano + Basic Yellow 40 & 4 & 3 & $\mathrm{Y}$ & 79563 & 11 & 41 \\
\hline 206 & $\mathrm{O}$ & Glass & Cyano + Basic Yellow 40 & 5 & 4 & $\mathrm{Y}$ & 62582 & 13 & 34 \\
\hline 206 & $\mathrm{O}$ & Glass & Cyano + Basic Yellow 40 & 5 & 3 & $\mathrm{Y}$ & 153792 & 18 & 43 \\
\hline 206 & $\mathrm{M}$ & Glass & Merged & 5 & 4 & $\mathrm{Y}$ & 76496 & 14 & 46 \\
\hline 207 & $\mathrm{O}$ & Glass & Cyano & 1 & 4 & $\mathrm{Y}$ & 272160 & 20 & 44 \\
\hline 207 & $\mathrm{O}$ & Glass & Cyano + Basic Yellow 40 & 3 & 4 & $\mathrm{Y}$ & 173700 & 20 & 47 \\
\hline 207 & $\mathrm{O}$ & Glass & Cyano + Basic Yellow 40 & 5 & 4 & $\mathrm{Y}$ & 61677 & 9 & 26 \\
\hline
\end{tabular}




\begin{tabular}{|c|c|c|c|c|c|c|c|c|c|}
\hline 207 & $\mathrm{O}$ & Glass & Cyano + Basic Yellow 40 & 2 & 4 & $\mathrm{~N}$ & 63664 & 17 & 40 \\
\hline 207 & $\mathrm{M}$ & Glass & Merged & 1 & 2 & $\mathrm{Y}$ & 238464 & 27 & 44 \\
\hline 208 & $\mathrm{O}$ & Glass & Cyano & 5 & 4 & $\mathrm{Y}$ & 373934 & 23 & 44 \\
\hline 208 & $\mathrm{O}$ & Glass & Cyano + Basic Yellow 40 & 3 & 4 & $\mathrm{Y}$ & 258082 & 22 & 46 \\
\hline 208 & $\mathrm{O}$ & Glass & Cyano + Basic Yellow 40 & 2 & 4 & $\mathrm{Y}$ & 204426 & 18 & 42 \\
\hline 208 & $\mathrm{O}$ & Glass & Cyano + Basic Yellow 40 & 5 & 3 & $\mathrm{Y}$ & 214874 & 22 & 47 \\
\hline 208 & $\mathrm{M}$ & Glass & Merged & 5 & 4 & $\mathrm{Y}$ & 139587 & 17 & 44 \\
\hline 209 & $\mathrm{O}$ & Glass & Cyano & 4 & 4 & $\mathrm{Y}$ & 130663 & 19 & 43 \\
\hline 209 & $\mathrm{O}$ & Glass & Cyano + Basic Yellow 40 & 1 & 3 & $\mathrm{Y}$ & 158834 & 13 & 32 \\
\hline 209 & $\mathrm{O}$ & Glass & Cyano + Basic Yellow 40 & 3 & 4 & $\mathrm{~N}$ & 45089 & 11 & 32 \\
\hline 209 & $\mathrm{O}$ & Glass & Cyano + Basic Yellow 40 & 1 & 3 & $\mathrm{Y}$ & 267546 & 17 & 40 \\
\hline 209 & $\mathrm{M}$ & Glass & Merged & 4 & 3 & $\mathrm{Y}$ & 119275 & 13 & 39 \\
\hline 210 & $\mathrm{O}$ & Glass & Cyano & 2 & 4 & $\mathrm{Y}$ & 646625 & 25 & 49 \\
\hline 210 & $\mathrm{O}$ & Glass & Cyano + Basic Yellow 40 & 1 & 4 & $\mathrm{Y}$ & 1028720 & 38 & 57 \\
\hline 210 & $\mathrm{O}$ & Glass & Cyano + Basic Yellow 40 & 1 & 4 & $\mathrm{Y}$ & 395451 & 21 & 43 \\
\hline 210 & $\mathrm{O}$ & Glass & Cyano + Basic Yellow 40 & 4 & 4 & $\mathrm{Y}$ & 181920 & 20 & 49 \\
\hline 210 & $\mathrm{M}$ & Glass & Merged & 5 & 4 & $\mathrm{Y}$ & 413977 & 23 & 45 \\
\hline 211 & $\mathrm{O}$ & Glass & Cyano & 5 & 4 & $\mathrm{~N}$ & N/A & $\mathrm{N} / \mathrm{A}$ & $\mathrm{N} / \mathrm{A}$ \\
\hline 211 & $\mathrm{O}$ & Glass & Cyano + Basic Yellow 40 & 3 & 3 & $\mathrm{~N}$ & 52116 & 12 & 39 \\
\hline 211 & $\mathrm{O}$ & Glass & Cyano + Basic Yellow 40 & 1 & 4 & $\mathrm{Y}$ & 30297 & 4 & 30 \\
\hline 211 & $\mathrm{O}$ & Glass & Cyano + Basic Yellow 40 & 5 & 4 & $\mathrm{~N}$ & N/A & N/A & N/A \\
\hline 211 & $\mathrm{M}$ & Glass & Merged & 5 & 4 & $\mathrm{~N}$ & N/A & $\mathrm{N} / \mathrm{A}$ & $\mathrm{N} / \mathrm{A}$ \\
\hline 212 & $\mathrm{O}$ & Glass & Cyano & 1 & 3 & $\mathrm{Y}$ & 432033 & 21 & 56 \\
\hline 212 & $\mathrm{O}$ & Glass & Cyano + Basic Yellow 40 & 2 & 4 & $\mathrm{Y}$ & 818697 & 33 & 55 \\
\hline 212 & $\mathrm{O}$ & Glass & Cyano + Basic Yellow 40 & 4 & 3 & $\mathrm{Y}$ & 806288 & 28 & 47 \\
\hline 212 & $\mathrm{O}$ & Glass & Cyano + Basic Yellow 40 & 1 & 3 & $\mathrm{Y}$ & 368832 & 17 & 51 \\
\hline 212 & M & Glass & Merged & 2 & 3 & $\mathrm{Y}$ & 538524 & 21 & 55 \\
\hline 213 & $\mathrm{O}$ & Glass & Cyano & 1 & 4 & $\mathrm{Y}$ & 273196 & 22 & 50 \\
\hline 213 & $\mathrm{O}$ & Glass & Cyano + Basic Yellow 40 & 1 & 4 & $\mathrm{Y}$ & 132800 & 16 & 47 \\
\hline 213 & $\mathrm{O}$ & Glass & Cyano + Basic Yellow 40 & 5 & 3 & $\mathrm{Y}$ & 102697 & 17 & 42 \\
\hline 213 & $\mathrm{O}$ & Glass & Cyano + Basic Yellow 40 & 5 & 4 & $\mathrm{Y}$ & 82384 & 16 & 46 \\
\hline 213 & $\mathrm{M}$ & Glass & Merged & 3 & 4 & $\mathrm{Y}$ & 216220 & 19 & 44 \\
\hline 214 & $\mathrm{O}$ & Glass & Cyano & 5 & 3 & $\mathrm{Y}$ & 576531 & 27 & 57 \\
\hline 214 & $\mathrm{O}$ & Glass & Cyano + Basic Yellow 40 & 5 & 3 & $\mathrm{Y}$ & 376763 & 23 & 52 \\
\hline 214 & $\mathrm{O}$ & Glass & Cyano + Basic Yellow 40 & 1 & 3 & $\mathrm{Y}$ & 289660 & 20 & 57 \\
\hline 214 & $\mathrm{O}$ & Glass & Cyano + Basic Yellow 40 & 5 & 3 & $\mathrm{Y}$ & 1443629 & 37 & 59 \\
\hline 214 & $\mathrm{M}$ & Glass & Merged & 1 & 3 & $\mathrm{Y}$ & 1046675 & 25 & 57 \\
\hline 215 & $\mathrm{O}$ & Glass & Cyano & 1 & 4 & $\mathrm{Y}$ & 236265 & 19 & 48 \\
\hline 215 & $\mathrm{O}$ & Glass & Cyano + Basic Yellow 40 & 5 & 4 & $\mathrm{~N}$ & N/A & $\mathrm{N} / \mathrm{A}$ & $\mathrm{N} / \mathrm{A}$ \\
\hline 215 & $\mathrm{O}$ & Glass & Cyano + Basic Yellow 40 & 4 & 4 & $\mathrm{~N}$ & N/A & $\mathrm{N} / \mathrm{A}$ & $\mathrm{N} / \mathrm{A}$ \\
\hline 215 & $\mathrm{O}$ & Glass & Cyano + Basic Yellow 40 & 1 & 2 & $\mathrm{Y}$ & 36584 & 6 & 30 \\
\hline 215 & M & Glass & Merged & 5 & 4 & $\mathrm{~N}$ & N/A & N/A & N/A \\
\hline 216 & $\mathrm{O}$ & Glass & Cyano & 5 & 3 & $\mathrm{Y}$ & 1161690 & 30 & 46 \\
\hline 216 & $\mathrm{O}$ & Glass & Cyano + Basic Yellow 40 & 4 & 4 & $\mathrm{~N}$ & N/A & N/A & $\mathrm{N} / \mathrm{A}$ \\
\hline 216 & $\mathrm{O}$ & Glass & Cyano + Basic Yellow 40 & 4 & 4 & $\mathrm{~N}$ & N/A & N/A & N/A \\
\hline 216 & $\mathrm{O}$ & Glass & Cyano + Basic Yellow 40 & 5 & 2 & $\mathrm{~N}$ & N/A & N/A & $\mathrm{N} / \mathrm{A}$ \\
\hline 216 & $\mathrm{M}$ & Glass & Merged & 4 & 4 & $\mathrm{Y}$ & 742716 & 23 & 37 \\
\hline 217 & $\mathrm{O}$ & Glass & Cyano & 2 & 4 & $\mathrm{Y}$ & 142672 & 16 & 47 \\
\hline 217 & $\mathrm{O}$ & Glass & Cyano + Basic Yellow 40 & 3 & 4 & $\mathrm{Y}$ & 139536 & 17 & 46 \\
\hline 217 & $\mathrm{O}$ & Glass & Cyano + Basic Yellow 40 & 4 & 4 & $\mathrm{~N}$ & 34940 & 10 & 44 \\
\hline 217 & $\mathrm{O}$ & Glass & Cyano + Basic Yellow 40 & 1 & 3 & $\mathrm{Y}$ & 59584 & 14 & 37 \\
\hline 217 & $\mathrm{M}$ & Glass & Merged & 4 & 3 & $\mathrm{Y}$ & 81887 & 13 & 49 \\
\hline
\end{tabular}




\begin{tabular}{|c|c|c|c|c|c|c|c|c|c|}
\hline 218 & $\mathrm{O}$ & Glass & Cyano & 4 & 4 & $\mathrm{Y}$ & 179400 & 15 & 42 \\
\hline 218 & $\mathrm{O}$ & Glass & Cyano + Basic Yellow 40 & 5 & 4 & $\mathrm{Y}$ & 129523 & 17 & 39 \\
\hline 218 & $\mathrm{O}$ & Glass & Cyano + Basic Yellow 40 & 4 & 4 & $\mathrm{Y}$ & 259146 & 17 & 42 \\
\hline 218 & $\mathrm{O}$ & Glass & Cyano + Basic Yellow 40 & 2 & 2 & $\mathrm{Y}$ & 495462 & 22 & 41 \\
\hline 218 & M & Glass & Merged & 1 & 2 & $\mathrm{~N}$ & 45988 & 13 & 41 \\
\hline 219 & $\mathrm{O}$ & Glass & Cyano & 4 & 3 & $\mathrm{Y}$ & 80388 & 14 & 45 \\
\hline 219 & $\mathrm{O}$ & Glass & Cyano + Basic Yellow 40 & 4 & 4 & $\mathrm{Y}$ & 109226 & 13 & 42 \\
\hline 219 & $\mathrm{O}$ & Glass & Cyano + Basic Yellow 40 & 5 & 2 & $\mathrm{~N}$ & N/A & N/A & N/A \\
\hline 219 & $\mathrm{O}$ & Glass & Cyano + Basic Yellow 40 & 3 & 4 & $\mathrm{~N}$ & N/A & N/A & N/A \\
\hline 219 & $\mathrm{M}$ & Glass & Merged & 3 & 4 & $\mathrm{Y}$ & 98424 & 9 & 47 \\
\hline 220 & $\mathrm{O}$ & Glass & Cyano & 1 & 3 & $\mathrm{~N}$ & N/A & N/A & N/A \\
\hline 220 & $\mathrm{O}$ & Glass & Cyano + MBD & 5 & 3 & $\mathrm{~N}$ & N/A & N/A & N/A \\
\hline 220 & $\mathrm{M}$ & Glass & Merged & 1 & 3 & $\mathrm{~N}$ & N/A & N/A & N/A \\
\hline 221 & $\mathrm{O}$ & Glass & Cyano & 5 & 4 & $\mathrm{~N}$ & 37026 & 11 & 37 \\
\hline 221 & $\mathrm{O}$ & Glass & Cyano + MBD & 1 & 3 & $\mathrm{~N}$ & N/A & N/A & N/A \\
\hline 221 & $\mathrm{M}$ & Glass & Merged & 5 & 3 & $\mathrm{~N}$ & N/A & N/A & $\mathrm{N} / \mathrm{A}$ \\
\hline 222 & $\mathrm{O}$ & Glass & Cyano & 5 & 3 & $\mathrm{Y}$ & 88980 & 12 & 29 \\
\hline 222 & $\mathrm{O}$ & Glass & Cyano + MBD & 5 & 3 & $\mathrm{Y}$ & 18641 & 7 & 21 \\
\hline 222 & $\mathrm{M}$ & Glass & Merged & 5 & 4 & $\mathrm{~N}$ & 13870 & 4 & 23 \\
\hline 223 & $\mathrm{O}$ & Glass & Cyano & 4 & 4 & $\mathrm{Y}$ & 515168 & 34 & 49 \\
\hline 223 & $\mathrm{O}$ & Glass & Cyano + MBD & 5 & 4 & $\mathrm{Y}$ & 271570 & 26 & 47 \\
\hline 223 & $\mathrm{M}$ & Glass & Merged & 2 & 4 & $\mathrm{Y}$ & 535600 & 26 & 52 \\
\hline 224 & $\mathrm{O}$ & Glass & Cyano & 3 & 4 & $\mathrm{Y}$ & 414575 & 25 & 58 \\
\hline 224 & $\mathrm{O}$ & Glass & Cyano + MBD & 1 & 3 & $\mathrm{Y}$ & 1044414 & 27 & 56 \\
\hline 224 & M & Glass & Merged & 5 & 3 & $\mathrm{Y}$ & 732660 & 30 & 57 \\
\hline 225 & $\mathrm{O}$ & Glass & Cyano & 1 & 4 & $\mathrm{Y}$ & 533675 & 25 & 56 \\
\hline 225 & $\mathrm{O}$ & Glass & Cyano + MBD & 5 & 4 & $\mathrm{Y}$ & 313704 & 12 & 51 \\
\hline 225 & $\mathrm{M}$ & Glass & Merged & 5 & 3 & $\mathrm{Y}$ & 185264 & 16 & 54 \\
\hline 226 & $\mathrm{O}$ & Glass & Cyano & 2 & 4 & $\mathrm{Y}$ & 95936 & 15 & 42 \\
\hline 226 & $\mathrm{O}$ & Glass & Cyano + MBD & 2 & 4 & $\mathrm{~N}$ & N/A & N/A & N/A \\
\hline 226 & $\mathrm{M}$ & Glass & Merged & 3 & 3 & $\mathrm{Y}$ & 96694 & 13 & 31 \\
\hline 227 & $\mathrm{O}$ & Glass & Cyano & 2 & 3 & $\mathrm{Y}$ & 433419 & 21 & 53 \\
\hline 227 & $\mathrm{O}$ & Glass & Cyano + MBD & 1 & 4 & $\mathrm{Y}$ & 185263 & 13 & 51 \\
\hline 227 & $\mathrm{M}$ & Glass & Merged & 5 & 4 & $\mathrm{Y}$ & 446992 & 14 & 48 \\
\hline 228 & $\mathrm{O}$ & Glass & Cyano & 1 & 4 & $\mathrm{Y}$ & 491986 & 19 & 44 \\
\hline 228 & $\mathrm{O}$ & Glass & Cyano + MBD & 5 & 2 & $\mathrm{Y}$ & 295584 & 24 & 44 \\
\hline 228 & $\mathrm{M}$ & Glass & Merged & 2 & 4 & $\mathrm{Y}$ & 521576 & 22 & 43 \\
\hline 229 & $\mathrm{O}$ & Glass & Cyano & 3 & 3 & $\mathrm{Y}$ & 227430 & 18 & 44 \\
\hline 229 & $\mathrm{O}$ & Glass & Cyano + MBD & 4 & 4 & $\mathrm{Y}$ & 298809 & 21 & 45 \\
\hline 229 & $\mathrm{M}$ & Glass & Merged & 3 & 4 & $\mathrm{~N}$ & 90720 & 18 & 47 \\
\hline 230 & $\mathrm{O}$ & Glass & Cyano & 1 & 2 & $\mathrm{Y}$ & 79662 & 17 & 42 \\
\hline 230 & $\mathrm{O}$ & Glass & Cyano + MBD & 4 & 4 & $\mathrm{Y}$ & 335925 & 25 & 38 \\
\hline 230 & M & Glass & Merged & 4 & 2 & $\mathrm{Y}$ & 329916 & 19 & 42 \\
\hline 231 & $\mathrm{O}$ & Glass & Cyano & 5 & 4 & $\mathrm{Y}$ & 2001320 & 40 & 55 \\
\hline 231 & $\mathrm{O}$ & Glass & Cyano + MBD & 3 & 2 & $\mathrm{Y}$ & 523962 & 31 & 51 \\
\hline 231 & $\mathrm{M}$ & Glass & Merged & 1 & 2 & $\mathrm{Y}$ & 752832 & 32 & 57 \\
\hline 232 & $\mathrm{O}$ & Glass & Cyano & 3 & 3 & $\mathrm{~N}$ & N/A & N/A & N/A \\
\hline 232 & $\mathrm{O}$ & Glass & Cyano + MBD & 1 & 3 & $\mathrm{~N}$ & N/A & N/A & N/A \\
\hline 232 & $\mathrm{M}$ & Glass & Merged & 2 & 4 & $\mathrm{~N}$ & N/A & N/A & N/A \\
\hline 233 & $\mathrm{O}$ & Glass & Cyano & 1 & 2 & $\mathrm{Y}$ & 294528 & 26 & 48 \\
\hline 233 & $\mathrm{O}$ & Glass & Cyano + MBD & 2 & 4 & $\mathrm{Y}$ & 1218624 & 32 & 46 \\
\hline 233 & $\mathrm{M}$ & Glass & Merged & 4 & 4 & $\mathrm{Y}$ & 709590 & 21 & 50 \\
\hline
\end{tabular}




\begin{tabular}{|r|r|c|c|r|r|r|r|r|r|}
\hline 234 & $\mathrm{O}$ & Glass & Cyano & 5 & 3 & $\mathrm{Y}$ & 98189 & 13 & 32 \\
\hline 234 & $\mathrm{O}$ & Glass & Cyano + MBD & 2 & 4 & $\mathrm{~N}$ & 66671 & 11 & 30 \\
\hline 234 & $\mathrm{M}$ & Glass & Merged & 2 & 3 & $\mathrm{Y}$ & 197205 & 15 & 36 \\
\hline 235 & $\mathrm{O}$ & Glass & Cyano & 4 & 4 & $\mathrm{~N}$ & $\mathrm{~N} / \mathrm{A}$ & N/A & N/A \\
\hline 235 & $\mathrm{O}$ & Glass & Cyano + MBD & 4 & 4 & $\mathrm{~N}$ & N/A & N/A & N/A \\
\hline 235 & $\mathrm{M}$ & Glass & Merged & 3 & 4 & $\mathrm{~N}$ & N/A & N/A & N/A \\
\hline
\end{tabular}




\section{APPENDIX C}

NFIQ Scores
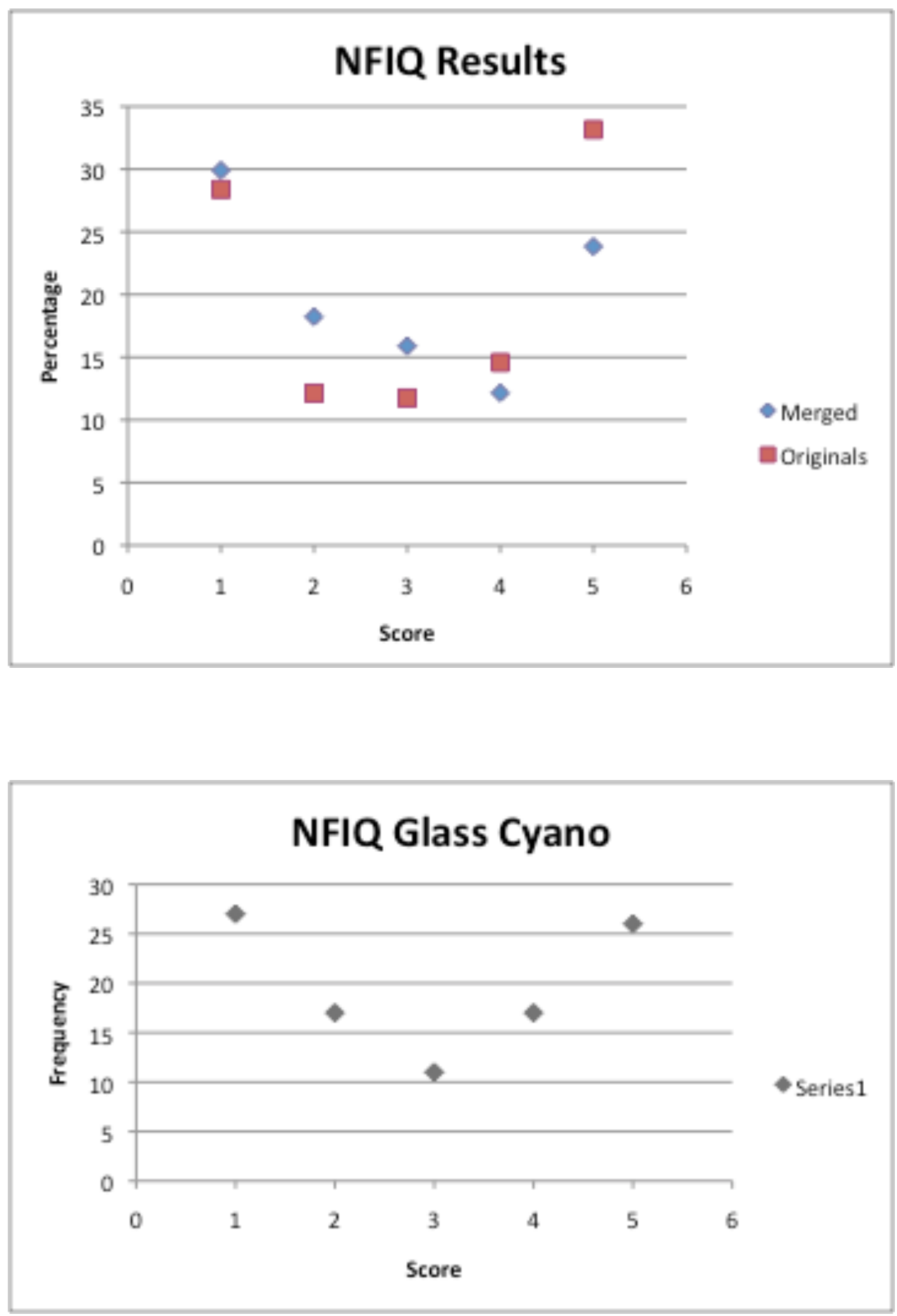

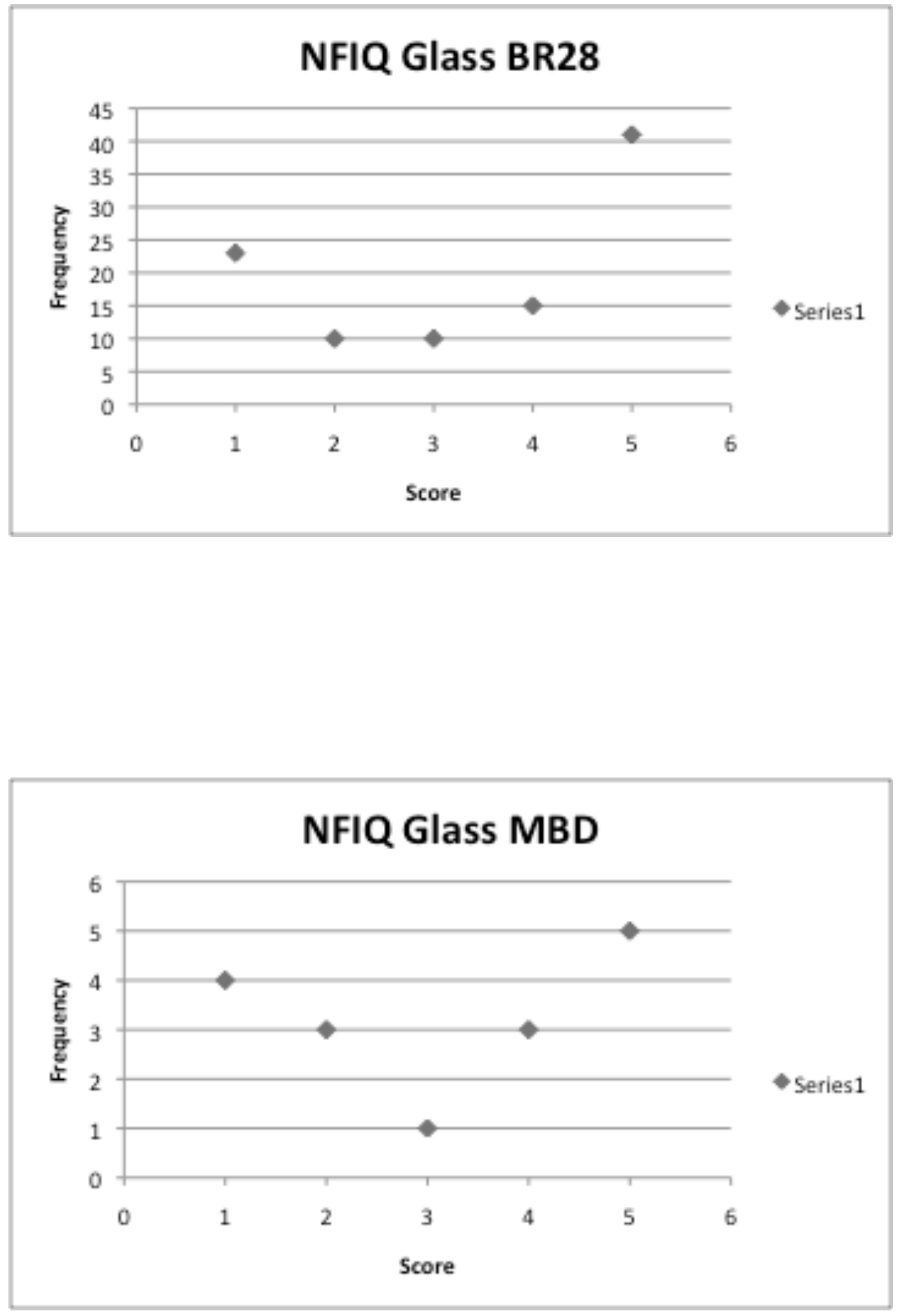

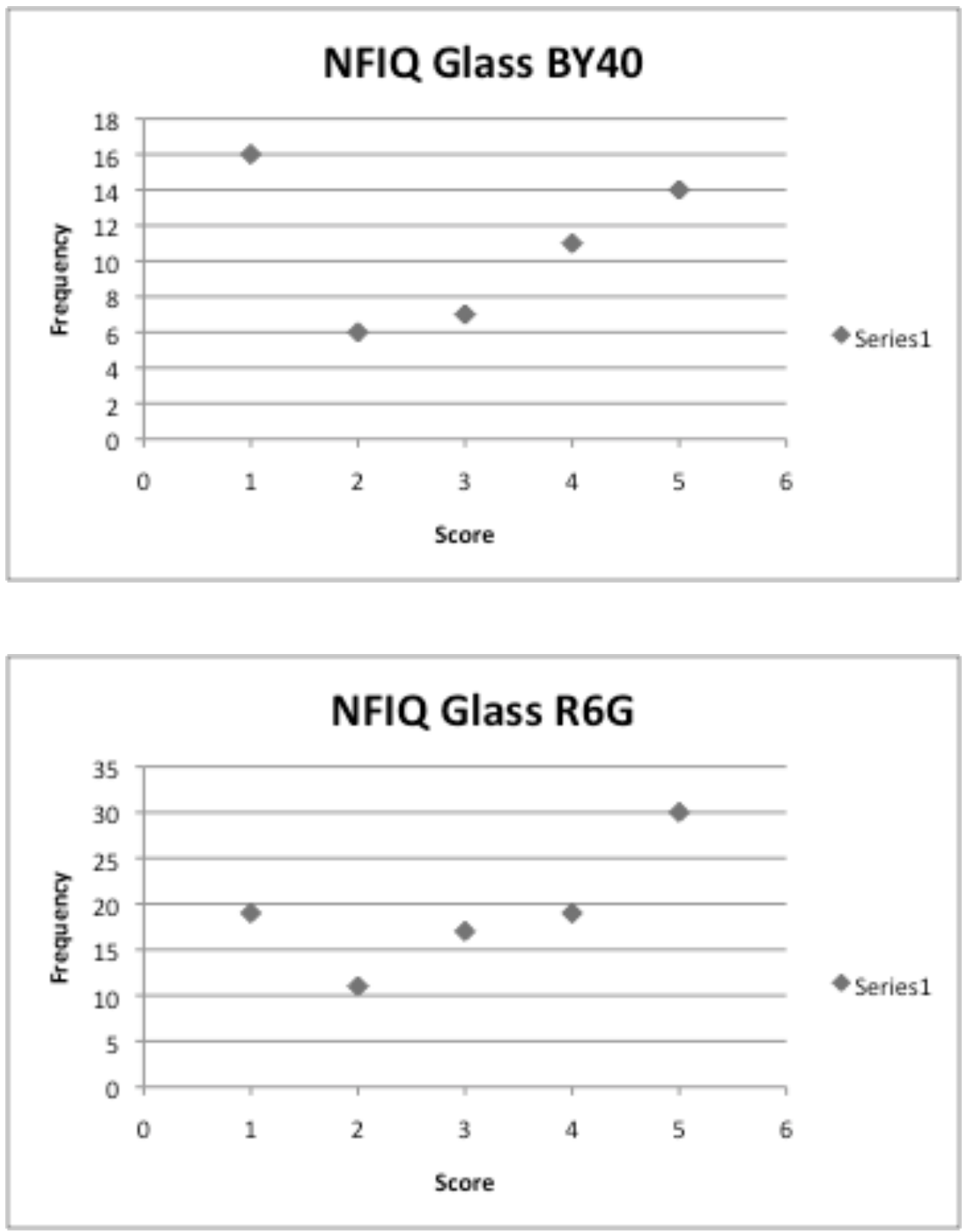

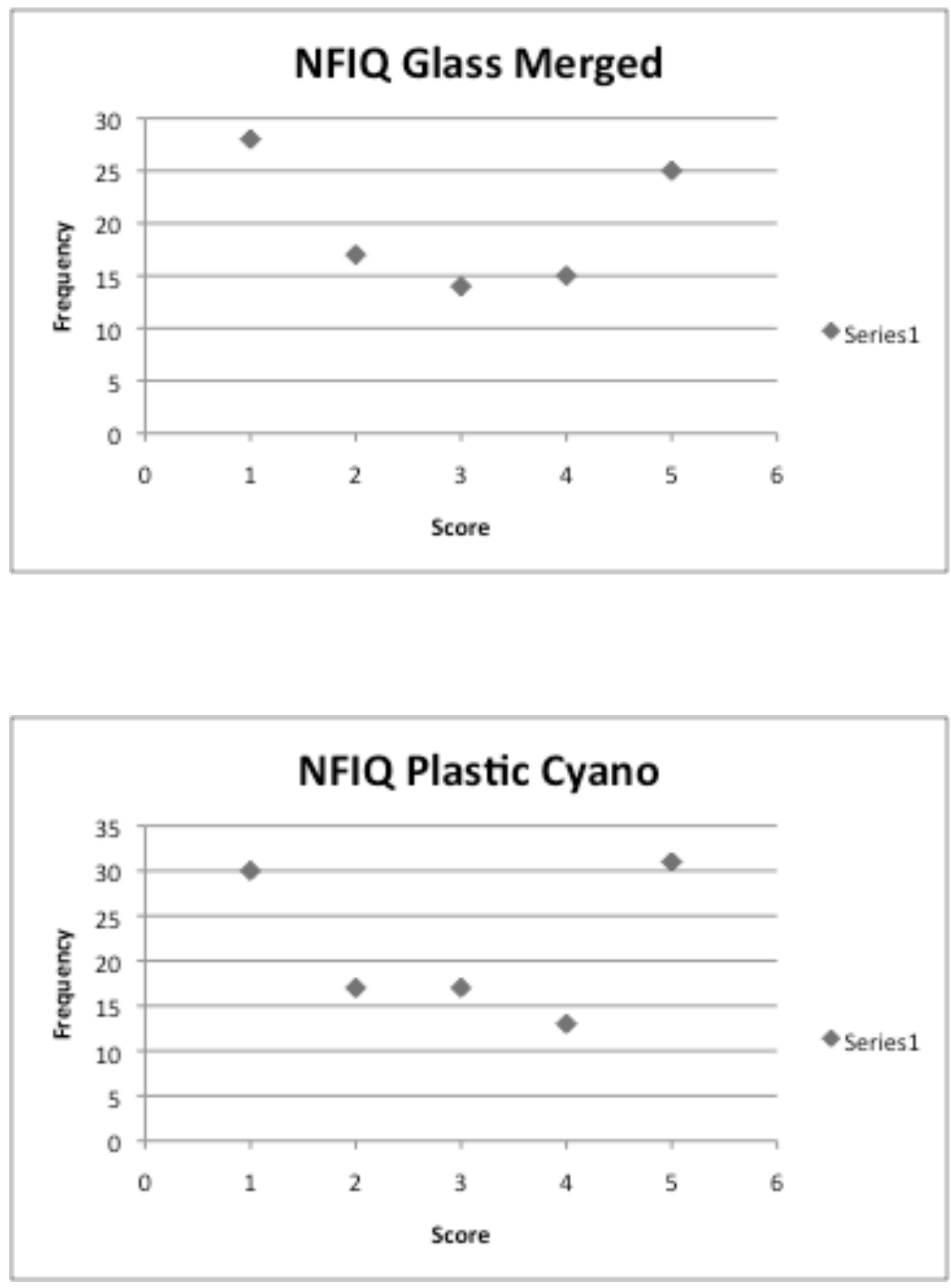

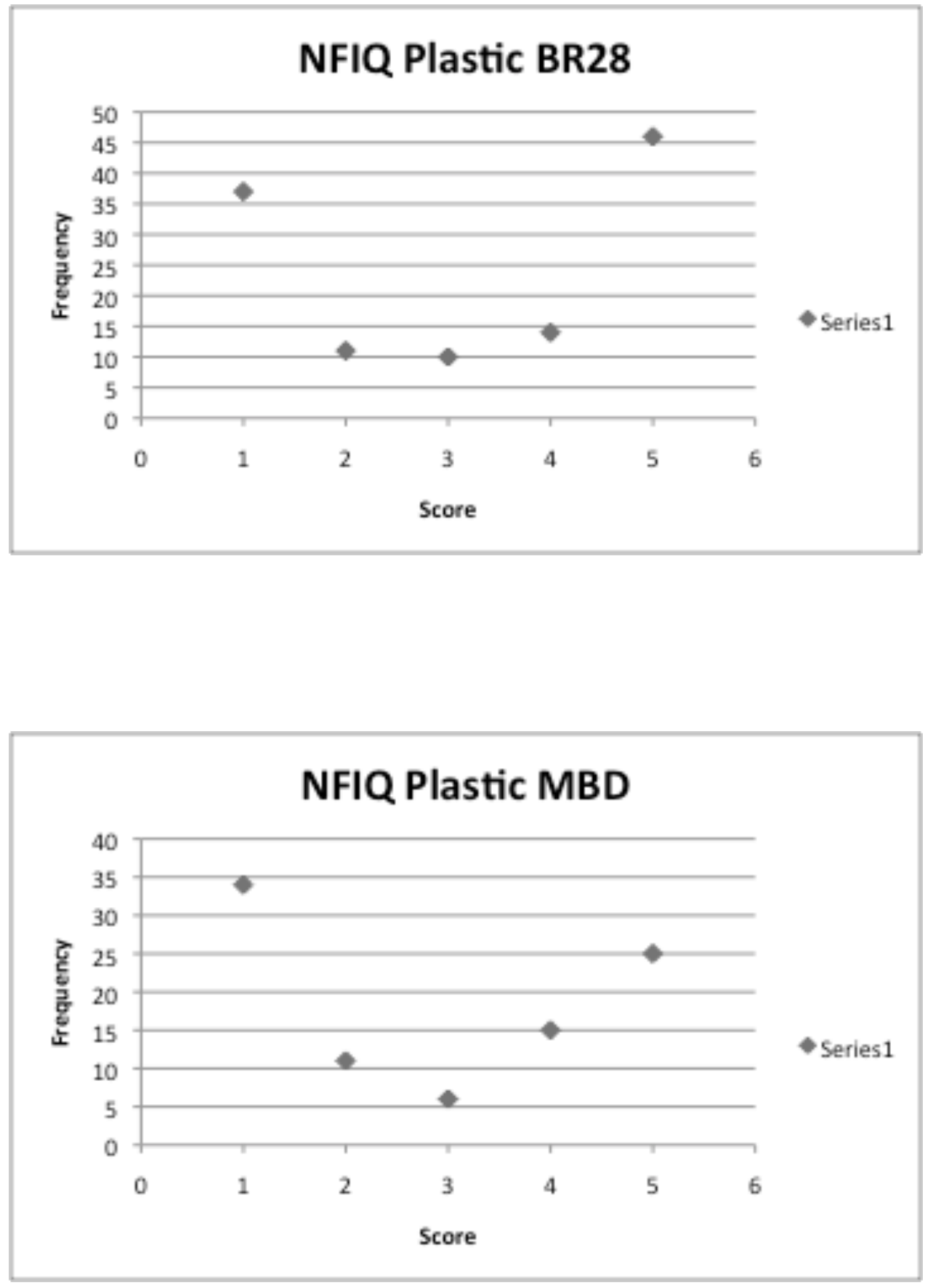

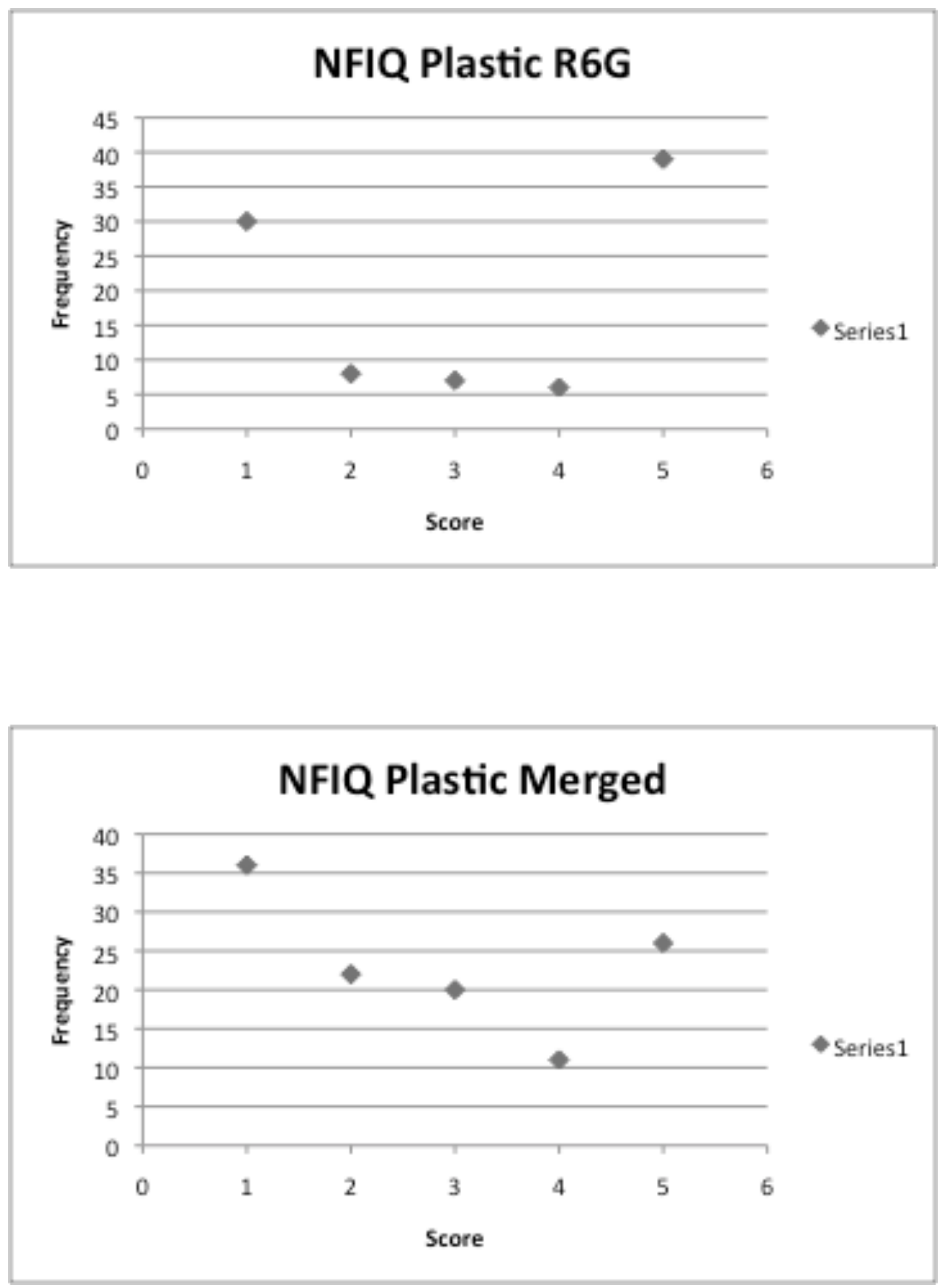
Bandey Score Frequency
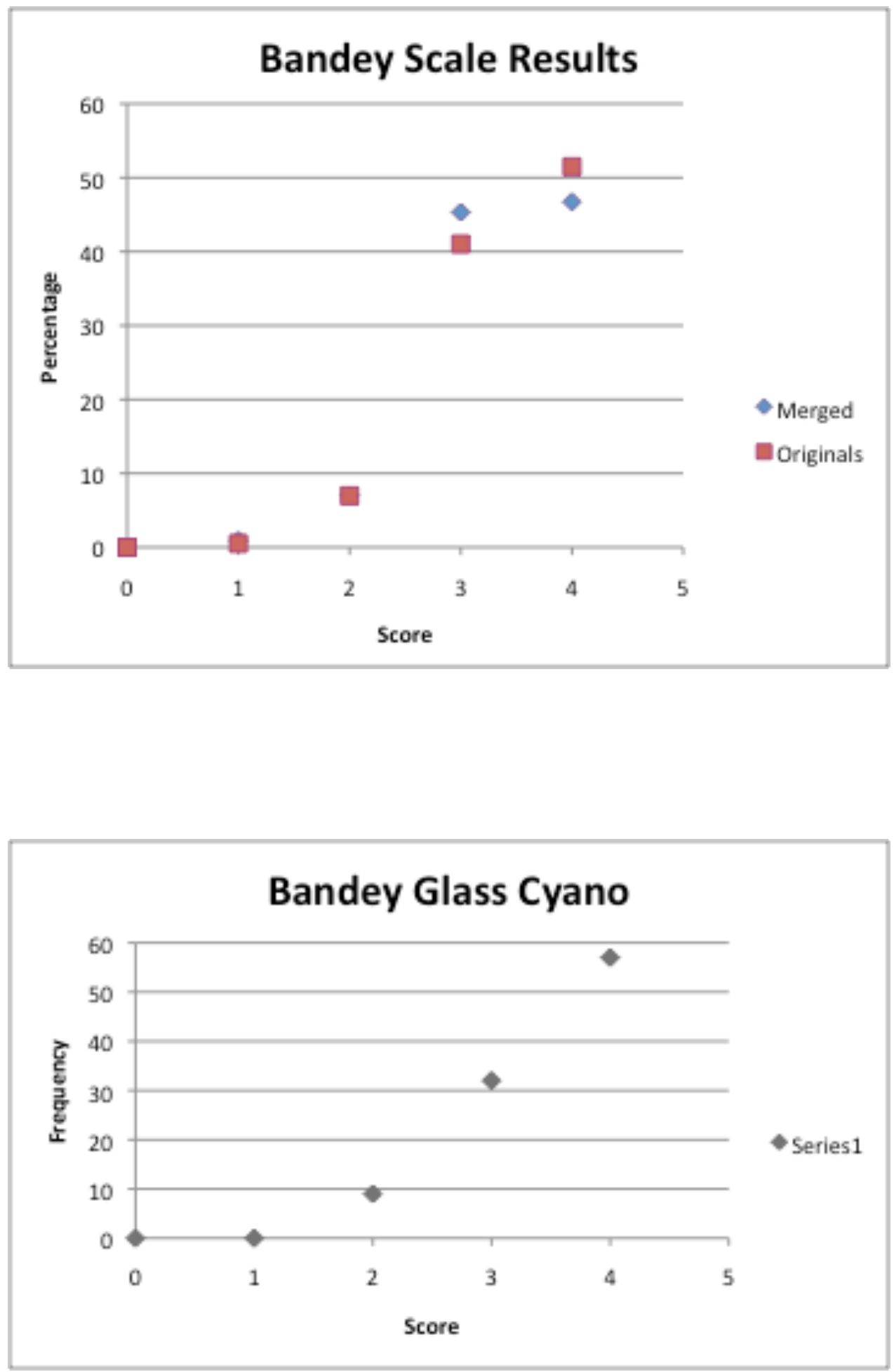

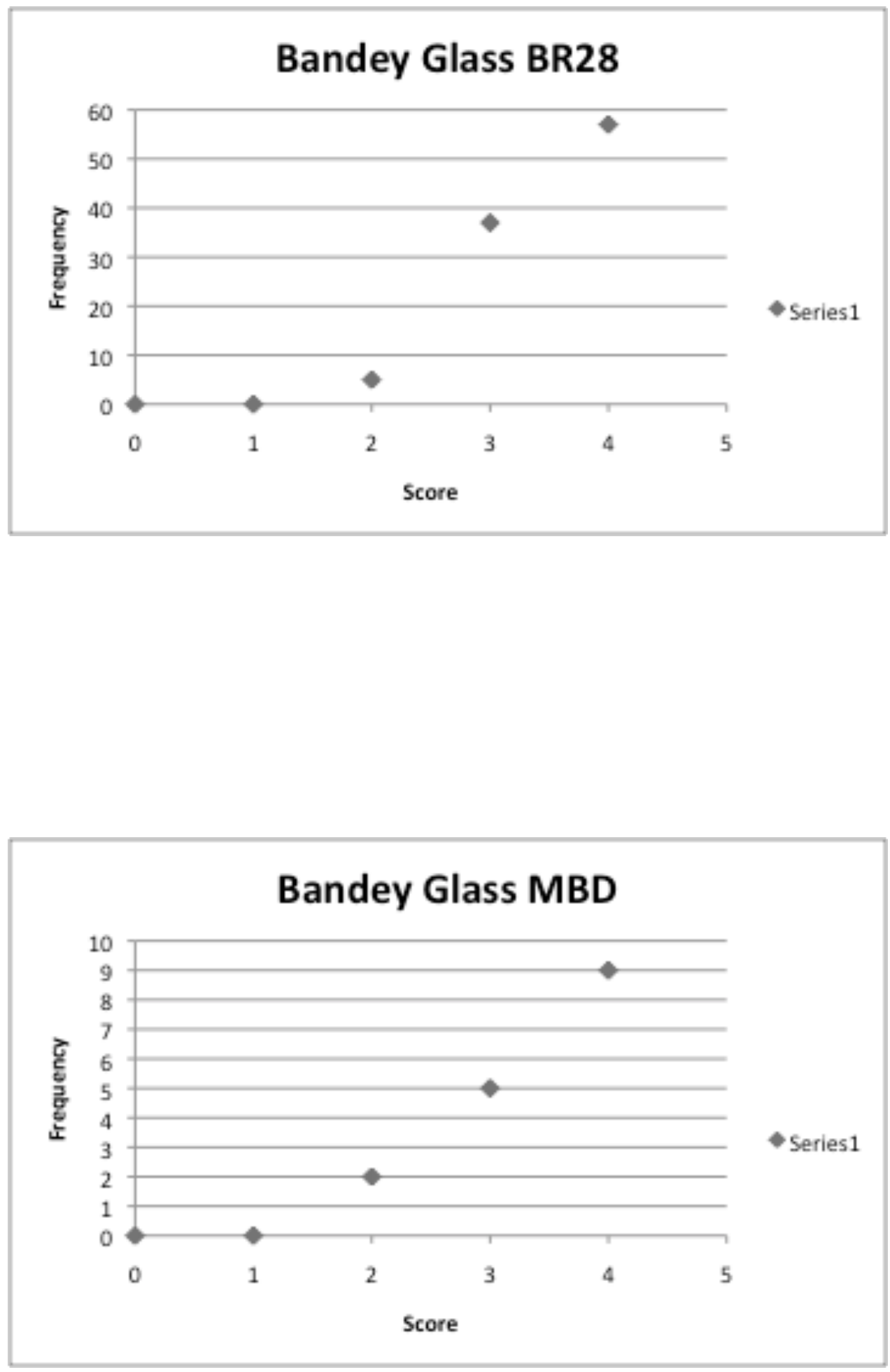

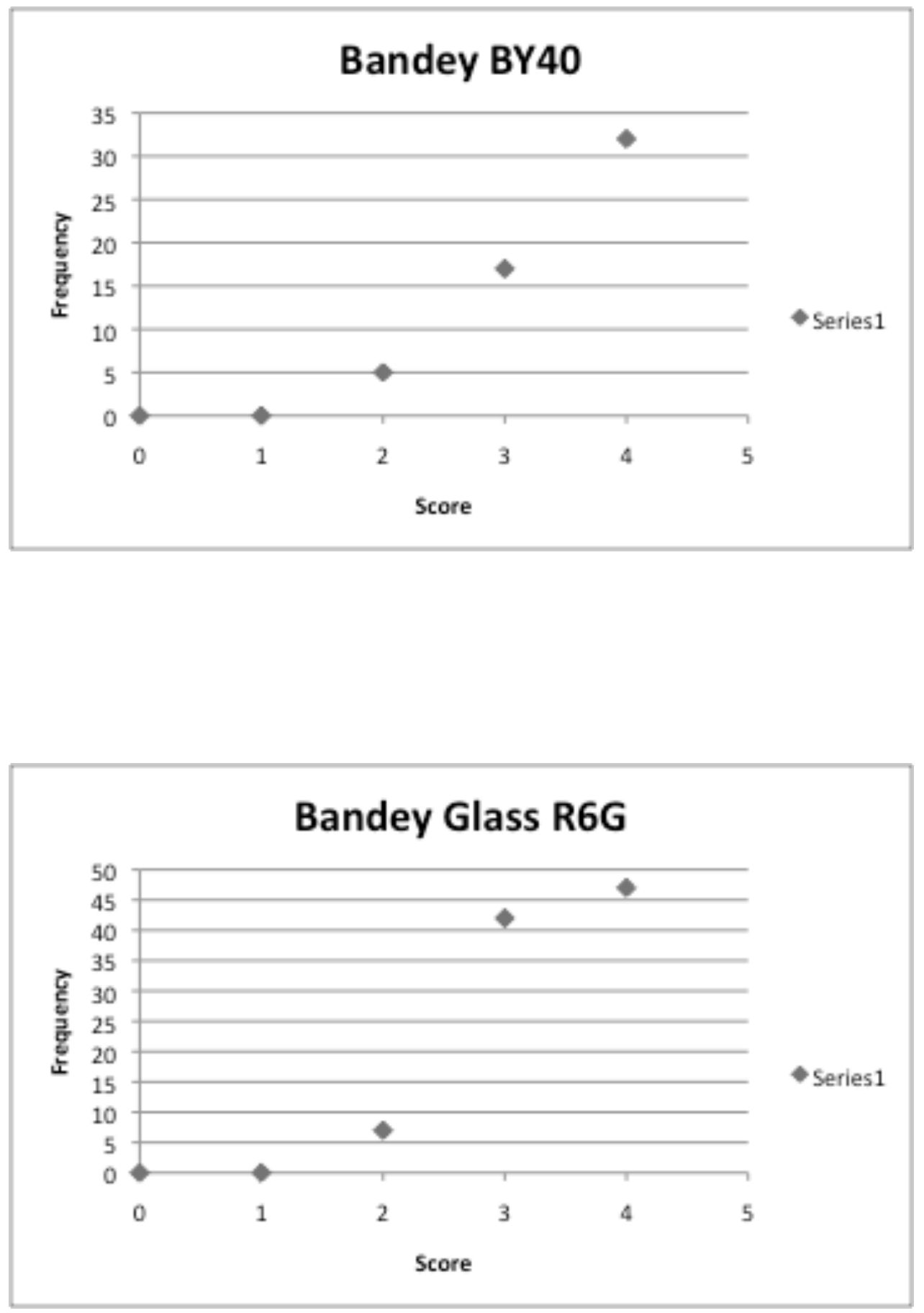

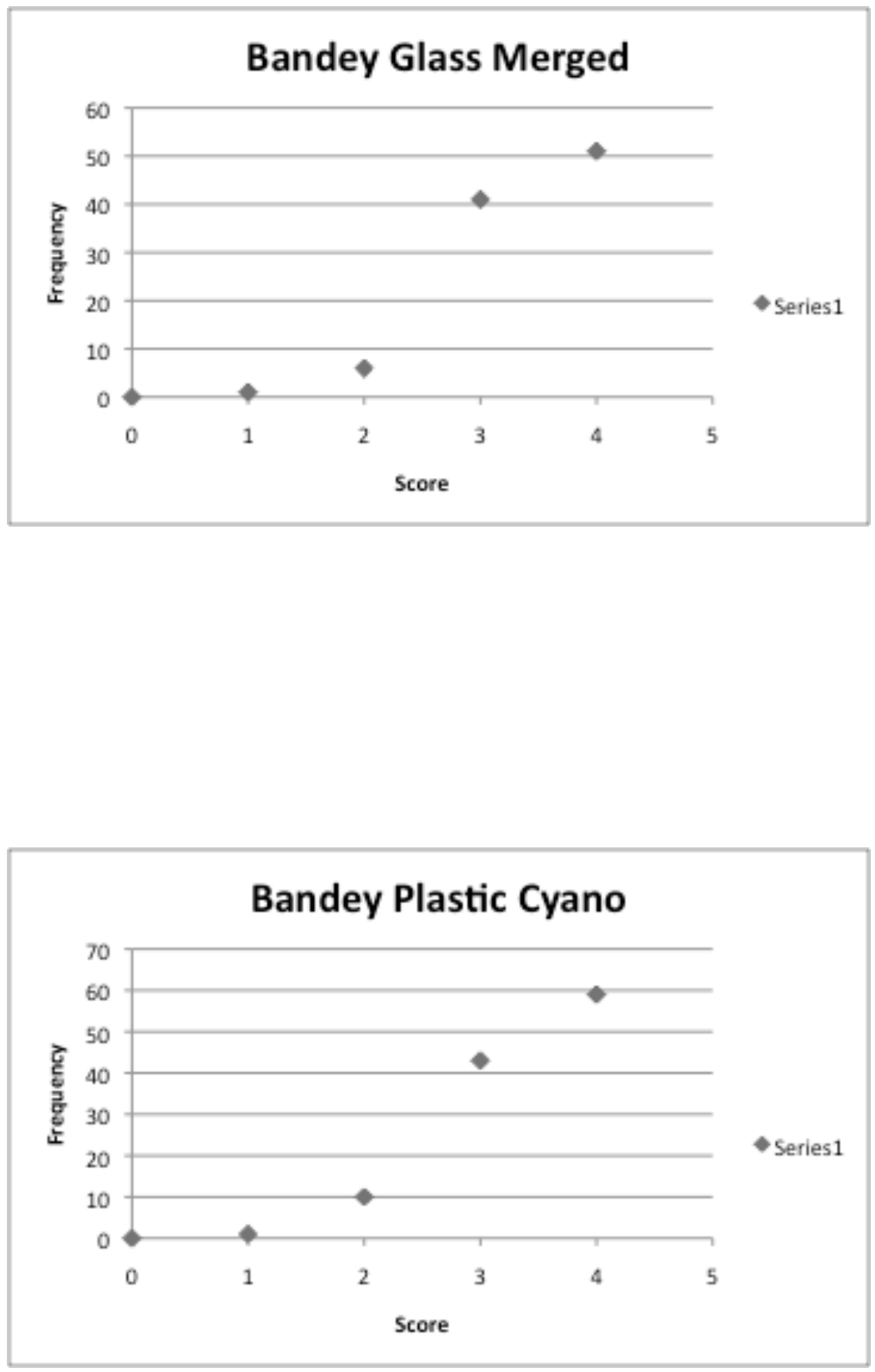

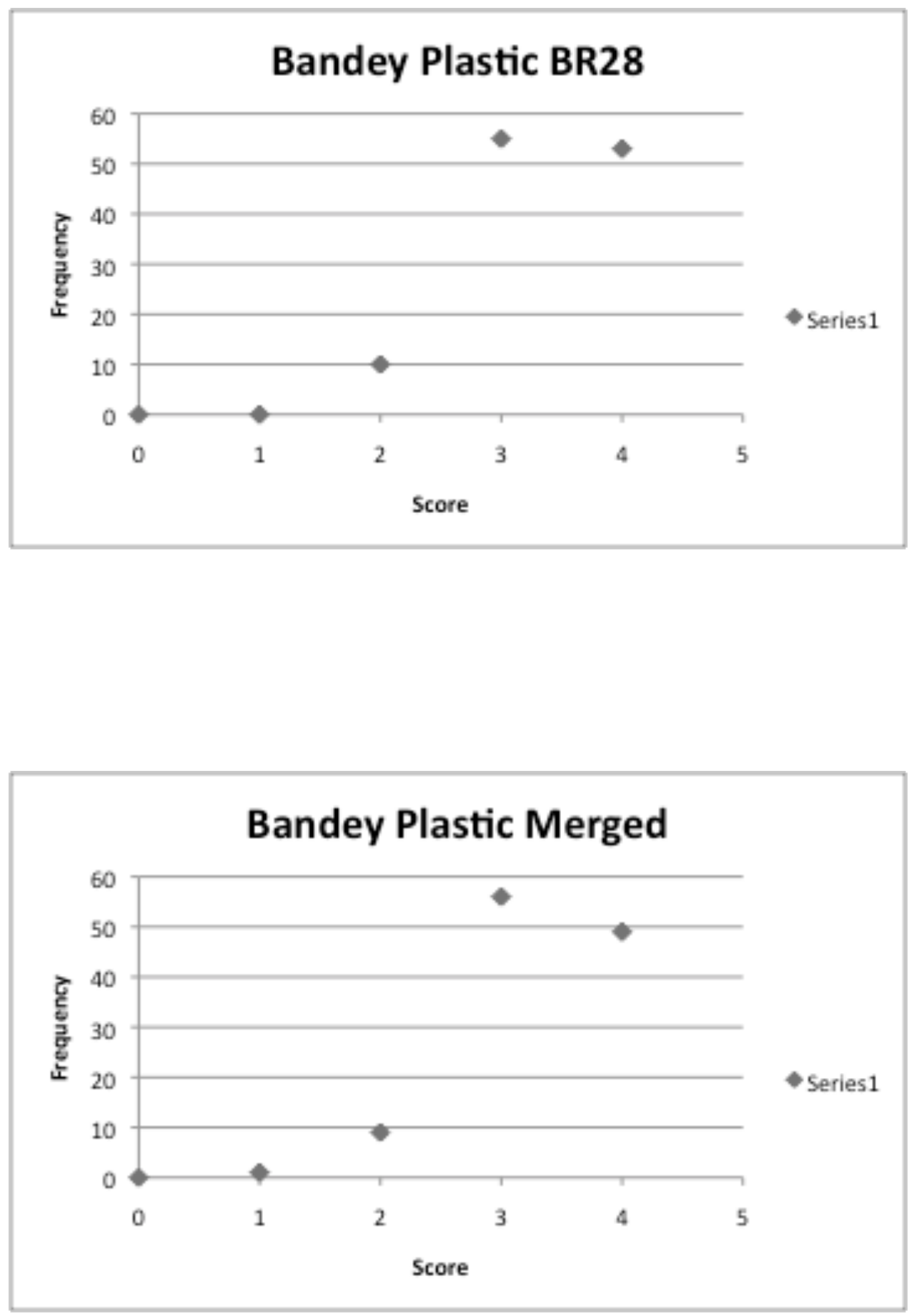

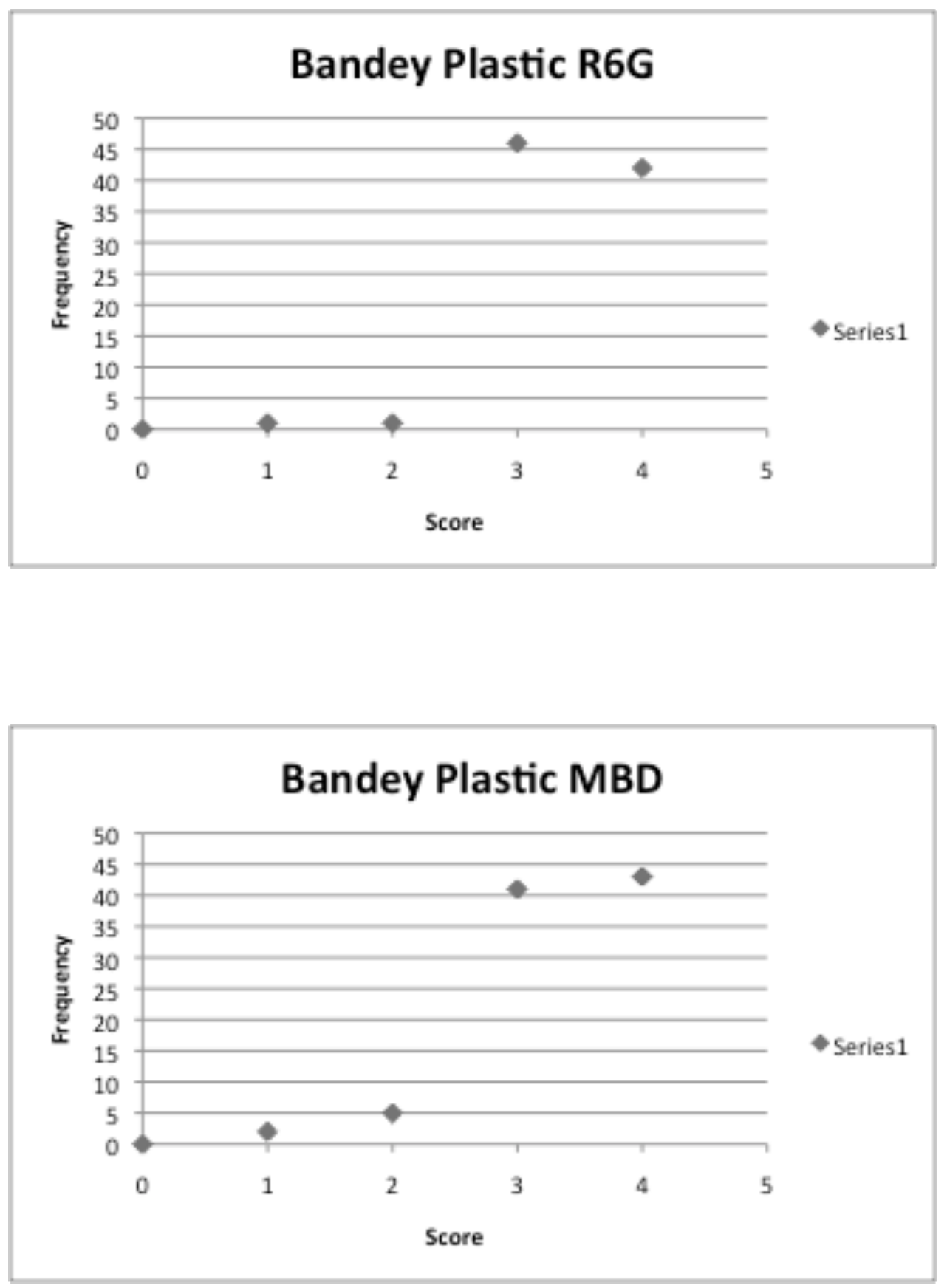


\section{Appendix D}

\section{NFIQ script}

$>$ for file in *.jpg

$>d o$

$>$ part_l=\$file

$>$ part_2="\$(\$a \$ffile $\}-d) ”$

>echo “\$part_1 \$part_2" >> a.txt

$>$ done 